\title{
Analyse der in-vivo Funktion der Transkriptionsfaktoren TGA2.1 und TGA2.2 aus Tabak nach Fusion mit einer konstitutiven Aktivierungsdomäne
}

\author{
Dissertation \\ zur Erlangung des Doktorgrades \\ der Mathematisch-Naturwissenschaftlichen Fakultäten \\ der Georg-August-Universität zu Göttingen
}

\author{
vorgelegt von \\ Ingo Lenk \\ aus Herford
}

Göttingen 2001 
Zum Forschen gehört Glück, zum Erfinden Geist,

und beide können beides nicht entbehren.

Johann Wolfgang von Goethe 
für Andrea und Frederik 


\section{Inhaltsverzeichnis}

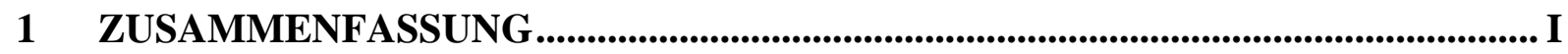

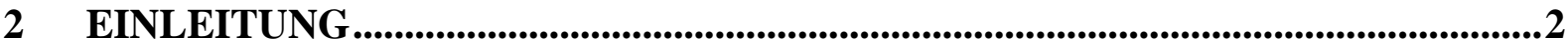

2.1 DIE ROLLE VON SALICYLSÄURE IN DER PFLANZLICHEN PATHOGENABWEHR...............2

2.2 AS-1 IST EIN CIS-ELEMENT IN PROMOTOREN PFLANZLICHER ABWEHRGENE, DAS

SALICYLSÄURE-INDUZIERBARKEIT VERMITTELT .....................................................4

2.3 ASF-1 UND DIE FAMILIE DER TGA-TRANSKRIPTIONSFAKTOREN ...............................

2.4 ZIELSETZUNG UND EXPERIMENTELLER ANSATZ DER ARBEIT .................................... 10

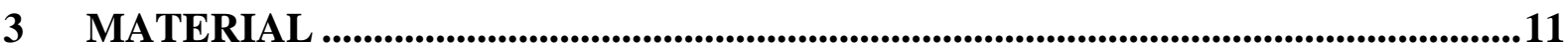

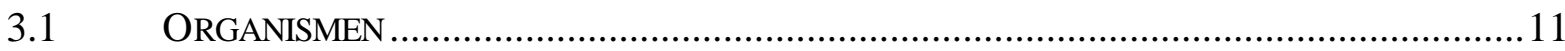

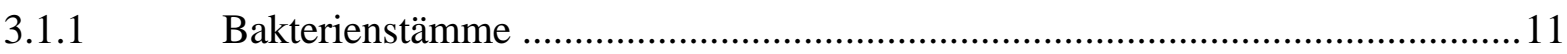

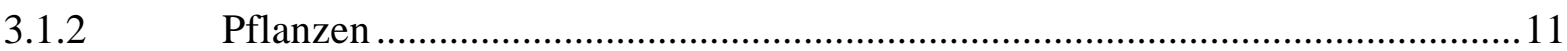

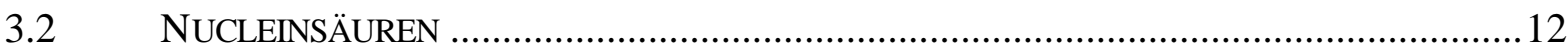

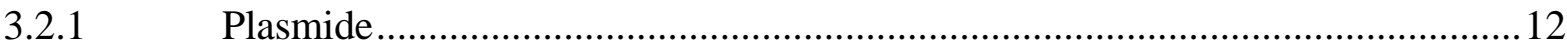

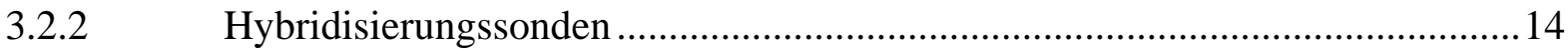

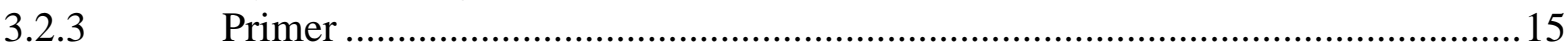

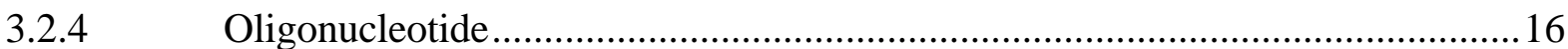

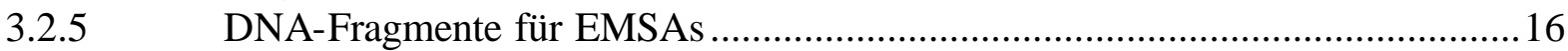

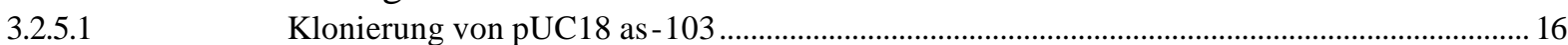

3.2.5.2 Klonierung von pUC1 8-pas-a ............................................................................................. 16

3.2.5.3 Gewinnung der im EMSA eingesetzten Fragmente ...................................................................... 16

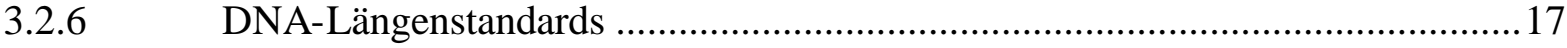

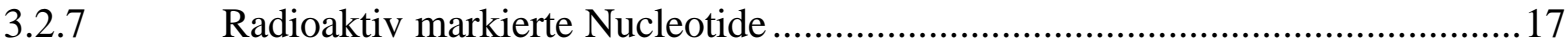

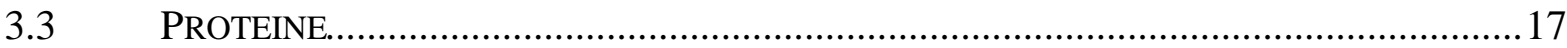

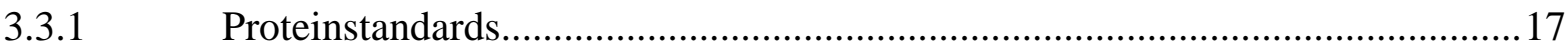

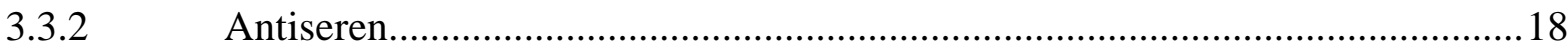

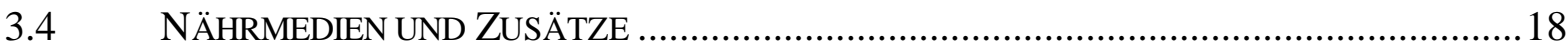

3.4.1 Medien zur Anzucht von Bakterien........................................................... 18

3.4.2 Medien zur Anzucht von Pflanzen und Suspensionskulturen von

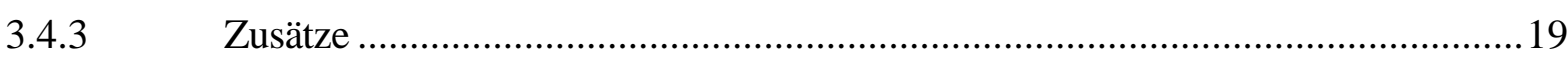

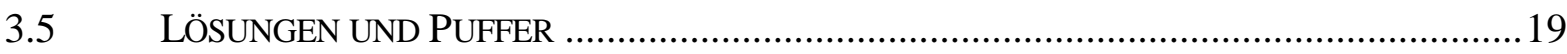

3.6 CHEMIKALIEN, VERBRAUCHSMITTEL UND GERÄTE..............................................22

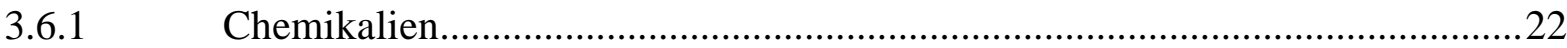

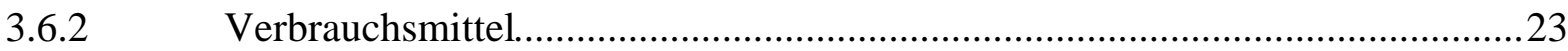

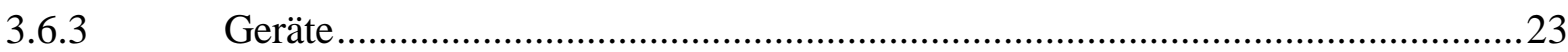

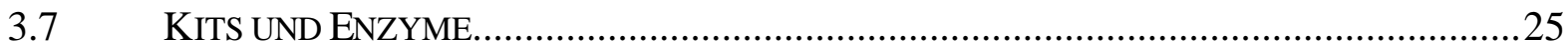

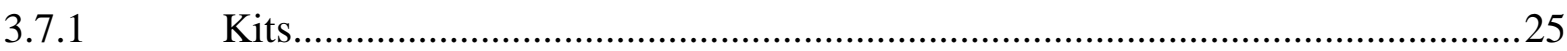

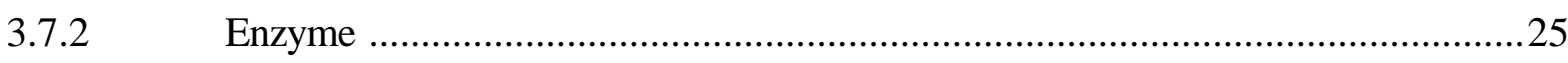

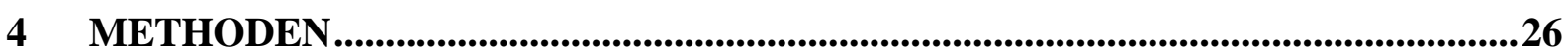

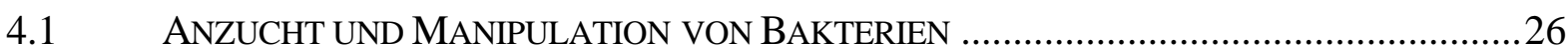

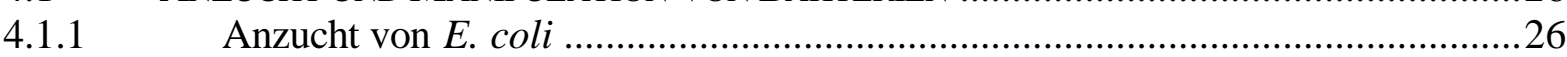

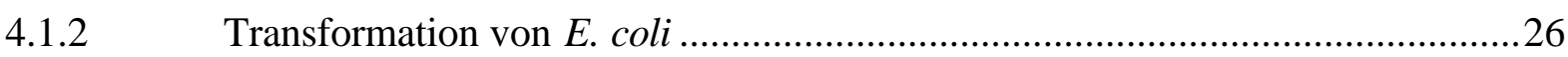

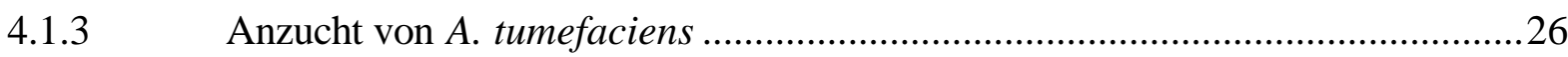

4.1.4 Transformation von A. tumefaciens durch Elektroporation................................26 
ANZUCHT UND MANIPULATION VON PFLANZEN …………….................................22

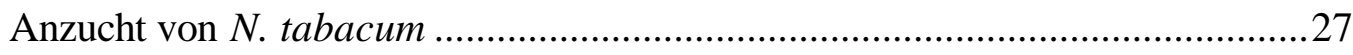

Alkalische Lyse (modifiziert nach ISH-HORROWICZ und BURKE, 1981) .................................29

Schnell-Lyse für anschließende PCR ....................................................................................... 30

Plasmidpräparation für die Sequenzierung ................................................................................. 30

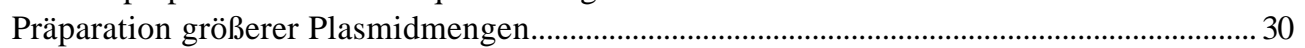

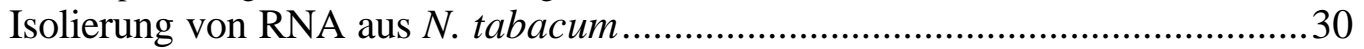

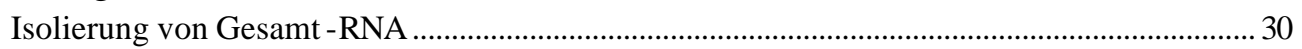

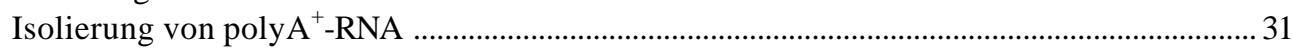

Isolierung von cDNA-Sondenmolekülen aus $N$. tabacum ..................................31

Ethanolfällung von DNA (SAMBROOK et al., 1989) .............................................31

Quantifizierung von Nucleinsäuren (SAMBROOK et al., 1989) ............................31

Methoden zur Klonierung von Nucleinsäuren................................................. 32

Restriktionsspaltung von DNA (SAMBROOK et al., 1989) ..................................................... 32

Isolierung von DNA-Fragmenten aus Agarosegelen .................................................................... 32

Ligation von Restriktionsfragmenten ....................................................................................... 32

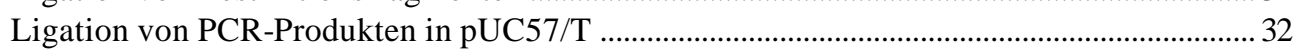

Klonierung eines Kassettensystems für die Fusion zwischen TGA-

Faktoren und Aktivierungs- bzw. Silencerdomänen .........................................33

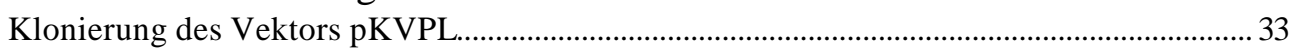

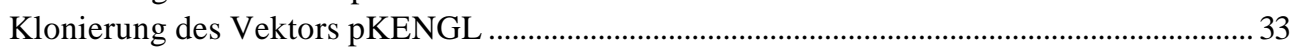

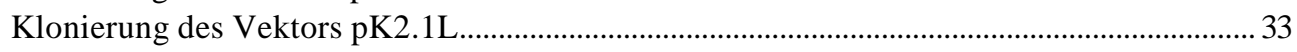

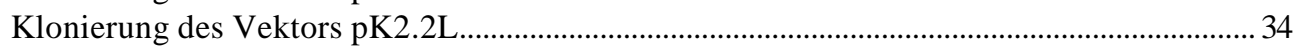

Klonierung des Vektors pLVPs .............................................................................................. 34

Klonierung des Vektors pLENGs .................................................................................... 34

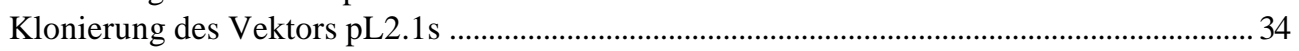

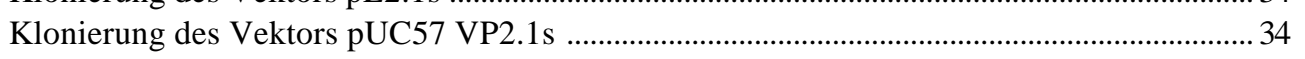

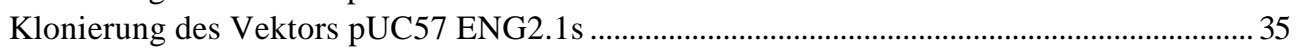

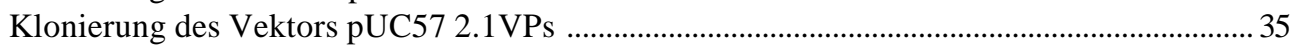

Klonierung des Vektors pUC57 2.1ENGs .............................................................................. 35

Klonierung des Vektors pSK 2.2VPs ........................................................................................ 35

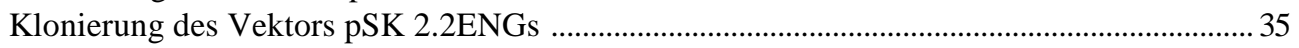

Klonierung des Vektors pUC57 2.1-57s .................................................................................... 35

Umklonieren der zuvor beschriebenen Derivate in den Vektor pBINHyg-TX .........................35

PCR (Polymerase Chain Reaction) (modifiziert nach MULLIS und

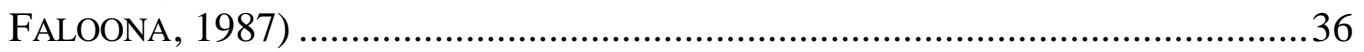

PCR zur Charakterisierung von rekombinanten Klonen ............................................................ 36

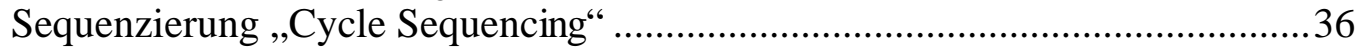

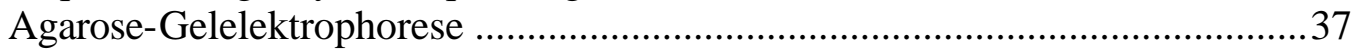

Auftrennung von DNA im Agarosegel.............................................................................. 37

Auftrennung von RNA im denaturierenden Agarosegel (FOURNEY et al., 1988).................... 37

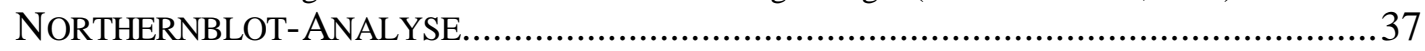

Herstellung radioaktiv markierter Sondenmoleküle ......................................... 37

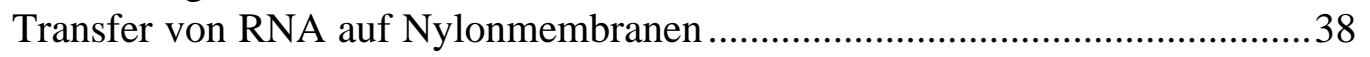

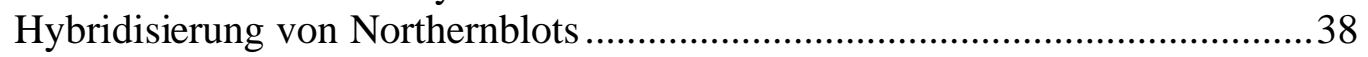

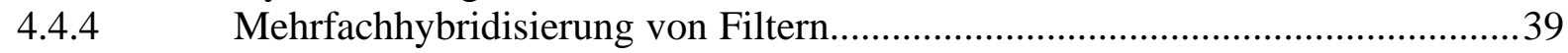




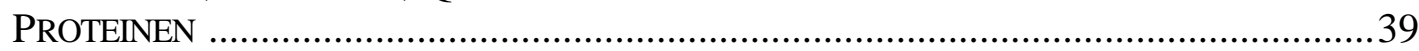

4.5.1

4.5.1.1

4.5.1.2

4.5.1.3

4.5.1.4

4.5.1.5

4.5.2

4.5.3

4.5.4

4.5.5

4.6

4.6.1

4.6.2

4.6.2.1

4.6.2.2

4.7

4.7.1

4.7.2

4.7.3

4.7.4

Isolierung von Proteinen aus N. tabacum.

39

Denaturierende Gesamtzellextrakte ....................................................................................... 39

Denaturierende Kernproteinextrakte (modifiziert nach PRAT et al., 1989;

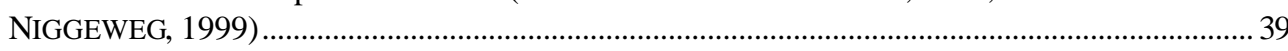

Normalisierung der Proteinmengen mittels SDS-PAGE und Coomassie-Färbung .................. 40

Native Gesamtzellextrakte (JUPIN und CHUA, 1996) ................................................................ 40

Native FixProt-Gesamt zellextrakte (modifiziert nach KEGLER, unveröffentlicht).................. 41

Fällung von Proteinen (nach WESSEL und FLÜGGE, 1984)...............................41

Konzentrationsbestimmung von Proteinextrakten (nach BRADFORD, 1976)......41

Affinitätsaufreinigung von Antiseren (modifiziert nach OLMSTED, 1981) ........41

SDS-Polyacrylamid-Gelelektrophorese (SDS-PAGE) (LAEMMLI, 1970) ..........42

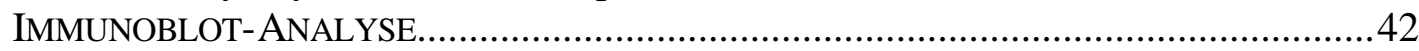

Proteintransfer auf Polyvinylidenflourid (PVDF)-Membranen (modifiziert

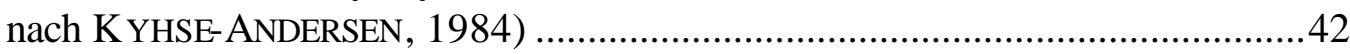

Detektion mit spezifischen Antiseren (Immunoblot-Analyse) .........................43

Detektion mit affinitätsgereinigtem Antiserum gegen TGA2.2 ……………………………..... 43

Detektion mit affinitätsgereinigtem Antiserum gegen TGA2.1 bzw. polyklonalem

Antiserum gegen Streptag $₫$ II ............................................................................................................. 43

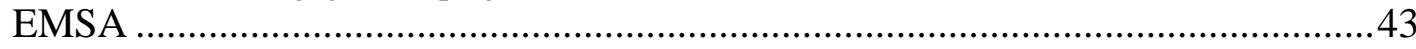

Herstellung radioaktiv markierter DNA-Fragmente für den EMSA .................43

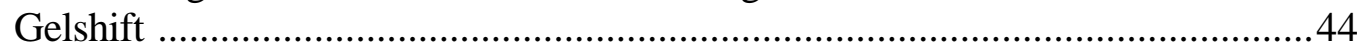

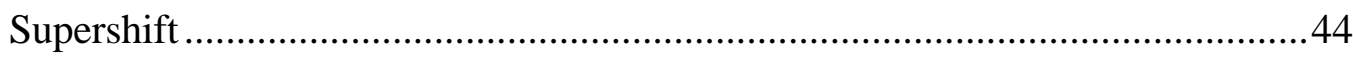

Quantitative Auswertung von EMSAs .......................................................44

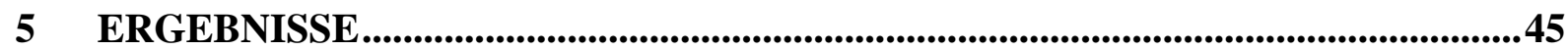

5.1 HERSTELLUNG VERSCHIEDENER FUSIONS- UND DELETIONSDERIVATE VON

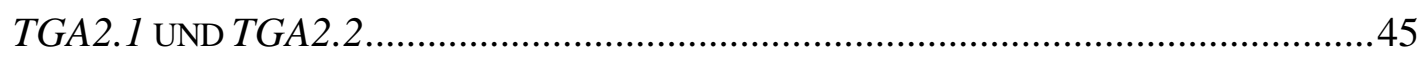

5.2 HERSTELLUNG UND CHARAKTERISIERUNG TRANSGENER TABAKPFLANZEN ..............46

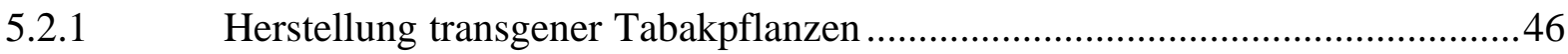

5.2.2 Charakterisierung der transgenen Pflanzen auf Protein-Ebene .........................47

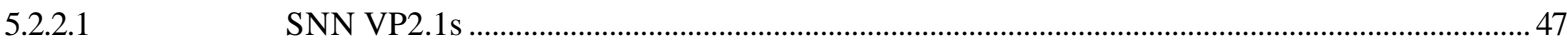

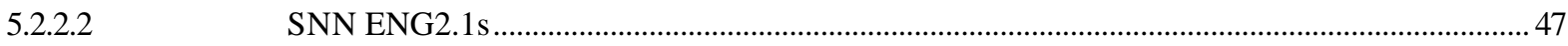

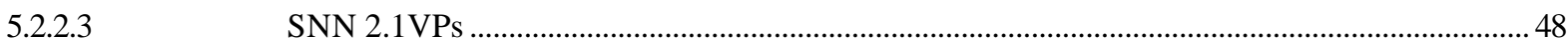

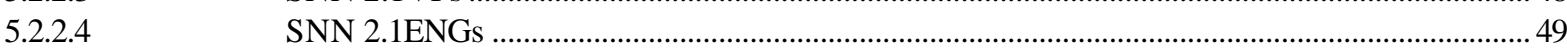

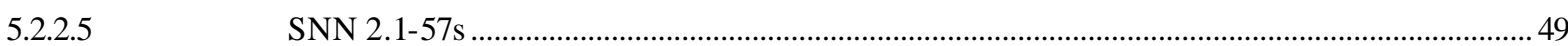

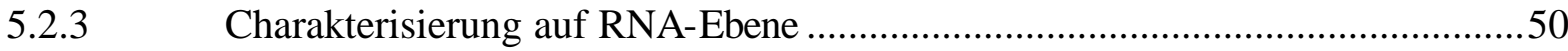

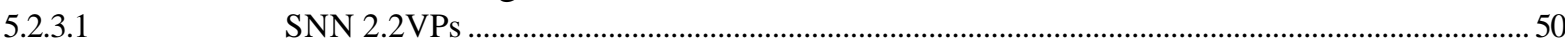

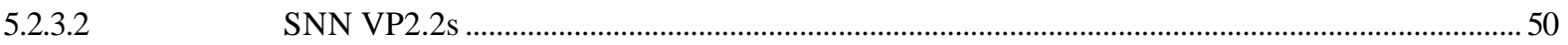

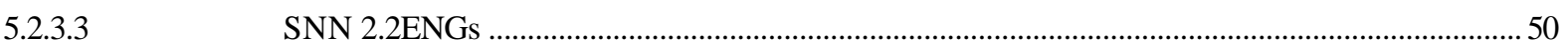

5.3 VERGLEICH DER RELATIVEN PROTEINMENGEN TRANSGENER UND ENDOGENER

TGA-FAKTOREN DER K LASSE II ......................................................................52

5.3.1 Vergleich der Proteinmengen in Gesamtzellextrakten .................................52

5.3.2 Vergleich der Proteinmengen in Kernextrakten ..............................................53

5.4 AUSWIRKUNG VON FUSIONSPROTEINEN AUS VP16-AKTIVIERUNGS-DOMÄNE

UND TGA2.1 BZW. TGA2.2 AUF DIE EXPRESSION VON ZIELGENEN NACH

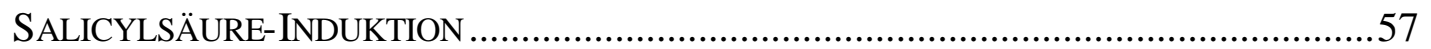

5.4.1 Untersuchungen zur Expression von Zielgenen drei Stunden nach

Salicylsäure-Induktion.........................................................................5

5.5 EINFLUSS VON C YCLOHEXIMID AUF DIE EXPRESSION VON ZIELGENEN ....................59

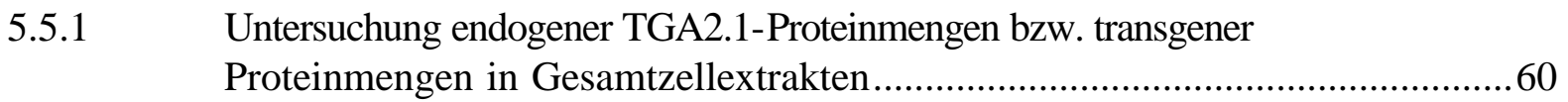


Untersuchung endogener TGA-Proteinmengen bzw. transgener

Proteinmengen in Kernextrakten.

Einfluss von Cycloheximid auf die Expression von $a s-1-G U S$.

Einfluss von Cycloheximid auf die Expression von Nt103

Bewertung des Einflusses der Fusionsproteine im Vergleich zum Einfluß

der überexprimierten Wildtyp-TGA-Faktoren

AUSWIRKUNG VON FUSIONSPROTEINEN AUS ENG-SILENCERDOMÄNE UND

TGA2.1 BZW. TGA2.2 AUF DIE EXPRESSION VON NT103 NACH SALICYLSÄURE-

INDUKTION

5.7 AUSWIRKUNG DES VERKÜRZTEN PROTEINS 2.1-57S AUF DIE EXPRESSION VON

NT103 NACH SALICYLSÄURE-INDUKTION

Expressionsverlauf von Nt103 nach Auxin-Induktion................................................................ 79

Expressionsverlauf von parA nach Auxin-Induktion............................................................. 79

In-vitro-Bindungsaktivität an as-1-ähnliche Elemente in nativen Gesamtzellextrakten

Nachweis der Proteine TGA2.1 und TGA2.2 in Gesamtzellextrakten (nach JUPIN und CHUA, 1996) von SNN 2.1 $\Delta$ N29 \# 8-Suspensionskulturen..

Einfluss von Natriumfluorid auf das Bindeverhalten an $a s-1$ in

6 DISKUSSION

6.1 IN BLÄTTERN KOMMT ES NACH SALICYLSÄURE ZUR TRANSIENTEN BINDUNG DER TRANSKRIPTIONSFAKTOREN TGA2.1 UND TGA2.2 AN DAS AS-1-ELEMENT ......90

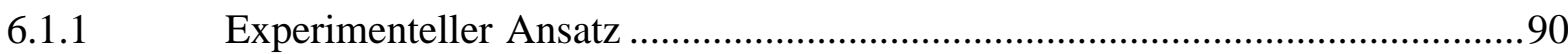

6.1.2 Die Menge der Fusionsproteine übersteigt im Kern nicht die Menge der endogenen TGA-Faktoren ..........................................................................99

6.1.3 Direkte Effekte der Fusionsproteine aus die Zielgenexpression .......................93

6.2 DIE BINDUNG DER FUSIONSPROTEINE ZWISCHEN VP16 UND TGA2.1 BZW.

6.2.1 ASF-1 ist im uninduzierten Zustand mit einem Bindungsinhibitor assoziiert

6.2.2 Die Bindungsaktivität von ASF-1 wird durch zwei getrennte Ereignisse reguliert. 
6.2.3 Die transiente Bindung von ASF-1 wird durch einen Salicylsäure-

induzierten Bindungsinhibitor gewährleistet.

6.3 DER PROMOTORKONTEXT DER ZIELGENE MODULIERT DEN EINFLUSS AS-1 -

ÄHNLICHER ELEMENTE AUF DIE TRANSKRIPTION .98

6.3.1 Im Promotor von Nt103 übernehmen weitere $c i s$-Elemente regulatorische

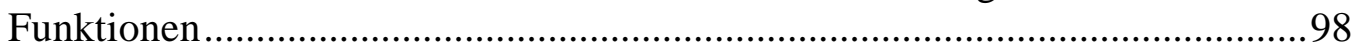

6.3.2 Der CaMV 35S Promotor wird durch Cycloheximid-Behandlung hyperaktiviert 100

6.4 DIE ENGRAILED-SILENCERDOMÄNE ZEIGT IN FUSION MIT TGA2.1 BZW. TGA2.2 KEINEN REPRESSORISCHEN EFFEKT AUF DIE EXPRESSION VON NT103 ........103

6.5 DIE SA-INDUZIERTE AS-1-AKTIVIERUNG IN BLÄTTERN UND SUSPENSIONSZELLEN ERFOLGT IN UNTERSCHIEDUCHER WEISE .............................. 103

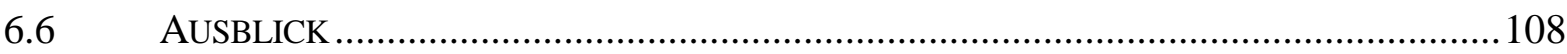

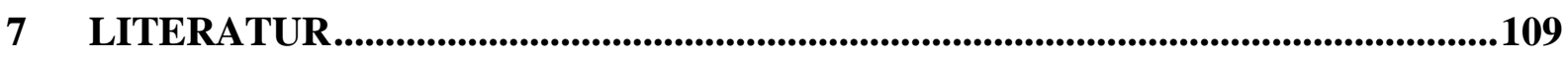

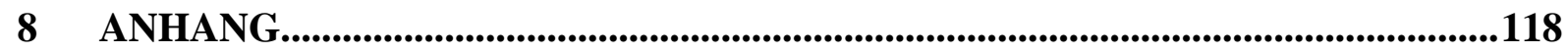

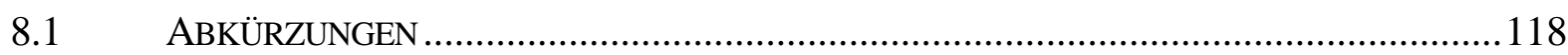

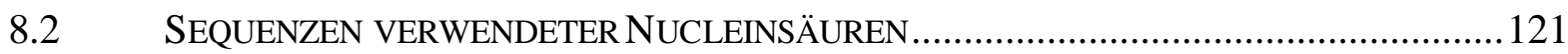

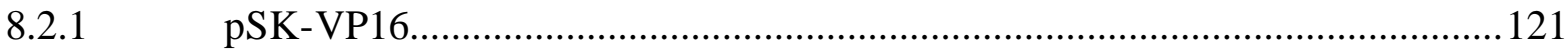

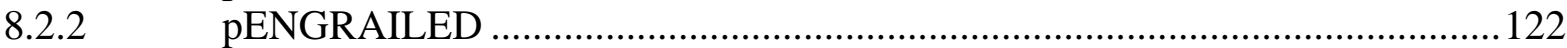

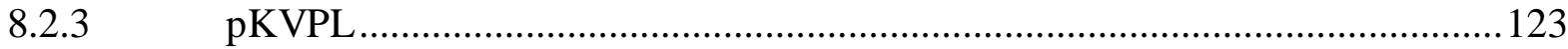

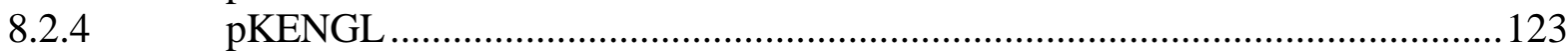

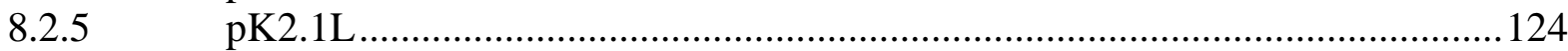

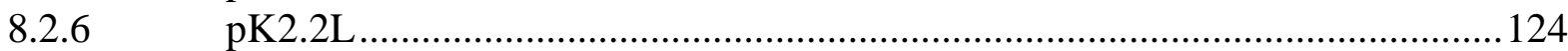

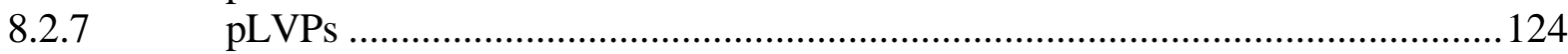

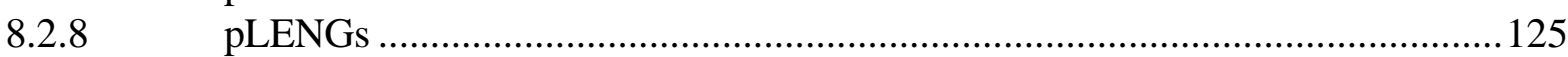

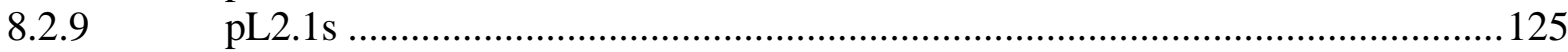

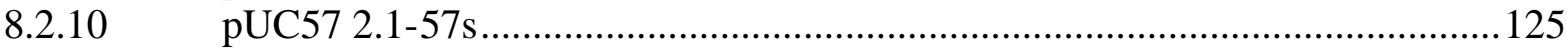

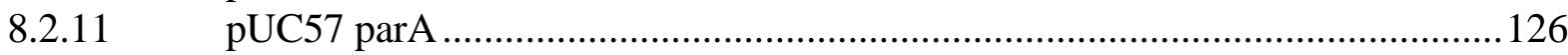




\section{Zusammenfassung}

Salicylsäure (SA) ist für die pflanzliche Pathogenantwort eine Signalsubstanz von entscheidender Bedeutung. In vielen SA-induzierbaren Promotoren findet sich das cis-Element activating sequence 1 (as-1). An dem Proteinkomplex ASF-1 / SARP, der an as-1 und as-1ähnliche Elemente bindet, sind die bZIP-Transkriptionsfaktoren TGA2.1 und TGA2.2 beteiligt. Eine SA-abhängige Veränderung der Bindungseigenschaften von TGA2.1 bzw. TGA2.2 ist ein möglicher Regulationsmechanismus der as-1-vermittelten Genexpression.

Ziel dieser Arbeit war die zeitlich aufgelöste Untersuchung der in-vivo-Bindungseigenschaften von ASF-1 / SARP in Abhängigkeit von SA. Dazu sollten Fusionsproteine zwischen der konstitutiven Aktivierungsdomäne des viralen Proteins 16 (VP16) aus Herpes simplex und den Transkriptionsfaktoren TGA2.1 bzw. TGA2.2 in transgenen Pflanzen überexprimiert werden. Da diese Aktivierungsdomäne einen möglichen SA-regulierten Transaktivierungsschritt ersetzt, können durch die Analyse der Expression von Zielgenen Rückschlüsse auf eine konstitutive oder SA-induzierte Bindung von ASF-1 / SARP gezogen werden. Ferner sollte durch Inhibitorstudien in Tabaksuspensionskulturen die phosphorylierungsabhängige Bindung von ASF-1 / SARP untersucht werden.

Es konnte gezeigt werden, dass die Überexpression von TGA-Fusionsproteinen mit der VP16Domäne eine SA-induzierte Steigerung der Expression der Zielgene as-1-GUS und Nt103 zur Folge hat. Demzufolge lässt sich auf eine SA-induzierte Bindung von TGA2.1 und TGA2.2 an das as-1-Element schließen. In Gegenwart des Proteinsynthese-Inhibitors Cycloheximid (CHX), der in-vitro zur schnellen Verstärkung der Bindeaffinität von ASF-1 / SARP an as-1 führt, vermittelten die Fusionsproteine nicht die Aktivierung der Zielgene, was impliziert, dass die alleinige CHX-Behandlung in-vivo nicht die schnelle Bindung von ASF-1 / SARP zur Folge hat. Dies steht im Widerspruch zu dem 1996 von JUPIN und CHUA aus in-vitroDaten abgeleiteten Modell, nach dem die Behandlung mit SA oder CHX zur Dissoziation eines SARP/Inhibitorkomplexes führt, was unmittelbar die Bindung an das as-1-Element nach sich zieht. Aufgrund der hier gewonnenen Daten wird ein zweiter, SA-spezifischer Aktivierungsschritt der Bindung postuliert, der in-vitro bislang nicht gezeigt werden konnte.

In Untersuchungen der SA-induzierten Signaltransduktion in Zellkulturen zeigten sich grundsätzliche Unterschiede zur Situation in Blättern. Die SA-induzierte Expression der Zielgene Nt103 und parA war anders als im Blatt bei Überexpression von TGA2.1 $\Delta$ N29 nicht erhöht sondern erniedrigt. Auch die Bindung an das as-1-Element war nach SA-Behandlung in Extrakten aus Wildtyp-Zellkulturen nicht wie im Blatt verstärkt sondern verringert. 


\section{Einleitung}

\subsection{Die Rolle von Salicylsäure in der pflanzlichen Pathogenabwehr}

Höhere Pflanzen sind einer ständigen Bedrohung durch Pathogene ausgesetzt. Sie haben deshalb Mechanismen entwickelt, sich gegen Angriffe von Pathogenen zur Wehr zu setzen. Dabei spielt die schnelle Erkennung des Pathogens durch die Pflanze eine entscheidende Rolle für die effektive Eindämmung des Pathogenwachstums (Resistenz). Der Erkennung nachgeschaltet werden verschiedene Signaltransduktionswege aktiviert, in denen die mobilen Signalstoffe Salicylsäure (SA), Jasmonsäure (JA) und Ethylen Schlüsselkomponenten darstellen (zur Übersicht: DONG, 1998). Da sich diese Arbeit mit der SA-induzierten Genexpression beschäftigt, werden im folgenden insbesondere diese Signaltransduktionsprozesse zusammengefasst.

In resistenten Pflanzen kommt es unmittelbar nach der Erkennung des Pathogens am Ort der Infektion zur Ausprägung der sogenannten Hypersensitiven Reaktion (HR, HAMMONDKOSACK und JONES, 1996), die das örtlich begrenzte Absterben des Gewebes an der Infektionsstelle zur Folge hat.

Pflanzen, die eine pathogene Erstinfektion überleben, zeigen eine erhöhte Resistenz gegenüber einem breiten Spektrum von Pathogenen (KLESSIG und MALAMY, 1994; MALAMY et al., 1992). Diese Resistenz zeigt sich nicht nur am Ort der Infektion, sondern umfasst die gesamte Pflanze, und wird Systemisch erworbene Resistenz (Systemic Acquired Resistance, SAR; Ross, 1961) genannt. Sie wird von der Expression definierter PR-Proteine (Pathogenesis Related Proteins) begleitet. Nach Inokulation eines resistenten Tabakkultivars mit dem Tabak Mosaik Virus (TMV) kommt es sowohl in lokalen als auch in systemischen Tabakblättern zu einem Anstieg der SA-Menge um den Faktor 50 bzw. 10 (MALAMY et al., 1990). Da sich durch SA die gleichen PR-Proteine induzieren lassen wie durch Pathogeninfektion (MALECK et al., 2000; UKNES et al., 1993), lag die Bedeutung von SA für die Ausbildung der SAR nahe. Tatsächlich konnte die Notwendigkeit der SA-Akkumulation für die Ausbildung der SAR durch zahlreiche verschiedene Analysen untermauert werden. Transgene Pflanzen (N.tabacum und A. thaliana), die durch die Überexpression einer bakteriellen Salicylat Hydroxylase $(n a h G)$ nicht mehr in der Lage sind, SA zu akkumulieren, bilden nach Pathogenbefall keine SAR mehr aus (DELANEY et al., 1994; GAFFNEY et al., 1993). Umgekehrt zeigen Mutanten von A. thaliana, die konstitutiv erhöhte SA-Mengen akkumulieren (ssil, SHAH et al., 1999; lsd1, 6, 7, DANGL et al., 1996; PETERSON et al., 2000), 
eine gesteigerte Resistenz gegenüber bakteriellen und pilzlichen Pathogenen und eine konstitutive $P R$-Genexpression. Insbesondere die Analyse von Arabidopsis-Mutanten führte jedoch auch zu der Erkenntnis, dass die Wirkung von SA in der SAR durch JA und Ethylen auf positive und negative Weise beeinflusst wird.

Eine mögliche Schlüsselrolle in der SA-induzierten Signalkette könnte der Interaktion von SA mit Proteinen in der Zelle zukommen. Bislang konnte eine solche Interaktion für zwei verschiedene Proteine SABP (CHEN und KLESSIG, 1991) und SABP2 (DU und KLESSIG, 1997) nachgewiesen werden. Die Bindung von SA und funktionellen Analoga wie Benzothiadiazol (BTH; GÖRLACH et al., 1996) bzw. 2,6-Dichloroisonicotinsäure (INA) korreliert mit dem Potential dieser Substanzen, die SAR auszulösen (CONRATH et al., 1995; DURNER und KLESSIG, 1996; WENDEHENNE et al., 1998).

Höchstwahrscheinlich kann SA durch die Interaktion mit einem oder mehreren Proteinen in der Zelle eine Signaltransduktionskette aktivieren, die zur Transkriptionsaktivierung bestimmter Gene führt. Die Modifikation von Proteinen durch Phosphorylierung bzw. Dephosphorylierung ist ein häufig anzutreffender Mechanismus in Signaltransduktionsketten. So konnte auch für die SA-induzierte $P R$-1-Genexpression eine Abhängigkeit von Dephosphorylierungsereignissen nachgewiesen werden (CONRATH et al., 1997). Eine mindestens ebenso wichtige Rolle bei der SA-gesteuerten Signaltransduktion scheint Mitogen Aktivierten Protein- (MAP-) Kinasen zuzukommen. In den letzten Jahren wurden mehrere MAP-Kinasen beschrieben, deren Aktivität durch SA induziert wird. Prominentester Vertreter ist die SA-induzierte Protein Kinase (SIPK, ZHANG und KLESSIG, 1997; AtMPK6 in A. thaliana, MizoGuchi et al., 1995; MizOGUCHI et al., 1996), die durch SA und deren funktionelle Analoga sowie durch Elicitorbehandlung (ZHANG et al., 1998; ROMEIS et al., 1999) und Verwundung (ZHANG und KLESSIG, 1998) bzw. Applikation exogener NOSynthase (KUMAR und KLESSIG, 2000) aktiviert wird. Zusammen genommen können die Daten in der Form interpretiert werden, dass verschiedene Signaltransduktionswege gemeinsame Komponenten eines übergeordneten Proteinkomplexes benutzen (ELION, 1998). Auf diese Weise könnte es zu einer Integration bzw. Feinabstimmung (sog. cross-talk) der verschiedenen Signalwege untereinander kommen. Mit Hilfe der Mutante mpk4 konnte in A. thaliana gezeigt werden, dass die gleiche Kinase SA- und Jasmonsäure- (JA) Signalwege in unterschiedlicher Weise beeinflussen kann (PETERSON et al., 2000). MPK4 unterdrückt im uninduzierten Zustand die SAR und ist gleichzeitig notwendig für JA-induzierte Expression bestimmter Gene. Diese MAP-Kinase könnte somit für die Vernetzung verschiedener Signale 
von entscheidender Bedeutung sein. Obwohl das Wissen über die Signaltransduktion von SA noch lückenhaft ist, fällt Phosphorylierungs- bzw. Dephosphorylierungsereignissen sicher eine zentrale Bedeutung bei deren Regulation $\mathrm{zu}$, zumal über diese Mechanismen auch Transkriptionsfaktoren direkt modifiziert werden können (z. B. DRÖGE-LASER et al., 1997).

\subsection{As-1 ist ein cis-Element in Promotoren pflanzlicher Abwehrgene, das Salicylsäure-Induzierbarkeit vermittelt}

Durch SA-Applikation wird die Expression zahlreicher Gene induziert, die auch in der Pathogenabwehr involviert sind (MALECK et al., 2000; SCHENK et al., 2000). Man unterscheidet bei SA-induzierten Genen zwischen frühen Genen, für deren transiente Induktion nach SA keine Proteinneusynthese notwendig ist, und späten Genen, deren Expression erst nach etwa sieben bis zwölf Stunden einsetzt und strikt von Proteinneusynthese abhängt. $\mathrm{Zu}$ den frühen Genen zählen insbesondere Glutathion $S$ Transferasen (GSTs, BOOT et al., 1993), Glucosyltransferase(n) (HORVATH und CHUA, 1996) und weitere, zum Teil noch nicht näher charakterisierte Gene (HORVATH et al., 1998; SCHENK et al., 2000), für die aber diskutiert wird, dass sie eine Bedeutung für die späte Antwort haben könnten. Auch einige Promotoren von pflanzlichen Pathogenen (nos-Promotor aus A. tumefaciens, LAM et al., 1990; ocs-Promotor aus A.tumefaciens, BOUCHEZ et al., 1989; FROMM et al., 1989; CaMV 35S Promotor, QIN et al., 1994) zeigen eine SA-Induzierbarkeit. In diesen Promotoren wurde zuerst die activator sequence-1 (as-1, auch als ocs-Element bezeichnet) als cis-Element identifiziert, das die SA-Induzierbarkeit unabhängig von Proteinneusynthese (QIN et al., 1994) vermittelt. Das as-1-Element des CaMV 35S Promotors besteht aus zwei nicht perfekten TGACGTCA-Palindromen, die durch eine 4 bp lange Sequenz getrennt sind. Der Cauliflower Mosaic Virus (CaMV) 35S Promotor st in seiner vollen Länge konstitutiv in nahezu allen Pflanzenteilen aktiv (ODELL et al., 1985). Nach Verkürzung des Promotors auf einen Bereich von -90 bp bis zum Transkriptionsstart (Domäne A, enthält das as-1-Element und die TATA-Box) kommt es zur Aktivierung nur noch in Wurzelspitzen, Kalluszellen und Protoplasten (BENFEY et al., 1989; FROMM et al., 1989), bzw. durch SA (QIN et al., 1994) und Auxin (NIGGEWEG et al., 2000a). In vielen der zuvor genannten SA-induzierbaren Gene wurden ebenfalls as-1-ähnliche Sequenzen gefunden (CHEN et al., 1996; Ellis et al., 1993; UlMASOV et al., 1994; VAN DER ZAAL et al., 1996). Zu den aus N. tabacum isolierten Genen dieser Klasse zählen z. B. Nt103 (VAN DER ZAAL et al., 1987) und parA (protoplast auxin-regulated, TAKAHASHI et al., $1989=\mathrm{Nt114}$, VAN DER ZAAL et al., 1987), die aus BY2-Zellsuspensionen bzw. aus Protoplasten isoliert wurden, und die 
sowohl durch SA als auch durch Auxin, JA und $\mathrm{H}_{2} \mathrm{O}_{2}$ induzierbar sind (BOOT et al., 1993; TAKAHASHI et al., 1990; XIANG et al., 1996; NIGGEWEG et al., 2000a). Für beide Promotoren konnten durch Deletions- bzw. Mutationsanalysen as-1-ähnliche Sequenzen als notwendig und ausreichend für die Induzierbarkeit durch SA bzw. Auxin identifiziert werden (DROOG et al., 1995; SAKAI et al., 1998; TAKAHASHI et al., 1990; TAKAHASHI et al., 1995a). Es konnte weiterhin gezeigt werden, dass die Stärke von as-1 bzw. as-1-ähnlicher Elemente abhängig von der Übereinstimmung mit der as-1-Konsensussequenz ist (QIN et al., 1994; VAN DER ZAAL et al., 1996).

Die Genprodukte der Gene Nt103 und parA zeigen GST-Aktivität (DrOOG et al., 1993; TAKAHASHI et al., 1995b). Da eine Reihe von GSTs durch SA-Behandlung induzierbar sind, liegt eine Bedeutung dieser Enzyme in der Pathogenantwort nahe (ZHANG und SINGH, 1994). Durch Überexpression einer Glutathion S-Transferase/Glutathion Peroxidase konnte z. B. der schädigende Effekt von ROS drastisch gesenkt werden (ROXAS et al., 2000). Da die GSTAktivität des parA-Genprodukts aber deutlich unter der des Nt103-Genprodukts liegt (DROOG et al., 1993; TAKAHASHI et al., 1995a), wurde für ParA bereits früh vermutet, es könnte weitere noch nicht näher charakterisierte Funktionen in der Zelle übernehmen. Subzelluläre Lokalisationsstudien deuten z. B. auf eine Funktion im Nucleus hin (TAKAHASHI et al., 1995a).

Unter den späten SA-induzierten Genen in N. tabacum ist vor allem PR-la (MALAMY et al., 1990) zu nennen. Nach exogener SA-Applikation bzw. Pathogeninfektion kommt es in Abhängigkeit von Proteinneusynthese zur Induktion von PR-1a (QIN et al., 1994). Durch Deletionsanalysen konnte auch im Promotor von $P R$ - $1 a$ ein as-1-ähnliches Element für die SA-Induzierbarkeit verantwortlich gemacht werden (STROMPEN et al., 1998). Die Abhängigkeit von Proteinneusynthese lässt jedoch vermuten, dass das as-1-ähnliche Element nicht allein die starke Induktion von $P R-1 a$ bewerkstelligen kann. Frühere Arbeiten haben außerdem gezeigt, dass ein Minimalpromotor bestehend aus dem as-1-Element und einer TATA-Box die SA-abhängige Transkription eines Reportergens weniger stark induzieren kann, als ein as-1-ähnliches Element im Promotorkontext z. B. von PR-1a (QIN et al., 1994). Deshalb liegt die Vermutung nahe, dass as-1 in synergistischer Weise mit anderen cisElementen zusammenwirken kann. 
Durch genetische Screens auf die unterdrückte Expression von $P R-1$ in A. thaliana konnten mehrere Mutanten des Gens NPR1 identifiziert werden (CAO et al., 1994). NPR1 codiert für ein Protein, das sich durch eine Ankyrin-Repeat-Domäne auszeichnet, die essentiell für seine Funktion in der SAR ist (CAO et al., 1997). Im Hefe Two-Hybrid-System konnte nachgewiesen werden, dass NPR1 mit einer Reihe von TGA-Faktoren aus A. thaliana (DESPRES et al., 2000; ZHANG et al., 1999; ZHOU et al., 2000) und aus N. tabacum (NIGGEWEG et al., 2000b) interagiert. Diese bZIP-Proteine wiederum binden über ihre basische Domäne an das as-1-ähnliche Element im PR-1-Promotor (LEBEL et al., 1998). Darüber hinaus konnte gezeigt werden, dass die Anwesenheit von NPR1 die Bindung distinkter TGA-Faktoren an dieses as-1-ähnliche Element im Electro mobility shift assay (EMSA) erhöht, ohne selbst Bestandteil des Bindekomplexes zu sein (DESPRES et al., 2000). Zusammengenommen mit der Beobachtung, dass es nach SA-Behandlung zur Anreicherung von NPR1 im Zellkern kommt und es bei Retention von NPR1 im Cytoplasma nicht zur PR1-Induktion kommt (KINKEMA et al., 2000), unterstützen diese Daten die Annahme, dass NPR1 die Bindung der TGA-Faktoren nach SA-Stimulus auch in-vivo reguliert. Es ist aber nicht geklärt, ob die alleinige Anreicherung von NPR1 hinreichend für die Bindungsregulation ist, oder ob weitere (posttranslationale) Modifikationen notwendig sind. Die Rolle von NPR1 in der frühen SA-induzierten Antwort ist darüber hinaus nicht geklärt.

\subsection{ASF-1 und die Familie der TGA-Transkriptionsfaktoren}

Im Jahr 1989 wurde erstmals ein Proteinkomplex aus Kernextrakten von N. tabacum beschrieben, der an das as-1-Element des 35S Promotors des Cauliflower Mosaic Virus bzw. das ocs-Element im Promotor des Octopinsynthase-Gens aus A. tumefaciens bindet und als ASF-1 (Activating sequence factor 1) bezeichnet wurde (FROMM et al., 1989; KATAGIRI et al., 1989). Eine entsprechende Bindeaktivität kann auch in Gesamtzellextrakten nachgewiesen werden und wird in diesem Fall SARP (Salicylic acid responsive protein) genannt (JUPIN und CHUA, 1996). Für beide Faktoren konnte eine SA-abhängige Verstärkung der Bindeaktivität im EMSA gezeigt werden (JUPIN und CHUA, 1996; STANGE et al., 1997).

Als erstes as-1-bindendes Protein wurde der bZIP-Transkriptionsfaktor TGA1a isoliert (KATAGIRI et al., 1989). TGA1a zeichnet sich durch eine hochkonservierte bZIP-Region aus, die in ihrem basischen Bereich durch die Ausbildung einer $\alpha$-Helix die Bindung an DNA gewährleistet (VINSON et al., 1989). Der Leucin-Zipper ermöglicht über eine coiled-coilStruktur die Dimerisierung zweier TGA-Faktoren (LANDSCHULZ et al., 1988). 
Bei Überexpression eines mutierten Derivats von TGA1a, das bindungsunfähig aber weiterhin in der Lage ist, über seinen Leucin-Zipper Dimere mit anderen bZIP-Proteinen der TGAKlasse zu bilden, konnte die Bindeaktivität von ASF-1 reduziert werden (MIAO und LAM, 1995; RIEPING et al., 1994). TGA1a oder heterodimerisierende TGA-Faktoren sind demnach integraler Bestandteil von ASF-1 und binden nur in Form eines Dimers an ein Palindrom des as-1-Elements (KATAGIRI et al., 1992). Das as-1-Element kann also insgesamt von zwei Dimeren aus TGA-Faktoren erkannt werden. Die Dimerisierung von TGA1a wird durch den C-terminalen Bereich unterstützt (KATAGIRI et al., 1992), der zusätzlich über eine glutaminreiche Region verfügt. Entgegen der Hypothese von KATAGIRI et al. (1989), trägt nicht diese sondern eine saure Domäne im N-terminalen Bereich zur Transkriptionsaktivierung bei (NEUHAUS et al., 1994; PASCUZZI et al., 1998).

Es konnte nachgewiesen werden, dass es im nicht induzierten Zustand der Zelle im Cterminalen Bereich von TGA1a zur Interaktion mit einem $120 \mathrm{kDa}$ großen Protein kommt (JOHNSON et al., 2001). Durch Behandlung mit Auxin kommt es zur Dissoziation des Komplexes. Unter der Annahme, dass es sich bei dem 120 kDa-Protein um einen Inhibitor handelt, könnte auf diese Weise eine Bindungsregulation von TGA1a bewerkstelligt werden.

Mit Hilfe von EMSAs konnte in Kernextrakten von Tabakblättern TGA1a jedoch nicht in ASF-1 detektiert werden (LAM und LAM, 1995; NIGGEWEG et al., 2000a). Dies könnte an der niedrigen Expression von TGA1a in Blattgewebe liegen (NIGGEWEG et al., 2000b), denn die Injektion von rekombinantem TGAla-Protein führt zur Transkription eines as-1kontrollierten Reportergens (PASCUZZI et al., 1998).

Neben TGA1a konnten weitere Transkriptionsfaktoren isoliert werden, die an das as-1Element binden. In $A$. thaliana sind bislang sieben TGA-Faktoren beschrieben (TGA1 bis TGA6 und PERIANTHIA, CHUANG et al., 1999; KAWATA et al., 1992; MiAO et al., 1994; SCHINDLER et al., 1992; XIANG et al., 1997; ZHANG et al., 1993). Die aus N. tabacum bekannten TGA-Faktoren werden gemäß der Ähnlichkeit zu den TGA-Faktoren aus $A$. thaliana in die für diese Spezies vorgeschlagenen Klassen (XIANG et al., 1997) eingeordnet: TGA1a und PG13 (Fromm et al., 1991) zählen zur Klasse I, TGA2.1 (NIGGEWEG und GATZ, 1997) und TGA2.2 (NIGGEWEG et al., 2000b) zur Klasse II, und TGA7 (SCHIERMEYER, unveröffentlicht) bildet aufgrund seines langen N-Terminus eine eigene Klasse. TGA7 zeigt aber insbesondere im C-terminalen Bereich große Ähnlichkeit zu den TGA-Faktoren der Klasse II. 
Die Klasse II TGA-Faktoren TGA2.1 und TGA2.2 aus $N$. tabacum weisen im C-terminalen und im bZIP-Bereich mit $87 \%$ eine sehr starke Homologie auf (NIGGEWEG, 1999). Beide Faktoren unterscheiden sich jedoch in ihrer N-terminalen Domäne. Dem 170 Aminosäuren langen N-Terminus von TGA2.1 konnte im Hefe Two-Hybrid-System eine Transaktivierungsfunktion zugewiesen werden (NIGGEWEG et al., 2000b). Für TGA2.2 konnte in Hefe kein Aktivierungspotential nachgewiesen werden.

TGA2.2 bildet als in-vitro-Kotranslatat mit TGA2.1 bzw. TGA1a im EMSA bereitwillig bindende Heterodimere wie auch Homodimere aus, die sowohl eine als auch beide Halbseiten des as-1-Elements besetzen können (NIGGEWEG, 1999; NIGGEWEG et al., 2000b). In analogen Versuchen konnte auch die Heterodimerisierung von TGA2.1 mit TGA1a nachgewiesen werden, wenn auch mit deutlich geringerer Bindeaffinität. TGA2.1-Homodimere sind nur in der Lage, in Form von zwei Dimeren an das as-1-Element zu binden. Für diesen Effekt konnte in EMSA-Versuchen mit Deletionsderivaten der N-Terminus von TGA2.1 verantwortlich gemacht werden (KRAWCZYK, 1999; NIGGEWEG et al., 2000b).

Ferner konnte durch Northernblot-Analysen gezeigt werden, dass TGA2.1 und TGA2.2 sowohl in Blättern als auch in Wurzeln exprimiert werden (NIGGEWEG et al., 2000b). Die relative Expressionsstärke unterscheidet sich für beide Faktoren nicht zwischen Wurzel und Blatt, die TGA2.1-mRNA ist in beiden Geweben jedoch etwa 4 - 5 mal häufiger anzutreffen als die TGA2.2-mRNA. In Blättern konnten beide Faktoren im Kern nachgewiesen werden. In Gesamtzellextrakten war nur der Nachweis von TGA2.1 möglich (NIGGEWEG, 1999).

Durch Supershift-Analysen mit spezifischen Antiseren gegen TGA2.1, TGA2.2 und TGA1a konnte TGA2.2 als die Hauptkomponente von SARP bzw. ASF-1 (s. o.) in Blättern identifiziert werden (NIGGEWEG et al., 2000a). Demnach ist in Kernen TGA2.2 etwa 6 - 7 mal stärker in ASF-1 vertreten wie TGA2.1. In Gesamtzellextrakten ist dieses Verhältnis nur etwa halb so stark.

Die in-vivo-Relevanz dieser Ergebnisse wird durch Studien an transgenen Pflanzen unterstrichen, die jeweils einen der beiden TGA-Faktoren überexprimieren. Beide Pflanzen zeigen eine verstärkte Expression des as-1-kontrollierten Zielgens Nt103 nach SA- bzw. 2,4-D-Behandlung. Umgekehrt führt die Überexpression transdominanter Suppressorvarianten beider Faktoren in transgenen Pflanzen zur verringerten Expression des Zielgens (NIGGEWEG et al., 2000a; KEGLER, unveröffentlicht). Nur die transdominante Variante von TGA2.2 zeigt einen deutlichen (negativen) Einfluss auf die $P R$ - $1 a$-Expression nach SA-Applikation. In TGA2.2-überexprimierenden Pflanzen konnte lediglich ein marginaler positiver Effekt auf $P R$ - $1 a$ nachgewiesen werden. 
Im Hefe Two-Hybrid-System konnte die Interaktion von TGA2.1 und TGA2.2 mit NPR1 aus A. thaliana (NIGGEWEG et al., 2000b) und N. tabacum (THUROW, unveröffentlicht) nachgewiesen werden. Wie bereits erwähnt, könnte diese Interaktion möglicherweise für die ASF-1-Bindungsverstärkung verantwortlich sein, die nach SA-Applikation nachgewiesen werden konnte (JUPIN und CHUA, 1996). Für diese Bindungsregulation konnte gezeigt werden, dass Phosphorylierungsereignisse sich positiv auf die Bindung auswirken, während Dephosphorylierung die Bindung von ASF-1 bzw. SARP verhindert (JUPIN und CHUA, 1996; STANGE et al., 1997).

Alternativ bzw. zusätzlich könnte ASF-1 im Komplex mit einem Inhibitor der Bindung SAI assoziiert vorliegen, der nach SA-Induktion dissoziiert, was die Bindung von ASF-1 an das as-1-Element ermöglicht (JUPIN und CHUA, 1996). Dafür sprechen Daten, wonach dissoziierende Agenzien die Bindung an das as-1-Element fördern. Als möglicher Kandidat für diesen Inhibitor kommt ein Protein in Frage, das in ähnlicher Weise wirkt, wie der für TGA1a postulierte Bindungsinhibitor (JOHNSON et al., 2001). Da alle TGA-Faktoren trotz distinkter Unterschiede eine relativ hohe Homologie im Bereich des C-Terminus teilen, könnte es sich hierbei um einen generelleren Regulationsmechanismus der Bindung von TGA-Faktoren handeln. Verschiedene Inhibitormoleküle könnten für die reizspezifische Freigabe verschiedener aktivierender TGA-Faktoren verantwortlich sein.

$\mathrm{Da}$ in unserem Labor trotz intensiver Bemühungen die SA-induzierte Bindungsverstärkung nicht im EMSA gezeigt werden konnte, besteht außerdem die Möglichkeit eines alternativen Modells, wonach ASF-1 konstitutiv an das as-1-Element bindet, die SA-induzierte Aktivierung der Transkription jedoch erst durch Interaktion des gebundenen Komplexes mit einem Koaktivator erfolgt. Beide Modelle sind vergleichend in Abbildung 2-1 dargestellt.

a)

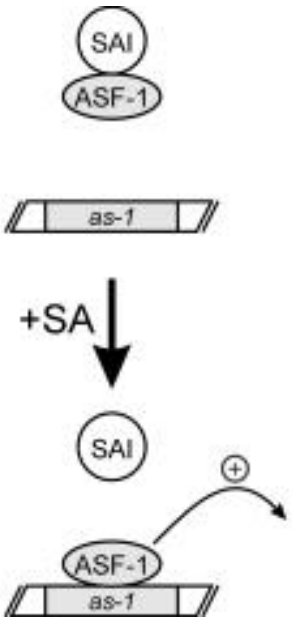

b)
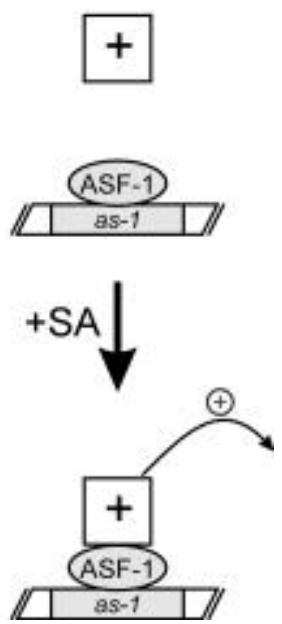

Abbildung 2-1: Alternative Modelle der SA-induzierten Transkriptionsaktivierung an as-1. a) Modell der SA-induzierten Dissoziation eines SAI/ASF-1- Komplexes und / oder der Bindungsverstärkung durch NPR1. b) Modell der konstitutiven Bindung an as -1 und der Aktivierung durch einen Koaktivator [+]. 


\subsection{Zielsetzung und experimenteller Ansatz der Arbeit}

Die Komponenten der auf dem as-1-Element mündenden SA-Signaltransduktionskette stehen im Mittelpunkt unseres Forschungsinteresses. Durch die Identifikation der Hauptbestandteile von ASF-1 / SARP in N. tabacum stehen in der Arbeitsgruppe mit TGA2.1 und TGA2.2 zwei wichtige Endkomponenten der Signalkette zur Verfügung. Die Regulation der Transaktivierung durch ASF-1 stellt den letzten möglichen Kontrollpunkt der Signaltransduktionskette dar. Das Verständnis dieser Regulation ist deshalb wichtig für die Aufklärung der gesamten SA-gesteuerten Signaltransduktion.

Bislang wurde das Bindungsverhalten von ASF-1 bzw. SARP nach SA-Behandlung nur anhand von in-vitro-Bindungsstudien untersucht. Eine Analyse der in-vivo-Situation stand noch aus.

Um die in-vivo-Bindungseigenschaften von ASF-1 näher zu untersuchen, sollten Fusionsproteine bestehend aus TGA2.1 bzw. TGA2.2 und der konstitutiven Aktivierungsdomäne des viralen Proteins 16 (VP16) aus Herpes simplex in transgenen Tabakpflanzen überexprimiert werden. $\mathrm{Zu}$ Beginn der Arbeit war nicht eindeutig geklärt, ob es nach SA-Induktion in-vivo zur induzierten Bindung der TGA-Faktoren an das as-1Element kommt, oder ob die TGA-Faktoren konstitutiv gebunden vorliegen und die Aktivierung der Transkription durch die Rekrutierung eines Koaktivators geschieht. Durch die Analyse der Transkription verschiedener potentieller Zielgene von TGA2.1 und TGA2.2 sollten die Bindungseigenschaften der beiden TGA-Faktoren in Abhängigkeit von SA aufgeklärt werden. Die VP16-Aktivierungsdomäne der Fusionsproteine sollte bei konstitutiver Bindung der TGA-Faktoren bereits im uninduzierten Zustand zur Aktivierung der Zielgene führen. Auf diese Weise sollte insbesondere das postulierte Modell von JUPIN und CHUA, 1996 überprüft werden.

An transgenen Tabaksuspensionskulturen sollten ergänzende Studien bezüglich der Rolle von TGA2.1 bei der SA-induzierten, frühen Genexpression durchgeführt werden, wobei besonders die Möglichkeit genutzt werden sollte, mit Phosphatase- bzw. Kinase-Inhibitoren den Einfluß von Phosphorylierung auf die Bindung von ASF-1 / SARP zu untersuchen. 


\section{Material}

\subsection{Organismen}

\subsubsection{Bakterienstämme}

\begin{tabular}{|c|c|c|}
\hline Bakterium & Eigenschaften & Referenz \\
\hline $\begin{array}{l}\text { Escherichia coli } \\
\text { DH5 } \alpha\end{array}$ & $\begin{array}{l}\text { recA1 relA1 thi-1 } \Delta \text { lacU169 } \phi 80 \\
\left.(\text { lacZ } \Delta \mathrm{M} 15) \text { hsdR17( } \mathrm{r}_{\mathrm{k}}-\mathrm{m}_{\mathrm{k}}+\right) \\
\text { Klonier- und Sequenzierstamm }\end{array}$ & HANAHAN, 1983 \\
\hline $\begin{array}{l}\text { Escherichia coli } \\
\text { XL1-Blue }\end{array}$ & $\begin{array}{l}\text { recA1 endA1 gyrA96 thi- } 1 \text { hsdR17 supE44 } \\
\left.\left.\text { relA1 lac [F' proAB lacI }{ }^{\mathrm{q}} \mathrm{Z} \Delta \mathrm{M} 15 \mathrm{Tn} 10 \text { (tet }^{\mathrm{r}}\right)\right] \text {, } \\
\text { Klonier- und Sequenzierstamm }\end{array}$ & BULLOCK et al., 1987 \\
\hline $\begin{array}{l}\text { Escherichia coli } \\
\text { XL2-Blue }\end{array}$ & $\begin{array}{l}\text { recA1 endA1 gyrA96 thi-1 hsdR17 supE44 } \\
\left.\text { relA1 lac [F' proAB lacl }{ }^{\mathrm{q}} \mathrm{Z} \Delta \mathrm{M} 15 \mathrm{Tn} 10 \text { (tet }^{\mathrm{r}}\right) \\
\left.\text { amy cam }{ }^{\mathrm{r}}\right] \\
\text { Klonier- und Sequenzierstamm }\end{array}$ & Stratagene \\
\hline $\begin{array}{l}\text { Agrobacterium } \\
\text { tumefaciens } \\
\text { C58-C1-R } \\
\text { pGV2660 }\end{array}$ & Rif', $\mathrm{Cm}^{r}$ & DEBLAERE et al., 1985 \\
\hline
\end{tabular}

\subsubsection{Pflanzen}

Es wurden ausschließlich Nicotiana tabacum-Pflanzen vom Kultivar Samsun NN (SNN) verwendet. Folgende transgene Pflanzen wurden eingesetzt:

\begin{tabular}{|c|c|c|}
\hline Pflanze & Eigenschaften & Referenz \\
\hline Hö as-1-GUS & "CaMV 35S::tetR, as-1-GUS, $\mathrm{Km}^{\mathrm{r}}, \mathrm{Ppt}^{\mathrm{r}}$ & "GATZ, unveröffentlicht \\
\hline SNN 2.1 & CaMV 35S::TGA2.1, $\mathrm{Hyg}^{\mathrm{r}}$ & KEGLER, unveröffentlicht \\
\hline SNN $2.1 \Delta$ N29 & CaMV 35S::TGA2.1 $\Delta \mathrm{N} 29, \mathrm{Hyg}^{\mathrm{r}}$ & KEGLER, unveröffentlicht \\
\hline SNN 2.1-57s & CaMV 35S::TGA2.1-57, $\mathrm{Hyg}^{\mathrm{r}}$ & 5.2 .2 .5 \\
\hline SNN 2.1ENGs & CaMV 35S::TGA2.1-ENG, $\mathrm{Hyg}^{\mathrm{r}}$ & 5.2.2.4 \\
\hline SNN 2.1trD & CaMV 35S::TGA2.1trD, Hyg $^{\mathrm{r}}$ & KEGLER, unveröffentlicht \\
\hline SNN 2.1VPs & CaMV 35S::TGA2.1-VP16, $\mathrm{Hyg}^{\mathrm{r}}$ & 5.2.2.3 \\
\hline SNN 2.2 & CaMV 35S::TGA2.2, $\mathrm{Hyg}^{\mathrm{r}}$ & NIGGEWEG, 1999: SNN TGA2.2 UE \\
\hline SNN 2.2ENGs & CaMV 35S::TGA2.2-ENG, $\mathrm{Hyg}^{\mathrm{r}}$ & 5.2 .3 .2 \\
\hline SNN 2.2VPs & CaMV 35S::TGA2.2-VP16, $\mathrm{Hyg}^{\mathrm{r}}$ & 5.2.3.1 \\
\hline SNN as-1-GUS & as-1-GUS, $\mathrm{Ppt}^{\mathrm{r}}$ & GATZ, unveröffentlicht \\
\hline SNN ENG2.1s & CaMV 35S::ENG-TGA2.1, $\mathrm{Hyg}^{\mathrm{r}}$ & 5.2.2.2 \\
\hline SNN VP2.1s & CaMV 35S::VP16-TGA2.1, Hyg $^{\mathrm{r}}$ & 5.2.2.1 \\
\hline SNN VP2.2s & CaMV 35S::VP16-TGA2.2, $\mathrm{Hyg}^{\mathrm{r}}$ & CZEKO, 2000 \\
\hline
\end{tabular}




\subsection{Nucleinsäuren}

\subsubsection{Plasmide}

\begin{tabular}{|c|c|c|}
\hline Plasmid & Eigenschaften & Referenz \\
\hline $\begin{array}{l}\text { pBHTX- } \\
2.1-57 \mathrm{~s} \\
\end{array}$ & $\begin{array}{l}\text { enthält ein } 1111 \mathrm{bp} \text { großes KpnI / XbaI-Insert aus } \\
\text { pUC57 2.1-57s in pBINHyg-TX, Km }\end{array}$ & 4.3 .7 .15 \\
\hline $\begin{array}{l}\text { pBHTX- } \\
2.1 \mathrm{ENGs}\end{array}$ & $\begin{array}{l}\text { enthält ein } 2375 \text { bp großes KpnI / StuI-Insert aus } \\
\text { pUC57 2.1ENGs zwischen KpnI und SmaI in } \\
\text { pBINHyg-TX, Km }\end{array}$ & 4.3 .7 .15 \\
\hline pBHTX-2.1VPs & $\begin{array}{l}\text { enthält ein } 1856 \text { bp großes KpnI / StuI-Insert aus } \\
\text { pUC57 2.1VPs zwischen KpnI und SmaI in } \\
\text { pBINHyg-TX, Km }\end{array}$ & 4.3 .7 .15 \\
\hline $\begin{array}{l}\text { pBHTX- } \\
\text { 2.2ENGs }\end{array}$ & $\begin{array}{l}\text { enthält ein } 1973 \text { bp großes } K p n I \text { / XbaI-Insert aus } \\
\text { pSK 2.2ENGs in pBINHyg-TX, Km }\end{array}$ & 4.3 .7 .15 \\
\hline pBHTX-2.2VPs & $\begin{array}{l}\text { enthält ein } 1454 \text { bp großes } K p n I \text { / XbaI-Insert aus } \\
\text { pSK 2.2VPs in pBINHyg-TX, Km }\end{array}$ & 4.3 .7 .15 \\
\hline $\begin{array}{l}\text { pBHTX- } \\
\text { ENG2.1s }\end{array}$ & $\begin{array}{l}\text { enthält ein } 2365 \text { bp großes KpnI / StuI-Insert aus } \\
\text { pUC57 ENG2.1s zwischen KpnI und SmaI in } \\
\text { pBINHyg-TX, Km }\end{array}$ & 4.3 .7 .15 \\
\hline pBHTX-VP2.1s & $\begin{array}{l}\text { enthält ein } 1846 \text { bp großes } K p n \mathrm{I} / \text { StuI-Insert aus } \\
\text { pUC57 VP2.1s zwischen KpnI und SmaI in } \\
\text { pBINHyg-TX, Km }\end{array}$ & 4.3 .7 .15 \\
\hline pBINHyg-TX & $\begin{array}{l}\text { Derivat des binären Pflanzentransformationsvektors } \\
\text { pBINHyg, enthält den TX-Promotor und die } \\
\text { Terminatorsequenz pAnos, } \mathrm{Km}^{\mathrm{r}}\end{array}$ & $\begin{array}{l}\text { RIEPING et al., } \\
1994\end{array}$ \\
\hline pENGRAILED & $\begin{array}{l}\text { enthält ein } 1706 \text { bp großes Fragment bestehend aus } \\
\left(5^{\prime} \rightarrow 3^{\prime}\right) \text { CaMV } 35 \mathrm{~S} \text { Promotor - TMV-omega- } \\
\text { leader }-E N G R A I L E D \text {-Silencerdomäne - polyA- } \\
\text { Signal in pUC, Amp }{ }^{r}\end{array}$ & $\begin{array}{l}\text { WERR, } \\
\text { unveröffentlicht }\end{array}$ \\
\hline $\mathrm{pK} 2.1 \mathrm{~L}$ & $\begin{array}{l}\text { enthält ein } 1407 \text { bp großes KpnI / BamHI-Fragment } \\
\text { bestehend aus }\left(5^{\prime} \rightarrow 3^{\prime}\right) \text { Kozak-Sequenz }- \text { TGA2.1- } \\
\text { Peptidlinkersequenz in pUC57, Amp }{ }^{\mathrm{r}}\end{array}$ & 4.3 .7 .3 \\
\hline $\mathrm{pK} 2.2 \mathrm{~L}$ & $\begin{array}{l}\text { enthält ein } 1015 \text { bp großes } K p n I \text { / BamHI-Fragment } \\
\text { bestehend aus }\left(5^{\prime} \rightarrow 3^{\prime}\right) \text { Kozak-Sequenz }- \text { TGA2.2- } \\
\text { Peptidlinkersequenz in } \mathrm{pSK}, \mathrm{Amp}^{\mathrm{r}}\end{array}$ & 4.3.7.4 \\
\hline pKENGL & $\begin{array}{l}\text { enthält ein } 959 \text { bp großes PCR-Fragment bestehend } \\
\text { aus }\left(5^{\prime} \rightarrow 3^{\prime}\right) \text { Kozak-Sequenz - ENGRAILED-Silen- } \\
\text { cerdomäne - Peptidlinkersequenz in pUC57, Amp }{ }^{r}\end{array}$ & 4.3 .7 .2 \\
\hline pKVPL & $\begin{array}{l}\text { enthält ein } 405 \text { bp großes PCR-Fragment bestehend } \\
\text { aus }\left(5^{\prime} \rightarrow 3^{\prime}\right) \text { Kozak-Sequenz - VP16-Aktivierungs- } \\
\text { domäne - Peptidlinkersequenz in pUC57, Amp }{ }^{r}\end{array}$ & 4.3 .7 .1 \\
\hline pL2.1s & $\begin{array}{l}\text { enthält ein } 1422 \text { bp großes BamHI-Fragment } \\
\text { bestehend aus (5' } \rightarrow \text { 3') Peptidlinkersequenz - } \\
\text { TGA2.1 - Streptag }{ }^{\circledR} \text { II-Sequenz in pUC57, Amp }{ }^{\mathrm{r}}\end{array}$ & 4.3 .7 .7 \\
\hline pLENGs & 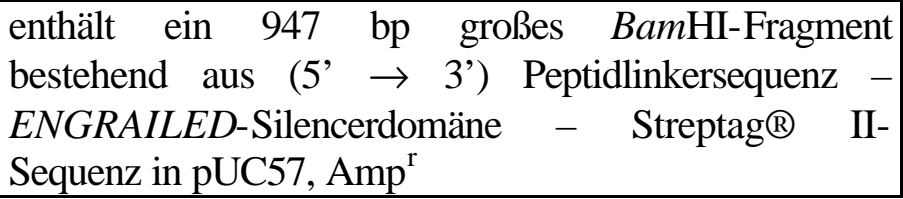 & 4.3 .7 .6 \\
\hline
\end{tabular}




\begin{tabular}{|c|c|c|}
\hline Plasmid & Eigenschaften & Referenz \\
\hline pLVPs & 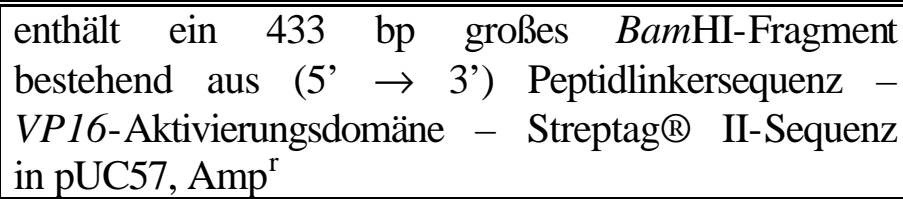 & 4.3.7.5 \\
\hline $\mathrm{pSK}$ & lacZ $\alpha, \mathrm{Amp}^{\mathrm{r}}$, Klonier- und Sequenziervektor & Stratagene \\
\hline pSK 2.2ENGs & $\begin{array}{lllll}\text { enthält die } 1944 \text { bp lange } & \text { Codierregion für } & \text { ein } \\
\text { Fusionsprotein bestehend } & \text { aus } \text { TGA2.2 } & - \\
\text { ENGRAILED-Silencerdomäne }^{-} & - & \text {Streptag® } & \text { II } & \text { in } \\
\text { pSK, Amp } & \end{array}$ & 4.3 .7 .13 \\
\hline pSK 2.2VPs & $\begin{array}{l}\text { enthält die } 1425 \text { bp lange Codierregion für ein } \\
\text { Fusionsprotein bestehend aus TGA2.2 - VP16- } \\
\text { Aktivierungsdomäne - Streptag® II in pSK, Amp }{ }^{\mathrm{r}}\end{array}$ & 4.3 .7 .12 \\
\hline $\begin{array}{l}\text { pSK TGA2.1 } \\
\text { in vitro }\end{array}$ & $\begin{array}{l}\text { enthält TGA2.1-cDNA } \text { aus } \text { N. tabacum mit } \\
\text { Kozaksequenz vor dem ATG (AACCATG) unter } \\
\text { der Kontrolle des } \\
\text { und 3 UTR, Amp }{ }^{\mathrm{r}}\end{array}$ & NIGGEWEG, 1999 \\
\hline $\begin{array}{l}\text { pSK TGA2.2 } \\
\text { in vitro }\end{array}$ & $\begin{array}{l}\text { enthält TGA2.2-cDNA } \text { aus N. tabacum mit } \\
\text { Kozaksequenz vor dem ATG (AACCATG) unter } \\
\text { der Kontrolle des T7 RNA-Polymerase-Promotors, } \\
\text { Amp }^{\text {r }}\end{array}$ & NIGGEWEG, 1999 \\
\hline pSK-2811 PCR & $\begin{array}{l}\text { enthält die vollständige, } 980 \text { bp lange cDNA von } \\
\text { TGA2.2 aus N. tabacum, } \mathrm{Amp}^{\mathrm{r}}\end{array}$ & NIGGEWEG, 1999 \\
\hline pSKTGA2.1-57 & 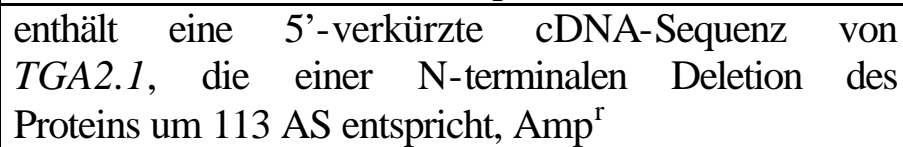 & KRAWCZYK, 1999 \\
\hline pSK-VP16 & $\begin{array}{l}\text { enthält ein } 400 \text { bp großes PCR-Produkt der VP16- } \\
\text { Aktivierungsdomäne aus Herpes simplex, Amp }{ }^{\mathrm{r}}\end{array}$ & $\begin{array}{l}\text { NIGGEWEG, } \\
\text { unveröffentlicht }\end{array}$ \\
\hline pTGA2.1 & $\begin{array}{l}\text { enthält die vollständige cDNA-Sequenz von TGA2.1 } \\
\text { aus N. tabacum mit 3'-fusionierter Sequenz für den } \\
\text { Streptag@ II in pUC57, } \text { Amp }^{\text {r }}\end{array}$ & $\begin{array}{l}\text { KEGLER, } \\
\text { unveröffentlicht }\end{array}$ \\
\hline pTGA2.1 trD II & $\begin{array}{l}\text { enthält die komplette cDNA-Sequenz für eine } \\
\text { bindungsinhibierte Mutante von TGA2.1, die in } \\
\text { ihrer basischen Domäne zwei Aminosäure- } \\
\text { austausche }(\mathrm{AA} \rightarrow \mathrm{PP}) \text { aufweist, } \mathrm{Amp}^{\mathrm{r}}\end{array}$ & $\begin{array}{l}\text { KEGLER, } \\
\text { unveröffentlicht }\end{array}$ \\
\hline pUC18 & lacZ $\alpha, \mathrm{Amp}^{\mathrm{r}}$, Klonier- und Sequenziervektor & $\begin{array}{l}\text { YANISCH-PERRON } \\
\text { et al., } 1985\end{array}$ \\
\hline pUC18 as- 1 BpiI & $\begin{array}{l}\text { enthält das as-1-Element des CaMV 35S Promotors } \\
\text { als PCR-Fragment, verwendbar als Bpil-Fragment } \\
\text { (as-1-short), Amp }{ }^{\mathrm{r}}\end{array}$ & $\begin{array}{l}\text { KEGLER, } \\
\text { unveröffentlicht }\end{array}$ \\
\hline pUC18-as-1 & 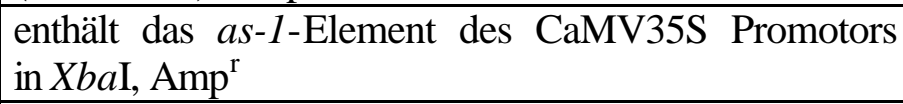 & $\begin{array}{l}\text { THUROW, } \\
\text { unveröffentlicht }\end{array}$ \\
\hline pUC18-as-103 & $\begin{array}{l}\text { enthält das as-1-Element des Promotors von } N t 103 \\
\text { in } \mathrm{Xba \textrm {I } , \mathrm { Amp }}{ }^{\mathrm{r}}\end{array}$ & 3.2 .5 .1 \\
\hline pUC18-pas-a & $\begin{array}{l}\text { enthält das as-1-Element des Promotors von parA in } \\
X b a \mathrm{I}, \mathrm{Amp}^{\mathrm{r}}\end{array}$ & 3.2 .5 .2 \\
\hline pUC57 & lacZ $\alpha, \mathrm{Amp}^{\mathrm{r}}$, Klonier- und Sequenziervektor & $\begin{array}{l}\text { MARCHUK et al., } \\
1990\end{array}$ \\
\hline
\end{tabular}




\begin{tabular}{|c|c|c|}
\hline Plasmid & Eigenschaften & Referenz \\
\hline pUC57 2.1-57s & 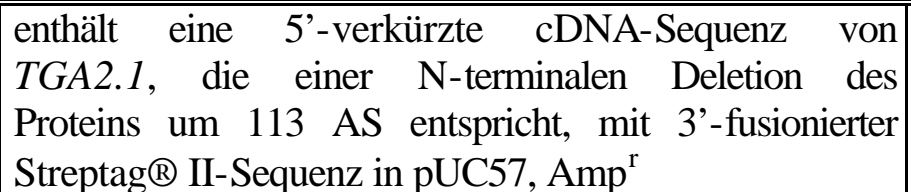 & 4.3 .7 .14 \\
\hline pUC57 2.1ENGs & $\begin{array}{lllll}\text { enthält die } 2343 \text { bp lange } & \text { Codierregion für } & \text { ein } \\
\text { Fusionsprotein } & \text { bestehend } & \text { aus } & \text { TGA2.1 } & - \\
\text { ENGRAILED-Silencerdomäne } & - & \text { Streptag® } & \text { II } & \text { in } \\
\text { pUC57, Amp } & \end{array}$ & 4.3 .7 .11 \\
\hline pUC57 2.1VPs & $\begin{array}{l}\text { enthält die } 1818 \text { bp lange Codierregion für ein } \\
\text { Fusionsprotein bestehend aus TGA2.1 - VP16-Akti- } \\
\text { vierungsdomäne - Streptag® II in pUC57, Amp }{ }^{\mathrm{r}}\end{array}$ & 4.3 .7 .10 \\
\hline pUC57 ENG2.1s & 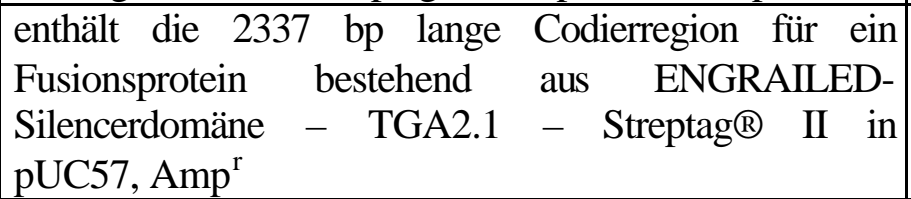 & 4.3 .7 .9 \\
\hline pUC57 parA & $\begin{array}{l}\text { enthält ein } 696 \text { bp großes cDNA-Fragment der kom- } \\
\text { pletten Codierregion von parA in pUC57/T, Amp }{ }^{\text {r }}\end{array}$ & 4.3 .3 \\
\hline pUC57 VP2.1s & $\begin{array}{l}\text { enthält die } 1812 \text { bp lange Codierregion für ein } \\
\text { Fusionsprotein bestehend aus VP16-Aktivierungs- } \\
\text { domäne - TGA2.1 - Streptag } ® \text { II in pUC57, Amp }{ }^{r}\end{array}$ & 4.3 .7 .8 \\
\hline pUC57/T & $\begin{array}{l}\text { pUC57-Derivat, lacZ, } \mathrm{Amp}^{\mathrm{r}} \text {, mit Eco32I linearisiert } \\
\text { und ddT-Überhängen an den 3'-Enden versehen, } \\
\text { Klonier- und Sequenziervektor }\end{array}$ & $\begin{array}{l}\text { MARCHUK et al., } \\
1990\end{array}$ \\
\hline
\end{tabular}

\subsubsection{Hybridisierungssonden}

\begin{tabular}{|c|c|c|}
\hline Sonde & \begin{tabular}{|l} 
Eigenschaften \\
\end{tabular} & Referenz \\
\hline 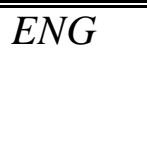 & $\begin{array}{l}946 \text { bp BamHI-Fragment aus pLENGs }(3.2 .1)=\text { cDNA der } \\
\text { Silencerdomäne von ENGRAILED aus Drosophila } \\
\text { melanogaster }\end{array}$ & POOLE et al., 1985 \\
\hline GUS & $\begin{array}{l}2 \text { kb SacI-Fragment aus pGUS = cDNA-Sequenz der } \beta \text { - } \\
\text { Glucuronidase (ohne Intron) }\end{array}$ & $\begin{array}{l}\text { KÖSTER-TÖPFER } \text { et } \\
a l ., 1989 \\
\end{array}$ \\
\hline Nt103 & $\begin{array}{l}1 \mathrm{~kb} \text { EcoRI-Fragment aus dem Vektor pCNT103 = } \\
\text { vollständige cDNA des Gens Nt103 aus N. tabacum. } \\
\text { (pCNT103 wurde von E.J. VAN DER ZAAL zur Verfügung } \\
\text { gestellt) }\end{array}$ & $\begin{array}{l}\text { VAN DER ZAAL } \text { et al., } \\
1991\end{array}$ \\
\hline parA & $\begin{array}{l}715 \text { bp Fragment } X b a \mathrm{I} / \text { Bam HI-Fragment aus dem Vektor } \\
\text { pUC57 parA (s. } 3.2 .1)=\text { vollständige cDNA des protoplast } \\
\text { auxin regulated-Gens aus } N \text {. tabacum }\end{array}$ & $\begin{array}{l}\text { TAKAHASHI } \text { et al., } \\
1989\end{array}$ \\
\hline$P R-1 a$ & $\begin{array}{l}531 \text { bp EcoRI / BamHI-Fragment der cDNA des } \\
\text { pathogenesis-related protein la von N. tabacum aus dem } \\
\text { Vektor pPR-1a; (pPR-1a wurde von M. DRÖGE zur } \\
\text { Verfügung gestellt) }\end{array}$ & CUTT et al., 1988 \\
\hline tetR & $\begin{array}{l}0,7 \text { kb XbaI-Fragment aus pTet1 = cDNA des Tn10- } \\
\text { codierten Tetracyclin-Repressors }\end{array}$ & GATZ et al., 1991 \\
\hline$T G A 2.1$ & $\begin{array}{l}\text { 1,3 kb KpnI / BamHI-Fragment aus dem Vektor pSK- } \\
\text { TGA2.1 in vitro = vollständige cDNA des TGA2.1-Gens } \\
\text { aus } N . \text { tabacum (pSK-TGA2.1 in vitro wurde von R. } \\
\text { NIGGEWEG zur Verfügung gestellt) }\end{array}$ & $\begin{array}{l}\text { NIGGEWEG und } \\
\text { GATZ, } 1997\end{array}$ \\
\hline
\end{tabular}




\begin{tabular}{|l|l|l|}
\hline Sonde & Eigenschaften & Referenz \\
\hline \hline TGA2.2 & $1,0 \mathrm{~kb}$ KpnI / BamHI-Fragment aus dem Vektor pSK- & NIGGEWEG, 1999 \\
& TGA2.2 in vitro = vollständige cDNA des TGA2.2-Gens & \\
& aus N. tabacum (pSK-TGA2.2 in vitro wurde von R. & \\
& NIGGEWEG zur Verfügung gestellt) & \\
\hline VP16 & $\begin{array}{l}\text { 427 bp BamHI-Fragment aus pLVPs } 3.2 .1)=\text { cDNA der } \\
\text { Aktivierungsdomäne des viral protein 16 aus Herpes } \\
\text { simplex }\end{array}$ & WEINMANN et al., \\
\hline
\end{tabular}

\subsubsection{Primer}

Die Synthese von Primern wurde bei den Firmen ROTH, Karlsruhe und NAPS, Göttingen in Auftrag gegeben. Die Bindepositionen der Primer sind im Anhang aufgeführt.

Die Schmelztemperatur der Primer wurde nach folgender Formel berechnet:

$\mathrm{T}_{\mathrm{m}}\left[{ }^{\circ} \mathrm{C}\right]=69,3+\left(41 \mathrm{x}\left(\mathrm{n}_{\mathrm{G} / \mathrm{C}} / \mathrm{n}_{\text {gesamt }}\right)-650 / \mathrm{n}_{\mathrm{gesamt}} \quad(\mathrm{n}=\right.$ Anzahl der Nucleotide $)$

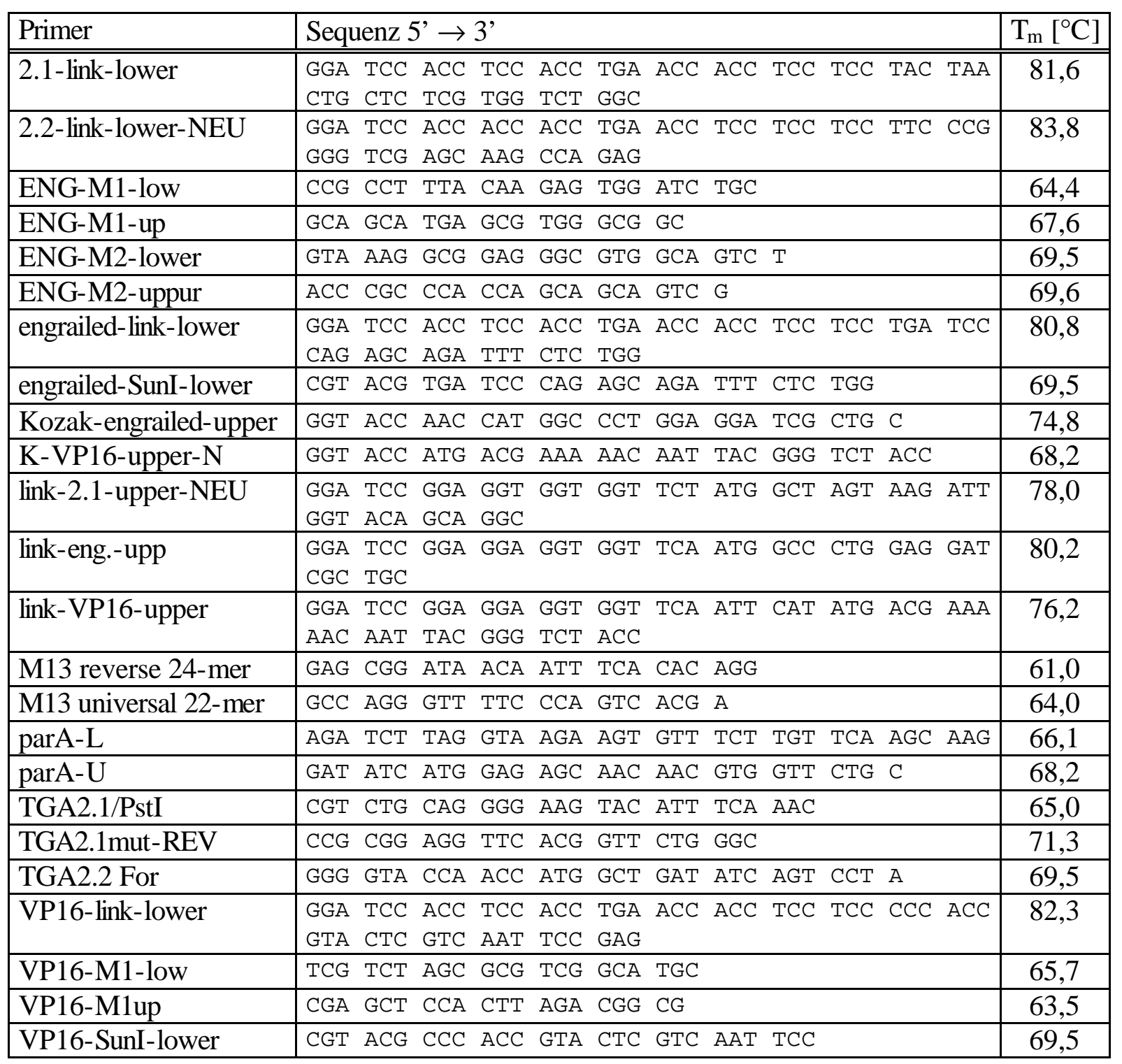




\subsubsection{Oligonucleotide}

Folgende Oligonucleotide wurden zur Generierung von DNA-Fragmenten für den EMSA als Auftragssynthese von der Firma NAPS, Göttingen bezogen:

\begin{tabular}{|l|l|}
\hline Oligonucleotid & Sequenz 5' $\rightarrow$ 3' \\
\hline \hline $\begin{array}{l}\text { as-103-lower } \\
(20401 N)\end{array}$ & CTA GAA TAC GTA AGC ACT TAG CTA TTC TAG AGT CGA CCT GCA \\
\hline $\begin{array}{l}\text { as-103-upper } \\
(20400 N)\end{array}$ & GGT CGA CTC TAG AAT AGC TAA GTG CTT ACG TAT T \\
\hline $\begin{array}{l}\text { pas-A-lower } \\
(20399 N)\end{array}$ & CTA GAA GAT GTC ATT GCT TGC GTA ATC TAG AGT CGA CCT GCA \\
\hline $\begin{array}{l}\text { pas-A-upper } \\
(20398 N)\end{array}$ & GGT CGA CTC TAG ATT ACG CAA GCA ATG ACA TCT T \\
\hline
\end{tabular}

\subsubsection{DNA-Fragmente für EMSAs}

\subsubsection{Klonierung von pUC18 as- 103}

Äquimolare Mengen der unter 3.2.4 beschriebenen Oligonucleotide as-103-lower und as-103upper wurden $1 \mathrm{~min}$ im Wasserbad gekocht und anschließend im heißen Wasserbad über Nacht auf RT heruntergekühlt (annealing). Die doppelsträngigen Oligonucleotide wurden in den PstI / XbaI-geschnittenen Vektor pUC18 einkloniert und sequenziert.

\subsubsection{Klonierung von pUC18-pas-a}

Äquimolare Mengen der unter 3.2.4 beschriebenen Oligonucleotide pas-a-lower und pas-aupper wurden $1 \mathrm{~min}$ im Wasserbad gekocht und anschließend im heißen Wasserbad über Nacht auf RT heruntergekühlt (annealing). Die doppelsträngigen Oligonucleotide wurden in den PstI / XbaI-geschnittenen Vektor pUC18 einkloniert und sequenziert.

\subsubsection{Gewinnung der im EMSA eingesetzten Fragmente}

Im Rahmen dieser Arbeit wurden für den EMSA folgende DNA-Fragmente radioaktiv markiert:

$\begin{array}{ll}\text { as }-1 & \text { TGACGTAAggatGACGCAC } \\ & \text { ACTGCATTCCCtACTGCGTG } \\ \text { as-103 } & \text { ATAGCTAAgtgctTACGTAT } \\ & \text { TATCGATTCacgAATGCATA } \\ \text { pas-a } & \text { TTACGCAAgcaatGACATCT } \\ & \text { AATGCGTTcgttACTGTAGA }\end{array}$

als EcoRI / NdeI-Fragment aus pUC18 as-1 (3.2.1)

als EcoRI / NdeI-Fragment aus pUC18 as- 103 (3.2.5.1)

als EcoRI / NdeI-Fragment aus pUC18 pas-a (3.2.5.2)

Die zuvor genannten Fragmente wurden für alle EMSAs mit nativen Extrakten nach JUPIN und CHUA, 1996 (4.5.1.4) verwendet. 
Für EMSAs mit nativen Extrakten nach dem FixProt-Protokoll wurde das folgende as-1Fragment verwendet, das sich dadurch auszeichnet, dass an seinen Enden mehr $\left[\alpha^{32} \mathrm{P}\right] \mathrm{dATP}$ eingebaut werden kann:

as-1-short TGACGTAAgggatGACGCAC ACTGCATTCCCtACTGCGTG als BpiI-Fragment aus dem Vektor pUC18 as- 1 BpiI (3.2.1)

\subsubsection{DNA-Längenstandards}

Die Größe von DNA-Fragmenten wurde im Agarosegel durch Vergleich mit DNALängenstandards bestimmt. Die Fragmentgrößen dieser Marker (in bp) sind im folgenden aufgeführt.

pUC19 HpaII (aus Eigenherstellung)

$501 / 489$ / 404 / 331 / 242 / 190 / 147 / 111 / 110 / 67

$\underline{\lambda P s t \mathrm{I}}$ (aus Eigenherstellung)

14057 / 11497 / 5077 / 4749 / 4507 / 2838 / 2459 / 2443 / 2140 / 1986 / 1700 / 1159 / 1093 / 805 / 514 / 468 / 448

$\underline{1 \mathrm{~kb}-\text { Leiter }}$ (GIBCO BRL)

12216 / 11198 / 10180 / 9162 / 8144 / 7126 / 6108 / 5090 / 4072 / 3054 / 2036 / 1636 / 1018 / 517 / 506 / 396 / 344 / 298 / 220 / 201 / 154 / 134 / 75

\subsubsection{Radioaktiv markierte Nucleotide}

Zur radioaktiven Markierung von DNA-Sondenmolekülen wurden folgende Chemikalien von der Firma Hartmann Analytik, Braunschweig bezogen:

$\left[\alpha^{32} \mathrm{P}\right] \mathrm{dATP}$

$\left[\alpha^{32} \mathrm{P}\right] \mathrm{dCTP}$

Beide Verbindungen besaßen eine spezifische Aktivität von $800 \mathrm{Ci} / \mathrm{mmol}$.

\subsection{Proteine}

\subsubsection{Proteinstandards}

Zur Abschätzung des Molekulargewichts von Proteinen in der SDS-PAGE wurden die Marker BENCHMARK $^{\mathrm{TM}}$ Prestained Protein Ladder der Firma GIBCO BRL und SeeBlue ${ }^{\mathrm{TM}}$ PreStained Standard der Firma NOVEX verwendet. 


\subsubsection{Antiseren}

\begin{tabular}{|l|l|l|}
\hline Antiserum & Eigenschaften & Referenz \\
\hline \hline$\alpha$ TGA1a & polyklonal aus Kaninchen, Rohserum & NIGGEWEG, 1999 \\
\hline$\alpha$ TGA2.1 & $\begin{array}{l}\text { polyklonal aus Kaninchen, Rohserum bzw. } \\
\text { affinitätsgereinigt }\end{array}$ & NIGGEWEG, 1999 \\
\hline$\alpha$ TGA2.2 & $\begin{array}{l}\text { polyklonal aus Kaninchen, Rohserum bzw. } \\
\text { affinitätsgereinigt }\end{array}$ & NIGGEWEG, 1999 \\
\hline$\alpha$ TGA7 & polyklonal aus Kaninchen, Rohserum & $\begin{array}{l}\text { SCHIERMEYER, } \\
\text { unveröffentlicht }\end{array}$ \\
\hline$\alpha$ Streptag® II & polyklonal aus Kaninchen, affinitätsgereinigt & IBA \\
\hline anti rabbit Ig & Peroxidase-gekoppelt, polyklonal aus Esel & Amersham \\
\hline
\end{tabular}

\subsection{Nährmedien und Zusätze}

\subsubsection{Medien zur Anzucht von Bakterien}

dYT: $\quad 16 \mathrm{~g} / \mathrm{l}$ Trypton, $10 \mathrm{~g} / \mathrm{l} \mathrm{Hefeextrakt,} 5 \mathrm{~g} / \mathrm{l} \mathrm{NaCl}$; $\mathrm{pH}$ ad 7,0 mit NaOH

LB: $\quad 10 \mathrm{~g} / \mathrm{l}$ Trypton, $5 \mathrm{~g} / \mathrm{l} \mathrm{Hefeextrakt,} 10 \mathrm{~g} / \mathrm{l} \mathrm{NaCl}$; $\mathrm{pH}$ ad 7,0 mit $\mathrm{NaOH}$

SOC-Medium: $20 \mathrm{~g} / \mathrm{l}$ Trypton, $5 \mathrm{~g} / \mathrm{l}$ Hefeextrakt, $10 \mathrm{mM} \mathrm{NaCl}, 2,5 \mathrm{mM} \mathrm{KCl}$, nach dem Autoklavieren steril dazu: $10 \mathrm{mM} \mathrm{MgCh}, 10 \mathrm{mM} \mathrm{MgSO}_{4}, 20 \mathrm{mM}$ Glucose

YEB: $\quad 10$ g/l Beefextrakt, 2 g/l Hefeextrakt, 5 g/l Pepton, 5 g/l Saccharose, $2 \mathrm{mM}$ $\mathrm{MgSO}_{4} ; \mathrm{pH}$ ad 7,0 mit $\mathrm{NaOH}$

Für LB- bzw. YEB-Festmedien zusätzlich 15 g/l Bacteriological Agar.

\subsubsection{Medien zur Anzucht von Pflanzen und Suspensionskulturen von N. tabacum}

2MS-Festmedium:

Shoot-induction-Festmedium: (SHI)

3LS-Flüssigmedium:

Kallus-Induktionsmedium:
4,59 g/l Murashige und Skoog Medium, $20 \mathrm{~g} / \mathrm{l}$ Saccharose, 6,4 g/l Select-Agar; pH 5,8 mit KOH einstellen

2MS-Festmedium autoklavieren; bei $50{ }^{\circ} \mathrm{C}$ steril dazu pipettieren: $1 \mathrm{mg} / \mathrm{l}$ 6-Benzylaminopurin (BAP), $200 \mathrm{mg} / \mathrm{l} \alpha$ Napthalinessigsäure (NAA), $500 \mathrm{mg} / \mathrm{l}$ Cefotaxim und Selektionsantibiotika entsprechend der Angaben unter 3.4.3

4,4 g/l Linsmaier und Skoog Medium, 30 g/l Saccharose, pH 5,8 mit $\mathrm{KOH}$ einstellen. Nach dem Autoklavieren zugeben: $1 \mu \mathrm{M}$ 2,4-D aus einer Stammlösung von $1,1 \mathrm{mg} / \mathrm{ml}$ in $50 \% \mathrm{EtOH}$

2MS-Festmedium mit $0,1 \mu \mathrm{g} / \mathrm{l}$ Kinetin und $0,5 \mu \mathrm{g} / \mathrm{l}$ NAA 


\subsubsection{Zusätze}

\begin{tabular}{|c|c|c|}
\hline Antibiotikum & Endkonzentration & Stammlösung \\
\hline \multicolumn{3}{|l|}{$\overline{E \text { E. coli }}$} \\
\hline Ampicillin (Amp) & $100 \mathrm{mg} / \mathrm{l}$ & $100 \mathrm{mg} / \mathrm{ml} \mathrm{H}_{2} \mathrm{O}$ \\
\hline Kanamycin $(\mathrm{Km})$ & $50 \mathrm{mg} / \mathrm{l}$ & $50 \mathrm{mg} / \mathrm{ml} \mathrm{H} \mathrm{H}_{2} \mathrm{O}$ \\
\hline Tetracyclin (Tet) & $5 \mathrm{mg} / \mathrm{l}$ & $5 \mathrm{mg} / \mathrm{ml} 50 \% \mathrm{EtOH}$ \\
\hline \multicolumn{3}{|l|}{ A. tumefaciens } \\
\hline Rifampicin (Rif) & $100 \mathrm{mg} / \mathrm{l}$ & $50 \mathrm{mg} / \mathrm{ml} 100 \% \mathrm{MeOH}$ \\
\hline Kanamycin $(\mathrm{Km})$ & $50 \mathrm{mg} / \mathrm{l}$ & $50 \mathrm{mg} / \mathrm{ml} \mathrm{H}_{2} \mathrm{O}$ \\
\hline Gentamycin $(\mathrm{Gm})$ & $25 \mathrm{mg} / \mathrm{l}$ & $25 \mathrm{mg} / \mathrm{ml} \mathrm{H}_{2} \mathrm{O}$ \\
\hline \multicolumn{3}{|l|}{ N. tabacum } \\
\hline Kanamycin $(\mathrm{Km})$ & $50 \mathrm{mg} / \mathrm{l}$ & $50 \mathrm{mg} / \mathrm{ml} \mathrm{H}_{2} \mathrm{O}$ \\
\hline Cefotaxim & $500 \mathrm{mg} / \mathrm{l}$ & $250 \mathrm{mg} / \mathrm{ml} \mathrm{H} \mathrm{H}_{2} \mathrm{O}$ \\
\hline Hygromycin B & $40 \mathrm{mg} / \mathrm{l}$ & $50 \mathrm{mg} / \mathrm{ml}$ Methanol \\
\hline Phosphinotricin $(\mathrm{Ppt})$ & $6 \mathrm{mg} / \mathrm{l}$ & $10 \mathrm{mg} / \mathrm{ml} \mathrm{H}_{2} \mathrm{O}$ \\
\hline
\end{tabular}

X-Gal und IPTG

X-Gal-Stammlösung: $\quad 20 \mathrm{mg} / \mathrm{ml} \mathrm{N}, \mathrm{N}$-Dimethylformamid IPTG-Stammlösung: $\quad 23,8 \mathrm{mg} / \mathrm{ml} \mathrm{H}_{2} \mathrm{O}$

\subsection{Lösungen und Puffer}

1 x FixProt-Puffer

2 x FixProt-Puffer

$1 \times$ PBS

$1 \times$ PBS-T

10 x DNA-Probenpuffer
$50 \mathrm{mM}$ Hepes (pH 7,5 bei $25^{\circ} \mathrm{C}$ ), $20 \mathrm{mM} \mathrm{KCl}, 2,5 \mathrm{mM}$ DTT oder $10 \mathrm{mM}$ ß-Mercaptoethanol, ProteinaseInhibitoren $(50 \mu \mathrm{g} / \mathrm{ml}$ Antipain, $2 \mu \mathrm{g} / \mathrm{ml}$ Aprotinin, $20 \mu \mathrm{g} / \mathrm{ml}$ Chymostatin, $5 \mu \mathrm{g} / \mathrm{ml}$ E- $64,5 \mathrm{mM}$ EGTA, $0,5 \mu \mathrm{g} / \mathrm{ml}$ Leupeptin, $1 \mathrm{mg} / \mathrm{ml}$ Pefabloc SC, $1 \mu \mathrm{g} / \mathrm{ml}$ Pepstatin, $10 \mathrm{mM}$ 1,10-Phenantroline)

$100 \mathrm{mM}$ Hepes (pH 7,5), $40 \mathrm{mM} \mathrm{KCl,} 5 \mathrm{mM}$ DTT oder $20 \mathrm{mM}$ B-Mercaptoethanol, ggf. $100 \mathrm{mM} \mathrm{NaF}, 20 \%$ (v/v) 10 x Proteinase-Inhibitoren-Mix

$140 \mathrm{mM} \mathrm{NaCl}, 2,7 \mathrm{mM} \mathrm{KCl}, 1,5 \mathrm{mM} \mathrm{KH}_{2} \mathrm{PO}_{4}, 4 \mathrm{mM}$ $\mathrm{Na}_{2} \mathrm{HPO}_{4}$

1 x PBS mit $0,05 \%$ Tween- 20

$67 \% \quad$ Saccharose, $50 \mathrm{mM} \quad$ EDTA, $0,42 \% \quad$ (w/v) Bromphenolblau, $0,42 \% \quad(\mathrm{w} / \mathrm{v}) \quad$ Xylencyanol, $0,42 \%$ (w/v) Orange G 
$10 \times \mathrm{KGB}$

10 x MOPS-Puffer

10 x Proteinase-Inhibitoren-Mix

$10 \times \mathrm{TBE}$

$100 \times$ TE-Puffer

$2 \times$ Protein-Probenpuffer

$20 \times \mathrm{SSC}$

$20 \times \mathrm{TAE}$

3 x RNA-Probenpuffer

4 x Ladepuffer

$5 \mathrm{x}$ Bindepuffer

Anodenpuffer I

Anodenpuffer II

Coomassie-Färbelösung

Coomassie-Entfärbelösung

Coomassie-Fixierlösung

Dialyse-Puffer

Elutionspuffer
$1 \mathrm{M}$ Kaliumglutamat, $250 \mathrm{mM}$ Tris-Acetat (pH 7,5), $100 \mathrm{mM}$ Magnesiumacetat, $5 \mathrm{mM}$ ß-Mercaptoethanol, $500 \mu \mathrm{g} / \mathrm{ml} \mathrm{BSA}$

0,2 M MOPS, $10 \mathrm{mM}$ EDTA, $50 \mathrm{mM}$ Natriumacetat, pH 7,0 mit $\mathrm{NaOH}$ einstellen

$500 \mu \mathrm{g} / \mathrm{ml} \quad$ Antipain, $20 \mu \mathrm{g} / \mathrm{ml}$ Aprotinin, $200 \mu \mathrm{g} / \mathrm{ml}$ Chymostatin, $50 \mu \mathrm{g} / \mathrm{ml}$ E-64, $50 \mathrm{mM}$ EGTA, $5 \mu \mathrm{g} / \mathrm{ml}$ Leupeptin, $10 \mathrm{mg} / \mathrm{ml}$ Pefabloc SC, $10 \mu \mathrm{g} / \mathrm{ml}$ Pepstatin, $100 \mathrm{mM}$ 1,10-Phenantroline

0,9 M Tris, 0,9 M Borsäure, 2 mM EDTA; $p H ~ 8,0$

(stellt sich selbst ein)

$1 \mathrm{M}$ Tris, 0,1 M EDTA, $\mathrm{pH}$ 8,0 mit $\mathrm{HCl}$ einstellen

0,2 M Tris, $15 \%$ (v/v) Glycerin, 6\% (w/v) SDS, 0,05\% (w/v) Bromphenolblau, $10 \%$ (v/v) B-Mercaptoethanol

$2 \mathrm{M} \mathrm{NaCl}, 0,3 \mathrm{M}$ Natriumcitrat; $\mathrm{pH}$ 7,0 mit $\mathrm{HCl}$ einstellen

0,8 M Tris, 2,3\% (v/v) Essigsäure, 20 mM EDTA $(\mathrm{pH} 7,5-7,8)$

ad $10 \mathrm{ml}: 12 \%$ (v/v) Glycerin, $1 / 3$ Vol. $10 \times$ MOPS, $0,025 \% \quad(\mathrm{w} / \mathrm{v}) \quad$ Bromphenolblau, $0,025 \% \quad(\mathrm{w} / \mathrm{v})$ Xylencyanol, $4 \mathrm{mM}$ EDTA, 42,9\% (v/v) deionisiertes Formamid, 3,7 \% (v/v) Formaldehyd

$42 \%(\mathrm{v} / \mathrm{v})$ Bindepuffer, $58 \%$ (v/v) Glycerin

$125 \mathrm{mM}$ Hepes- $\mathrm{KOH}$ (pH 7,6), $50 \mathrm{mM} \mathrm{MgCh}, 1 \mathrm{mM}$ $\mathrm{CaCl}_{2}, 50 \%$ (v/v) Glycerin, 5 mM DTT, 2 mM PMSF

0,3 M Tris (pH 10,4), $10 \%$ (v/v) Methanol

$25 \mathrm{mM}$ Tris (pH 10,4), $10 \%$ (v/v) Methanol

$10 \%$ (v/v) Essigsäure, 0,01\% (w/v) Coomassie Brilliant Blue G-250

$10 \%(\mathrm{v} / \mathrm{v})$ Essigsäure

$25 \%$ (v/v) Isopropanol, $10 \%$ (v/v) Essigsäure

$100 \mathrm{mM} \mathrm{KCl}, 20 \mathrm{mM}$ Hepes (pH 7,5), $10 \% \quad(\mathrm{v} / \mathrm{v})$ Glycerin, 0,2 mM EDTA, 0,5 mM DTT, 0,2 mM PMSF

25 mM Tris, 192 mM Glycin, 0,025 \% (w/v) SDS 
Harnstoffextraktionspuffer

Hybridisierungslösung

Kathodenpuffer

EMSA-Markierungspuffer

NEB-Puffer

Neutralisierungslösung

NLB-Puffer

PCI-Mix

Ponceau-Lösung

Puffer $0,5 \mathrm{~A}$

Puffer 1 A

RNase freies $\mathrm{H}_{2} \mathrm{O}$

SDS-Laufpuffer

Sephadex G-50
4 M Harnstoff, 16,6\% (v/v) Glycerin, $5 \%$ (v/v) BMercaptoethanol, $5 \% \quad(\mathrm{w} / \mathrm{v}) \quad$ SDS, $0,5 \% \quad(\mathrm{w} / \mathrm{v})$ Bromphenolblau

$50 \% \quad(\mathrm{v} / \mathrm{v})$ deionisiertes Formamid, $10 \% \quad(\mathrm{w} / \mathrm{v})$ Dextransulfat, $1 \%$ (w/v) SDS, $1 \mathrm{M} \mathrm{NaCl}, 50 \mathrm{mM}$ Natriumphosphatpuffer (pH 6,8)

$25 \mathrm{mM}$ Tris, $40 \mathrm{mM}$ Glycin $(\mathrm{pH} 9,4), \quad 10 \% \quad(\mathrm{v} / \mathrm{v})$ Methanol

$50 \%$ (v/v) Glycerin, 0,4 \% (w/v) Bromphenolblau

$25 \mathrm{mM}$ Hepes-KOH (pH 7,5), $40 \mathrm{mM} \quad \mathrm{KCl}, \quad 0,5 \mathrm{mM}$ EDTA, 1 mM DTT, 0,2 mM PMSF, $10 \%$ (v/v) Glycerin

1,5 M NaCl, 0,5 M Tris- $\mathrm{HCl}(\mathrm{pH} 8,0)$

$15 \mathrm{mM}$ Hepes- $\mathrm{KOH} \quad(\mathrm{pH} 7,5), 110 \mathrm{mM} \quad \mathrm{KCl}, 5 \mathrm{mM}$ $\mathrm{MgCl}_{2}, \quad 1 \mathrm{mM}$ DTT, $50 \mathrm{mg} / \mathrm{l}$ Antipain, 0,5 mg/l Leupeptin, 0,2 mM Pefabloc, 0,2 mM PMSF

25 Vol. Phenol, 24 Vol. Chloroform, 1 Vol. Isoamylalkohol

0,1 \% (w/v) Ponceau S, $5 \%$ (v/v) Essigsäure

0,5 M Hexylenglykol, 0,25 M Saccharose, 20mM TAPES ( $\mathrm{pH} 8,5$ bei $25^{\circ} \mathrm{C}$ ), $10 \mathrm{mM} \mathrm{MgCh}, 0,15 \mathrm{mM}$ Spermin, 0,5 mM Spermidin, 0,6\% (v/v) Nonidet P-40, frisch dazu $80 \mathrm{mM}$ ß-Mercaptoethanol

1 M Hexylenglykol, 0,25 M Saccharose, 20mM TAPES $\left(\mathrm{pH} 8,5\right.$ bei $25^{\circ} \mathrm{C}$ ), $10 \mathrm{mM} \mathrm{MgCh}, 0,15 \mathrm{mM}$ Spermin, $0,5 \mathrm{mM}$ Spermidin, 0,6\% (v/v) Nonidet P-40, frisch dazu $80 \mathrm{mM}$ ß-Mercaptoethanol

$\mathrm{H}_{2} \mathrm{O}$ über Nacht mit $0,1 \%$ DEPC inkubiert und anschließend autoklaviert

25 mM Tris, 190 mM Glycin, 0,1 \% (w/v) SDS

$10 \mathrm{~g}$ in TE $\mathrm{pH} 8,0$ quellen lassen, zweimal mit TE $\mathrm{pH} 8,0$ waschen und autoklavieren 


\subsection{Chemikalien, Verbrauchsmittel und Geräte}

\subsubsection{Chemikalien}

\begin{tabular}{|c|c|}
\hline Chemikalie & Hersteller / Lieferant \\
\hline 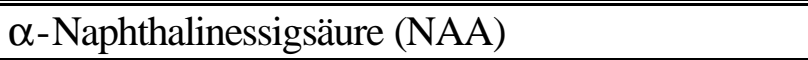 & Sigma \\
\hline 2,4 Dichlorphenoxyessigsäure (2,4-D) & Sigma \\
\hline 2-Methyl-2,4-petandiol & Aldrich \\
\hline 6-Benzylaminopurin (BAP) & Sigma \\
\hline Agar Bacteriological & Life Technologies \\
\hline Agarose SeaKem LE & Biozym \\
\hline Ampicillin & AGS \\
\hline Antipain & Serva \\
\hline Aprotinin & Biomol \\
\hline $\mathrm{BION} \circledast$ & Novartis \\
\hline Cefotaxim & Duchefa \\
\hline Chloroform & Merck \\
\hline Chlortetracyclin & Sigma \\
\hline Chymostatin & Sigma \\
\hline Coomassie R-250 & Merck \\
\hline Dimethylsulfoxid (DMSO) & Sigma \\
\hline di-Natriumhydrogenphosphat & Merck \\
\hline Dithiothreitol (DTT) & Sigma \\
\hline dNTPs & MBI; Roth \\
\hline Ethylendiamintetraacetat (EDTA) & AppliChem \\
\hline Ficoll 400 & Sigma \\
\hline Gelatine & Hilmer Brauer \\
\hline Gentamycin & Duchefa \\
\hline Glycogen & Fluka \\
\hline Heringssperma-DNA (HSP) & Boehringer Mannheim \\
\hline Hydroxyethyl-Cellulose medium vis. (HEC) & Fluka \\
\hline Hygromycin & Duchefa \\
\hline Isopropylthiogalactosid (IPTG) & BioTech Trade \\
\hline Kaliumacetat & Merck \\
\hline Kanamycin & Sigma \\
\hline Linsmaier und Skoog Medium & Duchefa \\
\hline Magnesiumchlorid $\left(\mathrm{MgCh}_{2}\right)$ & AppliChem \\
\hline Magnesiumsulfat-Heptahydrat $\left(\mathrm{MgSO}_{4} 7 \mathrm{H}_{2} \mathrm{O}\right)$ & AppliChem \\
\hline Murashige und Skoog Medium & Duchefa \\
\hline $\mathrm{N}, \mathrm{N}$-Dimethylformamid & J.T. Baker Chemicals B. V. \\
\hline $\mathrm{NaOH}$ & Merck \\
\hline Nonidet P-40 & Fluka \\
\hline Orange $\mathrm{G}$ & Sigma \\
\hline Penassay Broth & Difco \\
\hline Pepstatin & Biomol \\
\hline Phenol & AppliChem \\
\hline Phenymethansulfonylchlorid (PMSF) & Fluka \\
\hline Polydeoxyinosine-deoxycytidylic acid (poly dIdC) & Sigma \\
\hline
\end{tabular}




\begin{tabular}{|l|l|}
\hline Chemikalie & Hersteller / Lieferant \\
\hline \hline Polyvinylpyrrolidon (PVP)-40 & Sigma \\
\hline Quercetin & Sigma \\
\hline Rifampicin & Duchefa \\
\hline Rinderextrakt (LAB LEMCO) & Duchefa \\
\hline Salicylsäure (SA) & Merck \\
\hline Salzsäure (HCl) & Merck \\
\hline Select Agar & Life Technologies \\
\hline Select Yeast extract (Hefeextrakt) & GIBCO BRL \\
\hline Tetracyclin & Duchefa \\
\hline Trypton & Oxoid \\
\hline X-Gal & BioTech Trade \\
\hline
\end{tabular}

Alle nicht aufgeführten Chemikalien wurden von der Firma Roth bezogen.

\subsubsection{Verbrauchsmittel}

\begin{tabular}{|l|l|}
\hline Produkt & Hersteller \\
\hline \hline 3MM-Fließpapier & Whatman \\
\hline IP-Screen & Fuji \\
\hline Kunststoff-Einwegmaterial & Biozym; Eppendorf; Greiner; Roth \\
\hline Micro Spin ${ }^{\mathrm{TM}}$ G25 Column & Amersham \\
\hline Miracloth & Calbiochem \\
\hline Nylon-Membran Nytran ${ }^{8}$ & Schleicher und Schuell \\
\hline Parafilm M & American National Can ${ }^{\mathrm{TM}}$ \\
\hline $\begin{array}{l}\text { Polyacrylamid (PAA)-Mix: 30 \% PAA + Bisacrylamid } \\
(37,5: 1)\end{array}$ & Roth \\
\hline $\begin{array}{l}\text { Polyacrylamid (PAA)-Mix: 40 \% PAA + Bisacrylamid } \\
(19: 1)\end{array}$ & Roth \\
\hline PVDF-Membran Immobilon ${ }^{\mathrm{TM}}$-P & Millipore \\
\hline Röntgen Entwickler LX24 & Kodak \\
\hline Röntgen Fixierer AL4 & Kodak \\
\hline Röntgenfilme Cronex 4, Cronex 10T & DuPont \\
\hline Röntgenfilme X-omat AR & Kodak \\
\hline Sephadex G50 & Pharmacia \\
\hline
\end{tabular}

\subsubsection{Geräte}

\begin{tabular}{|l|l|l|}
\hline Gerät & Modell & Hersteller \\
\hline \hline Autoklav & 3870 ELV & Tuttnauer \\
\hline Biofuge & pico & Heraeus \\
\hline Bioimager (Phosphoimager) & BAS-1000 & Fuji \\
\hline Elektoporationsapparatur & $\begin{array}{l}\text { Gene pulser }{ }^{\circledR} \text { II } \\
\text { Pulse Controller Plus }\end{array}$ & BioRad \\
\hline Geldokumentationsstation & & MWG Biotech \\
\hline Gelelektrophoresekammer & & Werkstatt der Universität \\
\hline Geltrockner & Phero-Temp & Biotec-Fischer \\
\hline
\end{tabular}




\begin{tabular}{|c|c|c|}
\hline Gerät & Modell & Hersteller \\
\hline Heizblock & & Boekel Scientific \\
\hline Heizrührer & RCT basic & IKA Labortechnik \\
\hline Hybridisierungsofen & & Bachhofer \\
\hline Hybridisierungswasserbad & Belly Dancer & Stovall \\
\hline Inkubationsschränke & & WTC binder; memmert \\
\hline Kühlzentrifuge & Sorvall RC 5B Plus & DuPont \\
\hline Netzgeräte & E 323 & Benedikt Heinemann \\
\hline Netzgeräte & EC 105 & EC Apparatus Corporation \\
\hline PCR-Gerät, MiniCycler ${ }^{\mathrm{TM}}$ & PTC-150 & MJ Research, USA \\
\hline pH-Meter & HI 9321 & Hanna Instruments \\
\hline Photometer & Unikon 720 LC & Kontron \\
\hline RNA-/DNA-Calculator & GeneQuant II & Pharmacia \\
\hline Scanner & ScanJet 4c & Hewlett Packard \\
\hline Sequenziergerät & ABI PRISM 310 & Perkin-Elmer \\
\hline Speed vac Konzentrator & SK $100 \mathrm{H}$ & Sarvant \\
\hline Spektralphotometer & Novaspek Biochrom & LKB \\
\hline $\begin{array}{l}\text { Spektralphotometer für } \\
\text { Microtiterplatten }\end{array}$ & MRX & Dynex \\
\hline Szintillationsmeßgerät & & raytest Isotopenmeßgeräte $\mathrm{GmbH}$ \\
\hline Tischzentrifuge, gekühlt & 5403 & Eppendorf \\
\hline Ultraschallgerät & Soniprep 150 & Scientific Instruments \\
\hline $\begin{array}{l}\text { Ultrazentrifuge } \\
\text { Rotoren: }\end{array}$ & $\begin{array}{l}\text { Centrikon T-1065 } \\
\text { TFT } 30.58 \\
\text { TFT } 65.13 \\
\end{array}$ & Kontron \\
\hline UV-Transilluminator / FluoLink & FLX-20 M & Vilber Lourmat \\
\hline Vakuumblotapparatur & VACUGENE 2016 & Pharmacia \\
\hline $\begin{array}{l}\text { Vertical-Gelelektrophorese- } \\
\text { Apparatur }\end{array}$ & V 15-17 & GIBCO BRL \\
\hline $\begin{array}{l}\text { Vertical-Gelelektrophorese- } \\
\text { Apparatur }\end{array}$ & Joey $^{\mathrm{TM}}$ \#JGC-4 & AGS \\
\hline Vortex & $\mathrm{L} 46$ & Labinco BV \\
\hline Wasseraufbereitungsanlage & Option 4, Maxima & ELGA \\
\hline
\end{tabular}




\subsection{Kits und Enzyme}

\subsubsection{Kits}

\begin{tabular}{|l|l|}
\hline Kit & Hersteller \\
\hline \hline BigDye $^{\mathrm{TM}}$ Terminator Cycle Sequencing Ready Reaction Kit & Perkin-Elmer \\
\hline ECL-Kit, ECL+-Kit & Amersham Life Science \\
\hline GeneClean ${ }^{\circledR}$ II - Kit & Bio 101, Inc. \\
\hline Megaprime $^{\mathrm{TM}}$ DNA Labelling Systems & Amersham Life Science \\
\hline Oligotex $^{\mathrm{TM}}$-Kit & Qiagen \\
\hline Qiagen Plasmid-Preparations-Kits (Mini, Midi, Maxi) $^{\text {QIAprep Spin Miniprep Kit }}$ & Qiagen \\
\hline RNeasy Plant Mini Kit & Qiagen \\
\hline T-Cloning Kit & Qiagen \\
\hline $1^{\text {st }}$ strand cDNA Kit & MBI Fermentas \\
\hline & Boehringer \\
\hline
\end{tabular}

\subsubsection{Enzyme}

\begin{tabular}{|l|l|}
\hline Enzym & Hersteller \\
\hline \hline AmpliTaq ${ }^{\circledR}$ DNA-Polymerase, FS & ABI PRISM ${ }^{\mathrm{TM}}$ \\
\hline Klenow DNA-Polymerase exo & MBI Fermentas \\
\hline Restriktionsenzyme & MBI Fermentas, GIBCO BRL \\
\hline RNase A (DNase-frei) & Sigma; Qiagen \\
\hline T4 DNA-Ligase & MBI Fermentas \\
\hline
\end{tabular}




\section{Methoden}

\subsection{Anzucht und Manipulation von Bakterien}

\subsubsection{Anzucht von E. coli}

Die Anzucht von E. coli erfolgte bei $37^{\circ} \mathrm{C}$ über Nacht und in Gegenwart geeigneter Antibiotika entweder auf LB-Platten im Brutschrank oder in Flüssigmedium (LB oder dYT) im Schüttler bei $250 \mathrm{rpm}$.

\subsubsection{Transformation von E. coli}

Da E. coli von Natur aus nicht in der Lage ist, nackte DNA aus seiner Umgebung aufzunehmen, müssen die Zellen kompetent gemacht werden, um sie mit Plasmid-DNA transformieren zu können. Dies kann z. B. durch eine Behandlung mit $\mathrm{RbCh}_{2}$ geschehen. Die Herstellung chemisch- bzw. RbCh-kompetenter Zellen erfolgte nach INOUE et al., 1990 bzw. nach HANAHAN, 1983. Die Transformation kompetenter Zellen erfolgte nach HANAHAN, 1983. Die Zellen wurden auf Eis aufgetaut und anschließend mit $1 \mathrm{ng}$ (Plasmid-DNA) bis $100 \mathrm{ng}$ (Ligationsansatz) für $30 \mathrm{~min}$ auf Eis inkubiert. Nach einer Hitzebehandlung für $90 \mathrm{sec}$ bei $42{ }^{\circ} \mathrm{C}$ wurden die Zellen weitere $5 \mathrm{~min}$ auf Eis gehalten und nach Zugabe von $700 \mu \mathrm{l}$ SOC-Medium $30 \mathrm{~min}$ bei $37^{\circ} \mathrm{C}$ geschüttelt. Zur Selektion der transformierten Bakterien wurden unterschiedliche Mengen der Bakterienkultur auf LB-Festmedium mit dem entsprechenden Antibiotikum ausplattiert und über Nacht bei $37^{\circ} \mathrm{C}$ inkubiert. Ggf. wurden die Platten zuvor zum Zwecke einer Blau-Weiß-Selektion mit IPTG und X-Gal (s. 3.4.1) beschichtet.

\subsubsection{Anzucht von A. tumefaciens}

Die Anzucht von A. tumefaciens erfolgte bei $28^{\circ} \mathrm{C}$ über zwei Tage in Gegenwart geeigneter Antibiotika auf YEB-Festmedium im Brutschrank oder in YEB-Flüssigmedium bei $250 \mathrm{rpm}$ im Schüttler.

\subsubsection{Transformation von A. tumefaciens durch Elektroporation}

A. tumefaciens besitzt wie E. coli keine natürliche Kompetenz zur Aufnahme von DNA. Die Herstellung kompetenter Zellen erfolgte nach DOWER et al., 1988.

Da die Elektroporation durch Salzrückstände in der DNA-Lösung beeinträchtigt wird, wurde Plasmid-DNA für diesen Zweck immer in $\mathrm{H}_{2} \mathrm{O}$ (up) gelöst.

Zur Elektroporation wurden $40 \mu \mathrm{l}$ kompetenter Zellen auf Eis aufgetaut, mit 50-100 ng Plasmid-DNA vermischt und 30-60 sec auf Eis inkubiert. Diese Suspension wurde in eine spezielle, eisgekühlte Elektroporations-Küvette $(\mathrm{d}=0,2 \mathrm{~cm})$ überführt und mittels einer Elektroporationsapparatur einem elektrischen Puls ausgesetzt (Parameter: $25 \mu \mathrm{F}, 200 \Omega$ und $2,5 \mathrm{kV})$. Die vom Gerät angezeigte Zeitkonstante sollte dabei nicht wesentlich von 4,6 ms abweichen.

Anschließend wurden die Zellen sofort in $1 \mathrm{ml}$ eiskaltes SOC-Medium aufgenommen und anschließend $2 \mathrm{~h}$ bei $28^{\circ} \mathrm{C}$ im Roller inkubiert. Zur Selektion der transformierten Zellen wurden unterschiedliche Mengen der Bakterienkultur auf YEB-Festmedium mit den entsprechenden Antibiotika ausplattiert und zwei Tage bei $28^{\circ} \mathrm{C}$ inkubiert. 


\subsection{Anzucht und Manipulation von Pflanzen}

\subsubsection{Anzucht von N. tabacum}

Tabakpflanzen wurden in steriler Sprosskultur (Gewebekultur) auf 2MS-Festmedium gehalten. Die Anzucht erfolgte in Klimakammern bzw. Klimaschränken bei $24^{\circ} \mathrm{C}$ am Tag und $22{ }^{\circ} \mathrm{C}$ in der Nacht in einem Licht-Dunkel-Rhythmus von $16 \mathrm{~h}: 8 \mathrm{~h}$. Die Subkultivierung der Pflanzen erfolgte alle $6-8$ Wochen. Hierzu wurde die Sprossspitze der zu vermehrenden Pflanze abgetrennt und zum Bewurzeln auf 2MS-Festmedium überführt.

Zur Produktion von Samen und größeren Gewebemengen wurden die Pflanzen aus der Sterilkultur in Erde umgesetzt und in Klimakammern bei $22{ }^{\circ} \mathrm{C}$ am Tag und $19{ }^{\circ} \mathrm{C}$ in der Nacht bei $85 \%$ Luftfeuchte in einem Licht-Dunkel-Rhythmus von $16 \mathrm{~h}: 8 \mathrm{~h}$ kultiviert.

\subsubsection{Transformation von $N$. tabacum (modifiziert nach HoRSCH et al., 1985)}

Zur stabilen Transformation von Tabak kann man sich den natürlichen Infektionsmechanismus von A.tumefaciens zunutze machen. Agrobakterien dringen in frische Pflanzenwunden ein und induzieren dort durch das tumor-inducing (Ti)-Plasmid die Bildung von Wurzelhalstumoren. Bei diesem Vorgang wird ein Teil des Ti-Plasmids, die T-DNA, mit Hilfe der vom Ti-Plasmid in der vir-Region codierten Virulenz-Proteine stabil ins Pflanzengenom integriert. Ersetzt man die Tumor-auslösenden Gene der T-DNA durch Fremdgene, so kann das Agrobakterium die Tumorbildung nicht mehr induzieren, sondern dient ausschließlich als Genfähre und ermöglicht so die Integration von Fremdgenen ins Pflanzengenom. Derart modifizierte Ti-Plasmide lassen sich zur Transformation von Tabak als binäre Plasmide nutzen. Das binäre System besteht aus einem Helferplasmid und dem binären Vektorplasmid, die beide gleichzeitig im Agrobakterium vorliegen. Bei dem Helferplasmid handelt es sich um ein Ti-Plasmid mit der vir-Region, aber ohne TDNA. Das binäre Vektorplasmid enthält die T-DNA mit allen $\mathrm{zu}$ übertragenden Genen und bakterielle Replikationsstartpunkte zur Vermehrung in E. coli und A.tumefaciens. Resistenzgene auf Vektor- und Helferplasmid ermöglichen die Selektion auf die Plasmide während der Anzucht der Agrobakterien.

Die Transformation wurde nach der "leaf-disc"-Methode durchgeführt. $10 \mathrm{ml}$ einer überNacht-Kultur von einer transformierten A.tumefaciens-Einzelkolonie wurden bei $4000 \mathrm{~g}$ pelletiert und in $20 \mathrm{ml}$ YEB-Flüssigmedium resuspendiert. Blätter von steril angezogenen Tabakpflanzen der zu transformierenden Linie wurden in $1-2 \mathrm{~cm}^{2}$ große Stücke zerteilt und für 2-3 min in die Agrobakterien-Suspension getaucht. Die Blattstücke wurden anschließend mit der Blattunterseite auf 2MS-Festmedium gelegt und für zwei Tage abgedunkelt im Klimaschrank bei $24{ }^{\circ} \mathrm{C}$ mit den Agrobakterien cokultiviert. Die Cokulturphase ermöglicht das Eindringen der Agrobakterien in das Gewebe und die stabile Integration der Fremd-DNA ins Pflanzengenom. Anschließend wurden die Blattstïcke auf selektives SHI-Medium umgelegt und im Klimaschrank mit einem Licht-Dunkel-Rhythmus von $16 \mathrm{~h}: 8 \mathrm{~h}$ kultiviert. Die Hormone im Medium induzieren die Bildung von Kallusgewebe, aus dem sich Sprosse regenerieren können. Die Antibiotika dienen zum einem dem Abtöten der Agrobakterien (Cefotaxim) und zum anderen der Selektion transgener Pflanzenzellen (Hygromycin).

Das Umlegen der Blattstïcke auf frisches SHI-Medium wurde im Abstand von höchstens zwei Wochen oder bei Bedarf früher wiederholt, bis sich Sprosse ausgebildet hatten. Diese wurden zur Bewurzelung auf 2MS-Medium mit Cefotaxim und Hygromycin umgesetzt. 


\subsubsection{Induktion von Tabakpflanzen mit Salicylsäure bzw. Cycloheximid}

Um die Salicylsäure (SA)-induzierte Genexpression in Blattgewebe aus Tabak zu untersuchen, wurden Pflanzen wie unter 4.2.1 beschrieben bis zu einem Alter von $6-8$ Wochen in Erde angezogen. Für Versuche wurden Pflanzen benutzt, die keine äußerlich sichtbaren Zeichen von Seneszenz zeigten, und die noch keine Blütenknospen angesetzt hatten.

Für die Induktion mit SA wurden bevorzugt aus den oberen Blättern der Pflanzen mit einem Korbbohrer $(\mathrm{d}=2,6 \mathrm{~cm})$ pro Zeitpunkt $4-6$ Blattscheiben ausgestochen und bis zur weiteren Behandlung in einer Petrischale mit angefeuchtetem Zellstoff aufbewahrt.

Zur „einfachen“ Induktion mit SA ohne Vorbehandlung mit anderen Chemikalien wurden die Blattscheiben auf $1 \mathrm{mM} \mathrm{SA}$ in $50 \mathrm{ml} 50 \mathrm{mM}$ Kaliumphosphatpuffer (pH 5,8) gelegt.

Um die Proteinneusynthese während eines Induktionsversuchs $\mathrm{zu}$ unterdrücken, wurden die Blattscheiben mit Cycloheximid (CHX) vorbehandelt. Dazu wurden die Blattscheiben unter einem Metallsieb (vollständig untergetaucht) in einer Lösung aus $100 \mathrm{mg} / \mathrm{l} \mathrm{CHX}$ in $50 \mathrm{mM}$ Kaliumphosphatpuffer $(\mathrm{pH} 5,8)$ in einem Exsikkator für $90 \mathrm{sec}$ evakuiert und anschließend die Lösung durch scharfes Belüften in die Interzellularen infiltriert. Die Blattscheiben wurden in der gleichen Lösung für eine Stunde in Petrischalen inkubiert, um die optimale Wirkung des CHX zu gewährleisten. Anschließend erfolgte die SA-Induktion wie zuvor beschrieben, jedoch in Gegenwart von $100 \mathrm{mg} / \mathrm{l} \mathrm{CHX}$.

Die SA-Induktion von Blattgewebe zur Isolierung von Kernproteinen erfolgte mit ca. $8 \mathrm{~g}$ Blättern (ohne Mittelrippe) pro Zeitpunkt. Die Blätter wurden in ca. $25 \mathrm{~cm}^{2}$ große Stücke zerteilt und in einem $1000 \mathrm{ml}$ Becherglas analog der zuvor beschriebenen Prozedur mit Kaliumphosphatpuffer (pH 5,8) mit bzw. ohne $100 \mathrm{mg} / \mathrm{l}$ CHX infiltriert, eine Stunde inkubiert und anschließend in Photoschalen auf Kaliumphosphatpuffer mit $1 \mathrm{mM} \mathrm{SA}$, mit bzw. ohne $100 \mathrm{mg} / \mathrm{l} \mathrm{CHX}$ induziert.

SA und CHX wurden aus einer 1000fachen Stammlösung in DMSO entnommen, die für jeden Versuch frisch hergestellt wurde. In allen Fällen wurden entnommene Proben in flüssigem Stickstoff ( $\mathrm{N}_{2}$ liq.) eingefroren und bis zur Aufarbeitung bei $-80{ }^{\circ} \mathrm{C}$ aufbewahrt.

\subsubsection{Induktion von Tabakpflanzen mit $\mathrm{BION} B$}

BION® (Benzothiadiazol, BTH) (GÖRLACH et al., 1996; LAWTON et al., 1996) ist ein funktionelles SA-Analogon, das jedoch bei gleicher Konzentration eine stärkere Wirkung auf SA-induzierte Gene zeigt. Die Chemikalie stand als Formulatur mit 50\% (w/w) wirksamer Substanz zur Verfügung. Aus der Formulatur wurde eine wässrige Suspension mit $100 \mu \mathrm{M}$ $\mathrm{BION} ®$ hergestellt und die oberirdischen Organe der $\mathrm{zu}$ behandelnden Pflanzen in zweiwöchigem Abstand eingesprüht.

\subsubsection{Etablierung und Kultivierung von Suspensionskulturen N. tabacum}

Suspensionskulturen aus N. tabacum bestehen aus sog. Microkalli, deren wenige Zellen direkten Kontakt zum umgebenden Medium haben. Dieser direkte Kontakt zum Medium und die Möglichkeit, durch die relativ hohe Zellteilungsrate in kurzer Zeit viel Biomasse zu produzieren, machen Suspensionskulturen zu einem interessanten Objekt für Versuche mit Induktoren und Inhibitoren.

Um Suspensionskulturen aus N. tabacum zu etablieren, wurden Stängel von steril in Gewebekultur gezogenen Pflanzen in ca. $1 \mathrm{~mm}$ dicke Scheiben geschnitten und auf KallusInduktionsmedium im Dunkeln bei $25^{\circ} \mathrm{C}$ ca. drei Wochen kultiviert. Das sich bildende Kallusgewebe wurde in 3LS-Flüssigmedium mit $1 \mu \mathrm{M}$ 2,4-D überführt, mit einer Pinzette 
zerkleinert und in einem Gesamtvolumen von $30 \mathrm{ml}$ 3LS $(+$ 2,4-D) im $100 \mathrm{ml}$ Erlenmeyerkolben im Dunkeln bei $25^{\circ} \mathrm{C}$ bei $80 \mathrm{rpm}$ geschüttelt. In wöchentlichem Abstand wurden die Zellen zunächst im Verhältnis 1:6 subkultiviert. Hatte sich nach einiger Zeit eine homogene Suspension gebildet, wurden die Zellen im Verhältnis 1: 10 unter den zuvor beschriebenen Bedingungen subkultiviert.

\subsubsection{Behandlung von Tabaksuspensionskulturen mit Induktoren und Inhibitoren}

Die Kultivierung der Zellsuspensionen erfolgte in Gegenwart von 2,4-D, welches in der Lage ist, as-1-ähnliche Elemente zu induzieren. Deshalb wurden die Zellen vor der Zugabe von asl-induzierenden Substanzen in hormonfreiem Medium gewaschen. Dies geschah, indem die Zellen pelletiert und das Medium gegen hormonfreies Medium ausgetauscht wurde. Nach dreimaliger Wiederholung dieser Waschprozedur wurden die Zellen in hormonfreiem 3LSFlüssigmedium bis zur Induktion drei weitere Tage geschüttelt.

Die Induktion erfolgte durch Zugabe der Induktoren in die hormonfreie Zellsuspension.

Konzentrationen:

$$
\begin{array}{ll}
\text { SA } & 100 \mu \mathrm{M} \\
\text { 2,4-D } & 50 \mu \mathrm{M} \\
\text { Quercetin } & 50 \mu \mathrm{M}
\end{array}
$$

Alle Substanzen wurden frisch hergestellten 1000fachen Stammlösungen entnommen.

\subsection{Isolierung, Reinigung, Quantifizierung, Darstellung und Manipulation von Nucleinsäuren}

\subsubsection{Isolierung von Plasmid-DNA}

Je nach Verwendungszweck wurden verschiedene Arten der Plasmidisolierung angewendet.

\subsubsection{Alkalische Lyse (modifiziert nach ISH-HORROWICZ und BURKE, 1981)}

Die alkalische Lyse ermöglicht die Isolierung von Phasmid-DNA aus E. coli und aus A. tumefaciens.

$1,5 \mathrm{ml}$ einer stationären E. coli-Kultur wurden durch Zentrifugation $(30 \mathrm{sec}, 13.000 \mathrm{rpm}$, Biofuge) im Eppendorfgefäß pelletiert. Nach Dekantieren des Überstandes wurde das Pellet in $100 \mu \mathrm{l}$ HB1 resuspendiert. Durch Zugabe von $200 \mu \mathrm{HB} 2$ und anschließendes mehrmaliges Invertieren erfolgte der Aufschluss der Zellen, wobei die Suspension klar und viskos wurde. Durch Zugabe von $170 \mu 1 \mathrm{HB} 3$ und sofortiges gründliches Invertieren wurde die Lösung neutralisiert, so dass die DNA renaturierte. Anschließend wurden die Proben $10 \mathrm{~min}$ auf Eis inkubiert, um die chromosomale DNA und einen großen Teil der Proteine zu fällen. Durch anschließende Zentrifugation (10 min, $13.000 \mathrm{rpm}$, Biofuge) wurden die Proteine präzipitiert, wobei die Plasmid-DNA im Überstand verblieb. Der Überstand wurde zur Entfernung der restlichen Proteine einer Phenol/Chloroform-Extraktion mit $500 \mu \mathrm{l}$ PCI-Mix unterzogen. Nach einer Zentrifugation (3 min, $13.000 \mathrm{rpm}$, Biofuge) wurde die im Überstand enthaltene Plasmid-DNA mit $1 \mathrm{ml} 98 \%$ EtOH gefällt und mittels Zentrifugation (10 min, $13.000 \mathrm{rpm}$, Biofuge) pelletiert. Das Pellet wurde anschließend mit $500 \mu \mathrm{l} 70 \% \mathrm{EtOH}$ gewaschen und nach kurzem Trocknen bei $65^{\circ} \mathrm{C}$ in $50 \mu 1 \mathrm{H}_{2} \mathrm{O}$ gelöst.

Zur Isolierung der binären low-copy Vektoren aus A.tumefaciens wurden $5 \mathrm{ml}$ einer stationären Kultur verwendet. Der Aufschluss und die Phenol/Chloroform-Extraktion erfolgte mit dem 2fachen Volumen der für E. coli angegebenen Lösungen. Nach dem Fällen der Plasmid DNA wurde das Pellet in $20 \mu 1 \mathrm{H}_{2} \mathrm{O}$ resuspendiert. 


\subsubsection{Schnell-Lyse für anschließende PCR}

Zur schnellen Identifizierung rekombinanter Klone wurden Einzelkolonien ( $\mathrm{d}=1-2 \mathrm{~mm}$ ) einer Transformation von E. coli im Eppendorfgefäß in $50 \mu \mathrm{l} \mathrm{H}_{2} \mathrm{O}$ resuspendiert, $5 \mathrm{~min}$ im Wasserbad aufgekocht und anschließend zentrifugiert (1 min, $13.000 \mathrm{rpm}$, Biofuge). $10 \mu \mathrm{ldes}$ klaren Überstandes dienten als Template für eine PCR mit geeigneten Primern zur Identifizierung rekombinanter Klone.

\subsubsection{Plasmidpräparation für die Sequenzierung}

Für die Sequenzierung mittels Cycle Sequencing wurde hochreine Plasmid-DNA mit Hilfe des QIAprep Spin Miniprep Kits der Firma Qiagen isoliert. Hierbei werden zunächst die Zellen ähnlich der unter 4.3.1.1 beschriebenen Alkalischen Lyse aufgeschlossen. Anschließend wird mit Hilfe eines Zentrifugationsschritts die Plasmid-DNA an eine Ionenaustauscher-Säule gebunden, durch Zugabe verschiedener Puffer in weiteren Zentrifugationsschritten gereinigt und schließlich eluiert.

Die Durchführung erfolgte gemäß den Herstellerangaben (QIAGEN Plasmid Purification Handbook, 1997).

\subsubsection{Präparation größerer Plasmidmengen}

Zur Isolierung größerer Plasmidmengen wurde der Midi- bzw. Maxi-Kit der Firma Qiagen eingesetzt. Die Durchführung erfolgte gemäß den Herstellerangaben (QIAGEN Plasmid Purification Handbuch, 1997).

\subsubsection{Isolierung von RNA aus $N$. tabacum}

\subsubsection{Isolierung von Gesamt-RNA}

Zur Präparation von RNA aus Blattgewebe und aus Suspensionskulturen wurde der RNeasy Plant Mini-Kit der Firma Qiagen verwendet. Die Durchführung erfolgte nach Herstellerangaben (QIAGEN RNeasy Mini Handbook, 1999) mit folgenden Parametern bzw. Modifikationen:

- Bei einer größeren Anzahl aufzuarbeitender Proben wurde die Präparation nach Schritt 2 unterbrochen und die Proben bei $-80^{\circ} \mathrm{C}$ aufbewahrt.

- Um ein stabileres Pellet zu erzielen, wurde die Zentrifugation in Schritt 3 auf 5 min ausgedehnt.

- Mit $\geq 8000 \mathrm{xg}$ angegebene Zentrifugationsschritte wurden bei $11.000 \mathrm{rpm}$ in der Biofuge durchgeführt.

- Alle Zentrifugationsschritte dauerten mindestens $1 \mathrm{~min}$.

- Vor der Elution wurde das verwendete $\mathrm{H}_{2} \mathrm{O}$ auf $65^{\circ} \mathrm{C}$ erhitzt und heiß auf die Säule pipettiert.

- Die Elution erfolgte mit $50-60 \mu \mathrm{H}_{2} \mathrm{O}$. Der Durchfluss der ersten Elution wurde zwecks Konzentrationserhöhung ein zweites Mal auf die Säule gegeben und eluiert. Die zweite Elution erfolgte durch Zentrifugation bei maximaler Geschwindigkeit, um die maximale Volumenausbeute an Eluat zu erhalten. 


\subsubsection{Isolierung von polyA ${ }^{+}-\mathrm{RNA}$}

Die Isolierung von polyA ${ }^{+}$-RNA erfolgte ausgehend von Gesamt-RNA mit Hilfe des QIAGEN Oligotex $^{\mathrm{TM}}$-Kits gemäß den Herstellerangaben (QIAGEN Oligotex ${ }^{\mathrm{TM}}$ Handbook, 1998).

\subsubsection{Isolierung von cDNA-Sondenmolekülen aus $\mathbf{N}$. tabacum}

Um die Expression von Genen untersuchen zu können, sind Sondenmoleküle notwendig, die z. B. mittels PCR aus cDNA isoliert werden können. Die unter 3.2.2 beschriebene Sonde für parA (TAKAHASHI et al., 1989) wurde auf diese Weise isoliert.

Die Erzeugung von cDNA erfolgte mit Hilfe des Boehringer 1st strand cDNA Kits. Als Ausgangsmaterial dienten $100 \mathrm{ng}$ polyA ${ }^{+}$-RNA aus SNN wt Blattgewebe, das $7 \mathrm{~h}$ mit 2,4-D behandelt worden war. In einem $20 \mu \mathrm{l}$-Ansatz wurde mittels AMV reverser Transkriptase entsprechend den Herstellerangaben mit Hilfe eines Thermocyclers die cDNA synthetisiert. $1 \mu \mathrm{l}$ der cDNA diente als Template für eine PCR mit jeweils 25 pmol der Primer parA-U und parA-L, die ein 696 bp großes Amplifikat lieferte. Dieses wurde in pUC57/T einkloniert, sequenziert und als komplette parA-Codierregion identifiziert. Der entstandene Vektor ist das unter 3.2.1 beschriebene Plasmid pUC57 parA.

\subsubsection{Ethanolfällung von DNA (SAMBROoK et al., 1989)}

Die Ethanolfällung wurde eingesetzt, um DNA von Salzverunreinigungen zu befreien und sie zu konzentrieren.

Die Löslichkeit von DNA hängt von dem Salzgehalt und der Temperatur der Lösung ab. Durch die Erhöhung der Konzentration monovalenter Kationen und gleichzeitiger Erniedrigung der Temperatur kann die DNA in Anwesenheit von Ethanol präzipitieren.

Zur Fällung der Plasmid-DNA oder von PCR-Produkten wurde der Ansatz mit $1 / 10$ x Vol. 2,5 M Natriumacetat pH 5,2 und 2 x Vol. $100 \%$ EtOH versetzt. Die Präzipitation erfolgte durch Inkubation für $30 \mathrm{~min}$ bei RT. Nach Zentrifugation (20 min, $13.000 \mathrm{rpm}$, Biofuge) wurde das Pellet mit $70 \% \mathrm{EtOH}$ gewaschen, an der Luft oder bei $65{ }^{\circ} \mathrm{C}$ getrocknet und schließlich in einem adäquaten Volumen $\mathrm{H}_{2} \mathrm{O}$ aufgenommen.

\subsubsection{Quantifizierung von Nucleinsäuren (SAMBROoK et al., 1989)}

Die Bestimmung der Konzentration von DNA und RNA erfolgte photometrisch mit dem GeneQuant II. Die Absorption bei 260 nm stellt ein direktes Maß für die Menge der gelösten Nucleinsäuren da. So entspricht $\mathrm{E}_{260}=1$ bei einer Schichtdicke der Lösung in der Meßküvette von $1 \mathrm{~cm} 40 \mu \mathrm{g} / \mathrm{ml}$ RNA bzw. $50 \mu \mathrm{g} / \mathrm{ml}$ dsDNA. Um eine ausreichende Genauigkeit zu gewährleisten, sollten die gemessenen Extinktionswerte im Bereich von 0,1-1,0 liegen. Zusätzlich wurden die Extinktionen bei $280 \mathrm{~nm}$ und für RNA-Lösungen auch bei $320 \mathrm{~nm}$ bestimmt. Diese Werte geben Aufschluss über die Reinheit der DNA bzw. RNA. Über die Absorption bei einer Wellenlänge von $280 \mathrm{~nm}$ werden Kontaminationen von Phenol und Proteinen erfasst. Salzrückstände wurden durch positive Extinktionswerte bei $320 \mathrm{~nm}$ angezeigt. Der Quotient $\mathrm{E}_{260} / \mathrm{E}_{280}$ stellt ein $\mathrm{Maß}$ für die Reinheit dar; optimale Werte liegen für RNA bei 1,9 - 2,0 und für DNA bei 1,8.

Im Normalfall waren nur Nucleinsäurekonzentrationen von mehr als $0,1 \mu \mathrm{g} / \mu \mathrm{l}$ mit hinreichender Genauigkeit photometrisch messbar. Die Konzentration geringerer DNAMengen konnte durch Gelelektrophorese und Ethidiumbromid (EtBr)-Färbung bestimmt werden. Die Konzentration des in die DNA interkallierten EtBr ist direkt proportional zur 
Konzentration der DNA. Die auf dem UV-Schirm vom EtBr emittierte Fluoreszenzstrahlung stellt somit ein Maß für die DNA-Menge dar. Die Konzentration der DNA-Lösung wurde durch den Vergleich mit einem DNA-Standard bekannter Konzentration abgeschätzt.

\subsubsection{Methoden zur Klonierung von Nucleinsäuren}

\subsubsection{Restriktionsspaltung von DNA (SAMBROOK et al., 1989)}

Restriktionsendonucleasen erkennen spezifische Basenpaarsequenzen und spalten daraufhin die Phosphodiester-Bindungen der doppelsträngiger DNA. Je nach Enzym entstehen glatte DNA-Enden ('blunt ends") oder 5'- bzw. 3'-überhängende Enden ("sticky ends").

Zur Restriktionsspaltung von DNA wurden die Enzyme gemäß den Herstellerangaben bei optimalen Puffer- und Temperaturbedingungen eingesetzt. Die jeweils eingesetzte Enzymmenge errechnete sich wie folgt:

$\mathrm{U} / \mu \mathrm{g}$ DNA $=($ bps $[\lambda] \times$ Schnittstellen $[\mathrm{DNA}]) /($ bps $[\mathrm{DNA}] \mathrm{x}$ Schnittstellen $[\lambda])$

bps $[\lambda]=48.500$

Die Volumina der Ansätze wurden so gewählt, dass die Konzentration an Glycerin nicht höher als 5\% war. Da die meisten Enzyme in einem Puffer mit 50\% Glycerin gelagert werden, entsprach der maximale Anteil an Enzym $1 / 10$ des Endvolumens.

\subsubsection{Isolierung von DNA-Fragmenten aus Agarosegelen}

Die Elution von DNA-Fragmenten aus Agarosegelen wird vorgenommen, um ein bestimmtes DNA-Fragment aus einem Gemisch von Fragmenten (z. B. Restriktion oder PCR) zu isolieren. Verschiedene Verfahren machen sich die selektive Bindung der DNA an eine SilicaMatrix zunutze.

Im Rahmen dieser Arbeit wurde auf das QIAquick Gel Extraction Kit der Firma Qiagen und das GeneClean II Kit der Firma Bio 101 zurückgegriffen. Die Isolierung erfolgte jeweils nach den Herstellerangaben.

\subsubsection{Ligation von Restriktionsfragmenten}

Zur Ligation zweier doppelsträngiger DNA-Enden mittels T4-DNA-Ligase müssen folgende Kriterien erfüllt sein:

- Die Enden müssen kompatibel sein.

- Mindestens ein Ende muss phosphoryliert vorliegen.

- Die Reaktion benötigt neben geeigneten Pufferbedingungen zwingend ATP.

Die Ligationsreaktion wurde routinemäßig für $2 \mathrm{~h}$ bei RT oder bei $16{ }^{\circ} \mathrm{C}$ über $\mathrm{Nacht}$ in Ligationspuffer der Firma MBI durchgeführt. Bei Ligationen in einen geöffneten Vektor wurde im allgemeinen ein Vektor : Insert - Verhältnis von $1: 10$ eingehalten.

\subsubsection{Ligation von PCR-Produkten in pUC57/T}

Während einer PCR-Reaktion fügt die Taq DNA-Polymerase bevorzugt ein zusätzliches dATP an das 3'-Ende des neu synthetisierten Stranges an. Um PCR-Fragmente effizienter in 
einen Vektor ligieren zu können, besitzt der Vektor pUC57/T 3'-überhängende dTs, so dass die Enden von Vektor und Fragment eine komplementäre Basenpaarung ausbilden können. Das Verhältnis der Enden von Vektor zu PCR-Fragment sollte 1:3 betragen. Die Ligation erfolgte gemäß den Herstellerangaben mit Hilfe des T-Cloning-Kits (MBI FERMENTAS TCloning Kit Handbook).

\subsubsection{Klonierung eines Kassettensystems für die Fusion zwischen TGA- Faktoren und Aktivierungs- bzw. Silencerdomänen}

Das hier beschriebene Kassettensystem bietet die Möglichkeit, Fusionsderivate zwischen folgenden Modulen herzustellen: TGA2.1, TGA2.2, ENGRAILED-Silencerdomäne bzw. VP16-Aktivierungsdomäne. Dabei gibt es Akzeptorplasmide $(\mathbf{p K} n n \mathbf{L})$, die eine sog. KozakSequenz (AACC) vor dem Translationsstart (KOZAK, 1989), das Gen für den N-terminalen Anteil des Fusionsproteins und einen Teil einer Peptidlinkersequenz $\left(\mathrm{G}_{4} \mathrm{~S}\right)_{2}$ zur Verfügung stellen. Über die Schnittstelle BamHI kann der C-terminale Fusionspartner eingefügt werden, welcher aus Donorplasmiden (pLnns) herausgespalten wird. Dieses C-terminale Fragment umfasst den übrigen Teil der Peptidlinkersequenz $\left(\mathrm{G}_{4} \mathrm{~S}\right)$, die Codierregion des zweiten Fusionspartners und vor dem Stop-Codon die Sequenz für den Streptag® II, einen acht Aminosäuren langen Affinitätstag, der von einem polyklonalen Antiserum erkannt wird oder z. B. eine Affinitätsaufreinigung mittels einer Biotin-gekoppelten Säule ermöglicht. Alle über BamHI entstehenden Fusionen sind automatisch im Leseraster.

\subsubsection{Klonierung des Vektors pKVPL}

Der Vektor enthält die Sequenz für die VP16-Aktivierungsdomäne mit vorangestellter KozakSequenz und anschließender Peptidlinkersequenz.

Auf dem Plasmid pSK-VP16 wurde mit Hilfe der Primer K-VP16-upper-N und VP16-linklower mittels PCR ein 405 bp großes Fragment erzeugt, mit Acc65I und BamHI geschnitten und in den ebenso geschnittenen pUC57 kloniert.

\subsubsection{Klonierung des Vektors pKENGL}

Der Vektor enthält die ENGRAILED-Silencerdomäne mit vorangestellter Kozak-Sequenz und anschließender Peptidlinkersequenz.

Mittels PCR wurde auf dem Template pENGRAILED mit den Primern Kozak-engrailedupper und engrailed-link-lower ein 959 bp großes Fragment erzeugt und in den Vektor pUC57/T einkloniert.

\subsubsection{Klonierung des Vektors pK2.1L}

Der Vektor enthält die TGA2.1-Codierregion mit vorangestellter Kozak-Sequenz und nachfolgender Linker-Sequenz.

Mit den Primern TGA2.1/PstI und 2.1-link-lower wurde durch PCR auf einem KpnI / SalIFragment aus TGA2.1 ein 764 bp großes Amplifikat gewonnen, das den 3'-Anteil von TGA2.1 und die Sequenz für den Peptidlinker enthält. Über die Schnittstellen KpnI und Ppu10I wurde aus dem Vektor pSK TGA2.1 in vitro der 5'-Bereich von TGA2.1 in diesen Vektor inseriert. 


\subsubsection{Klonierung des Vektors pK2.2L}

Dieser Vektor trägt die Codierregion des TGA2.2, 5' mit der Kozak-Sequenz und 3' mit der Linker-Sequenz versehen.

Mit den Primern TGA2.2 For und 2.2-link-lower-NEU wurde mit Hilfe von PCR auf dem EcoRI-gespaltenen Plasmid pSK-2811 PCR ein 1040 bp großes Amplifikat erzeugt und in den EcoRV-geschnittenen Vektor pUC57 einkloniert. Ein 30 bp großes SmaI / BamHI-Fragment aus diesem Vektor, welches die Linkersequenz trug, wurde in den ebenso geschnittenen Vektor pSK TGA2.2 in vitro inseriert, so dass das Plasmid pK2.2L entstand.

\subsubsection{Klonierung des Vektors pLVPs}

Über PCR wurde mit Hilfe der Primer link-VP16-upper und VP16-SunI-lower auf dem Template pSK-VP16 ein 402 bp großes Fragment erzeugt und in den mit EcoRV geschnittenen Vektor pUC57 inseriert. Über die Schnittstellen EcoRI und SunI wurde in dem Vektor pUC57 2.1strepII die 2.1-Codierregion gegen ein 433 bp großes Fragment aus dem entstandenen Plasmid ausgetauscht, so dass der Vektor die Sequenz für die VP16Aktivierungsdomäne mit vorangestellter Peptidlinker- und nachfolgender Streptag® II Sequenz enthält.

\subsubsection{Klonierung des Vektors pLENGs}

Mit den Primern link-eng.-upp und engrailed-SunI-lower wurde mittels PCR auf dem Template pENGRAILED ein 921 bp großes Fragment erzeugt und in den Vektor pUC57/T einkloniert. In dem Vektor pUC57 2.1strepII wurde die TGA2.1-Codierregion gegen ein EcoRI / SunI-Fragment aus dem entstandenen Plasmid ausgetauscht. Resultat war ein Vektor, der die Sequenz für die ENGRAILED-Silencerdomäne mit 5'-fusionierter Linkersequenz und 3'-fusionierter Sequenz für den Streptag® II trägt.

\subsubsection{Klonierung des Vektors pL2.1s}

Dieser Vektor enthält die Codierregion des Transkriptionsfaktors TGA2.1. Am 5'-Ende trägt sie die Sequenz für den beschriebenen Peptidlinker, am 3'-Ende die Sequenz für den Streptag® II.

Auf einem KpnI / SalI-Fragment aus dem Vektor pTGA2.1mut-strep entstand durch PCR mit den Primern link-2.1-upper-NEU und TGA2.1mut-REV ein 564 bp großes Fragment, welches in den EcoRV geschnittenen Vektor pUC57 inseriert wurde. Über die Schnittstellen BglII und SalI wurde das 3'-Ende der Codierregion gegen ein 1107 bp großes Fragment aus dem Vektor pUC57 2.1strepII ausgetauscht, welches 5' die korrekte Sequenz für die basische Region und 3' die Sequenz für den Streptag® II trägt.

\subsubsection{Klonierung des Vektors pUC57 VP2.1s}

Über die Schnittstelle BamHI wurde in den Vektor pKVPL ein 1421 bp großes Fragment aus dem Vektor pL2.1s inseriert. 


\subsubsection{Klonierung des Vektors pUC57 ENG2.1s}

Über die Schnittstelle BamHI wurde in den Vektor pKENGL ein 1421 bp großes Fragment aus dem Vektor pL2.1s inseriert.

\subsubsection{Klonierung des Vektors pUC57 2.1VPs}

Über die Schnittstelle BamHI wurde in den Vektor pK2.1L ein 428 bp großes Fragment aus dem Vektor pLVPs inseriert.

\subsubsection{Klonierung des Vektors pUC57 2.1ENGs}

Über die Schnittstelle BamHI wurde in den Vektor pK2.1L ein 947 bp großes Fragment aus dem Vektor pLENGs inseriert.

\subsubsection{Klonierung des Vektors pSK 2.2VPs}

Über die Schnittstelle BamHI wurde in den Vektor pK2.2L ein 428 bp großes Fragment aus dem Vektor pLVPs inseriert.

\subsubsection{Klonierung des Vektors pSK 2.2ENGs}

Über die Schnittstelle BamHI wurde in den Vektor pK2.2L ein 947 bp großes Fragment aus dem Vektor pLENGs inseriert.

\subsubsection{Klonierung des Vektors pUC57 2.1-57s}

Über die Schnittstellen Acc65I und Eco130I wurde in dem Vektor pL2.1s der 5'-Bereich der TGA2.1-Codierregion gegen ein 758 bp großes Fragment aus dem Vektor pSKTGA2.1-57 ausgetauscht.

\subsubsection{Umklonieren der zuvor beschriebenen Derivate in den Vektor pBINHyg-TX}

Alle zuvor beschriebenen TGA2.1-Fusionsderivate wurden als Asp718 / StuI-Fragmente in den Asp718 / SmaI geschnittenen Vektor pBINHyg-TX inseriert.

TGA2.1-57s wurde, wie auch alle zuvor beschriebenen TGA2.2-Derivate, über die Schnittstellen Asp 718 und $\mathrm{XbaI}$ in den Vektor pBINHyg-TX einkloniert. 


\subsubsection{PCR (Polymerase Chain Reaction) (modifiziert nach MULLIS und FALOONA, 1987)}

Bei der PCR-Reaktion wird mit Hilfe einer DNA-Polymerase und zweier gegenläufiger Primer ein dazwischen liegender DNA-Abschnitt selektiv amplifiziert. Durch Denaturierung und anschließende Renaturierung wird den Primern die Bindung an ihre komplementären Sequenzen auf dem Matrizenstrang ermöglicht. Ausgehend von diesen Primern katalysiert eine hitzestabile DNA-Polymerase (im Rahmen dieser Arbeit meist die Taq-DNAPolymerase) die Synthese des vollständigen komplementären Strangs, der in folgenden Zyklen ebenfalls als Matrize für die Bindung der spezifischen Primer dient. Durch Wiederholung des beschriebenen Zyklus kommt es zur exponentiellen Vervielfältigung des DNA-Abschnitts zwischen den Primern.

PCR-Reaktionen wurden standardmäßig unter folgenden Bedingungen in einem Endvolumen von $50 \mu$ l durchgeführt: $20-200$ pg Matrizen-DNA, 25 pmol jeden Primers, $200 \mu \mathrm{M}$ dNTPs, 2,5 U Taq-Polymerase, 1 x Taq-Puffer mit $1,5 \mathrm{mM} \mathrm{MgCl}$. Nach einer initialen Denaturierung für 3 min bei $93{ }^{\circ} \mathrm{C}$ erfolgte die Denaturierung in jedem Zyklus für 1 min bei $94{ }^{\circ} \mathrm{C}$, das Annealing der Primer für $1 \mathrm{~min}$ bei der geringeren der für die beiden Primer errechneten $\mathrm{T}_{\mathrm{m}}$ (3.2.3) und die Elongation für $1 \mathrm{~min} / \mathrm{kb}$ bei $72{ }^{\circ} \mathrm{C}$. Der Zyklus wurde $30 \mathrm{x}$ wiederholt. Falls die PCR-Produkte anschließend einkloniert werden sollten, wurde das Reaktionsgemisch abschließend 5 min bei $72{ }^{\circ} \mathrm{C}$ inkubiert.

\subsubsection{PCR zur Charakterisierung von rekombinanten Klonen}

$10 \mu \mathrm{l}$ des Überstands der unter 4.3.1.2 beschriebenen Schnell-Lyse wurden als Template für eine PCR mit jeweils 25 pmol geeigneter Primer in einem Endvolumen von $50 \mu 1$ verwendet.

Um falsch positive Signale in der PCR zu vermeiden, wurde nach Möglichkeit nur einer der beiden Primer im neu inserierten Fragment gewählt. Die Bindestelle für den zweiten Primer lag wenn möglich im Rezipientenvektor.

\subsubsection{Sequenzierung „Cycle Sequencing“}

Die DNA-Sequenzierung wurde nach der Didesoxy-Methode mit fluoesceinmarkierten Terminatoren durchgeführt. Die Detektion der fluoreszenzmarkierten DNA-Fragmente erfolgte mit Hilfe des ABI PRISM 310 der Firma Perkin Elmer. Die Sequenzierreaktion erfolgte mit Hilfe des BigDye ${ }^{\mathrm{TM}}$ Terminator Cycle Sequencing Ready Reaction-Kits.

$400 \mathrm{ng}$ der zu sequenzierenden Plasmid-DNA wurden mit $4 \mu 1$ Terminator Ready ReactionMix (BigDye) und 3,2 pmol Primer (M13 universal, M13 reverse oder genspezifische Primer) gemischt und der Ansatz mit $\mathrm{H}_{2} \mathrm{O}$ auf $20 \mu \mathrm{l}$ aufgefüllt. Bei der PCR-Reaktion wurden im Thermocycler folgende Temperaturschritte durchlaufen: $25 \times\left(95^{\circ} \mathrm{C}, 5 \mathrm{sec} ; 50-60{ }^{\circ} \mathrm{C}\right.$ [abhängig von der Schmelztemperatur des Primers], $5 \mathrm{sec} ; 60^{\circ} \mathrm{C}, 4 \mathrm{~min}$ ); $60{ }^{\circ} \mathrm{C}, 10 \mathrm{~min}$; $4{ }^{\circ} \mathrm{C}, \infty$. Um nicht eingebaute Terminatoren zu entfernen, wurde der Ansatz nachfolgend einer EtOH-Fällung unterzogen. Die Eigenfluoreszenz der Terminatoren würde die Detektion der fluoreszenzmarkierten PCR-Produkte. Der Ansatz wurde mit $19 \mu 1 \mathrm{H}_{2} \mathrm{O}$ und $61 \mu 1 \quad 100 \%$ $\mathrm{EtOH}$ versetzt und $15 \mathrm{~min}$ bei RT inkubiert. Nach einer Zentrifugation (15 min, $13.000 \mathrm{rpm}$, Biofuge) wurde der Überstand vollständig entfernt, das DNA-Pellet mit $100 \mu \mathrm{l} 70 \% \mathrm{EtOH}$ gewaschen, anschließend $1 \mathrm{~min}$ bei $90^{\circ} \mathrm{C}$ getrocknet und in $20 \mu \mathrm{l}$ Template Suppression Reagent (TSR) gründlich resuspendiert. Nach dem Denaturieren bei $95^{\circ} \mathrm{C}$ fir 2 min wurde die Probe 5 - $10 \mathrm{~min}$ auf Eis gehalten und für die Sequenzanalyse in spezielle Sequenziergefäße überführt. 


\subsubsection{Agarose-Gelelektrophorese}

\subsubsection{Auftrennung von DNA im Agarosegel}

Die Agarosegelelektrophorese wurde eingesetzt, um DNA-Fragmente ihrer Größe nach aufzutrennen. Zur Herstellung von horizontalen Agarosegelen wurde eine Lösung aus 0,7 $2 \%$ Agarose in 1 x TAE aufgekocht und in Kammern der Größe $7 \times 10 \mathrm{~cm}$ auf RT heruntergekühlt. Alternativ wurde eine Lösung aus 0,7\% Hydroxyethylcellulose (HEC) und $1 \%$ Agarose in $1 \times$ TAE verwendet. Die Verwendung von HEC-Agarosegelen (PERLMAN et al., 1987) hat eine deutlich höhere Auflösung der Banden zur Folge. Vor der Auftragung wurden die Proben mit $1 / 10$ Volumen 10 x Probenpuffer versetzt und in die Taschen des nun in $1 \times$ TAE befindlichen Gels pipettiert. Durch Anlegen einer Spannung von $100-120$ V wurden die DNA-Fragmente im elektrischen Feld aufgetrennt. Nach adäquater Laufzeit wurde das Gel für $10 \mathrm{~min}$ in einer EtBr-Lösung $(1 \mathrm{mg} / \mathrm{l} \mathrm{EtBr}$ in $1 \mathrm{x}$ TAE) gefärbt und anschließend für $5 \mathrm{~min}$ in Wasser entfärbt. Das in die DNA-Fragmente interkalierte $\mathrm{EtBr}$ wurde auf dem UV-Transilluminator bei $302 \mathrm{~nm}$ sichtbar gemacht und das Bandenmuster mit einer CCDKamera in digitaler Form festgehalten. Zur vergleichenden Größenbestimmung dienten die unter 3.2.6 beschriebenen DNA-Längenstandards, die neben den Proben aufgetragen wurden.

\subsubsection{Auftrennung von RNA im denaturierenden Agarosegel (FOURNEY et al., 1988)}

RNA-Moleküle bilden stabile Sekundärstrukturen aus, die zu einem veränderten Verhalten in der Gelelektrophorese führen können. Aus diesem Grund werden RNA-Moleküle in einem denaturierenden Agarosegel aufgetrennt. 1,4 g Agarose wurden in $100 \mathrm{ml} \mathrm{H}_{2} \mathrm{O}$ aufgekocht, leicht abgekühlt und mit $14 \mathrm{ml} 10 \times$ MOPS und $21 \mathrm{ml} 37 \%$ Formaldehyd versetzt. Nach gründlichem Mischen ließ man die Lösung im Gießstand zu $10 \times 15 \mathrm{~cm}$ großen Gelen mit einer Dicke von etwa $5 \mathrm{~mm}$ erstarren. Jeweils $10 \mu \mathrm{g}$ einer Gesamt-RNA-Probe wurden mit $\mathrm{H}_{2} \mathrm{O}$ auf ein Endvolumen von $40 \mu \mathrm{l}$ verdünnt und mit $20 \mu \mathrm{l} 3 \times$ RNA-Probenpuffer versetzt. Das Gemisch wurde $10 \mathrm{~min}$ bei $65^{\circ} \mathrm{C}$ denaturiert und anschließend mindestens $5 \mathrm{~min}$ auf Eis gehalten. Das Gel wurde in einem Tank mit 1 xMOPS angeschichtet und beladen. Nach Laden der Proben wurden die Taschen mit 1x MOPS aufgefüllt und eine Spannung von 100 $120 \mathrm{~V}$ angelegt, wodurch die RNA-Moleküle elektrophoretisch aufgetrennt wurden. Nach 2 $3 \mathrm{~h}$ wurde die Auftrennung der RNA auf dem UV-Transilluminator (302 nm) mit der CCDKamera dokumentiert.

\subsection{Northernblot-Analyse}

\subsubsection{Herstellung radioaktiv markierter Sondenmoleküle}

Für die Herstellung radioaktiv markierter Sondenmoleküle wurden DNA-Fragmente ab einer Größe von etwa 400 bp verwendet, welche durch Restriktionsspaltung oder PCR und anschließende Elution aus dem Agarosegel gewonnen wurden. Die Markierungsreaktion erfolgte nach der random-prime-Methode (FEINBERG und VOGELSTEIN, 1983), wobei randomisierte Hexanucleotide nach Bindung an die Sonden-DNA als Ursprung einer Neusynthese des komplementären Strangs dienen. Diese Reaktion wird von einem KlenowFragment katalysiert, dem die Exonucleaseaktivität fehlt. 
25 - $50 \mathrm{ng}$ des Sondenmoleküls wurden mit 1,4 $\mu$ l eines random-prime-Mix durch Zugabe von $\mathrm{H}_{2} \mathrm{O}$ auf ein Volumen von $10 \mu \mathrm{l}$ gebracht, $5 \mathrm{~min}$ bei $100^{\circ} \mathrm{C}$ im Wasserbad inkubiert und anschließend 5 min auf RT äquilibriert. Nach Erreichen der RT wurden $5 \mu$ l Nucleotid-Mix [jeweils $500 \mu \mathrm{M}$ dCTP, dGTP und dTTP], $5 \mu 110 x$ Klenow-Puffer [MBI Fermentas] und $24 \mu \mathrm{l} \mathrm{H}_{2} \mathrm{O}$ zugegeben. Die Zugabe von $5 \mu \mathrm{l}\left[\alpha^{32} \mathrm{P}\right] \mathrm{dATP}$ und $1 \mu \mathrm{l}$ Klenow-Fragment exo ${ }^{-}$ [1 U/ $\mu \mathrm{l}]$ erfolgte im Isotopenlabor. Nach Zugabe des Enzyms wurde der Ansatz durch Anschnippen gemischt, kurz zentrifugiert und $3 \mathrm{~h}$ bei $37^{\circ} \mathrm{C}$ inkubiert. Dieser Ansatz wurde bei geringeren Mengen an benötigter radioaktiver Sonden-DNA proportional bis zu einem Endvolumen von $30 \mu \mathrm{l}$ reduziert, ohne dass die spezifische Radioaktivität der markierten Sondenmoleküle beeinträchtigt wurde.

Die Aufreinigung der Sondenmoleküle erfolgte mit Hilfe von in TE (pH 7,5) äquilibriertem Sephadex G-50, welches in einer Pasteurpipette als Säulenmaterial verwendet wurde. Die radioaktive Probe wurde auf die Säule geladen und die Elution erfolgte in $200 \mu \mathrm{l}$ Schritten mit TE ( $\mathrm{pH} 7,5)$, wobei die Position der radioaktiven Probe mit dem Zählrohr verfolgt wurde. Maximal drei $200 \mu \mathrm{l}$ - Fraktionen der austretenden, radioaktiven Moleküle wurden aufgefangen und im Scintilationsmessgerät ausgemessen, bevor sie vereinigt wurden. Bis zum Gebrauch wurde die aufgereinigte Sonde bei $-20^{\circ} \mathrm{C}$ aufbewahrt.

\subsubsection{Transfer von RNA auf Nylonmembranen}

Die wie unter 4.3.10.2 beschrieben aufgetrennte und dokumentierte RNA wurde durch Kapillarblot auf Nylonmembranen transferiert, um eine Hybridisierung mit radioaktiv markierten Sondenmolekülen zu ermöglichen.

$\mathrm{Zu}$ diesem Zweck wurde das Gel zunächst zweimal 15 min leicht in $\mathrm{H}_{2} \mathrm{O}$ geschüttelt, um die Konzentration an Formaldehyd im Gel zu reduzieren. Der Aufbau des Blots erfolgte luftblasenfrei von unten nach oben wie folgt in einer mit $10 \mathrm{x}$ SSC gefüllten Schale: 3 Lagen Fliesspapier 3MM (15 x $30 \mathrm{~cm}$, in 10 x SSC getränkt), Gel (Oberseite nach unten), Maske aus Parafilm (Ränder und Taschen des Gels abdeckend), Nytran®-Membran $(15$ x $10 \mathrm{~cm}$, zuvor kurz in $\mathrm{H}_{2} \mathrm{O}$ aktiviert), 3 Lagen Fliesspapier $3 \mathrm{MM}(15 \times 10 \mathrm{~cm}$, in $10 \times$ SSC getränkt), ca. $10 \mathrm{~cm}$ Zellstoff, Beschwerung (z. B. Chemikalienkatalog). Nach mindestens einer Nacht konnte die Apparatur wieder abgebaut werden. Der Filter mit der transferierten RNA wurde kurz unter fließendem $\mathrm{H}_{2} \mathrm{O}$ abgespült, um anhaftende Gelreste zu entfernen, und anschließend mindestens $1 \mathrm{~h}$ bei $80^{\circ} \mathrm{C}$ inkubiert. Durch diesen Schritt erfolgte die kovalente Bindung der RNA an die Filteroberfläche. Der trockene Filter wurde erneut mit Hilfe des UVTransilluminators dokumentiert und bis zur Weiterverwendung zwischen zwei Lagen Fließpapier trocken aufbewahrt.

\subsubsection{Hybridisierung von Northernblots}

Die Erkennung eines Transkripts auf der Filteroberfläche durch ein radioaktiv markiertes Sondenmolekül erfolgt durch die Erkennung der komplementären Basensequenz während des Hybridisierungsvorgangs. Durch anschließende, sequentiell stringentere Waschschritte wird die Hybridisierung hochspezifischer Basenpaarungen bevorzugt, während unspezifisch gebundene Sondenmoleküle abgewaschen werden.

Der Filter wurde in eine gründlich gereinigte Hybridisierungsröhre eingeführt und mit $10 \mathrm{ml}$ Dextransulfatlösung mindestens $30 \mathrm{~min}$ bei $43{ }^{\circ} \mathrm{C}$ vorhybridisiert. Wurden mehrere Filter pro Röhre hybridisiert, so betrug das Volumen der Dextransulfatlösung $15 \mathrm{ml}$. Die aufgereinigte, radioaktive Sonde und eine Heringssperma-DNA-Lösung (HSP) wurden 10 min bei $100{ }^{\circ} \mathrm{C}$ im Wasserbad inkubiert. Das heiße HSP wurde in einer Endkonzentration von $100 \mu \mathrm{g} / \mathrm{ml}$ in die Röhre pipettiert. Schließlich wurde ein geeignetes Volumen der radioaktiven Sonde in die 
Röhre gegeben, ohne die Filteroberfläche zunächst direkt zu berühren. Die Hybridisierung erfolgte über Nacht bei $43{ }^{\circ} \mathrm{C}$.

Das Waschen der Filter wurde bei $65^{\circ} \mathrm{C}$ in Schritten von mindestens 15 min Länge in der Röhre und bei abnehmender Radioaktivität im Schüttelwasserbad durchgeführt. Dazu wurde sukzessiv jeweils zweimal mit adäquaten Volumina folgender Lösungen gewaschen: 2 x SSC, $0,1 \%$ SDS, $1 \times$ SSC, $0,1 \%$ SDS, $0,5 \times$ SSC, $0,1 \%$ SDS, und wenn nötig $0,1 \times$ SSC, $0,1 \%$ SDS. Die Filter wurden im feuchten Zustand in Haushaltsfolie eingeschweißt und durch Auflegen auf einen zuvor gelöschten Phosphoimager-Screen exponiert. Die Exposition erfolgte im Regelfall über Nacht, bei sehr schwachen Signalen auch mehrere Tage. Nach Auslesen der Daten vom Screen im Phosphoimager wurden die Daten mit Hilfe des Programms PCBAS 2.09 der Firma raytest Isotopenmeßgeräte $\mathrm{GmbH}$ ausgewertet.

\subsubsection{Mehrfachhybridisierung von Filtern}

Nach Abwaschen hybridisierter radioaktiver Sondenmoleküle ist es möglich, einen Filter zur Hybridisierung mit weiteren Sonden zu verwenden. Das Abwaschen einer radioaktiven Sonde erfolgte durch zweimalige Inkubation des Filters mit $500 \mathrm{ml}$ kochender 0,1\%iger SDSLösung im Schüttelwasserbad bei $75^{\circ} \mathrm{C}$ für jeweils $30 \mathrm{~min}$. Der Filter konnte anschließend direkt einer neuen Vorhybridisierung zugefuihrt werden.

\subsection{Isolierung, Reinigung, Quantifizierung und Darstellung von Proteinen}

\subsubsection{Isolierung von Proteinen aus $\mathbf{N}$. tabacum}

\subsubsection{Denaturierende Gesamtzellextrakte}

Blattgewebe wurde unter $\mathrm{N}_{2}$ (liq.) aufgemörsert, 50 - $200 \mathrm{mg}$ des Pulvers im gefrorenen Zustand in ein Eppendorfgefäß eingewogen, mit der dreifachen Menge $(\mathrm{mg}=\mu \mathrm{l})$ Harnstoffextraktionspuffer $\left(65^{\circ} \mathrm{C}\right)$ gründlich vermischt und bei $65^{\circ} \mathrm{C}$ für $10 \mathrm{~min}$ geschüttelt. Nach 5 min Inkubation wurden die Eppendorfgefäße mehrmals invertiert. Anschließend wurde der Rohextrakt $15 \mathrm{~min}$ bei $15.000 \mathrm{rpm}$ und RT (Eppendorf 5403) zentrifugiert, um Zelltrümmer und hochmolekulare DNA abzutrennen. ${ }^{2} / 3$ Volumen des Überstandes wurden in ein neues Eppendorfgefäß überführt, ohne das Pellet zu verletzen. Die Proteinextrakte wurden bis zur weiteren Verwendung bei $-80{ }^{\circ} \mathrm{C}$ gelagert. Vor Auftragung in der SDS-PAGE wurden die Extrakte lediglich $5 \mathrm{~min}$ bei $65^{\circ} \mathrm{C}$ inkubiert. Die Auftragung erfolgte ohne Zusatz weiterer Lösungen.

\subsubsection{Denaturierende Kernproteinextrakte (modifiziert nach PRAT et al., 1989, NigGEWEG, 1999)}

Alle Schritte der Prozedur fanden soweit nicht anders angegeben bei $4{ }^{\circ} \mathrm{C}$ statt. $6-10 \mathrm{~g}$ Blattgewebe wurden unter Kühlung mit $\mathrm{N}_{2}$ (liq.) im Mixer $\mathrm{zu}$ einem homogenen Pulver zerkleinert und in $40 \mathrm{ml}$ Puffer 1A resuspendiert. Durch anschließende Filtration durch zwei Lagen Miracloth wurden größere Zelltrümmer von der Organellensuspension abgetrennt. Eine nachfolgende Zentrifugation (SS34, $1.100 \mathrm{rpm}, 2 \mathrm{~min} 40 \mathrm{sec}$ ) trennte verbleibende Zelltrümmer und Stärke ab. Der Überstand wurde in frische $50 \mathrm{ml}$ Röhrchen überführt und 
abermals zentrifugiert (SS34, $2.000 \mathrm{rpm}, 3 \mathrm{~min}$ ), um die Zellkerne zu pelletieren. Der verbleibende Überstand wurde verworfen und das Kernpellet mit einem Haarpinsel in $8 \mathrm{ml}$ Puffer 0,5A resuspendiert. Die Kernpelletierung wurde insgesamt viermal durchgeführt, um die Kerne von den leichteren Chloroplasten zu trennen. Das letzte Kernpellet wurde anstatt in 0,5A in $350-450 \mu \mathrm{l}$ Harnstoffextraktionspuffer aufgenommen, gründlich durch Verrühren und vortexen gemischt und für $10 \mathrm{~min}$ bei $60^{\circ} \mathrm{C}$ im Wasserbad inkubiert. Durch anschließende Ultraschallbehandlung wurde die hochmolekulare DNA fragmentiert und somit die Lösung weniger viskos. Durch eine abschließende Zentrifugation (Eppendorf 5403, $15.000 \mathrm{rpm}, \mathrm{RT}, 10 \mathrm{~min}$ ) wurden Membranbestandteile der Zellkerne pelletiert. Der verbleibende Überstand wurde in neue Eppendorfgefäße überführt. Im folgenden wurden die Extrakte wie die unter 4.5.1.1 beschriebenen denaturierenden Gesamtzellextrakte behandelt.

\subsubsection{Normalisierung der Proteinmengen mittels SDS-PAGE und Coomassie- Färbung}

Die Konzentration der unter 4.5.1.1 und 4.5.1.2 gewonnenen denaturierenden Proteinextrakte kann nicht mit Hilfe von photometrischen Verfahren ermittelt werden. Aus diesem Grund erfolgte die Normalisierung durch Auftrennung der Proteine in der SDS-PAGE und anschließende Färbung mit Coomassie-Brilliant-Blue.

$5-10 \mu \mathrm{l}$ der Extrakte wurden in einem 10\%igen SDS-Polyacrylamidgel elektrophoretisch aufgetrennt. Das Gel wurde $10 \mathrm{~min}$ in Fixierlösung geschüttelt, anschließend in CoomassieFärbelösung überführt und über Nacht bei RT leicht geschüttelt. Die Entfärbung erfolgte am nächsten Tag durch zweimal dreistündige Inkubation in Coomassie-Entfärbelösung bei RT unter leichtem Schütteln. Das Gel wurde mit einem handelsüblichen Durchlichtscanner aufgenommen und die gefärbten Proteine densitometrisch mit Hilfe des Programms PCBAS 2.09 ausgewertet. Aufgrund dieser Auswertung wurden die relativen Proteinkonzentrationen berechnet.

\subsubsection{Native Gesamtzellextrakte (JUPIN und CHUA, 1996)}

$2 \mathrm{~g}$ abgenutschte Suspensionszellen wurden unter $\mathrm{N}_{2}$ (liq.) im Mörser zerkleinert und in $4 \mathrm{ml}$ NLB-Puffer aufgenommen. Nach dem Auftauen wurde zu der Suspension unter langsamem Rühren tropfenweise $4 \mathrm{M}$ Ammoniumsulfat bis zu einer Endkonzentration von $10 \%$ gegeben. Nach vollständiger Zugabe des Ammoniumsulfat wurde die Lösung 30 min bei $4{ }^{\circ} \mathrm{C}$ langsam gerührt. Die ausgefällten, hochmolekularen Substanzen und Zelltrümmer wurden durch Zentrifugation für $90 \mathrm{~min}$ bei $150.000 \mathrm{~g}$ und $4{ }^{\circ} \mathrm{C}$ in der Ultrazentrifuge pelletiert und verworfen. Die im Überstand enthaltenen Proteine wurden mittels Ammoniumsulfat ausgefällt. Hierzu wurde zu der Probe unter langsamem Rühren 0,3 g/ml Ammoniumsulfat gegeben, und die Lösung $30 \mathrm{~min}$ bei $4{ }^{\circ} \mathrm{C}$ gerührt. Die Proteine wurden durch 20minütige Zentrifugation bei $10.800 \mathrm{~g}$ und $4{ }^{\circ} \mathrm{C}$ in der Sorvall-Kühlzentrifuge pelletiert. Im Anschluss wurde das Proteinpellet in 1,8 ml NEB-Puffer mit $50 \mathrm{mg} / \mathrm{l}$ Antipain, 0,5 mg/l Leupeptin und $0,2 \mathrm{mM}$ Pefabloc resuspendiert. Zur Entfernung des Ammoniumsulfats wurde der Extrakt zweimal 8-10 h gegen $500 \mathrm{ml}$ NEB-Puffer dialysiert.

Die Konzentrationsbestimmung des Proteinextraktes erfolgte nach der Methode von Bradford (s. 4.5.3). Zur Lagerung wurden Aliquots des Extraktes in flüssigem Stickstoff schockgefroren und bei $-80^{\circ} \mathrm{C}$ aufbewahrt. 


\subsubsection{Native FixProt-Gesamtzellextrakte (modifiziert nach KEGLER, unveröffentlicht)}

Blattgewebe bzw. abgenutschte Suspensionszellen wurden unter $\mathrm{N}_{2}$ (liq.) aufgemörsert und $100-300 \mathrm{mg}$ des Pulvers in einem gekühlten Eppendorfgefäß mit 2 Vol. 1,5 x FixProtExtraktionspuffer $\left(4^{\circ} \mathrm{C}\right)$ versetzt. Um die Proteinkonzentration von Extrakten aus Zellsuspensionen $\mathrm{zu}$ erhöhen, wurde für Extrakte dieser Art 1 Vol. 2 x FixProtExtraktionspuffer verwendet. Die Vermischung erfolgte mit Hilfe einer Pipettenspitze bzw. durch Vortexen strikt bei $4{ }^{\circ} \mathrm{C}$ im Kühlraum, bis die Probe homogen aufgetaut war. Nicht lösliche Bestandteile der Probe wurden durch anschließende Zentrifugation (Eppendorf 5403, $15000 \mathrm{rpm}, 2{ }^{\circ} \mathrm{C}, 10 \mathrm{~min}$ ) pelletiert und der Überstand in gekühlte Eppendorfgefäße überführt. Der Extrakt wurde nach Bestimmung der Proteinkonzentration nach Bradford (4.5.3) in gekühlte Eppendorfgefäße aliquotiert, in $\mathrm{N}_{2}$ (liq.) schockgefroren und bis zur weiteren Verwendung bei $-80{ }^{\circ} \mathrm{C}$ gelagert. Die Aliquotierung war notwendig, da wiederholtes Auftauen die Qualität der Extrakte unreproduzierbar veränderte.

\subsubsection{Fällung von Proteinen (nach WeSSEL und FLÜGGE, 1984)}

Zur Konzentrierung von Proteinextrakten wurden die Proteine mit Methanol/Chloroform gefällt. $100 \mu \mathrm{l}$ der Proteinlösung wurden mit $400 \mu \mathrm{l}$ Methanol, $100 \mu \mathrm{l}$ Chloroform und $300 \mu \mathrm{l}$ $\mathrm{H}_{2} \mathrm{O}$ vermischt. Zur Phasentrennung wurde die Probe $2 \mathrm{~min}$ bei $10.700 \mathrm{rpm}$ in der Biofuge zentrifugiert. Die obere wässrige Phase wurde abgezogen. Die in der Interphase befindlichen Proteine wurden durch Zugabe von $300 \mu \mathrm{l}$ Methanol ausgefällt. Nach dem Mischen wurden die Proteine durch Zentrifugation (3 min, $13.000 \mathrm{rpm}$, Biofuge) pelletiert. Das Pellet wurde $15 \mathrm{~min}$ bei RT getrocknet und in $30 \mu \mathrm{l} 1 \mathrm{x}$ Protein-Probenpuffer resuspendiert. Die Probe konnte nach Denaturierung für 5 min bei $100^{\circ} \mathrm{C}$ für die SDS-PAGE verwendet werden.

\subsubsection{Konzentrationsbestimmung von Proteinextrakten (nach BRADFORD, 1976)}

Ein geeignetes Volumen des Proteinextrakts wurde in einer Microtiterplatte vorgelegt und mit $200 \mu \mathrm{l}$ Bradfordreagenz (1: 5 mit $\mathrm{H}_{2} \mathrm{O}$ verdünnt) durch Pipettieren gemischt. Nach einer Reaktionszeit von $5 \mathrm{~min}$ wurde die Adsorption im Dynex Plate-Reader bei $595 \mathrm{~nm}$ bestimmt. Die Proteinkonzentration wurde mit Hilfe einer mit BSA erstellten Eichgerade ermittelt.

\subsubsection{Affinitätsaufreinigung von Antiseren (modifiziert nach OLMSTED, 1981)}

Die hier beschriebene Methode zur Affinitätsaufreinigung von polyklonalen Antiseren stellt eine Modifikation des Immunoblots dar. $1 \mathrm{mg}$ aus einer Affinitätschromatographie gewonnenen Fusionsproteins wurde in einem präparativen 10\%igen SDS-Polyacrylamidgel aufgetrennt, und anschließend auf eine PVDF-Membran transferiert. Durch Anfärben der Membran mit Ponceau-Lösung wurde das Fusionsprotein sichtbar gemacht und ausgeschnitten. Die Membran wurde in ca. $2 \mathrm{~mm}$ breite Streifen zerschnitten und die Membranstücke über Nacht bei $4{ }^{\circ} \mathrm{C}$ in PBS-T $(0,05 \%$ Tween-20) mit $5 \%$ Magermilch inkubiert. Nach 5minütigem Waschen in PBS-T bei RT wurde die Membran für $3 \mathrm{~h}$ in $10 \mathrm{ml}$ des entsprechenden 1:5 mit PBS-T verdünnten polyklonalen Antiserums unter Schütteln bei RT inkubiert. Unspezifisch gebundene Antikörper wurden durch $6 \times$ Waschen mit PBS-T für jeweils 10 min entfernt. 
Die Elution der Antikörper von der Membran erfolgte in vier Elutionsschritten. In jedem

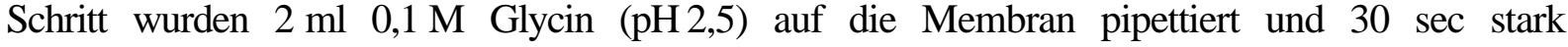
geschüttelt. Die eluierten Antikörper wurden in $1 \mathrm{ml}$ einer vorgelegten Neutralisierungslösung $\left(0,3 \mathrm{M}\right.$ Tris- $\mathrm{HCl} \mathrm{pH} 8,0,1 \mathrm{x}$ PBS, $\left.4{ }^{\circ} \mathrm{C}\right)$ dekantiert und sofort gemischt. Die vier Eluate wurden mit Hilfe von Centricon-50 Ultrazentrifugenröhrchen mit $2 \times 2 \mathrm{ml}$ PBS $(0,02 \%$ Natriumazid) umgepuffert und abschließend auf $200 \mu \mathrm{l}$ eingeengt. Zur Stabilisierung der Antikörper wurde BSA in einer Endkonzentration von $10 \mu \mathrm{g} / \mathrm{ml}$ zugesetzt. Die affinitätsgereinigten Antiseren wurden aliquotiert und bei $-80^{\circ} \mathrm{C}$ gelagert. Einmal aufgetaute Aliquots wurden bis zum Aufbrauchen bei $4{ }^{\circ} \mathrm{C}$ aufbewahrt. Die immunochemischen Eigenschaften der Eluate wurde durch Immunoblot-Analysen (4.6) ermittelt, wobei Konzentrationsreihen der Antiseren verwendet wurden.

\subsubsection{SDS-Polyacrylamid-Gelelektrophorese (SDS-PAGE) (LAEMMLI, 1970)}

Die Auftrennung von Proteine unter denaturierenden Bedingungen erfolgte in diskontinuierlichen SDS-Polyacrylamidgelen (10\% oder $12,5 \%$ PAA) unter 1 x PAGEPuffer. Trenngele enthielten $10-12,5 \%$ (w/v) Acrylamid/Bisacrylamid (19 : 1), 0,4 M Tris$\mathrm{HCl}(\mathrm{pH} 8,8), 0,1 \%(\mathrm{w} / \mathrm{v})$ SDS, 0,1\% TEMED und 0,1\% Ammoniumpersulfat (APS). Sammelgele enthielten $4 \%$ (w/v) Acrylamid/Bisacrylamid (37,5 : 1), $125 \mathrm{mM}$ Tris- $\mathrm{HCl}$ $(\mathrm{pH} 6,8), 0,1 \%(\mathrm{w} / \mathrm{v})$ SDS, 0,2 \% TEMED und 0,1\% APS. Vor Auftragung wurden die Proben in Harnstoffpuffer $5 \mathrm{~min}$ bei $65^{\circ} \mathrm{C}$ bzw. in Protein-Probenpuffer $5 \mathrm{~min}$ bei $100{ }^{\circ} \mathrm{C}$ denaturiert und vor dem Laden auf RT bzw. Eis abgekühlt. Vor dem Laden wurden durch Spülen mit einer Kanüle mögliche PAA-Reste aus den Taschen der Gele entfernt. Die elektrophoretische Auftrennung erfolgte je nach Gelgröße bei 80 bzw. 100 V im Sammelgel und 100 bzw. $130 \mathrm{~V}$ im Trenngel.

\subsection{Immunoblot-Analyse}

\subsubsection{Proteintransfer auf Polyvinylidenflourid (PVDF)-Membranen (modifiziert nach KYHSE-ANDERSEN, 1984)}

SDS-PAA-Gele wurden nach der Proteinauftrennung 2 x 15 min in Kathodenpuffer $(25 \mathrm{mM}$ Tris-HCl, $40 \mathrm{mM}$ Glycin, $10 \%$ Methanol; pH 9,4) äquilibriert. Die Aktivierung der PVDFMembran erfolgte in $100 \%$ Methanol. Die Membran wurde anschließend in Anodenpuffer II (25 mM Tris-HCl, $10 \%$ Methanol; pH 10,4) äquilibriert. Der Aufbau der Transferapparatur erfolgte von unten nach oben luftblasenfrei in folgender Weise: Graphitplatte, 2 Lagen Fließpapier 3MM (der Größe des Gels entsprechend) in Anodenpuffer I ( $0,3 \mathrm{M}$ Tris-HCl, $10 \%$ Methanol; pH 10,4) äquilibriert, 1 Lage Fließpapier 3MM (der Größe des Gels entsprechend) in Anodenpuffer II äquilibriert, aktivierte und äquilibrierte PVDF-Membran, äquilibriertes Gel, 3 Lagen Fließpapier 3MM (der Größe des Gels entsprechend) in Kathodenpuffer äquilibriert, Graphitplatte. Durch Anlegen eines Stroms von $1 \mathrm{~mA} / \mathrm{cm}^{2} / \mathrm{h}$ für 1 Stunde wurde der Transfer der Proteine auf die Membran gewährleistet. Nach dem Transfer wurde die PVDF-Membran kurz in $100 \%$ Methanol inkubiert und anschließend an der Luft getrocknet. Zur weiteren Verwendung der Membran musste zunächst eine erneute Aktivierung durch Inkubation in Methanol durchgefuihrt werden. 


\subsubsection{Detektion mit spezifischen Antiseren (Immunoblot-Analyse)}

\subsubsection{Detektion mit affinitätsgereinigtem Antiserum gegen TGA2.2}

Alle Schritte erfolgten bei RT. Nach Aktivierung mit Methanol wurde die Membran 5 min unter leichtem Schütteln in $1 \times$ PBS-T $(0,05 \%$ Tween-20) äquilibriert. Durch einstündige Inkubation in $1 \times$ PBS-T mit $5 \%(w / v)$ Magermilchpulver wurde die Membranoberfläche abgesättigt. Es folgten zwei Waschschritte für $5 \mathrm{~min}$ in $1 \times \mathrm{PBS}-\mathrm{T}$ mit $0,25 \%(\mathrm{w} / \mathrm{v})$ Magermilch. Anschließend erfolgte die Inkubation mit dem Antiserum gegen TGA2.2 (2. Elution 1: 5000 in PBS-T, 0,25\% (w/v) Magermilch) für 2,5 h. Durch darauffolgende Waschschritte $2 \times 5 \mathrm{~min}$ in $1 \times$ PBS-T, $0,25 \%$ (w/v) Magermilch und $2 \times 5$ min in $1 \times$ PBS-T wurden unspezifisch gebundene Erstantikörper entfernt. Die anschließende Inkubation mit dem zweiten Antikörper (Donkey anti rabbit Ig, Peroxidase-gekoppelt) erfolgte in einer $1: 30.000$ - Verdünnung für $1,5 \mathrm{~h}$ in $1 \mathrm{x}$ PBS-T. Unspezifisch gebundene Antikörper wurden durch abschließendes viermaliges Waschen für $5 \mathrm{~min}$ in $1 \mathrm{xPBS}-\mathrm{T}$ entfernt. zur Detektion gebundener Antikörper wurde der Enhanced Chemiluminescence Plus ${ }^{\mathrm{TM}}$ Kit der Firma Amersham entsprechend den Herstellerangaben verwendet. Die Detektion erfolgte durch Belichtung von Cronex Medical x-ray Filmen 10T der Firma Sterling Diagnostic Imaging, Inc Newark, DE 19714 USA.

\subsubsection{Detektion mit affinitätsgereinigtem Antisenum gegen TGA2.1 bzw. polyklonalem Antiserum gegen Streptag® II}

Die Detektion erfolgte analog der zuvor beschriebenen Prozedur mit folgenden Änderungen: Anstatt 5\% Magermilchpulver wurden 2\% BSA und anstatt 0,25\% Magermilch wurden $0,5 \%$ BSA in $1 \times$ PBS-T $(0,05 \%$ Tween-20) verwendet. Die verwendeten Erst-Antiseren waren $\alpha$ TGA2.1: 2 . Elution $1: 6.000$ verdünnt bzw. $\alpha$ Streptag® II: $1: 6.000$ verdünnt.

\subsection{EMSA}

Der Electromobility Shift Assay (EMSA) dient der sensitiven und quantitativen Detektion von Protein-DNA-Wechselwirkungen in-vitro. Dabei wird die Migrationsgeschwindigkeit radioaktiv markierter DNA-Fragmente im nativen PAA-Gel durch die Anlagerung von DNAbindenden Proteinen herabgesetzt, was wiederum durch autoradiografische Verfahren sichtbar gemacht werden kann. Der Supershift stellt ein Modifikation des EMSAs dar, bei der ein im Bindeansatz zugegebener Antikörper Proteine spezifisch erkennt, und so zu einer zusätzlichen Retardation des Komplexes führt, sofern sich das erkannte Protein im DNA-bindenden Komplex befindet.

\subsubsection{Herstellung radioaktiv markierter DNA-Fragmente für den EMSA}

Zur Markierung mit $\left[\alpha^{32} \mathrm{P}\right] \mathrm{dATP}$ wurden die unter 3.2 .5 beschriebenen DNA-Fragmente verwendet. Wie unter 3.2.5.3 geschildert, wurden die Fragmente durch Spaltung aus den entsprechenden Vektoren gewonnen.

Für die radioaktive Markierung der DNA-Fragmente wurde die Eigenschaft der KlenowPolymerase ausgenutzt, 3'-OH-Überhänge bis zum 5'-Phosphat-Ende aufzufüllen. 1,7 pmol gespaltener Vektor wurden in einem $20 \mu \mathrm{l}$ Ansatz unter folgenden Bedingungen für 2-3 h bei $37{ }^{\circ} \mathrm{C}$ inkubiert: 0,5 x KGB-Puffer, $25 \mu \mathrm{M}$ dTTP, $4,0 \mu \mathrm{l}[\alpha 32 \mathrm{P}]$-dATP $(40 \mu \mathrm{Ci})$ und $4 \mathrm{U}$ 
Klenow-Polymerase exo-. Durch Zugabe von EDTA $(\mathrm{pH} 8,0)$ auf eine Endkonzentration von $20 \mu \mathrm{M}$ wurde die Reaktion abgestoppt. Die Abtrennung nicht eingebauter Nucleotide erfolgte mit Hilfe einer Micro SpinTMG25 Column der Firma Amersham entsprechend den Herstellerangaben. Die weitere Aufarbeitung des Gelshiftfragments geschah durch Auftragung des gesamten Spaltungsansatzes auf ein 5\%iges natives PAA-Gel. Das radioaktiv markierte Fragment konnte durch Exposition eines Röntgenfilms genau lokalisiert werden und wurde ausgeschnitten. Die Sonde wurde aus dem PAA-Gelstiick durch Zugabe von $400 \mu \mathrm{l}$ TE-Puffer über Nacht eluiert. Die Strahlung der Sonde im Überstand wurde im Szintillationsmeßgerät quantifiziert. Ein Mikroliter der präparierten Sondenlösung enthielt 1,3 bis 1,6 fmol markiertes Fragment.

\subsubsection{Gelshift}

Eine geeignete Menge Protein wurde bei $4{ }^{\circ} \mathrm{C}$ in einem Endvolumen von $30 \mu \mathrm{l}$ in $1 \mathrm{x}$ Bindepuffer mit 1,5 - 3,0 $\mu \mathrm{g}$ poly $\mathrm{dI} / \mathrm{dC}$ gemischt. Bei Verwendung von FixProt-Extrakten wurden außerdem $3 \mu \mathrm{l} 10 \mathrm{x}$ Proteinase-Inhibitoren-Mix zugesetzt. Bei Bedarf erfolgte zusätzlich die Zugabe von $\mathrm{NaF}$ (Endkonzentration $12,5 \mathrm{mM}$ ) bzw. Quercetin (Endkonzentration 12,5 $\mu \mathrm{M}$ ). Nach Zugabe von $4 \mu \mathrm{l}$ radioaktiv markierten DNA-Fragments wurde der Bindeansatz auf RT gestellt und 10 min inkubiert. Anschließend wurden $10 \mu \mathrm{l}$ $4 \times$ Ladepuffer zugesetzt und der Ansatz aufs Gel aufgetragen. Die Auftrennung erfolgte bei $4{ }^{\circ} \mathrm{C}$ in einem nativen PAA-Gel (5\% Acrylamid / Bisacrylamid (19 : 1), $10 \%$ Glycerin, $0,04 \%$ TEMED und $0,06 \%$ APS in $1 \times \mathrm{TBE})$, das vor der Beladung einem Vorlauf $(1 \mathrm{~h}$, $150 \mathrm{~V}, 4{ }^{\circ} \mathrm{C}$ in $\left.1 \times \mathrm{TBE}\right)$ unterzogen wurde. Zur Auftrennung wurde über Nacht eine Spannung von $65 \mathrm{~V}$ angelegt. Das Gel wurde nach der Auftrennung auf zwei Lagen Fließpapier 3MM transferiert und im Geltrockner bei $80^{\circ} \mathrm{C}$ für $2 \mathrm{~h}$ getrocknet. Die Detektion radioaktiver Banden erfolgte durch Exposition eines Phosphoimager-Screens für mindestens $4 \mathrm{~h}$ und anschließendes Einlesen der Daten im Phosphoimager.

\subsubsection{Supershift}

Für die Supershift-Analyse wurde in den Bindeansatz zusätzlich $1 \mu 1$ der entsprechenden Rohantiseren pipettiert.

\subsubsection{Quantitative Auswertung von EMSAs}

Die Quantifizierung der Bandenintensitäten erfolgte nach Einlesen der Daten im Phosphoimager mit Hilfe des Programms PCBAS 2.09. Die Intensität einer Bande wurde in Prozent an der insgesamt geshifteten Menge radioaktiven Fragments errechnet. Dabei ist zu beachten, dass eine Bande, die die Doppelbesetzung repräsentiert (Bande 3) doppelt so viel gebundene TGA-Faktoren darstellt, wie eine Bande gleicher Intensität, die durch die Einfachbesetzung entstanden ist (Banden 1 und 2). 


\section{Ergebnisse}

\subsection{Herstellung verschiedener Fusions- und Deletionsderivate von TGA2.1 und TGA2.2}

Ein im Rahmen dieser Arbeit hergestelltes Kassettensystem ermöglicht die in-frame-Fusion der VP16-Aktivierungsdomäne bzw. der ENGRAILED-Silencerdomäne an das 5'- oder das 3'-Ende der Transkriptionsfaktoren TGA2.1 bzw. TGA2.2. Alle entstandenen Fusionsderivate tragen zwischen den Fusionspartnern die Sequenz für einen Peptidlinker mit der Aminosäuresequenz $\left(\mathrm{G}_{4} \mathrm{~S}\right)_{3}$, der durch einen vergrößerten Abstand eine sterische Behinderung der Fusionspartner minimieren soll. Außerdem wurde ein N-terminal um 113 Aminosäuren verkürztes Deletionsderivat von TGA2.1 (TGA2.1-57; KRAWCZYK, 1999) für die Überexpression in transgenen Tabakpflanzen hergestellt, um die Auswirkungen einer $\mathrm{N}$ terminalen Deletion auf die Funktion von TGA2.1 in-vivo untersuchen zu können. C-terminal befindet sich zudem bei allen in dieser Arbeit konstruierten Derivaten eine acht Aminosäuren lange Sequenz, die von einem polyklonalen Antiserum gegen Streptag® II erkannt wird.

Alle neu eingefügten Sequenzabschnitte wurden mittels Sequenzierung überprüft. Die verschiedenen Derivate wurden in high-copy Vektoren (pUC57 oder pSK) kloniert und anschließend in den binären Vektor pBINHyg-TX inseriert. Die verschiedenen Derivate der TGA-Faktoren stehen somit unter der Kontrolle eines Tetracyclin-induzierbaren CaMV $35 \mathrm{~S}$ Promotorderivats (GATZ et al., 1992), das in Abwesenheit des Tet-Repressors in transgenen Pflanzen die gleiche Aktivität zeigt wie der CaMV 35S Promotor. In Abbildung 5-1 sind schematisch die verschiedenen Fusions- und Deletionsderivate gezeigt, deren Wirkung im Rahmen dieser Arbeit in transgenem Tabak untersucht wurden. Die Klonierung der einzelnen Kassettenvektoren und der binären Vektoren ist in Kapitel 4.3.7 beschrieben. 
$\mathrm{MW}[\mathrm{kDa}]$

2.1VPs

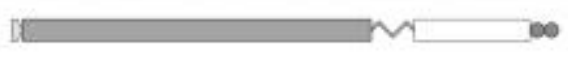

65,6

VP2.1s

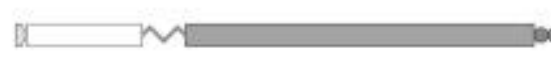

65,6

2.2VPs

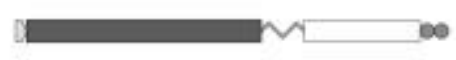

51,7

VP2.2s

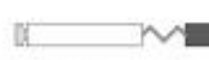

51,7

2.1ENGs

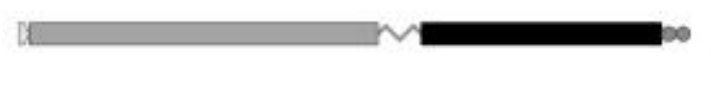

84,4

ENG2.1s

84,4

2.2ENGs

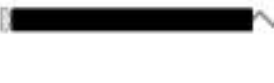

m

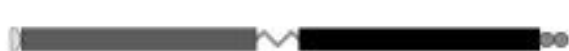

70,6

2.1

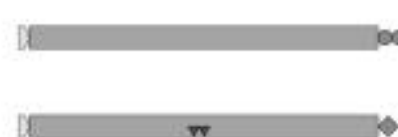

51,4

2.1 $\operatorname{trD}$

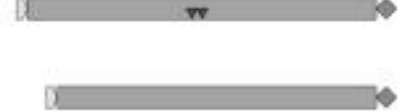

51,2

2.1 $\Delta \mathrm{N} 29$

48,2

2.1-57s

$x$

39,6

2.2

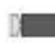

37,3

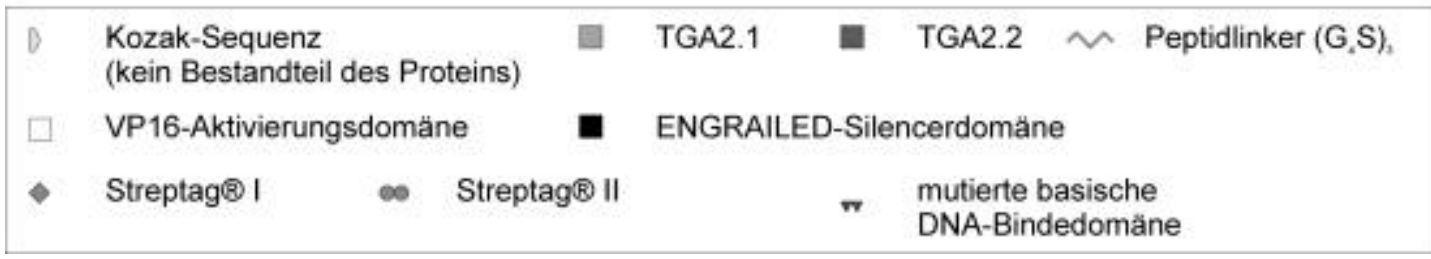

Abbildung 5-1: Schematische Darstellung der Fusions- bzw. Deletionsderivate, deren Wirkung im Rahmen dieser Arbeit in transgenen Pflanzen untersucht wurde.

\subsection{Herstellung und Charakterisierung transgener Tabakpflanzen}

\subsubsection{Herstellung transgener Tabakpflanzen}

Die unter 4.3.7.15 entstandenen binären Vektoren wurden in kompetente Agrobacterium tumefaciens Zellen vom Stamm GV2660 transformiert. Mit diesen wurden transgene Tabakpflanzen, die das as-1-GUS-Reporterkonstrukt trugen, mittels Agrobakterienvermitteltem Gentransfer transformiert. Hierbei handelte es sich um Pflanzen der Linie SNN as-1-GUS \#12. Bei der Bezeichnung der transgenen Linien wird im folgenden auf die Nennung des as-1-GUS-Reporters verzichtet. 


\subsubsection{Charakterisierung der transgenen Pflanzen auf Protein-Ebene}

Die Auswahl hochexprimierender Linien erfolgte im Falle der TGA2.1-Derivate aufgrund von Immunoblot-Analysen. Zur Analyse wurden von den $\mathrm{zu}$ testenden Gewebekulturpflanzen denaturierende Gesamtzellextrakte hergestellt, gleiche Volumina dieser Extrakte per SDSPAGE aufgetrennt und auf PVDF-Membranen geblottet. Die Detektion erfolgte mit Hilfe eines affinitätsgereinigten Antiserums gegen den N-Terminus von TGA2.1.

\subsubsection{SNN VP2.1s}

Es wurden neun unabhängige Transformanden getestet, von denen die Linien SNN VP2.1s \#2, \#4 und \#6 in der Immunoblot-Analyse eine starke Überexpression des transgenen Proteins VP2.1s zeigten (Abbildung 5-2). Für weitere Experimente wurden die Linien SNN VP2.1s \#2 und \#4 verwendet.

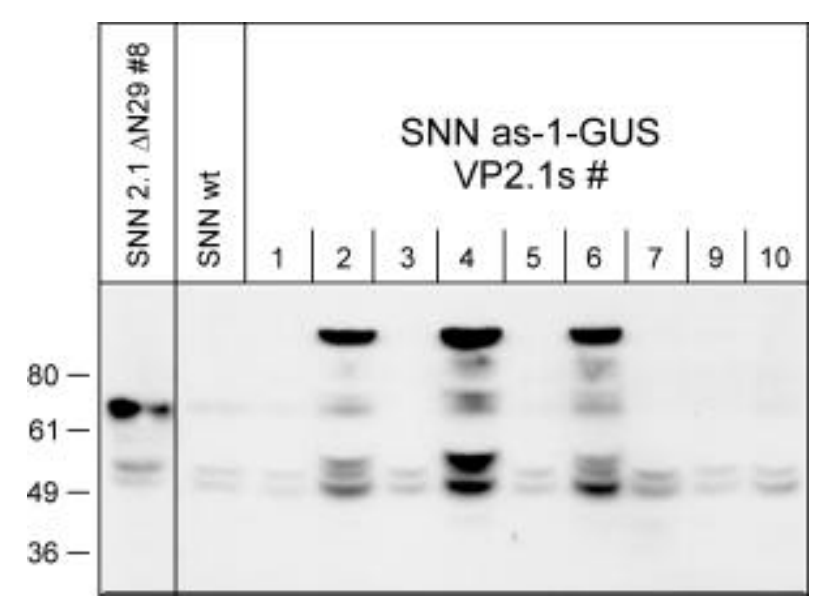

Abbildung 5-2: Immunoblot-Analyse zur Identifikation hochexprimierender SNN VP2.1s-Linien. Aufgetragen wurden jeweils gleiche Volumina von denaturierenden Gesamtzellextrakten der Linien SNN 2.1 4 N29 \#8 (Spur 1), SNN wt (Spur 2) und SNN VP2.1s \#1 - \#7 bzw. \#9 und \#10 (Spur 3 - 11). Die Detektion erfolgte mit affinitätsgereinigtem TGA2.1-Antiserum. Der Marker gibt das ungefähre Molekulargewicht in $\mathrm{kDa}$ an.

\subsubsection{SNN ENG2.1s}

Es wurden neun unabhängige Linien aus Gewebekultur getestet. Aufgrund der ImmunoblotAnalyse wurden für weitere Experimente die höchstexprimierenden Linien SNN ENG2.1s \#2 und \#4 ausgewählt (Abbildung 5-3). 


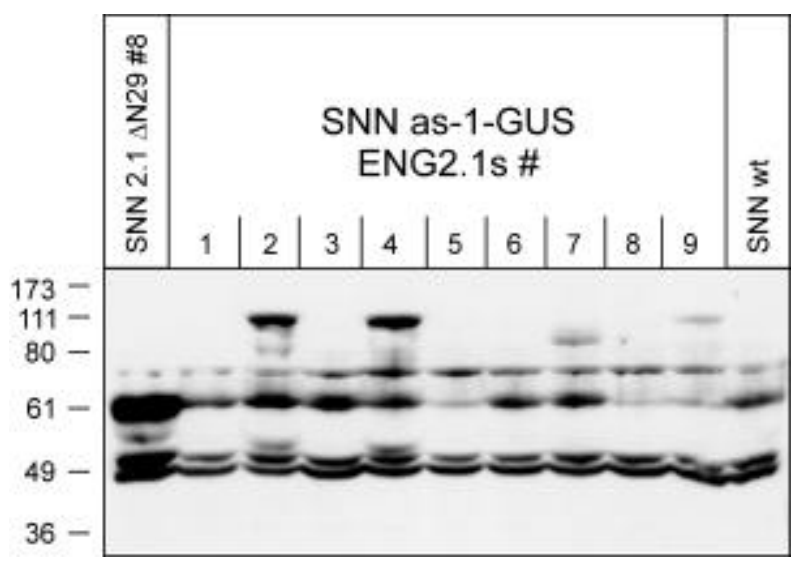

Abbildung 5-3: Immunoblot-Analyse zur Identifikation hochexprimierender SNN ENG2.1s-Linien. Aufgetragen wurden jeweils gleiche Volumina von denaturierenden Gesamtzellextrakten der Linien SNN 2.1 4 N29 \#8 (Spur 1), SNN ENG2.1s \#1 - \#9 (Spuren 2 - 10) und SNN wt (Spur 11). Die Detektion erfolgte mit affinitätsgereinigtem TGA2.1-Antiserum. Der Marker gibt das ungefähre Molekulargewicht in kDa an.

\subsubsection{SNN 2.1VPs}

Es wurden neun unabhängige Pflanzenlinien untersucht. Wie aus Abbildung 5-4 hervorgeht, konnten mittels Immunoblot-Analyse mit dem TGA2.1 Antiserum die Linien SNN 2.1VPs \#3 und \#6 als die beiden höchstexprimierenden Transformanden identifiziert werden. An ihnen wurden weitere Untersuchungen durchgeführt.

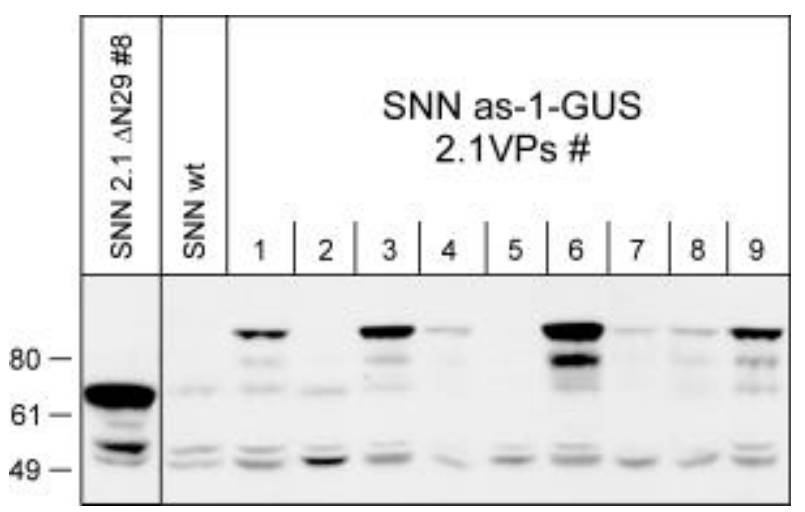

Abbildung 5-4: Immunoblot-Analyse zur Identifikation hochexprimierender SNN 2.1VPs-Linien. Aufgetragen wurden jeweils gleiche Mengen von denaturierenden Gesamtzellextrakten der Linien SNN 2.1 $\triangle$ N29 \#8 (Spur 1), SNN wt (Spur 2) und SNN 2.1VPs \#1 - \#9 (Spuren 3 - 11). Die Detektion erfolgte mit affinitätsgereinigtem TGA2.1-Antiserum. Der Marker gibt das ungefähre Molekulargewicht in $\mathrm{kDa}$ an. 


\subsubsection{SNN 2.1ENGs}

Von dieser Transformation wurden 18 unabhängige Linien untersucht. Als weiterzuverwendende, hochexprimierende Pflanzen wurden die Linien SNN 2.1ENGs \#4 und \#17 ausgewählt (Abbildung 5-5).
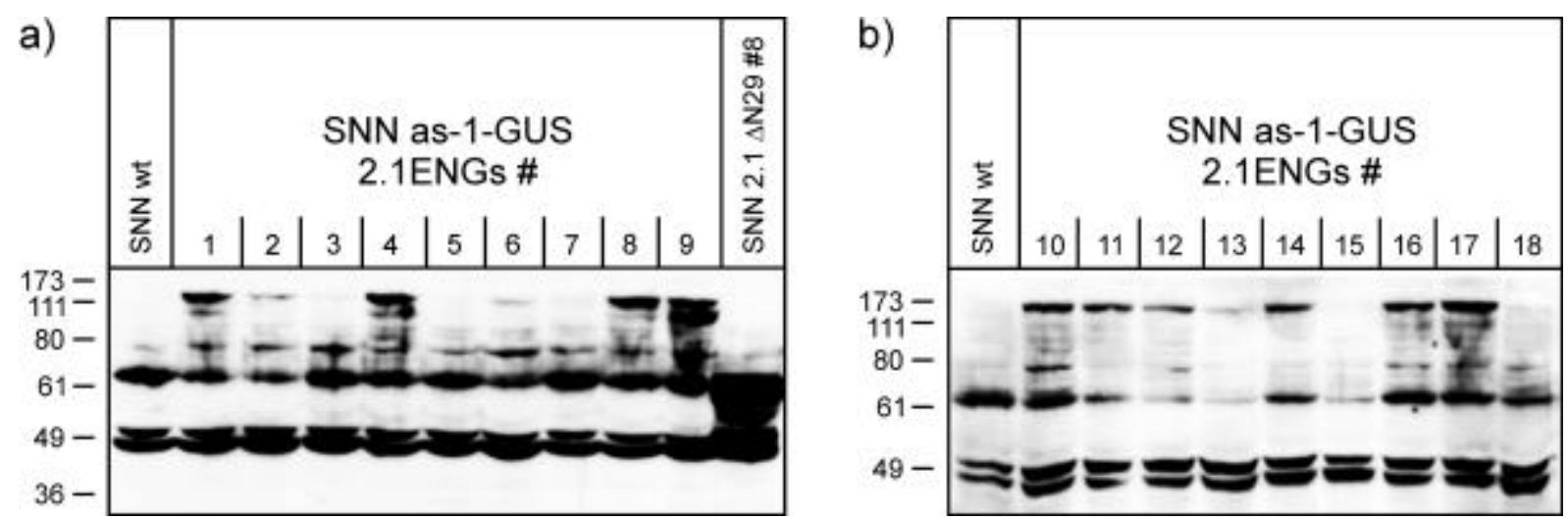

Abbildung 5-5: Immunoblot-Analyse zur Identifikation hochexprimierender SNN 2.1ENGs-Linien. Aufgetragen wurden jeweils gleiche Mengen von denaturierenden Gesamtzellextrakten der Linien a) SNN wt (Spur 1), SNN 2.1ENGs \#1 - \#9 (Spuren 2 - 10) und SNN $2.1 \Delta$ N29 \#8 (Spur 11) bzw.

b) SNN wt (Spur 1) und SNN 2.1ENGs \#10 - \#18 (Spuren 2 - 10). Für beide Immunoblots erfolgte die Detektion mit affinitätsgereinigtem TGA2.1-Antiserum. Der Marker gibt das ungefähre Molekulargewicht in kDa an.

\subsubsection{SNN 2.1-57s}

Es wurden neun unabhängige Linien getestet, von denen die Linien SNN 2.1-57s \#1, \#4, \#6 und \#8 eine sehr starke Expression des transgenen Proteins zeigen (Abbildung 5-6). Für Folgeuntersuchungen (Kapitel 5.7) wurde die Linie \# 8 verwendet.

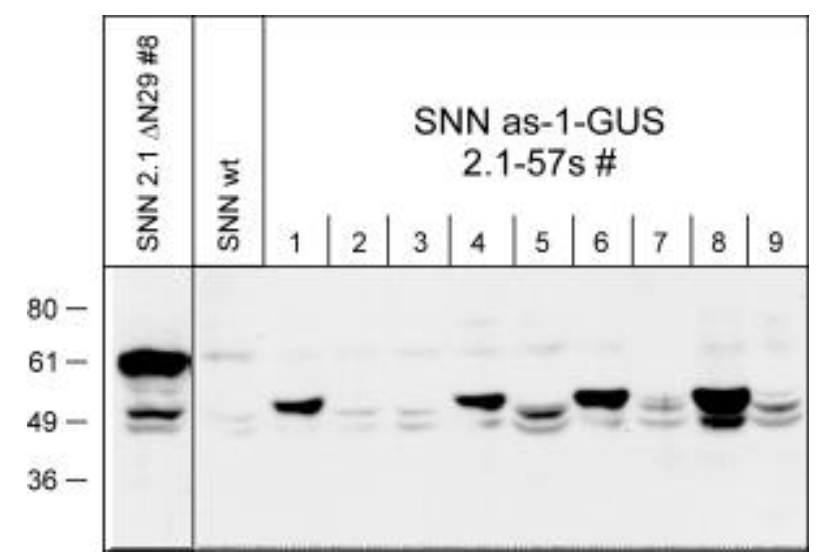

Abbildung 5-6: Immunoblot-Analyse zur Identifikation hochexprimierender SNN 2.1-57s-Linien. Aufgetragen wurden jeweils gleiche Mengen von denaturierenden Gesamtzellextrakten der Linien SNN 2.1 $\triangle$ N29 \#8 (Spur 1), SNN wt (Spur 2) und SNN 2.1-57s \#1 - \#9 (Spuren 3 - 11). Die Detektion erfolgte mit affinitätsgereinigtem TGA2.1-Antiserum. Der Marker gibt das ungefähre Molekulargewicht in $\mathrm{kDa}$ an. 


\subsubsection{Charakterisierung auf RNA-Ebene}

Da eine eindeutige Feststellung der Expressionsstärke der transgenen Proteine 2.2VPs, VP2.2s bzw. 2.2ENGs mittels Immunoblot aufgrund starker Kreuzreaktionen des Antiserums nicht praktikabel war, erfolgte in diesen Fällen die Auswahl hochexprimierender transgener SNN 2.2VPs-, VP2.2s- bzw. 2.2ENGs-Linien mit Hilfe von Northernblot-Analysen.

\subsubsection{SNN 2.2VPs}

Es wurde die Blatt-Gesamt-RNA von 13 Pflanzen aus Gewebekultur gewonnen, in einem denaturierenden Agarosegel aufgetrennt $(10 \mu \mathrm{g} / \mathrm{Spur})$ und auf eine Nytranmembran transferiert. Die Hybridisierung erfolgte mit einer radioaktiv markierten VP16-Sonde. Die Linien SNN 2.2VPs \#1 und \#2 wurden aufgrund ihrer Expressionsstärke (s. Abbildung 5-7) für weitere Versuche ausgewählt.

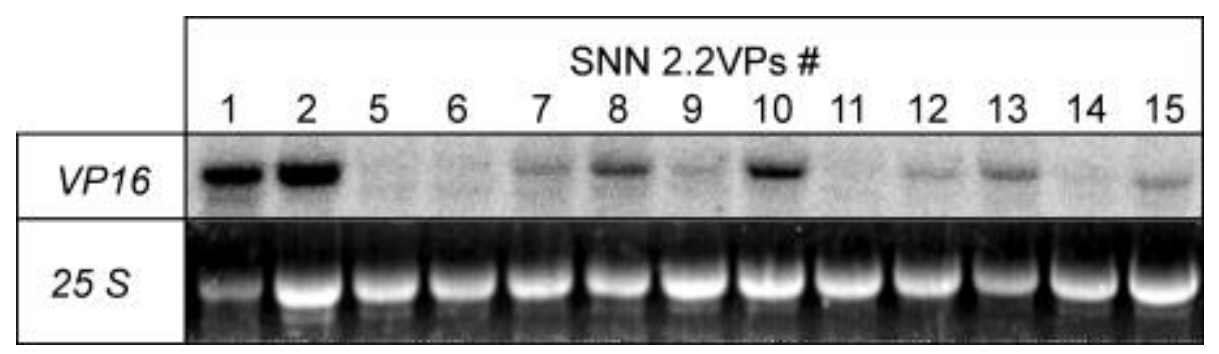

Abbildung 5-7: Northernblot-Analyse zur Identifikation hochexprimierender SNN 2.2VPs-Linien. Es wurden jeweils $10 \mu \mathrm{g}$ Gesamt-RNA der Linien SNN 2.2VPs \#1, \#2 und \#5 - \#15 aufgetragen. Der Filter wurde mit einer radioaktiv markierten VP16-Sonde hybridisiert.

\subsubsection{SNN VP2.2s}

Pflanzen vom Typ SNN VP2.2s wurden unter meiner Anleitung von ALEXANDRA CZEKO hergestellt und auf RNA-Ebene auf die Expression des Transgens getestet (s. CZEKO, 2000). Aufgrund dieser Charakterisierung wurden für Untersuchungen im Rahmen dieser Arbeit die Linien SNN VP2.2s \#3 und \#8 verwendet.

\subsubsection{SNN 2.2ENGs}

Es wurde von 13 Gewebekulturpflanzen Blatt-Gesamt-RNA präpariert. Jeweils $10 \mu \mathrm{g}$ RNA wurden im denaturierenden Agarosegel aufgetrennt, auf eine Nytranmembran geblottet und diese einer Hybridisierung mit einer radioaktiv markierten ENG-Sonde unterzogen. Die beiden Linien mit der stärksten Transgenexpression, SNN 2.2ENGs \#3 und \#7 (s. Abbildung 5-8), wurden für weitere Experimente ausgewählt. 


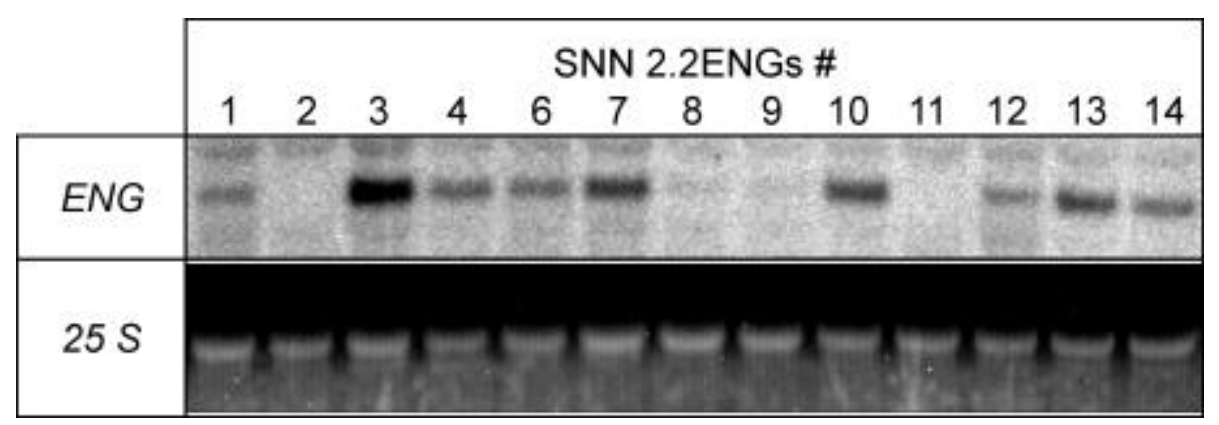

Abbildung 5-8: Northernblot-Analyse zur Identifikation hochexprimierender SNN 2.2ENGs-Linien. Es wurden jeweils $10 \mu \mathrm{g}$ Gesamt-RNA der Linien SNN 2.2ENGs \#1 - \#4 und \#6 - \#14 aufgetragen. Der Filter wurde mit einer radioaktiv markierten ENG-Sonde hybridisiert. 


\subsection{Vergleich der relativen Proteinmengen transgener und endogener TGA-Faktoren der Klasse II}

\subsubsection{Vergleich der Proteinmengen in Gesamtzellextrakten}

Um die Größenordnung der Proteinüberexpression in den verschiedenen verwendeten transgenen Linien miteinander vergleichen $\mathrm{zu}$ können, wurden denaturierende Gesamtzellextrakte der Linien SNN wt, SNN 2.1 $\Delta$ N29 \#8, SNN 2.1 \#22, SNN VP2.1s \#2 und \#4, SNN 2.1VPs \#3 und \#6, SNN 2.2 \#8, SNN 2.2VPs \#1 und \#2, SNN VP2.2s \#3 und \#8 hergestellt, in der SDS-PAGE aufgetrennt und auf PVDF-Membranen transferiert. Die Immunoblot-Analyse erfolgte unter Verwendung eines polyklonalen Antiserums gegen Streptag® II bzw. eines affinitätsgereinigten Antiserums gegen den N-Terminus von TGA2.1. Eine Detektion von TGA2.2 in Gesamtzellextrakten war aufgrund von sehr starken Kreuzreaktionen des TGA2.2-Antiserums nicht möglich.

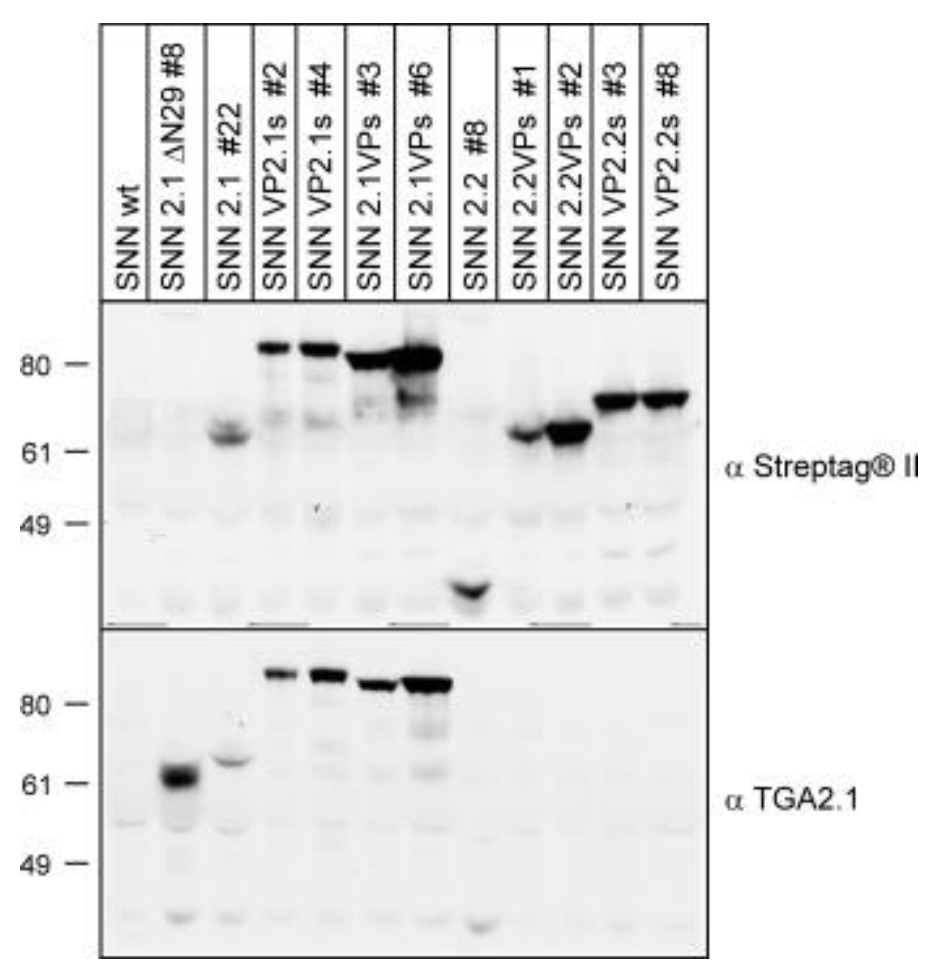

Abbildung 5-9: Vergleich der TGA-Proteinmengen in Gesamtzellextrakten mittels Immunoblot-Analyse. Beide Filter wurden identisch beladen: (von links nach rechts) SNN wt, SNN 2.1 $\triangle$ N29 \#8, SNN 2.1 \#22, SNN VP2.1s \#2 und \#4, SNN 2.1VPs \#3 und \#6, SNN 2.2 \#8, SNN 2.2VPs \#1 und \#2, SNN VP2.2s \#3 und \#8. Die Detektion erfolgte mit polyklonalem Antiserum gegen Streptag® II bzw. mit affinitätsgereinigtem Antiserum gegen TGA2.1. Der Marker gibt das ungefähre Molekulargewicht in $\mathrm{kDa}$ an. TGA2.1 $\triangle \mathrm{N} 29$ besitzt den Streptag ${ }^{\circledR}$ I. Alle anderen transgenen Proteine besitzen den Streptag® II (s. auch Abbildung 5-1). 
Die Immunoblot-Analyse in Abbildung 5-9 zeigt für Gesamtzellextrakte eine etwa gleichmäßig starke Überexpression der verschiedenen transgenen VP16-Fusionsproteine in nahezu allen untersuchten Linien. Ausnahmen sind die Linie SNN 2.2VPs \#1, die weniger transgenes Protein enthält, und die Linie SNN 2.1VPs \#6, die mehr transgenes Protein enthält als die übrigen Linien. In den Linien SNN 2.1 \#22 und SNN 2.2 \#8 lässt sich etwa die gleiche Menge an transgenem Protein detektieren wie in der Linie SNN 2.2VPs \#1. In der Linie SNN 2.1 $\triangle \mathrm{N} 29$ \#8 ist die Menge an transgenem Protein anhand der Detektion mit dem TGA2.1-Antiserum etwa in der Größenordnung der meisten Fusionsproteine einzustufen.

Bei Betrachtung des Laufverhaltens der verschiedenen Fusionsproteine fällt auf, dass Fusionsproteine mit N-terminaler VP16-Domäne langsamer laufen als die jeweils umgekehrte Fusion, obwohl beide Fusionsproteine das gleiche Molekulargewicht besitzen. Dieses Phänomen tritt in gleicher Weise für TGA2.1- und TGA2.2-Fusionsderivate auf, so dass offenbar die VP16-Domäne dafür verantwortlich ist. Es kann sich hierbei nicht um eine Cterminale Deletion handeln, da alle Proteine vom Antiserum gegen den Streptag® II erkannt werden. Auch die Klonierung einer zu kurzen VP16-Aktivierungsdomäne ist aufgrund von Sequenzbestimmungen äußerst unwahrscheinlich. Die Orientierung der Fusion mit der VP16Domäne verändert offenbar das Laufverhalten der Fusionsproteine in der SDS-PAGE unterschiedlich stark. Unabhängige Experimente lieferten die gleichen Resultate bezüglich des Laufverhaltens und der Expressionsstärke.

\subsubsection{Vergleich der Proteinmengen in Kernextrakten}

Für eine Beeinflussung der Zielgenexpression ist die Kernlokalisation der Fusionsproteine in ausreichend großer Menge eine notwendige Voraussetzung. Um die kernlokalisierten transgenen und endogenen Mengen von TGA2.1- und TGA2.2-Derivaten in den neu hergestellten transgenen Linien miteinander $\mathrm{zu}$ vergleichen, wurden aufgrund $\mathrm{der}$ in Abbildung 5-9 gezeigten Daten die Linien SNN VP2.1s \#4 und SNN 2.2VPs \#2 sowie SNN wt für die Herstellung von Kernextrakten verwendet. Obwohl SNN 2.1VPs \#6 die stärkste Überexpression eines Fusionsproteins zwischen TGA2.1 und der VP16Aktivierungsdomäne zeigte, wurde diese Linie nicht verwendet, da sie sowohl in Gewebe- als auch in Erdkultur ein abnormales Wachstum zeigte, das bei keiner der anderen Linien zu beobachten war.

Um gleichzeitig den Einfluß von SA auf die Kernlokalisation der Klasse II TGA-Faktoren zu untersuchen, wurden uninduzierte und SA-induzierte Blätter verglichen. Blätter der zuvor genannten Linien wurden mit $50 \mathrm{mM}$ Kaliumphosphatpuffer $(\mathrm{pH} 5,8)$ vakuuminfiltriert und 
nach einstündiger Vorinkubation mit $1 \mathrm{mM}$ SA behandelt. Aus uninduzierten und für drei Stunden SA-behandelten Blättern wurden Kernproteine (modifiziert nach PRAT et al., 1989; NIGGEWEG, 1999) isoliert und gleiche Proteinmengen in der SDS-PAGE aufgetrennt. Die aufgetrennten Proteine dreier identisch beladener Gele wurden auf PVDF-Membranen geblottet und im Immunoblot untersucht. Die Detektion erfolgte mit affinitätsgereinigten Antiseren gegen TGA2.1 und TGA2.2 bzw. dem polyklonalen Antiserum gegen Streptag® II.

Um ein Gesamtbild der Population an TGA-Faktoren der Klasse II und deren Derivaten im Zellkern der verwendeten transgenen Pflanzen zu gewinnen, wurden die Ergebnisse der zuvor beschriebenen Immunoblots in Abbildung 5-10 mit den Daten zweier Immunoblots von KLINGEBIEL verglichen, die unter meiner Anleitung entstanden sind und 2001 in ihrer Staatsexamensarbeit veröffentlicht werden. Das Ergebnis der halbquantitativen Auswertung ist in der folgenden Tabelle zusammengefasst.

Tabelle 5-1: a) Zusammenfassung der halbquantitativen Auswertung der kernlokalisierten TGA2.1und TGA2.2-Derivate in den Linien SNN wt, SNN VP2.1s \#4 und SNN 2.2VPs \#2 aus Abbildung 5-10. Angaben in Prozent der kernlokalisierten TGA2.2-Menge in SNN wt (fett und kursiv). b) Abschätzung der Mengenverteilung von TGA2.2-Homo- und Heterodimeren im Zellkern. Aufgrund des hohen Überschusses an TGA2.2 wird angenommen, dass die Majorität aller TGA-Dimere TGA2.2 enthält. Aus diesem Grund werden keine Angaben zu Homodimeren von TGA2.1-Derivaten gemacht, die zusätzlich deutlich schwächer binden.
a)
TGA2.1
TGA2.2
VP2.1s
2.2VPs

\begin{tabular}{lllll}
\hline \hline SNN wt & 7,5 & $\mathbf{1 0 0}$ & - & - \\
SNN VP2.1s \#4 & 7,5 & 200 & 75 & - \\
SNN 2.2VPs \#2 & 7,5 & 200 & - & 100 \\
\hline
\end{tabular}

b) TGA2.1/TGA2.2 TGA2.2/TGA2.2 VP2.1s/TGA2.2 2.2VPs/TGA2.2

SNN wt

SNN VP2.1s \#4

SNN 2.2VPs \#2

7,5

7,5

7,5
92,5

117,5

92,5
75

100


a)

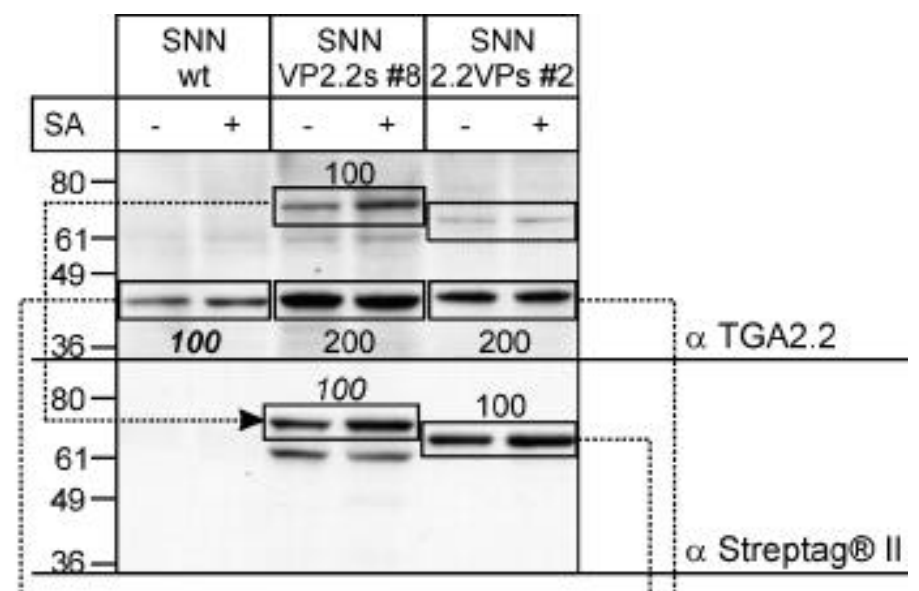

c)

d)

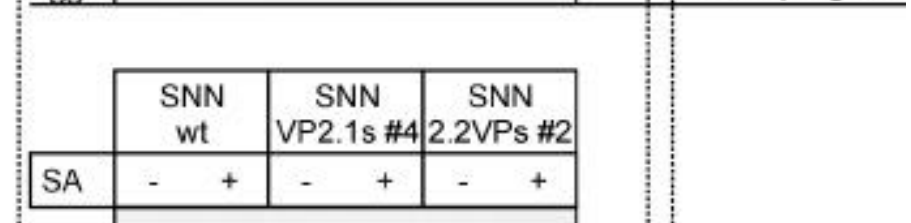

)

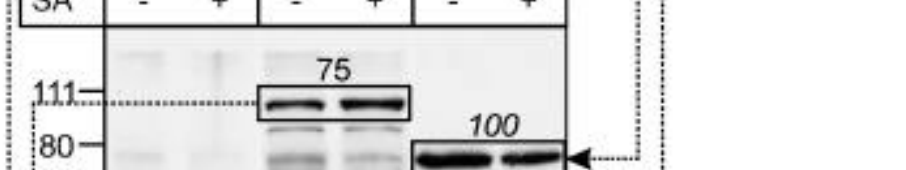

e)

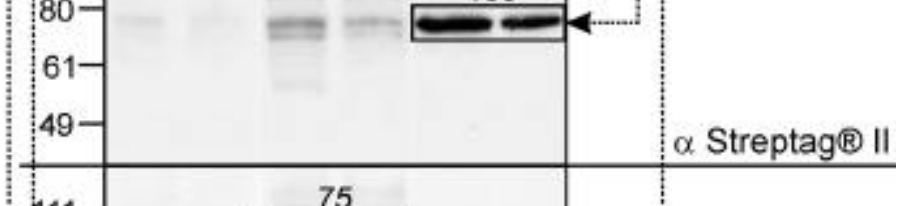

)

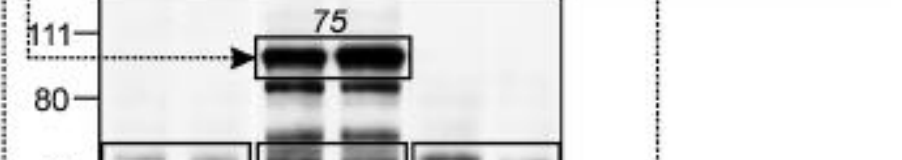

.

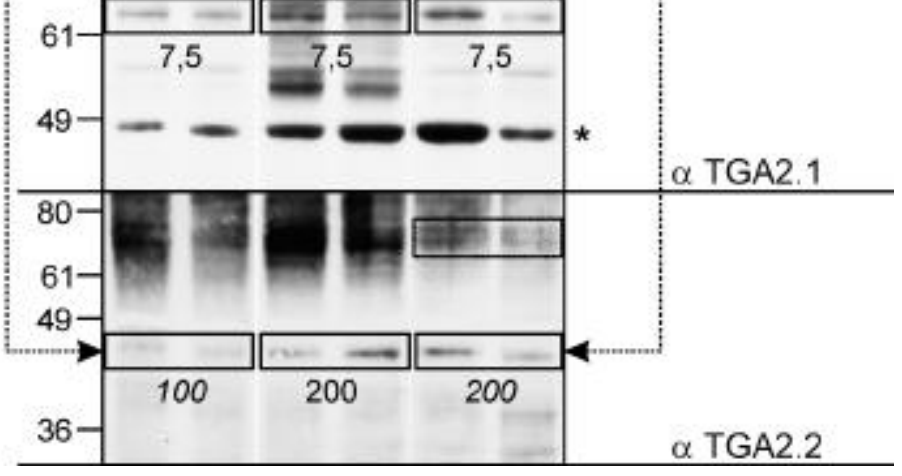

Abbildung 5-10: Vergleich der kernlokalisierten Proteinmengen von TGA2.1- und TGA2.2-Derivaten in transgenen Linien und SNN wt. Pro Gel wurden gleiche Proteinmengen aus Kernextrakten von uninduzierten (-) und für drei Stunden SA-behandelten (+) Blättern der Linien SNN wt, SNN VP2.2s \#8, SNN 2.2VPs \#2 und SNN VP2.1s \#4 aufgetragen, in der SDS-PAGE aufgetrennt und auf PVDF-Membranen geblottet. Die Detektion erfolgte mit den rechts angegebenen Antiseren. Links sind die ungefähren Molekulargewichte in $\mathrm{kDa}$ angegeben. Die PAA-Konzentration betrug in a), b) und e) $12,5 \%$ und in c) und d) $10 \%$. Die Immunoblots unter a) und b) wurden unter meiner Anleitung von KLINGEBIEL hergestellt und werden 2001 in ihrer Staatsexamensarbeit veröffentlicht. Werte in Prozent bezogen auf die TGA2.2-Menge in Kernen von SNN wt (100\%). Kursive Werte dienen als Basis der Mengenabschätzung innerhalb jedes Gels, Pfeile kennzeichnen die Herkunft von Basiswerten. 
Bezüglich der in Abbildung 5-10 dargestellten Ergebnisse sind folgende Anmerkungen zu machen:

In a) ist das mit dem TGA2.2-Antiserum detektierte Protein 2.2VPs gegenüber der in b) mit dem Streptag® II-Antiserum nachgewiesenen Menge dieses Proteins unterrepräsentiert. Aufgrund der Eindeutigkeit des Signals wurde der mit dem Streptag® II-Antiserum ermittelte Wert für die Berechnung herangezogen. Die Richtigkeit der Ergebnisse aus b) wird durch die in gezeigten Daten zur Proteinmenge in Gesamtzellextrakten unterstützt, nach denen in SNN 2.2VPs \#2 sogar mehr transgenes Protein zu finden ist als in SNN VP2.2s \#8.

Die Unterschiede in der detektierten VP2.1s-Proteinmenge in d) werden auf Ungleichbeladung zurückgeführt, wie an der mit * gekennzeichneten unspezifischen Kreuzreaktion abzulesen ist.

Obwohl eine Quantifizierung von endogenem TGA2.2 in e) problematisch ist, kann man durch den Vergleich mit a) schließen, dass auch in SNN VP2.1s \#4 die Menge an endogenem TGA2.2 im Kern erhöht ist.

Aus den Abschätzungen in Tabelle 5-1 und Abbildung 5-10 geht hervor, dass die Fusionsproteine aller untersuchten transgenen Pflanzen deutlich im Kern nachzuweisen sind. Es ist an dieser Stelle ausdrücklich darauf hinzuweisen, dass es sich lediglich um eine Abschätzung der Größenordnung der Proteinmengen handelt. Diesbezüglich sind folgende Punkte hervorzuheben:

- In SNN VP2.1s \#4 ist das transgene Protein etwa 10 mal stärker exprimiert als der endogene TGA2.1. In SNN 2.2VPs \#2 kommt die Transgenexpression nur etwa der Expression des endogenen TGA2.2 im Wildtyp gleich.

- Zusätzlich ist zu beobachten, dass es in beiden transgenen Linien zu einer konstitutiven Erhöhung der kernlokalisierten Menge an endogenem TGA2.2 um etwa $100 \%$ kommt. Da sich in der Pflanze Heterodimere zwischen TGA2.1 und TGA2.2 bilden, muss unter dieser Voraussetzung die jeweilige Menge an transgenem Protein in Bezug zur Summe aller Klasse II TGA-Faktoren gesetzt werden. Demnach beträgt der Anteil der transgenen Proteine am der Gesamtheit der Klasse II TGA-Faktoren in den transgenen Linien zwischen 33 und $36 \%$.

- Wie aus Tabelle 5-1b) abzulesen ist, wird die Menge an TGA2.1/TGA2.2Heterodimeren mit etwa 7,5\% der Gesamtheit an Dimeren im Wildtyp in beiden transgenen Linien nicht beeinflusst. Auch die Menge an TGA2.2-Homodimeren ist in den transgenen Linien mit einer Abweichung von $\pm 12,5 \%$ unverändert zum Wildtyp. Demnach liegen die Mengen an TGA2.2/VP2.1s bzw. TGA2.2/2.2VPs-Heterodimeren 
mit $75-100 \%$ der Gesamtmenge an Dimeren im Wildtyp in derselben Größenordnung.

- Ferner lässt sich anhand der Daten in Tabelle 5-1 ablesen, dass in SNN wt die relative kernlokalisierte Menge an TGA2.2 etwa 13 mal höher ist als die Menge an TGA2.1. In vorherigen Studien konnte im EMSA in ASF-1 aus Kernextrakten von SNN wtBlättern ebenfalls deutlich mehr TGA2.2 als TGA2.1 nachgewiesen werden (NIGGEWEG, 1999).

\subsection{Auswirkung von Fusionsproteinen aus VP16-Aktivierungs- domäne und TGA2.1 bzw. TGA2.2 auf die Expression von Zielgenen nach Salicylsäure-Induktion}

Salicylsäure (SA) ist ein starker Induktor von Genen, deren Promotoren as-1-ähnliche Elemente enthalten. $\mathrm{Zu}$ diesen Promotoren zählen in Tabak u. a. das Gen Nt103, das für eine Gluthathion S-Transferase codiert und das Gen PRla, das für das pathogenesis related protein 1a codiert. Neben diesen beiden Genen liegt in den im Rahmen dieser Arbeit hergestellten transgenen Pflanzen das as-1-GUS-Reporterkonstrukt vor, das die Sequenz des CaMV 35S Promotors vom Transkriptionsstart bis zur Position -90 (as-1-Element) fusioniert an das Gen für die $\beta$-Glucuronidase beinhaltet. Durch die Untersuchung der Transkription dieser Zielgene in den zuvor charakterisierten, transgenen Pflanzen lassen sich Aussagen über die in-vivo DNA-Bindung der TGA-Faktoren machen.

\subsubsection{Untersuchungen zur Expression von Zielgenen drei Stunden nach Salicylsäure-Induktion}

Zur Untersuchung der frühen SA-induzierten Transkription möglicher Zielgene von TGA2.1 und TGA2.2 wurden Blattscheiben der Linien SNN as-1-GUS \#12 (SNN wt), SNN 2.1 $1 \Delta 29$ \#8, SNN 2.1 \#22, SNN VP2.1s \#2 und \#4, SNN 2.1VPs \#3 und \#6, SNN 2.2 \#8, SNN 2.2VPs \#1 und \#2 und SNN VP2.2s \#3 und \#8 auf $50 \mathrm{mM}$ Kaliumphosphatpuffer $(\mathrm{pH} 5,8)$ mit $1 \mathrm{mM}$ SA gelegt. Proben wurden im uninduzierten Zustand und drei Stunden nach Induktion entnommen und die Gesamt-RNA im Northern-Blot untersucht. Zunächst wurden die entstandenen Filter mit radioaktiv markierten Sonden gegen GUS und Nt103 hybridisiert. Die Ergebnisse dieser Hybridisierungen sowie die quantitative Auswertung der Transkriptmengen ist in Abbildung 5-11 dargestellt. 

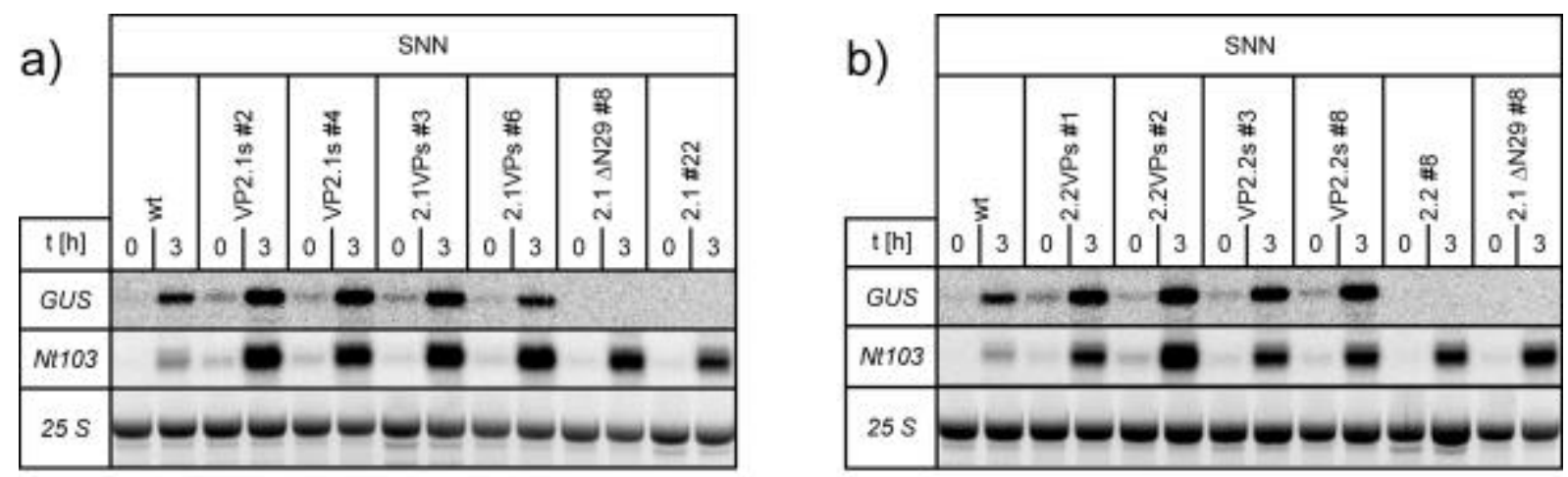

c)

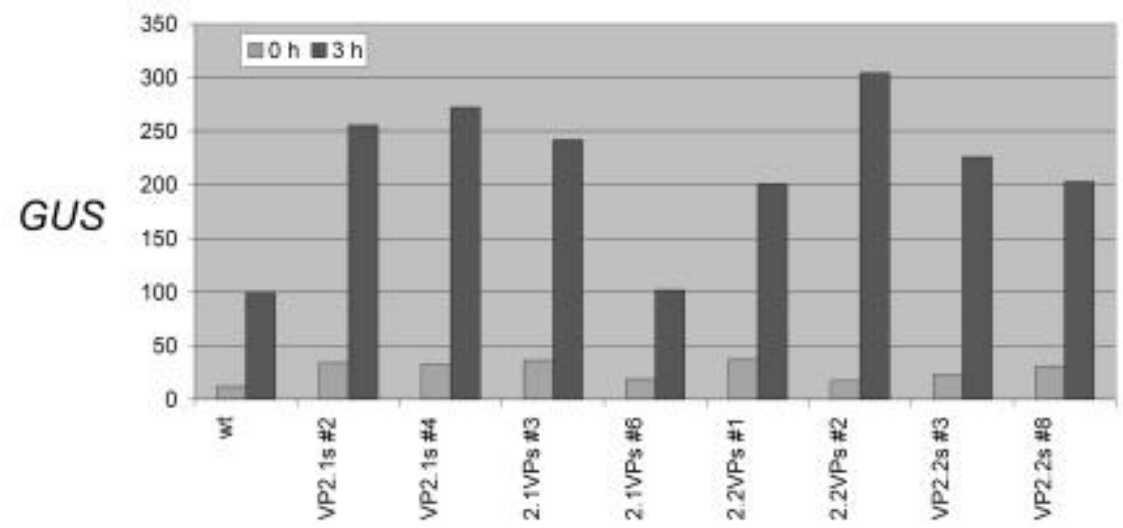

d)

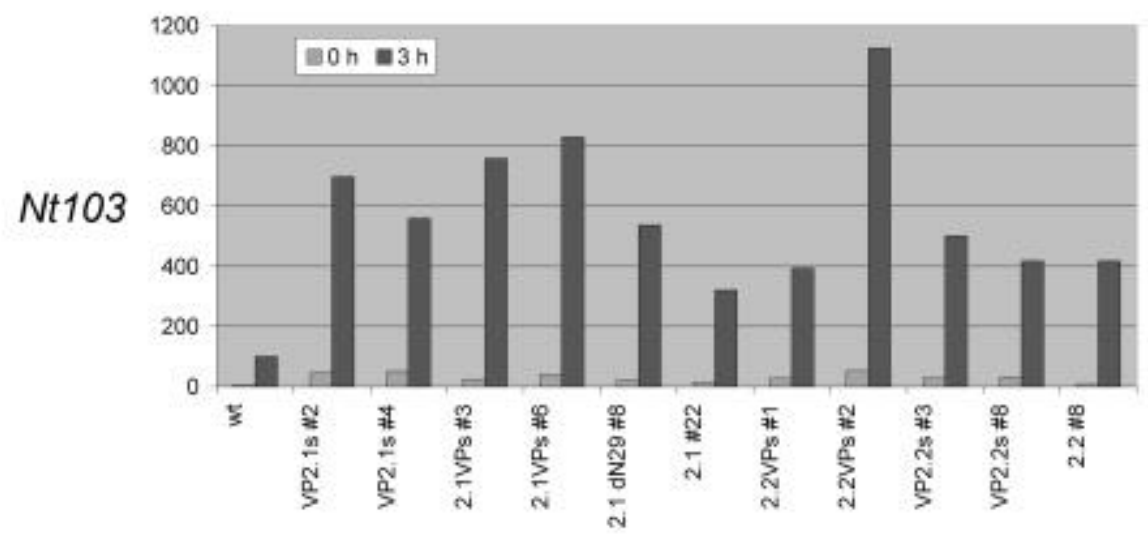

Abbildung 5-11: Expression der Zielgene GUS und Nt103 in transgenen Tabakpflanzen 0 und $3 \mathrm{~h}$ nach SA-Induktion. Blattscheiben der angegebenen Linien wurden mit $1 \mathrm{mM} S A$ in $50 \mathrm{mM}$ Kaliumphosphatpuffer $(\mathrm{pH} 5,8)$ für drei Stunden inkubiert. $10 \mu \mathrm{g}$ Gesamt-RNA pro Spur wurden im denaturierenden Agarosegel aufgetrennt und auf Nytranmembran geblottet. Die Filter wurden nacheinander mit radioaktiv markierten Sonden gegen GUS und Nt103 hybridisiert und mittels Phosphoimager ausgewertet ( a) und b)). c) Quantitative Auswertung der GUS-Transkriptmengen. d) Quantitative Auswertung der Nt103-Transkriptmengen. Quantitative Angaben für c) und d) in Prozent des jeweiligen wt-Signals $3 \mathrm{~h}$ nach SA.

Die Linien SNN 2.1 $\Delta$ N29 \#8, SNN 2.1 \#22 und SNN 2.2 \#8 enthalten kein as-1-GUSReporterkonstrukt und zeigen deshalb für die GUS-Sonde kein Signal.

Die Expression der Zielgene bleibt abhängig von SA: sowohl im uninduzierten als auch im induzierten Zustand kommt es in Anwesenheit der transgenen Proteine zur Erhöhung der Transkription. Im uninduzierten Zustand liegt diese aber nie in der Größenordnung des 
induzierten Zustands. In einem weiteren Experiment dieser Art konnten qualitativ und quantitativ ähnliche Ergebnisse erzielt werden.

Im Vergleich der Northernblot-Analysen in Abbildung 5-11 mit den Immunoblot-Analysen in Kapitel 5.3.2 konnte eine Korrelation zwischen der Summe der kernlokalisierten TGAFaktoren und dem Maß der Transkriptionssteigerung des as-1-GUS-Reporterkonstrukts bzw. des Nt103-Promotors im uninduzierten wie im induzierten Zustand festgestellt werden.

Überträgt man die Daten für die kernlokalisierten Proteine auf die Linien, die nur auf Gesamtzellebene charakterisiert worden sind (Abbildung 5-9), so zeigt sich eine ähnliche Korrelation zwischen TGA-Menge und Transkriptionssteigerung der Zielgene.

\subsection{Einfluss von Cycloheximid auf die Expression von Zielgenen}

In Kapitel 5.4.1 konnte gezeigt werden, dass die Fusionsproteine aus TGA2.1 bzw. 2.2 und der VP16-Aktivierungsdomäne im uninduzierten Zustand nicht in der Lage sind, die Transkription effektiv zu steigern. Dieses Ergebnis könnte auf einen Inhibitor hindeuten, der im uninduzierten Zustand mit den TGA-Faktoren assoziiert ist und somit die Bindung an as-1 verhindert. Nach SA-Induktion könnte dieser Komplex zerfallen und die Bindung der TGAFaktoren an das as-1-Element zulassen. Ein solches Modell wurde bereits aufgrund von invitro Daten von JUPIN und CHUA, 1996 vorgeschlagen. Sie konnten nach SA-Behandlung von Blättern im EMSA eine verstärkte Bindung von Proteinen an as-1 zeigen. Zudem konnten die Autoren die as-1-Bindungsaktivität durch einstïndige Behandlung der Pflanzen mit Cycloheximid (CHX) um ein Vielfaches steigern. Mit den generierten transgenen Pflanzen lässt sich dieses Modell in-vivo überprüfen. Sollte eine Inkubation mit CHX auch in-vivo zum Zerfall eines TGA/Inhibitor-Komplexes führen, so hat die Bindung der Fusionsproteine aus TGA-Faktor und konstitutiver Aktivierungsdomäne die Transaktivierung der Zielgene auch ohne die Anwesenheit von SA zur Folge.

Es wurden mit ausgewählten Linien Induktionsversuche durchgeführt, in denen Blattscheiben entweder mit SA, CHX, oder mit beiden Chemikalien zugleich behandelt wurden. Über einen Zeitraum von 24 Stunden wurden Proben genommen, um die Transkription verschiedener Gene im Northernblot verfolgen zu können. Hierzu wurden die Blattscheiben zunächst mit Kaliumphosphatpuffer mit oder ohne CHX vakuuminfiltriert und eine Stunde vorinkubiert. Danach erfolgte ggf. die Induktion mit SA. Proben zur Gewinnung von Gesamtproteinextrakten und Gesamt-RNA wurden entnommen im unbehandelten (-1) Zustand, nach Vorinkubation mit bzw. ohne $\mathrm{CHX}$ (0) und für die verschiedenen Behandlungen nach 2, 3, 5, 7, 12 und 24 Stunden. 


\subsubsection{Untersuchung endogener TGA2.1-Proteinmengen bzw. transgener Proteinmengen in Gesamtzellextrakten}

Für die korrekte Interpretation der Ergebnisse aus den nachfolgenden NorthernblotExperimenten (5.5.3ff.) war es wichtig, zunächst die Expression und die Integrität der verschiedenen TGA-Derivate in den transgenen Linien über den gesamten Versuchsverlauf auf Proteinebene zu dokumentieren. Der Nachweis endogener bzw. transgener TGA2.1-Derivate erfolgte zunächst in Gesamtzellextrakten der Linien SNN VP2.1s \#4 und SNN 2.2VPs \#2 im Immunoblot. Transgene Proteine wurden zusätzlich über den Streptag® II detektiert.

Gleiche Proteinmengen aus Gesamtzellextrakten nach SA- und/oder CHX-Behandlung wurden in der SDS-PAGE aufgetrennt und auf PVDF-Membranen geblottet. Die Detektion erfolgte mit dem affinitätsgereinigten Antiserum gegen TGA2.1 (Abbildung 5-12 oben bzw. Abbildung 5-13 oben) bzw. dem polyklonalen Antiserum gegen Streptag® II (Abbildung 5-12 unten bzw. Abbildung 5-13 unten).

Für die beiden untersuchten Linien SNN VP2.1s \#4 und SNN 2.2VPs \#2 konnte im Rahmen von ladungs- und detektionsbedingten Abweichungen weder für endogenes TGA2.1-Protein noch für das jeweilige transgene Protein eine Expressionsveränderung über den Versuchsverlauf festgestellt werden. Insbesondere die Behandlung mit CHX hat keinen sichtbaren Einfluss auf die Menge und den Zustand an nachweisbarem Protein.

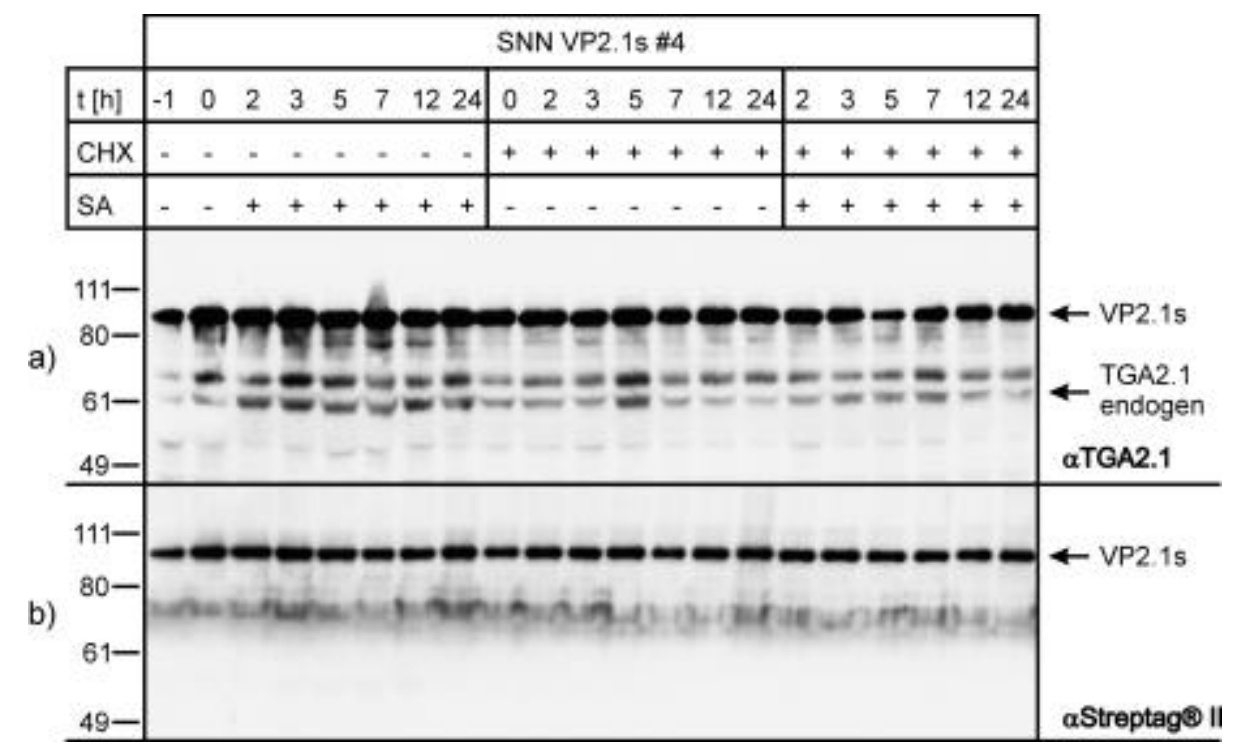

Abbildung 5-12: Verlauf der Expression von endogenem TGA2.1 und transgenem VP2.1s auf Proteinebene in SNN VP2.1s \#4. Aus dem unter 5.5 beschriebenen Probenmaterial von SNN VP2.1s \#4 wurden Gesamtzellextrakte hergestellt. Normalisierte Gesamtproteinmengen wurden in zwei identischen SDS-Polyacrylamidgelen elektrophoretisch aufgetrennt und auf PVDF-Membranen geblottet. Die immunologische Detektion erfolgte mit affinitätsgereinigtem Antiserum gegen TGA2.1 (oben) bzw. mit einem polyklonalen Antiserum gegen Streptag® II (unten). Der Marker gibt das ungefähre Molekulargewicht in $\mathrm{kDa}$ an. Pfeile bezeichnen endogenes TGA2.1-Protein bzw. transgenes VP2.1s-Protein. 


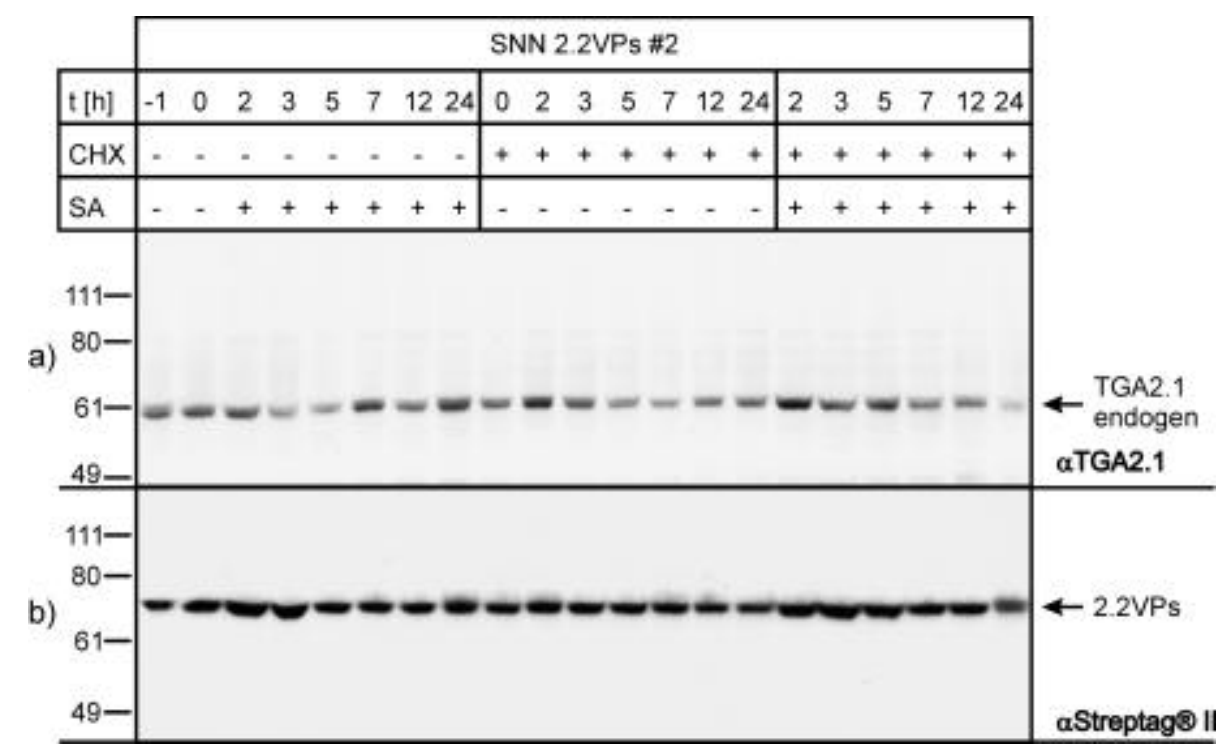

Abbildung 5-13: Verlauf der Expression von endogenem TGA2.1 und transgenem 2.2VPs auf Proteinebene in SNN 2.2VPs \#2. Aus dem unter 5.5 beschriebenen Probenmaterial von SNN 2.2VPs \#2 wurden Gesamtzellextrakte hergestellt. Alle weiteren Parameter wie in Abbildung 5-12 beschrieben. Pfeile bezeichnen endogenes TGA2.1-Protein bzw. transgenes 2.2VPs-Protein.

\subsubsection{Untersuchung endogener TGA-Proteinmengen bzw. transgener Proteinmengen in Kernextrakten}

Aufgrund der Qualität des Antiserums lässt sich TGA2.2 nur in Kernextrakten nachweisen. Um neben dem Einfluß einer SA-Behandlung auch die Wirkung von CHX auf die TGA2.2Menge im Kern abzuschätzen, wurden Blätter der unter 5.3.2 beschriebenen Pflanzen außerdem in gleicher Weise in Gegenwart von $100 \mathrm{mg} / \mathrm{l} \mathrm{CHX}$ infiltriert, eine Stunde vorinkubiert und anschließend für drei Stunden mit $1 \mathrm{mM}$ SA und $100 \mathrm{mg} / \mathrm{l}$ CHX behandelt. Es wurden ebenfalls Kernextrakte hergestellt, normalisierte Proteinmengen aller neun Extrakte mittels SDS-PAGE in der Weise aufgetrennt und auf PVDF-Membranen geblottet, so dass drei identische Filter entstanden. Diese wurden im Immunoblot entweder mit einem affinitätsgereinigten Antiserum gegen TGA2.1 bzw. TGA2.2 oder mit dem polyklonalen Antiserum gegen Streptag® II behandelt und die entsprechenden Proteinspezies mittels Chemilumineszenz detektiert (Abbildung 5-14). 


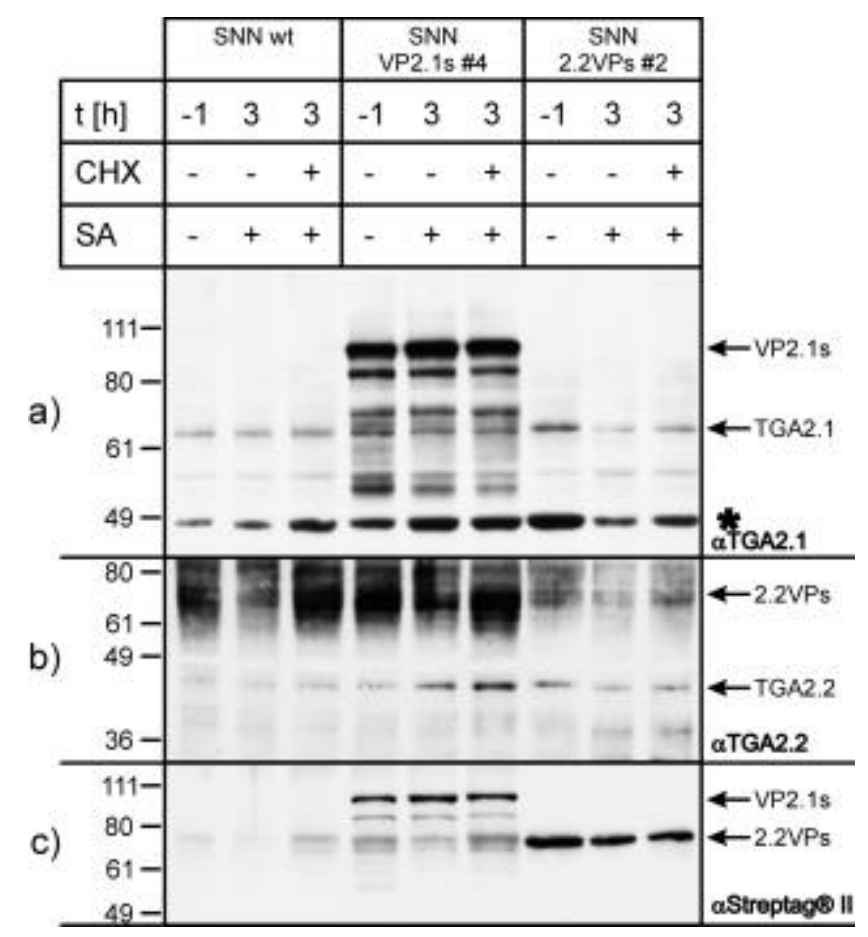

Abbildung 5-14: Nachweis von TGA2.1, TGA2.2 und transgenen Fusionsproteinen in Kernextrakten. Normalisierte Proteinmengen aus Kernextrakten von SA- bzw. CHX-behandelten Blättern der Linien SNN wt, SNN VP2.1s \#4 und SNN 2.2VPs \#2 wurden mittels SDS-PAGE aufgetrennt und auf PVDFMembranen geblottet. Proteine wurden im Immunoblot mittels verschienener Antiseren detektiert: a) affinitätsgereinigtes Antiserum gegen TGA2.1, b) affinitätsgereinigtes Antiserum gegen TGA2.2, c) polyklonales Antiserum gegen Streptag® II. Der Marker gibt die ungefähren Molekulargewichte in kDa an. Pfeile kennzeichnen die Laufweite der nachzuweisenden Proteine. Der Stern markiert eine starke, unspezifische Kreuzreaktion.

Die Behandlung mit CHX hatte keinen Einfluß auf die kernlokalisierten Proteinmengen von endogenem TGA2.1 (Abbildung 5-14a)) und transgenen Proteinen (Abbildung 5-14a) und c)).

Die Menge an endogenem TGA2.2 (Abbildung 5-14b)) scheint in den Linien SNN VP2.1s \#4 und SNN 2.2VPs \#2 konstitutiv leicht erhöht $\mathrm{zu}$ sein, was mit Daten von KLINGEBIEL (unveröffentlicht) übereinstimmt. Zudem scheint in SA- bzw. SA- und CHX-behandelten Proben der Linie SNN VP2.1s \#4 die Menge an kernlokalisiertem TGA2.2 anzusteigen. Bezieht man jedoch eine mögliche Ungleichbeladung des Gels mit ein, so relativieren sich diese Aussagen. Mit Hilfe des Antiserums gegen TGA2.2 lässt sich das transgene Protein 2.2VPs nicht eindeutig nachweisen.

Für beide endogenen TGA-Faktoren lässt sich nach SA-Behandlung eine sehr leichte Beschleunigung des Laufverhaltens beobachten. Dieses Phänomen, das auch KLINGEBIEL (unveröffentlicht) zeigen konnte, könnte auf posttranslationaler Modifikation (z. B. Phosphorylierung) beruhen.

Insgesamt ist festzustellen, dass weder SA noch CHX im frühen Verlauf der Induktion einen sichtbaren Einfluß auf die Menge an kernlokalisierten TGA-Faktoren der Klasse II haben. 


\subsubsection{Einfluss von Cycloheximid auf die Expression von as-1-GUS}

Aus den unter 5.5 entnommenen Proben wurde die Gesamt-RNA gewonnen und jeweils $10 \mu \mathrm{g}$ in denaturierenden Agarosegelen aufgetrennt und anschließend auf Nytranmembranen geblottet.

Die entstandenen Filter wurden zunächst mit der GUS-Sonde hybridisiert. Das Ergebnis dieser Hybridisierung ist in Abbildung 5-15 gezeigt.

a)

\begin{tabular}{|c|c|c|c|c|c|c|c|}
\hline $\mathrm{t}[\mathrm{h}]$ & $-1 \quad 0$ & 2 & 3 & 5 & 7 & 12 & \\
\hline $\mathrm{CHX}$ & - - & - & - & - & - & - & - \\
\hline SA & $-\quad-$ & + & + & + & + & + & + \\
\hline SNN wt & & \multicolumn{6}{|c|}{ 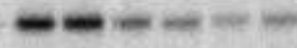 } \\
\hline SNN VP2.1s \#4 & Eine & \multicolumn{6}{|c|}{ 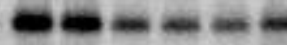 } \\
\hline $\mathrm{SNN} 2.2 \mathrm{VPs} \mathrm{N} 2$ & $F=$ & \multicolumn{6}{|c|}{ 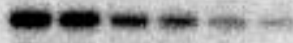 } \\
\hline
\end{tabular}

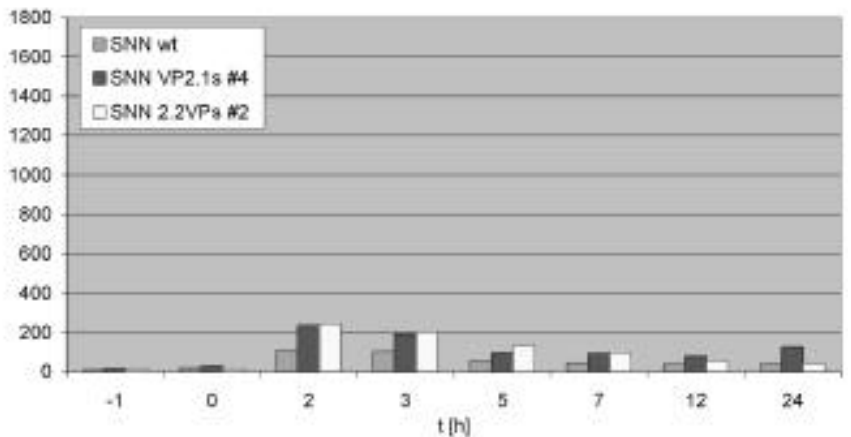

b)

\begin{tabular}{|c|c|c|c|c|c|c|c|c|}
\hline$t[\mathrm{~h}]$ & -1 & 0 & 2 & 3 & 5 & 7 & 12 & 24 \\
\hline $\mathrm{CHX}$ & . & + & + & + & + & + & + & + \\
\hline SA & - & - & - & - & - & - & - & - \\
\hline SNN wt & \multirow{3}{*}{ 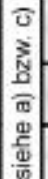 } & \multicolumn{7}{|c|}{ 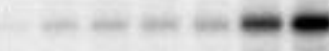 } \\
\hline SNN VP2. 1s \#4 & & \multicolumn{7}{|c|}{$-1-1=$} \\
\hline SNN 2.2 Ps $\# 2$ & & \multicolumn{7}{|l|}{ 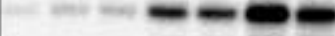 } \\
\hline
\end{tabular}

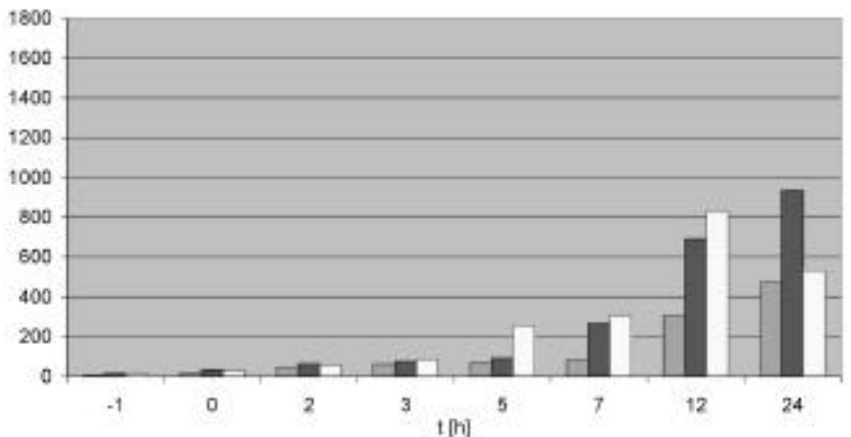

c)

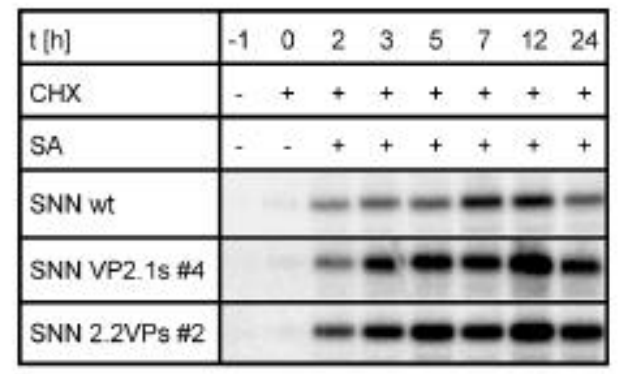

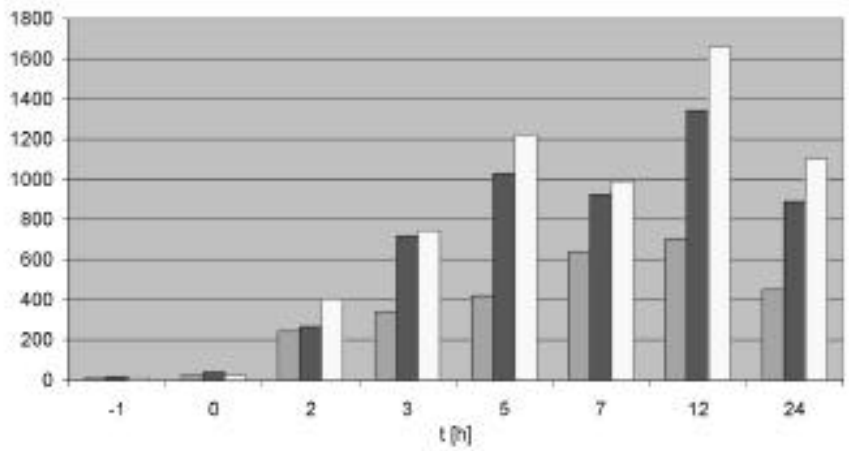

Abbildung 5-15: Induktionsversuche mit SA und CHX. Blattscheiben der Linien SNN as-1-GUS \#12 (SNN wt), SNN VP2.1s \#4 und SNN 2.2VPs \#2 wurden in $50 \mathrm{mM}$ Kaliumphosphatpuffer mit oder ohne $\mathrm{CHX}[100 \mathrm{mg} / \mathrm{l}]$ vakuuminfiltriert, eine Stunde inkubiert und anschließend dem Puffer ggf. SA [1 mM] zugesetzt. Die Probenentnahme erfolgte wie angegeben. $10 \mu \mathrm{g}$ Gesamt-RNA pro Spur wurden im denaturierenden Agarosegel aufgetrennt, auf Nytranmembranen geblottet und die Filter mit einer radioaktiv markierten GUS-Sonde hybridisiert. Gezeigt sind jeweils die Ergebnisse der GUSHybridisierung und die korrespondierende quantitative Auswertung der Signalstärken. Der Abgleich zwischen verschiedenen Filtern erfolgte mit Hilfe von hier nicht gezeigten Standardspuren. Quantitative Angaben entsprechen dem prozentualen Anteil an dem Wildtyp-Signal $3 \mathrm{~h}$ nach SABehandlung. a) Induktion nur mit SA, b) Induktion nur mit CHX, c) Induktion mit SA nach Vorinkubation mit $\mathrm{CHX}$. 
Als wichtige Ergebnisse aus Abbildung 5-15 können festgehalten werden:

- Grundsätzlich verhalten sich beide transgenen Linien gleich bezüglich ihrer Effekte auf die as-1-GUS-Transkription. Alle im Wildtyp zu beobachtenden Transkriptionserhöhungen sind in den transgenen Linien um den Faktor zwei bis drei verstärkt.

- Wie bereits in einem unabhängigen Experiment unter Abschnitt 5.4 .1 gezeigt, so konnte auch hier für die Linien SNN VP2.1s \#4 und SNN 2.2VPs \#2 im uninduzierten Zustand keine Aktivität des as-1-Elements beobachtet werden, die auf eine konstitutive Bindung der Fusionsproteine hindeuten würde (Abbildung 5-15a) bzw. c)). Es ist also wahrscheinlich, dass die Bindung erst nach SA-Behandlung induziert wird.

- Bezüglich der CHX-Labilität des postulierten TGA/Inhibitorkomplexes lässt sich feststellen, dass im Gegensatz $\mathrm{zu}$ den in-vitro-Experimenten von JUPIN und CHUA, 1996, an dem hier in-vivo untersuchten as-1-Element keine Bindungsverstärkung nach einstündiger CHX-Behandlung eintritt (Abbildung 5-15c), $-1 \mathrm{~h}$ und $0 \mathrm{~h}$ ).

- Erst nach sechs- bis achtstündiger $(\mathrm{t}=5 \mathrm{~h}$ bzw. 7h) Inkubation mit CHX (Abbildung 5-15b)) zeichnet sich eine verstärkte GUS-Transkription in den transgenen Pflanzen ab. Dies lässt auf eine Bindungsverstärkung der TGA-Faktoren schließen, für die eine kurzzeitige CHX-Behandlung wie bei JUPIN und CHUA, 1996 beschrieben nicht ausreicht.

- Die gleichzeitige Behandlung mit SA und CHX führt in allen Linien zu einer stärkeren Transkription von as-1-GUS, als die Summe beider Einzelbehandlungen zusammen (Abbildung 5-15c)). Beide Behandlungen wirken bereits im frühen Verlauf der Transkriptionsaktivierung synergistisch. Im späten Verlauf bleibt der synergistische Effekt erhalten. Der prozentuale Einfluß der transgenen Proteine auf die SAinduzierbare Steigerung der Promotoraktivität ist im Vergleich zum Wildtyp für die Behandlung mit SA und SA + CHX jedoch unverändert.

- Die transiente Aktivierung von as-1-GUS nach SA-Behandlung geht in Gegenwart von CHX verloren, da die Bindung der TGA-Faktoren nicht wieder aufgehoben wird. Die Behandlung mit CHX unterdrückt offenbar die SA-induzierte Neusynthese eines Bindungsinhibitors der TGA-Faktoren. 


\subsubsection{Einfluss von Cycloheximid auf die Expression von Nt103}

Die in Kapitel 5.5.3 entstandenen Filter wurden weiterhin mit einer radioaktiven Sonde gegen Nt103 hybridisiert. Die in Abbildung 5-16 dargestellten Ergebnisse lassen sich folgendermaßen zusammenfassen:

- In diesem Versuch ist die transiente Aktivierung der Nt103-Transkription nach SABehandlung nicht so deutlich ausgeprägt, wie sie normalerweise $\mathrm{zu}$ beobachten ist (vgl. NigGEWEG et al., 2000a). Dies hängt vermutlich damit zusammen, dass in diesem Versuch die Blattscheiben nicht nur auf Puffer aufgelegt, sondern zusätzlich vakuuminfiltriert wurden.

- Die Induktion nur mit SA führt zu frühen Zeitpunkten (2 und 3h) für beide transgenen Linien gegenüber dem Wildtyp zu einer etwa dreifach erhöhten Transkriptionsrate für Nt103. Dieser Einfluß ist mit den Beobachtungen für as-1-GUS vergleichbar.

- Im späten Induktionsverlauf verhält sich Nt103 nicht mehr so homogen wie as-1-GUS. Wahrscheinlich beeinflussen weitere cis-Elemente im Nt103-Promotor die Genexpression.

- Im Gegensatz zu as-1-GUS lässt sich Nt103 durch alleinige CHX-Behandlung nicht induzieren. Weitere cis-Elemente im Nt103-Promotor verhindern offenbar den für as-1-GUS zu beobachtenden Effekt der späten Transkriptionsaktivierung.

- Erfolgt die SA-Induktion nach einstündiger Vorinkubation mit $\mathrm{CHX}$, so lässt sich nach $2-3 \mathrm{~h}$ in beiden transgenen Linien die Transkription von Nt103 auf durchschnittlich $240 \%$ der Wildtyp-Transkription steigern. Im späten Verlauf kommt es erneut $\mathrm{zu}$ einem inhomogenen Verhalten der Transkription, das auf die Wirkung anderer cis-Elemente zurückzuführen ist.

- Der synergistische Effekt von CHX und SA auf die Transkription von Nt103 fällt weniger stark aus als bei $a s-1-G U S$. 
a)

\begin{tabular}{|c|c|c|c|c|c|c|}
\hline$t[h]$ & $\begin{array}{ll}-1 & 0\end{array}$ & 2 & 3 & 5 & 7 & 12 \\
\hline $\mathrm{CHX}$ & $=-$ & $=$ & - & - & - & - \\
\hline$S A$ & $-\quad-$ & + & + & + & + & + \\
\hline SNN wt & & 16 & & & e & 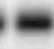 \\
\hline SNN VP2. 1s \#4 & 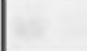 & 6 & & & es & $y$ \\
\hline SNN 2.2 Ps $\# 2$ & & & & & & \\
\hline
\end{tabular}

b)

\begin{tabular}{|c|c|c|c|c|c|c|c|c|}
\hline$t[h]$ & -1 & 0 & 2 & 3 & 5 & 7 & 12 & 24 \\
\hline $\mathrm{CHX}$ & - & + & + & + & + & + & + & + \\
\hline SA & - & - & - & - & - & - & - & - \\
\hline SNN wt & \multirow{3}{*}{ 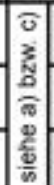 } & & & & & & & \\
\hline SNN VP2.1s \#4 & & & 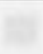 & 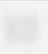 & 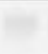 & 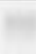 & & 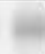 \\
\hline SNN $2.2 \mathrm{VPs} \# 2$ & & 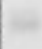 & & 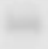 & 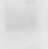 & & & \\
\hline
\end{tabular}

c)

\begin{tabular}{|c|c|c|c|c|c|c|}
\hline$t[\mathrm{~h}]$ & $\begin{array}{ll}-1 & 0\end{array}$ & 02 & 3 & 5 & 7 & 12 \\
\hline $\mathrm{CHX}$ & -+ & ++ & + & + & + & + \\
\hline SA & $-\quad-$ & + & + & + & + & + \\
\hline SNN wt & & $=$ & $=$ & $=$ & - & \\
\hline SNN VP2, is \#4 & & $=$ & & & & \\
\hline SNN 2.2 VPs $\# 2$ & & $=$ & & & & \\
\hline
\end{tabular}
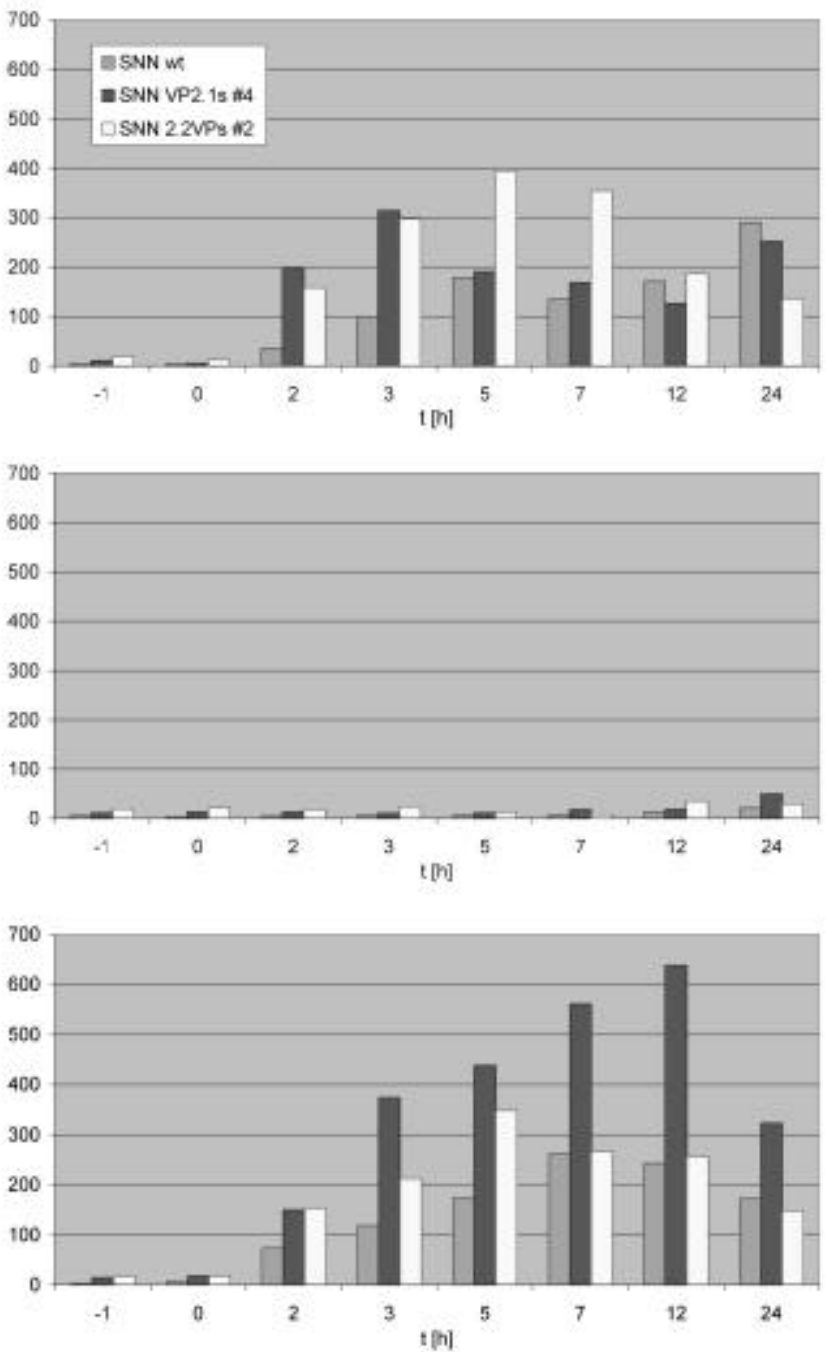

Abbildung 5-16: Induktionsversuche mit SA und $\mathrm{CHX}$ an den transgenen Linien SNN as-1-GUS \#12 (SNN wt), SNN VP2.1s \#4 und SNN 2.2VPs \#2. Die Filter wurden mit der Sonde gegen Nt103 hybridisiert. Alle weiteren Parameter wie in Abbildung 5-15 beschrieben. a) Induktion nur mit SA, b) Induktion nur mit $\mathrm{CHX}, \mathrm{c}$ ) Induktion mit SA nach Vorinkubation mit $\mathrm{CHX}$.

\subsubsection{Bewertung des Einflusses der Fusionsproteine im Vergleich zum Einfluß der überexprimierten Wildtyp-TGA-Faktoren}

Die in Kapitel 5.5 beschriebenen Versuche wurden neben den Linien SNN as-1-GUS \#12, SNN VP2.1s \#4 und SNN 2.2VPs \#2 auch mit den transgenen Linien SNN 2.1 $\Delta \mathrm{N} \# 8$, SNN 2.1 \#22 und SNN $2.2 \# 8$ durchgeführt. Auch diese Filter wurden mit der Sonde gegen Nt103 hybridisiert. In Abbildung 5-17 bzw. Abbildung 5-18 sind beispielhaft nur die Resultate der SA-Induktionen dargestellt, da in Anwesenheit von CHX die Linien SNN 2.1 $\Delta \mathrm{N} \# 8$, SNN 2.1 \#22 und SNN 2.2 \#8 im Mittel für diese Behandlungen nur marginal schwächere Effekte auf die Nt103-Expression zeigten als die Linien SNN VP2.1s \#4 
und SNN 2.2VPs \#2 (Daten nicht gezeigt). Die Ergebnisse entsprechen damit den Resultaten aus Abbildung 5-16.

\begin{tabular}{|c|c|c|c|c|c|c|c|}
\hline $\mathrm{t}[\mathrm{h}]$ & $\begin{array}{ll}-1 & 0\end{array}$ & 2 & 3 & 5 & 7 & 12 & 24 \\
\hline SA & $-\quad-$ & + & + & + & + & + & + \\
\hline SNN wt & & $x^{2}$ & $=$ & $\mathbf{0}$ & $=$ & & e \\
\hline SNN $2.1 \triangle N 29 \#$ & & - & & & & & \\
\hline SNN 2.1 \#22 & & 1 & & & & & \\
\hline SNN VP2. 18 \#4 & & 6 & & & & & $=$ \\
\hline
\end{tabular}

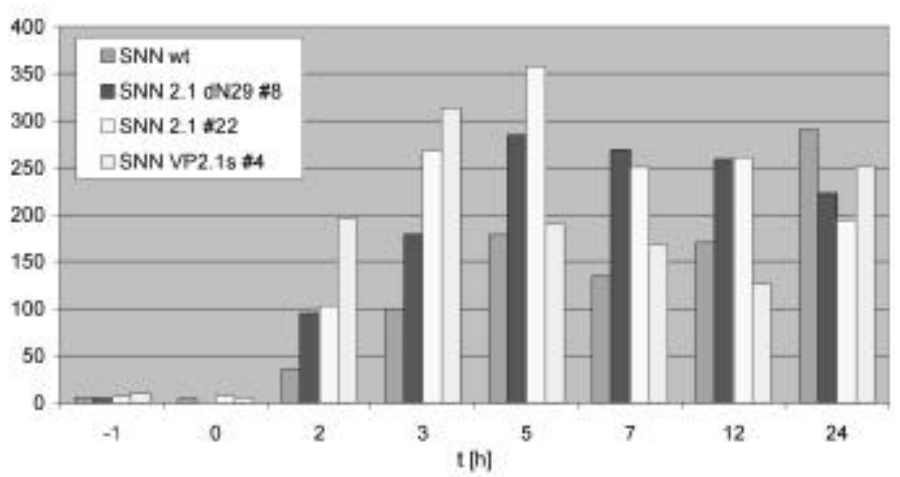

Abbildung 5-17: Induktionsversuche mit $\mathrm{SA}$ an transgenen Linien, die TGA2.1-Derivate überexprimieren. Die Filter wurden mit der Sonde gegen Nt103 hybridisiert. Alle weiteren Parameter wie in Abbildung 5-15 beschrieben.

\begin{tabular}{|c|c|c|c|c|c|c|}
\hline$t[h]$ & $\begin{array}{ll}-1 & 0\end{array}$ & 2 & 3 & 5 & 7 & 12 \\
\hline SA & $-\quad-$ & + & + & + & + & + \\
\hline SNN wt & & Me & es & $=$ & 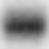 & $\mathbf{m}$ \\
\hline SNN $2.2 \# 8$ & & - & $=$ & $\mathbf{m}$ & $=$ & \\
\hline SNN 2.2 VPs \#2 & & & & & & \\
\hline
\end{tabular}

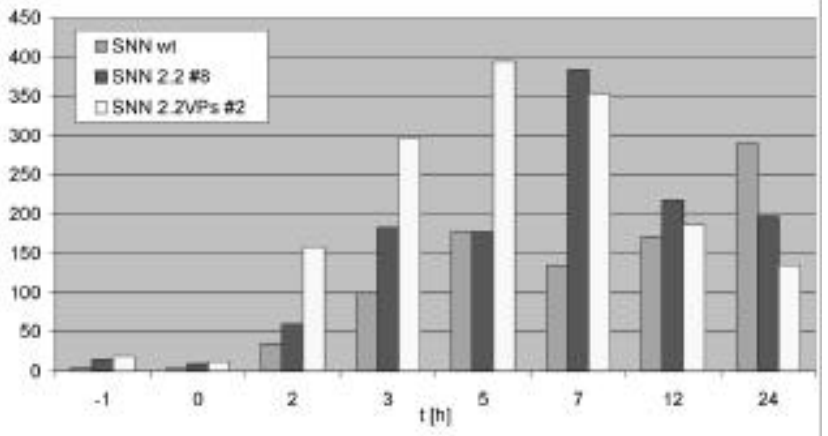

Abbildung 5-18: Induktionsversuche mit $\mathrm{SA}$ an transgenen Linien, die TGA2.2-Derivate überexprimieren. Die Filter wurden mit der Sonde gegen Nt103 hybridisiert. Alle weiteren Parameter wie in Abbildung 5-15 beschrieben.

Für Abbildung 5-17 und Abbildung 5-18 sind folgende Ergebnisse festzuhalten:

- Nach SA-Behandlung steigern alle transgenen Proteine die Transkription von Nt103 in einem Zeitraum von zwei bis drei Stunden.

- Die TGA2.2-Derivate der Linien SNN 2.2 \#8 und SNN 2.2VPs \#2 sind darüber hinaus auch zum Zeitpunkt 5h bzw. $7 \mathrm{~h}$ in der Lage, die Nt103-Transkription gegenüber dem Wildtyp anzuheben. Die durchschnittliche Transkriptionssteigerung zwischen zwei und sieben Stunden nach SA-Behandlung ist in diesen beiden Linien zwei- bzw. dreifach. 


\subsubsection{Einfluss der Fusionsproteine auf die Expression von PR-1a}

Da das PR-1a-Gen ein $a s-1$-ähnliches Element in seinem Promotor besitzt, dem eine tragende Bedeutung bei der SA-Induzierbarkeit des Promotors zukommt (STROMPEN et al., 1998), wurden die vorliegenden Filter mit einer radioaktiv markierten Sonde gegen dieses Transkript hybridisiert. Die Induktion von $P R-1 a$ ist abhängig von Proteinneusynthese (UKNES et al., 1993). Deshalb kommt es in Gegenwart von CHX in keiner der untersuchten Linien zur Transkription dieses Gens (Daten nicht gezeigt). Durch Induktion mit SA lässt sich die $P R$-1a-Transkription in allen Linien etwa gleich stark induzieren (Abbildung 5-19). Die Tatsache, dass das Maximum der Transkription in diesem Versuch zu unterschiedlichen Zeitpunkten erreicht wird, muss als versuchsbedingte Schwankung angesehen werden. Die Überexpression keines der TGA-Derivate hat also einen nennenswerten Einfluß auf die Expression von $P R-1 a$.

\begin{tabular}{|c|c|c|c|c|c|}
\hline$t[n]$ & $\begin{array}{lll}-1 & 0 & 2\end{array}$ & 23 & 5 & 7 & 12 \\
\hline $\mathrm{CHX}$ & $-\quad-$ & $-\quad-$ & - & - & - \\
\hline SA & $=-+$ & ++ & + & + & + \\
\hline SNN wt & & (3) & 38 & vin: & . \\
\hline SNN $2.1 \triangle N 29 \pm 8$ & & & & 98 & \\
\hline SNN 2.1 \#22 & & & 64 & $=$ & +5 \\
\hline SNN VP2. 1s \#4 & & 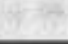 & & & $=$ \\
\hline SNN $2.2 \# 8$ & & & 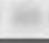 & $=$ & \\
\hline SNN 2.2 VPs \#2 & & & & & \\
\hline
\end{tabular}

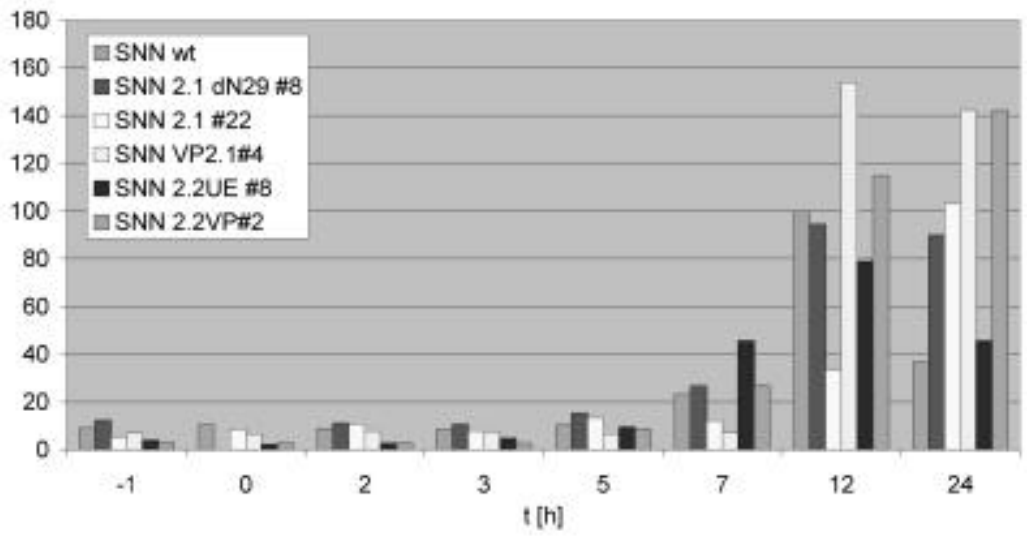

Abbildung 5-19: Induktion von PR-1a nach SA-Behandlung. Dargestellt sind ausschließlich die Filter aus Kapitel 5.5, die Proben nach SA-Behandlung tragen. Die Filter wurden mit der radioaktiven Sonde gegen PR-1a hybridisiert und autoradiografisch ausgewertet. Die entsprechenden Parameter sind wie in Abbildung 5-15 beschrieben. Die Transkriptionsrate des Wildtyps nach 12 Stunden wurde als $100 \%$ angenommen. 


\subsubsection{Einfluss der Fusionsproteine auf die Expression des CaMV 35S Promotors}

Durch das Einbringen des Transgens besitzt jede der untersuchten Pflanzen den CaMV 35S Promotor und damit ein as-1-Element im ursprünglichen Promotorkontext. Durch Vergleich der verschiedenen Transgentranskripte ist es möglich, Rückschlüsse auf das Bindungsverhalten des jeweiligen transgenen Proteins an den $35 \mathrm{~S}$ Promotor zu ziehen. $\mathrm{Zu}$ diesem Zweck wurden die Filter mit der jeweiligen Sonde gegen das Transgen hybridisiert und autoradiografisch ausgewertet. Die Signale der verschiedenen Sonden wurden auf den uninduzierten Zustand normalisiert und in Abbildung 5-20 dargestellt. Als Kontrolle diente die Pflanze Hö as-1-GUS\#1, die genauso wie die anderen Linien behandelt wurde. Diese Linie zeichnet sich durch die Überexpression des Tet-Repressors unter Kontrolle des CaMV 35S Promotors aus. Im Falle der Linie SNN 2.2VPs \#2 ist anzumerken, dass sich endogenes und transgenes Transkript überlagern. Der TGA2.2-Promotor ist aber weder durch SA noch durch CHX nennenswert stimulierbar (Kapitel 5.5.8.2 für SA, Daten für CHX nicht gezeigt). Die im Gesamt-Hybridisierungssignal enthaltenen endogenen Transkriptmengen von TGA2.2 können aufgrund der schwachen Expression vernachlässigt werden. Die Ergebnisse lassen sich wie folgt zusammenfassen:

- Allein die Infiltration mit anschließender einstïndiger Vorinkubation in Puffer (Abbildung 5-20a)) führt zu einer durchschnittlich halbierten Aktivität des CaMV 35S Promotors in allen transgenen Linien, die ein TGA-Derivat überexprimieren. Nur in der Kontrolllinie Hö as-1-GUS \#1 ist dies nicht zu beobachten.

- SA-Behandlung allein hat keinen Einfluß auf die Aktivität des CaMV 35S Promotors.

- Die Behandlung mit CHX (Abbildung 5-20b)) führt in allen Linien zur deutlichen Steigerung der CaMV 35S Promotoraktivität. Dabei zeichnet sich nach zwei und drei Stunden ein leicht steigernder Einfluß von TGA2.1 $\Delta$ N29 auf die Transkription ab, der aber nicht für VP2.1s zu beobachten ist. VP2.1s sowie TGA2.2 wirken sich im Vergleich zum Wildtyp negativ auf die Transkriptionssteigerung durch CHX aus.

- Bei gleichzeitiger Applikation von CHX und SA (Abbildung 5-20c)) kommt es zum einen zur CHX-induzierten Aktivitätssteigerung und zusätzlich zur synergistischen Verstärkung durch SA. Dieser synergistische Effekt wird durch die Überexpression von TGA2.1 und TGA2.1 $\Delta \mathrm{N} 29$ deutlich gesteigert. Typisch für SA-induzierte Aktivierung as-1-ähnlicher Elemente geschieht dies erst zwei Stunden nach SA-Gabe, jedoch nicht in transienter Weise. Die Linien SNN VP2.1s \#4, SNN 2.2 \#8 und SNN 2.2VPs \#2 verhalten sich wie der Wildtyp. 
a)
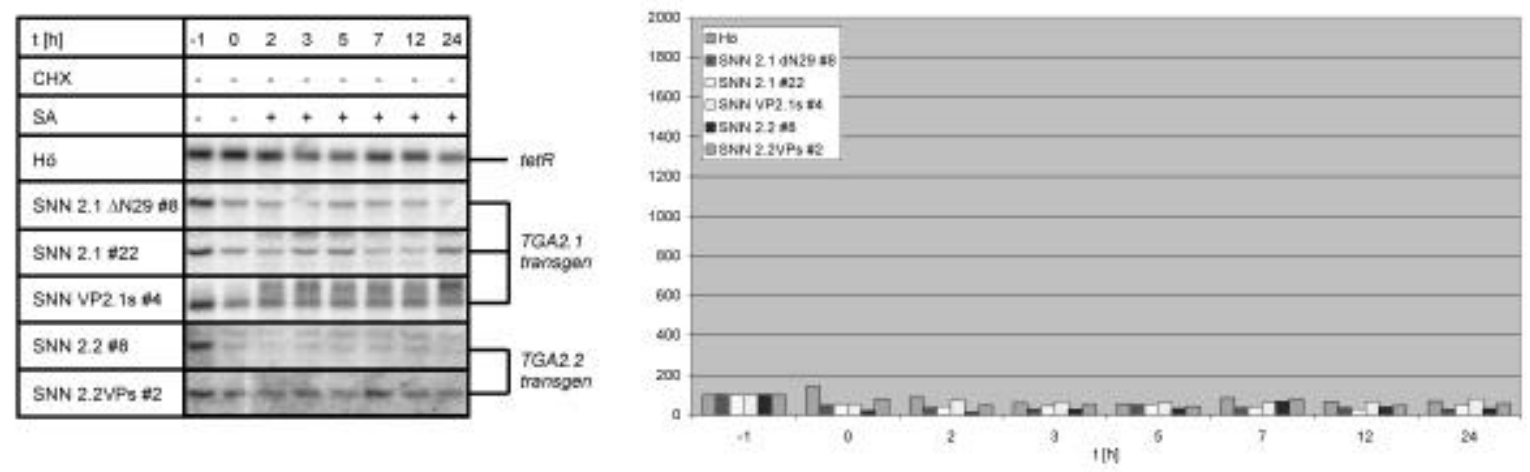

b)
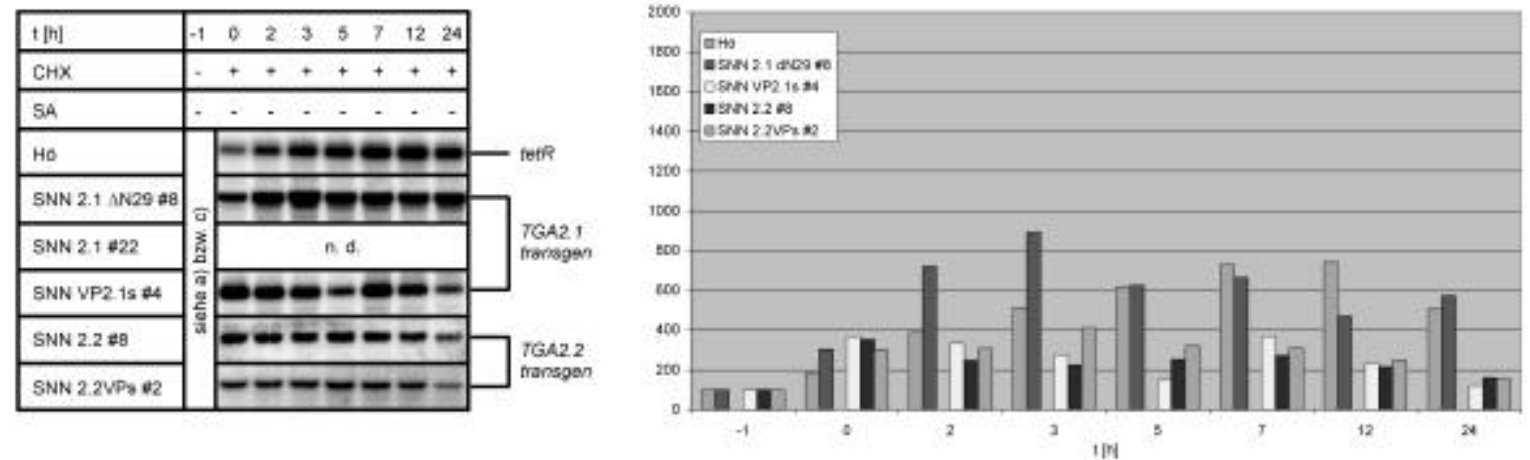

c)
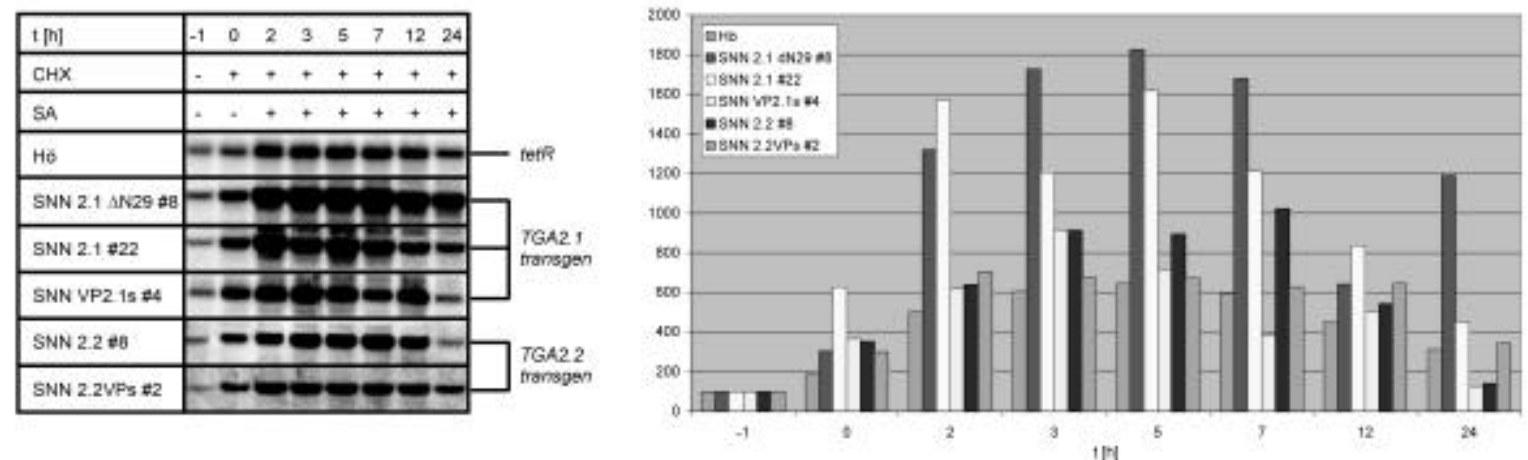

Abbildung 5-20: Einfluss von SA und $\mathrm{CHX}$ auf die Aktivität des 35S Promotors in transgenen Pflanzen. Filter für die Linien Hö as-1-GUS \#1 (Hö), SNN 2.1 $\triangle$ N29 \#8, SNN 2.1 \#22, SNN VP2.1s \#4, SNN 2.2 \#8 und SNN 2.2VPs \#2 wurden mit den entsprechenden Sonden gegen die Transgene tetR, TGA2.1 bzw. TGA2.2 hybridisiert und autoradiografisch ausgewertet. Alle weiteren Versuchsparameter wie in Abbildung 5-15 beschrieben. a) Induktion nur mit SA, b) Induktion nur mit $\mathrm{CHX}, \mathrm{c})$ Induktion mit SA nach Vorinkubation mit $\mathrm{CHX}$. 


\subsubsection{Untersuchungen zur Expression der endogenen Transkriptmengen von TGA2.1 bzw. TGA2.2}

Zur Identifizierung möglicher autoregulatorischer Mechanismen der endogenen TGA2.1- bzw. TGA2.2-Transkription wurde in den transgenen Linien die Transkription beider Gene nach SA-Behandlung untersucht.

\subsubsection{Untersuchung der endogenen Transkriptmengen von TGA2.1}

Die unter 5.5 beschriebenen Filter der SA-Induktionsversuche wurden mit der Sonde gegen TGA2.1 hybridisiert und autoradiografisch ausgewertet (Abbildung 5-21). Dabei konnten folgende Resultate festgehalten werden:

- In SNN wt kommt es nach SA-Behandlung zum kontinuierlichen Anstieg der TGA2.1Transkriptmenge. Nach 24 h hat sich die Transkriptmenge etwa verfünffacht.

- Im Wildtyp ist kein as-1-typischer, transienter Verlauf der Transkription zu beobachten.

- Die Überexpression von TGA-Derivaten der Klasse II führt zur SA-induzierten und transienten Verstärkung der Transkription von endogenem TGA2.1 nach drei Stunden. Die Verstärkung zeigt sich besonders deutlich in der Linie SNN VP2.1s \#4. Hier sind die Transkriptmengen auch nach 2 und 24 h gegenüber dem Wildtyp erhöht.

In die Regulation des TGA2.1-Promotors ist demnach voraussichtlich ein as-1-ähnliches Element involviert, welches jedoch in der Wildtypsituation in diesem Promotorkontext nicht für eine frühe Aktivierung nach zwei und drei Stunden empfänglich ist. Durch Überexpression von TGA-Faktoren der Klasse II lässt sich dieses cis-Element aktivieren.

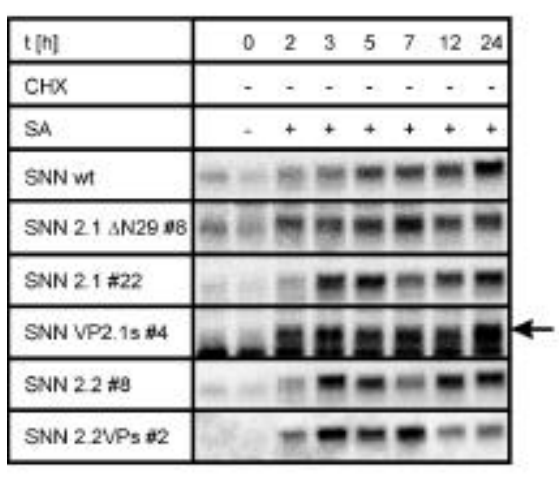

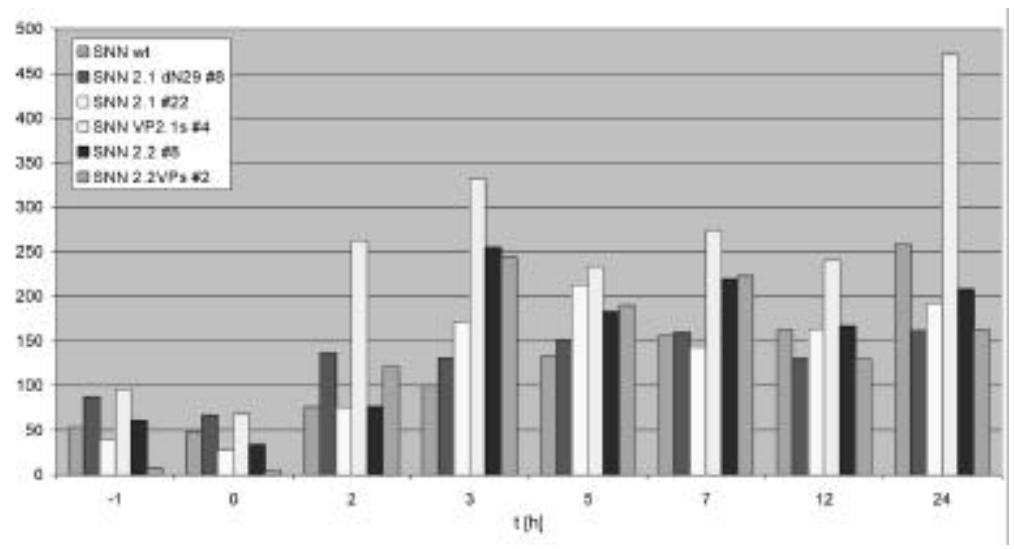

Abbildung 5-21: Untersuchung der endogenen TGA2.1-Transkription nach Behandlung mit SA. Gezeigt sind die Linien SNN as-1-GUS \#12 (SNN wt), SNN 2.1 $\triangle$ N29 \#8, SNN 2.1 \#22, SNN VP2.1s \#4 und SNN 2.2 \#8. Die Hybridisierung erfolgte mit einer radioaktiv markierten Sonde gegen TGA2.1. Alle weiteren Parameter wie in Abbildung 5-15 beschrieben. Der Pfeil kennzeichnet das endogene TGA2.1-Transkript. 


\subsubsection{Untersuchung der endogenen Transkriptmengen von TGA2.2}

Wie zuvor mit der Sonde gegen TGA2.1 wurden die Filter mit einer radioaktiv markierten Sonde gegen TGA2.2 hybridisiert und autoradiografisch ausgewertet (Abbildung 5-22). Da endogenes TGA2.2-Transkript und transgenes 2.2VPs-Transkript im denaturierenden Agarosegel komigrieren, erfolgt für die Linie SNN 2.2VPs \#2 keine Auswertung.

Bei Applikation von SA zeigt sich weder ein deutlicher Unterschied zwischen uninduziertem und induziertem Zustand, noch zwischen Wildtyp und transgenen Linien. In allen Linien ist durchschnittlich eine Verdoppelung der endogenen TGA2.2-Transkription $\mathrm{zu}$ verzeichnen. Ein direkter autoregulatorischer Mechanismus kann für TGA2.2 auf Transkriptionsebene ausgeschlossen werden.

\begin{tabular}{|c|c|c|c|c|c|c|}
\hline [ [h] & $\begin{array}{lll}-1 & 0 & 2\end{array}$ & 3 & 5 & 7 & 12 & 24 \\
\hline $\mathrm{CHX}$ & - . - & - & - & - & . & . \\
\hline SA & ..+ & + & + & + & + & + \\
\hline SNN wt & $-\infty-\infty$ & - & $=$ & $=$ & - & - \\
\hline SNN $21.4 N 29=8$ & 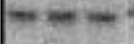 & 4 & - & $=$ & - & \\
\hline SNN $2.1 \pm 22$ & $-1-\cdots$ & $m$ & - & - & - & - \\
\hline SNN VP2.18 & $-m=-$ & $=$ & - & $=$ & $=$ & $=$ \\
\hline SNN $222 \pm 8$ & $-2=2$ & \pm & \pm & in: & $=$ & \\
\hline
\end{tabular}

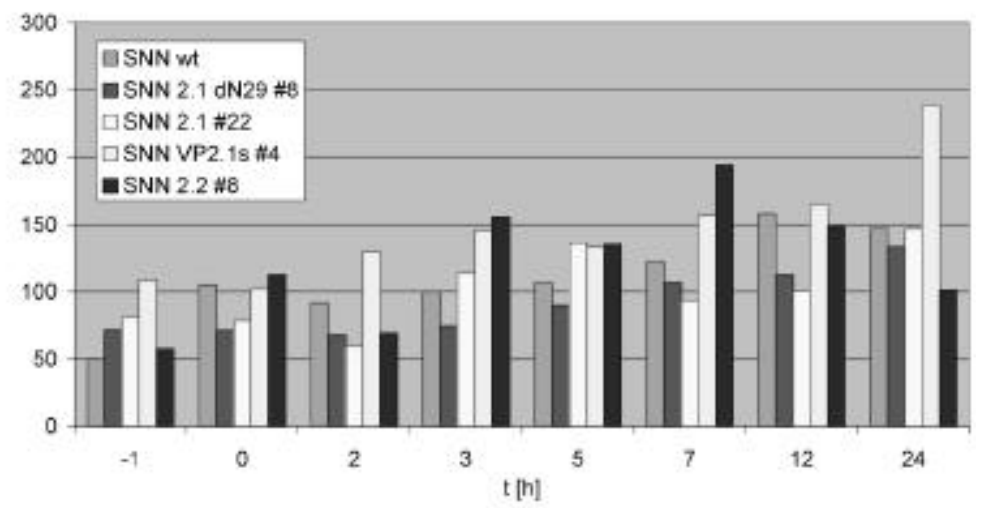

Abbildung 5-22: Untersuchung der endogenen TGA2.2-Transkription nach Behandlung mit SA. Gezeigt sind die Linien SNN as-1-GUS\#12 (SNN wt), SNN 2.1 $\quad$ N29 \#8, SNN 2.1 \#22, SNN VP2.1s \#4 und SNN 2.2 \#8. Die Hybridisierung erfolgte mit einer radioaktiv markierten Sonde gegen TGA2.2. Alle weiteren Parameter wie in Abbildung 5-15 beschrieben. Der Pfeil kennzeichnet das endogene TGA2.2-Transkript. 


\subsubsection{Phänotypische Beobachtungen an Pflanzen, die die Fusionsproteine VP2.1s bzw. 2.2VPs überexprimieren}

Wie in Abschnitt 5.3.2 geschildert, zeigen Pflanzen der Linie SNN 2.1VPs \#6 Störungen im Wachstum von Wurzeln und Blättern. Pflanzen vom Typ SNN VP2.1s und SNN 2.2VPs zeigen ebenfalls phänotypische Veränderungen. In Gewebekultur wachsen beide gedrungener gegenüber Wildtyppflanzen, woraus ein kürzerer Internodienabstand resultiert. Dieser Phänotyp manifestiert sich ebenso bei Kultivierung dieser Pflanzen in Erde. Um einen Zusammenhang dieses Phänotyps mit der gesteigerten Aktivität des as-1-Elements zu untersuchen, wurden Samen der geselbsteten Primärtransformanden SNN as-1-GUS \#12, SNN VP2.1s \#4 und SNN 2.2VPs \#2 oberflächensterilisiert und auf geeigneten Selektionsmedien zur Germination gebracht. Jeweils 16 resistente Keimlinge jeder Linie wurden in Erde pikiert und unter gleichen Bedingungen kultiviert. Nach dreiwöchiger Kultivierung in Erde wurden die Pflanzen jeder Linie entsprechend ihres Erscheinungsbilds in zwei möglichst identische Gruppen von jeweils acht Pflanzen unterteilt. Eine Gruppe jeder Linie wurde in etwa zweiwöchigem Abstand mit $100 \mu \mathrm{M}$ Benzothiadiazol (BION®), einem funktionellen Analogon von SA, besprüht. Die andere Gruppe diente als unbehandelte Kontrolle. Nach vierwöchiger Behandlung mit BION® wurde die Größe der Pflanzen und der Internodienabstand für beide Gruppen bestimmt (Abbildung 5-23).

a)

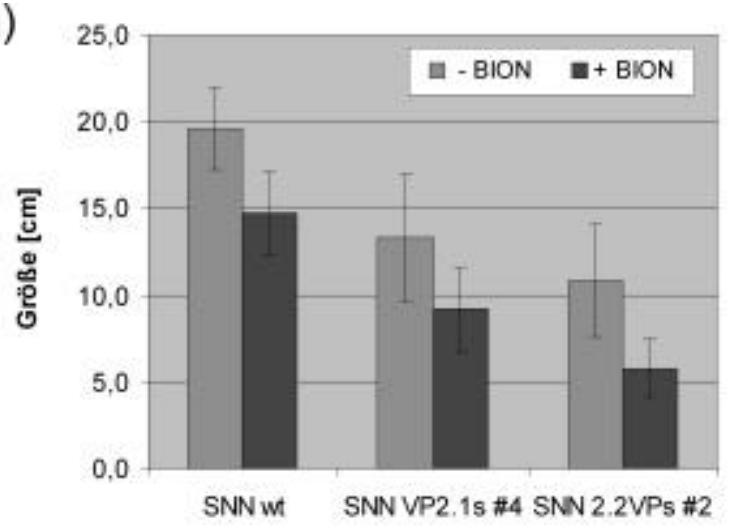

b)

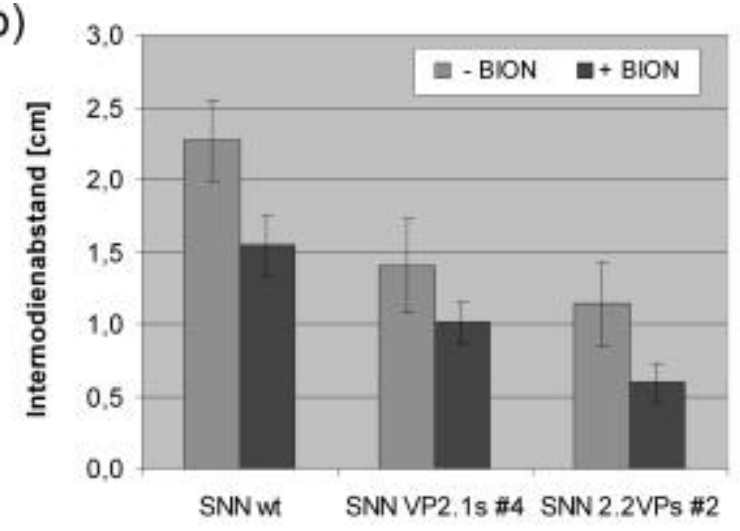

Abbildung 5-23: Phänotypische Veränderungen der transgenen Linien SNN VP2.1s \#4 und SNN 2.2VPs \#2 im Vergleich zu SNN as-1-GUS \#12 (SNN wt). a) Größe [cm] und b) Internodienabstand $[\mathrm{cm}]$ wurden für unbehandelte und $\mathrm{BION} \Theta$-behandelte [100 $\mu \mathrm{M}]$ Pflanzen der genannten transgenen Linien bestimmt. Fehlerbalken geben die Standardabweichung über jeweils acht Pflanzen an.

Während die Anzahl der Blätter pro Pflanze im Rahmen der Standardabweichung nicht verändert war, zeigte sich bei $\mathrm{BION} 囚$-behandelten Pflanzen ein eindeutig reduziertes Längenwachstum im Vergleich zu unbehandelten Pflanzen der gleichen Linie (Abbildung 
5-23a)). Auch zwischen den verschiedenen transgenen Linien zeigen sich Unterschiede bezüglich des Längenwachstums. Die transgenen Linien SNN VP2.1s \#4 und SNN 2.2VPs \#2 sind deutlich kleiner als der Wildtyp. Daraus resultiert ein deutlich reduzierter Internodienabstand (1.) innerhalb einer Linie nach BION®-Behandlung und (2.) der Linien SNN VP2.1s \#4 und SNN 2.2VPs \#2 im Vergleich zu SNNwt (Abbildung 5-23b)). Um Aussagen über die Empfindlichkeit der einzelnen Linien auf BION® machen zu können, wurde das Verhältnis der Internodienabstände zwischen uninduziertem und induziertem Zustand errechnet (Tabelle 5-2).

Dabei zeigte sich, dass bezogen auf eine induzierte Verkürzung des Internodienabstands nur die Linie SNN 2.2VPs \#2 eine erhöhte Empfindlichkeit gegenüber BION® aufweist.

Tabelle 5-2: Verhältnis der Internodienabstände zwischen uninduziertem und BION®-induziertem Zustand transgener Tabakpflanzen.

\begin{tabular}{ccc} 
SNN wt & SNN VP2.1s \#4 & SNN 2.2VPs \#2 \\
\hline \hline 1,5 & 1,4 & 1,9 \\
\hline
\end{tabular}

Es liegt die Vermutung nahe, dass es sich mindestens zum Teil um einen phänotypischen Effekt handelt, der durch as-1-gesteuerte Transkription hervorgerufen wird. Andererseits zeigen Pflanzen, die ein Fusionsprotein aus VP16-Aktivierungsdomäne und BZI-1, einem anderen bZIP-Transkriptionsfaktor überexprimieren, einen sehr ähnlichen Phänotyp (HEINEKAMP, unveröffentlicht). In diesen Studien wurden allerdings keine Induktionsversuche mit BION® durchgeführt. Dennoch könnte es sein, dass der Phänotyp zum Teil aus der Interaktion der VP16-Fusionsproteine mit einem weiteren Protein resultiert. Die direkte Interaktion von TGA2.1 bzw. TGA2.2 mit BZI-1 kann aufgrund von Hefe TwoHybrid-Studien (STRATHMANN, 1999) ausgeschlossen werden. 


\subsection{Auswirkung von Fusionsproteinen aus ENG-Silencerdomäne und TGA2.1 bzw. TGA2.2 auf die Expression von Nt103 nach Salicylsäure-Induktion}

Blattscheiben der unter 5.2.2.2, 5.2.2.4 und 5.2.3.2 charakterisierten transgenen Linien SNN 2.1ENGs \#2, SNN ENG2.1s \#17 und SNN 2.2ENGs \#3 wurden ebenso wie Blattscheiben von Wildtyppflanzen auf $50 \mathrm{mM}$ Kaliumphosphatpuffer (pH 5,8), $1 \mathrm{mM}$ SA gelegt. Nach 0, 1, 3, 7, 12 und $24 \mathrm{~h}$ wurden Proben für die Gewinnung von Gesamt-RNA genommen. Jeweils $10 \mu \mathrm{g}$ jeder Gesamt-RNA-Probe wurden im denaturierenden Agarosegel aufgetrennt und auf Nytranmembranen geblottet. Die Filter wurden mit einer radioaktiv markierten Sonde gegen Nt103 hybridisiert und anschließend autoradiografisch ausgewertet.

Die SA-induzierte Nt103-Transkription ist in allen transgenen Linien gegenüber der des Wildtyps verändert (Abbildung 5-24). Sie zeigen eine erhöhte Nt103-Transkription mit einem verzögerten Maximum nach sieben Stunden. Die Verstärkung fällt in den Linien SNN 2.1ENGs \#2 und SNN ENG2.1s \#17 deutlich geringer aus als in der Linie SNN 2.2ENGs \#3. Da die Silencerdomäne in Fusion mit beiden TGA-Faktoren in Blättern offensichtlich keine reprimierende Funktion erfuillen kann, wurde auf weitere Versuche mit diesen Pflanzen verzichtet.

\begin{tabular}{|c|c|c|c|c|c|}
\hline$t[h]$ & $\begin{array}{lll}0 & 1 & 3\end{array}$ & 7 & 12 & 24 & 36 \\
\hline SA & -++ & + & + & + & + \\
\hline SNN wt & E & $\mathbf{n}$ & 2 & $\mathrm{~s}$ & es \\
\hline SNN 2.1ENGs \#2 & 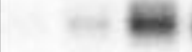 & est & $=$ & 16 & kes \\
\hline SNN ENG2.1s \#17 & $-\infty$ & $=$ & $=$ & $=$ & $=1$ \\
\hline SNN 2.2ENGs \#3 & $=0$ & e & $=$ & nos & $=1$ \\
\hline
\end{tabular}

Abbildung 5-24: SA-induzierte Nt103-Expression in transgenen Pflanzen. Blattscheiben der Linien SNN wt, SNN 2.1ENGs \#2, SNN ENG2.1s \#17 und SNN 2.2ENGs \#3 wurden mit $50 \mathrm{mM}$ Kaliumphosphatpuffer ( $\mathrm{pH}$ 5,8), $1 \mathrm{mM}$ SA behandelt, Gesamt-RNA nach der angegebenen Zeit isoliert, jeweils $10 \mu \mathrm{g}$ im denaturierenden Agarosegel aufgetrennt und auf Nytranmembranen geblottet. Die Filter wurden mit der radioaktiv markierten Sonde gegen Nt103 hybridisiert und autoradiografisch ausgewertet. 


\subsection{Auswirkung des verkürzten Proteins 2.1-57s auf die Expression von Nt103 nach Salicylsäure-Induktion}

Blattscheiben der Linien SNN wt, SNN 2.1 \#22 und SNN 2.1-57s \#8 wurden mit $1 \mathrm{mM}$ SA in $50 \mathrm{mM}$ Kaliumphosphatpuffer $(\mathrm{pH} \mathrm{5,8)} \mathrm{induziert.} \mathrm{Proben} \mathrm{wurden} \mathrm{nach} \mathrm{0,} \mathrm{3,} \mathrm{7,} 12$ und $24 \mathrm{~h}$ entnommen, um Gesamt-RNA zu präparieren. $10 \mu \mathrm{g}$ jeder Probe wurden im denaturierenden Agarosegel aufgetrennt und auf Nytranmembranen geblottet. Die Filter wurden mit einer radioaktiv markierten Sonde gegen Nt103 hybridisiert und autoradiografisch ausgewertet.

In beiden transgenen Linien zeigt sich eine gegenüber dem Wildtyp erhöhte Transkription von Nt103 (Abbildung 5-25). Die Deletion des N-Terminus von TGA2.1 hat offensichtlich keine Auswirkung auf die Funktionalität des Proteins im Zusammenhang mit einer SA-Induktion.

\begin{tabular}{|l|c|c|c|c|c|}
\hline $\mathrm{t}[\mathrm{h}]$ & 0 & 3 & 7 & 12 & 24 \\
\hline $\mathrm{SA}$ & - & + & + & + & + \\
\hline SNN wt & & & & & \\
\hline SNN 2.1 \#22 & & & & & \\
\hline SNN 2.1-57s \#8 & & & & & \\
\hline
\end{tabular}

Abbildung 5-25: SA-induzierte Nt103-Expression in transgenen Pflanzen. Blattscheiben der Linien SNN wt, SNN 2.1 \#22 und SNN 2.1-57s \#8 wurden mit $50 \mathrm{mM}$ Kaliumphosphatpuffer $(\mathrm{pH} 5,8), 1 \mathrm{mM}$ SA behandelt, Gesamt-RNA nach der angegebenen Zeit isoliert, jeweils $10 \mu \mathrm{g}$ im denaturierenden Agarosegel aufgetrennt und auf Nytranmembranen geblottet. Die Filter wurden mit der radioaktiv markierten Sonde gegen Nt103 hybridisiert und autoradiografisch ausgewertet. 


\subsection{Untersuchung der Expression von Zielgenen in transgenen Suspensionskulturen von $\mathbf{N}$. tabacum}

\subsubsection{Etablierung von Suspensionskulturen transgener Tabakpflanzen}

$\mathrm{Zu}$ Beginn der im folgenden beschriebenen Versuche lagen bereits Daten aus Blättern von transgenen Pflanzen vor, die TGA2.1 $\Delta \mathrm{N} 29$ bzw. TGA2.1trD überexprimieren (KEGLER, unveröffentlicht), wonach TGA2.1 $\Delta \mathrm{N} 29$ die SA-induzierte Zielgenexpression positiv und TGA2.1trD diese negativ beeinflusst. Um eine pharmakologische Untersuchung der Signaltransduktionskette mit Inhibitoren durchführen zu können, wurden aus Blättern und Stängeln der Linien SNNwt, SNN 2.1 $\Delta$ N29 \#8 und SNN 2.1trD \#2 Suspensionskulturen angelegt. Die Verwendung der transgenen Linien sollte Auskunft darüber geben, ob in Suspensionskulturen nach SA-Induktion die gleichen Faktoren eine Rolle spielen wie in Blättern. Die Linie SNN 2.1trD\#2 exprimiert eine transdominant negative Variante von TGA2.1, die unverändert mit anderen TGA-Faktoren dimerisieren kann, jedoch aufgrund zweier gezielter Aminosäureaustausche in der DNA-Bindedomäne nicht mehr in der Lage ist, an DNA zu binden (KEGLER, unveröffentlicht).

Die Suspensionszellen wurden standardmäßig auf Linsmaier \& Skoog - Medium mit $3 \%$ Saccharose und $1 \mu \mathrm{M}$ 2,4-D im zweiwöchigen Rhythmus 1:6 subkultiviert. Nach mindestens dreimonatiger Subkultivierung wurden Induktionsversuche durchgeführt. $\mathrm{Zu}$ diesem Zweck wurden die entsprechenden Kulturen drei Tage vor Induktion in $3 \times 1$ Volumen 2,4-D-freiem Medium gewaschen und bis zur Induktion ohne 2,4-D weiterkultiviert.

\subsubsection{Induktionsversuche mit Salicylsäure}

Suspensionskulturen der Linien SNN wt, SNN 2.1 $\triangle$ N29 \#8 und SNN 2.1trD \#2 wurden wie oben beschrieben gewaschen, mit $100 \mu \mathrm{M}$ SA versetzt und bis zur jeweiligen Probenentnahme weitergeschüttelt. Nach 0, 1, 3, 7, 12 und 24 h wurden Proben entnommen, die Gesamt-RNA isoliert, im denaturierenden Agarosegel aufgetrennt und auf Nytranmembranen geblottet.

\subsubsection{Expressionsverlauf von $N t 103$ nach Salicylsäure-Induktion}

Die unter 5.8.2 entstandenen Filter wurden mit einer radioaktiv markierten Sonde gegen Nt103 hybridisiert und autoradiografisch ausgewertet.

Die SA-induzierte Genexpression von Nt103 ist in beiden transgenen Linien für den Zeitraum zwischen 1 und $12 \mathrm{~h}$ gleichermaßen herabgesetzt. Zum Zeitpunkt der maximalen Nt103- 
Transkription im Wildtyp (nach $3 \mathrm{~h}$ ) erreicht die Transkription in den transgenen Linien durchschnittlich $31 \%$ des Wildtyps. Die Ergebnisse in Zellsuspensionen stehen somit in deutlichem Gegensatz zum Einfluß von TGA2.1 $\Delta \mathrm{N} 29$ auf die Nt103-Transkription in Blättern (vgl. Abbildung 5-11 und Abbildung 5-17).

\begin{tabular}{|c|c|c|c|c|c|}
\hline $\mathrm{t}[\mathrm{h}]$ & $\begin{array}{ll}0 & 1\end{array}$ & 3 & 7 & 12 & 24 \\
\hline $\mathrm{SA}$ & $-\quad+$ & + & + & + & + \\
\hline SNN wt & tes & & & & 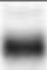 \\
\hline $\begin{array}{l}\text { SNN } 2.1 \\
\Delta N 29 \# 8\end{array}$ & 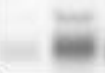 & & & & \\
\hline SNN 2.1trd \#2 & 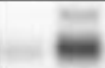 & & 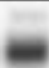 & $=$ & $=$ \\
\hline
\end{tabular}

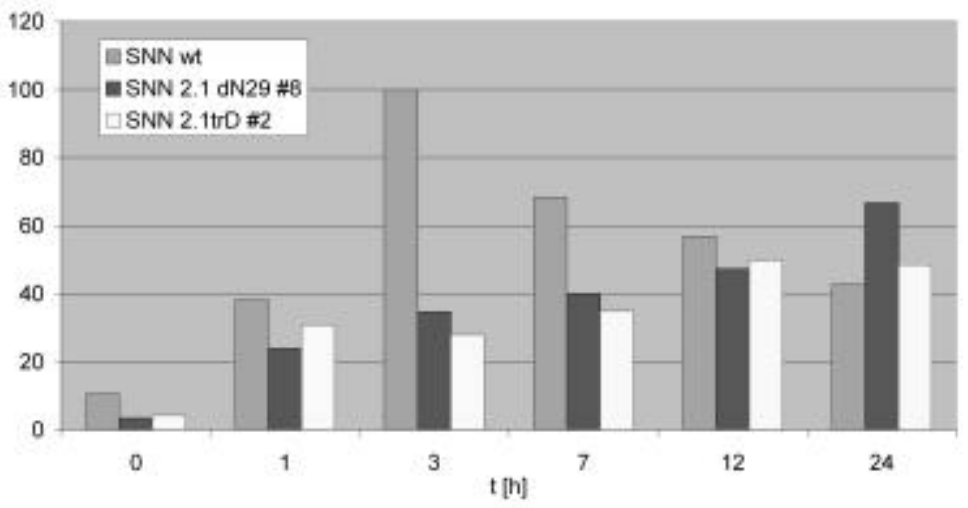

Abbildung 5-26: SA-induzierte Expression von Nt103 in Tabaksuspensionskulturen. Suspensionskulturen der Linien SNN wt, SNN 2.1 $\Delta$ N29 \#8 und SNN 2.1trD \#2 wurden mit $100 \mu \mathrm{M} \mathrm{SA}$ induziert und nach den angegebenen Zeiten die Gesamt-RNA isoliert. Pro Spur wurden $10 \mu \mathrm{g}$ Gesamt-RNA im denaturierenden Agarosegel aufgetrennt und auf Nytranmembran geblottet. Die Filter wurden mit einer radioaktiv markierten Sonde gegen Nt103 hybridisiert und anschließend autoradiografisch ausgewertet. Die Quantifizierung erfolgte mittels nicht gezeigter Normalisierungssignale. Werte beziehen sich auf die Transkriptionsrate des Wildtyps nach drei Stunden.

\subsubsection{Expressionsverlauf von parA nach Salicylsäure-Induktion}

Die unter 5.8.2 entstandenen Filter wurden mit einer radioaktiv markierten Sonde gegen parA hybridisiert und autoradiografisch ausgewertet.

In beiden transgenen Linien ist die SA-induzierte Transkription von parA gegenüber dem Wildtyp massiv unterdrückt. Sie erreicht zum Zeitpunkt $3 \mathrm{~h}$ durchschnittlich $5 \%$ des Wildtyps.

\begin{tabular}{|c|c|c|c|c|}
\hline$t[h]$ & $\begin{array}{ll}0 & 1\end{array}$ & 3 & 7 & 122 \\
\hline SA & -+ & + & + & ++ \\
\hline SNN wt & $=$ & & & $=$ \\
\hline $\begin{array}{l}\text { SNN } 2.1 \\
\Delta N 29 \# 8 \\
\end{array}$ & $=$ & $=$ & 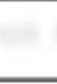 & \\
\hline SNN 2.1 trd \#2 & $=$ & eat & $=$ & $=$ \\
\hline
\end{tabular}

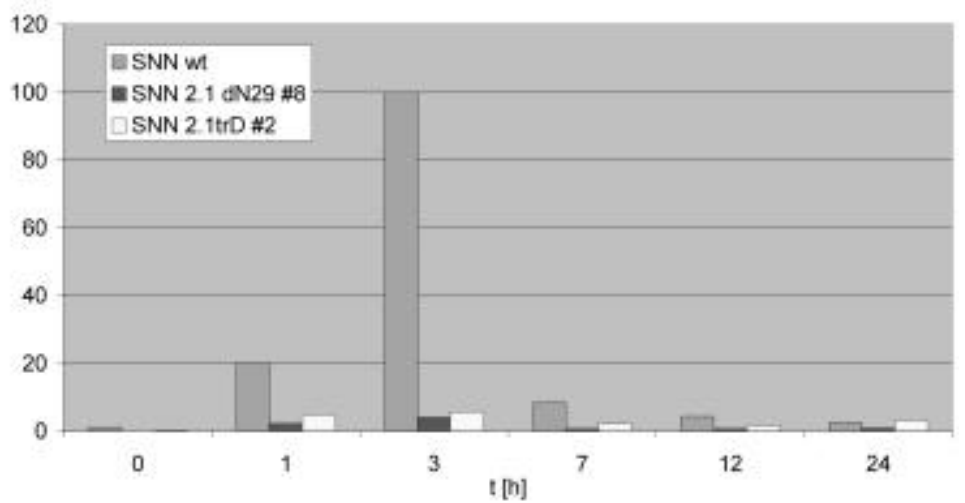

Abbildung 5-27: SA-induzierte Expression von parA in Tabaksuspensionskulturen. Die Hybridisierung der Filter erfolgte mit einer radioaktiv markierten Sonde gegen parA. Alle weiteren Parameter wie in Abbildung 5-26 beschrieben. 


\subsubsection{Induktionsversuche mit Auxin}

In Blättern konnte Auxin-Induktion kein Einfluß von TGA2.1 $\Delta \mathrm{N} 29$ oder TGA2.1trD auf die as-1-vermittelte Genexpression festgestellt werden (KEGLER, unveröffentlicht). Um auch in Zellkulturen den Einfluß der TGA-Faktoren auf diese Antwort zu untersuchen, wurden Suspensionskulturen der Linien SNN wt, SNN 2.1 $\triangle$ N29 \#8 und SNN 2.1trD \#2 analog der unter 5.8.2 beschriebenen Vorgehensweise mit $50 \mu \mathrm{M} 2,4 \mathrm{D}$ behandelt.

\subsubsection{Expressionsverlauf von Nt103 nach Auxin-Induktion}

Die unter 5.8.3 entstandenen Filter wurden mit einer radioaktiv markierten Sonde gegen Nt103 hybridisiert und autoradiografisch ausgewertet (Abbildung 5-28).

\begin{tabular}{|c|c|c|c|c|}
\hline$t[h]$ & 01 & 3 & 7 & 12 \\
\hline $2,4 \mathrm{D}$ & $-\quad+$ & + & + & + \\
\hline SNN wt & $-\mathrm{se}$ & 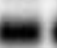 & & \\
\hline $\begin{array}{l}\text { SNN } 2.1 \\
\triangle N 29 \# 8\end{array}$ & $1=$ & & & \\
\hline SNN 2.1trd \#2 & $=$ & & & \\
\hline
\end{tabular}

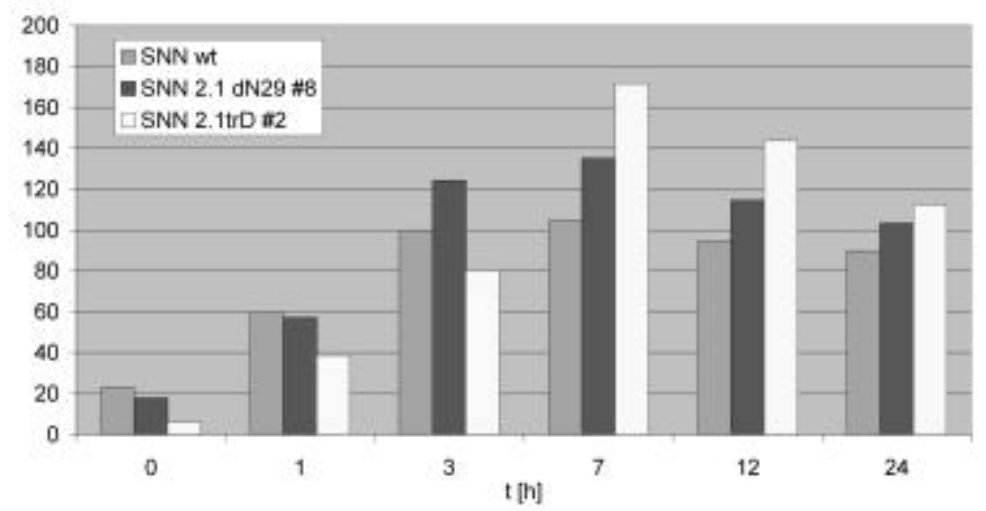

Abbildung 5-28: 2,4 D-induzierte Expression von Nt103 in Tabaksuspensionskulturen. Die Induktion erfolgte mit $50 \mu \mathrm{M}$ 2,4 D. Die Hybridisierung der Filter erfolgte mit einer radioaktiv markierten Sonde gegen Nt103. Alle weiteren Parameter wie in Abbildung 5-26 beschrieben.

Nach Induktion mit 2,4 D zeigt sich bezüglich der Nt103-Transkription in den untersuchten Linien kein Unterschied. Wie in Blättern führt auch in Suspensionszellen die Überexpression von TGA2.1 $\Delta \mathrm{N} 29$ nicht zur positiven und die Überexpression von TGA2.1trD nicht zur negativen Beeinflussung der 2,4-D-induzierten Nt103-Transkription. TGA2.1 ist nach diesen Ergebnissen eindeutig nicht an der Regulation der 2,4-D-induzierten Nt103-Transkription in Suspensionen beteiligt.

\subsubsection{Expressionsverlauf von parA nach Auxin-Induktion}

Die unter 5.8.3 entstandenen Filter wurden mit einer radioaktiv markierten Sonde gegen parA hybridisiert und autoradiografisch ausgewertet.

Beide transgenen Linien zeigen im frühen 2,4 D-induzierten Transkriptionsverlauf (bis $3 \mathrm{~h}$ ) eine Reduktion der parA-Transkription um etwa $50 \%$. Während sich die Transkription in der Linie SNN 2.1trD \#2 ab dem Zeitpunkt $7 \mathrm{~h}$ wie der Wildtyp verhält, verläuft sie in der Linie 
SNN 2.1 $\triangle$ N29 \#8 bis zum Ende des Versuchs mit gleichbleibend 20 - $30 \%$ der WildtypTranskription nach drei Stunden deutlich reduziert. Auf diesen Promotor scheint sich die Veränderung der TGA-Konstellation auszuwirken. Dieses Phänomen wurde aber nicht weiter untersucht.

\begin{tabular}{|c|c|c|c|c|c|}
\hline$t[h]$ & 01 & 3 & 7 & 12 & \\
\hline $2,4 \mathrm{D}$ & $-\quad+$ & + & + & + & \\
\hline SNN wt & $=$ & 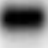 & 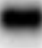 & $=$ & $=$ \\
\hline $\begin{array}{l}\text { SNN } 2.1 \\
\Delta N 29 \# 8\end{array}$ & 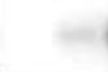 & $=$ & $=$ & $=$ & $=$ \\
\hline SNN 2.1 trd \#2 & $=$ & $m$ & & & \\
\hline
\end{tabular}

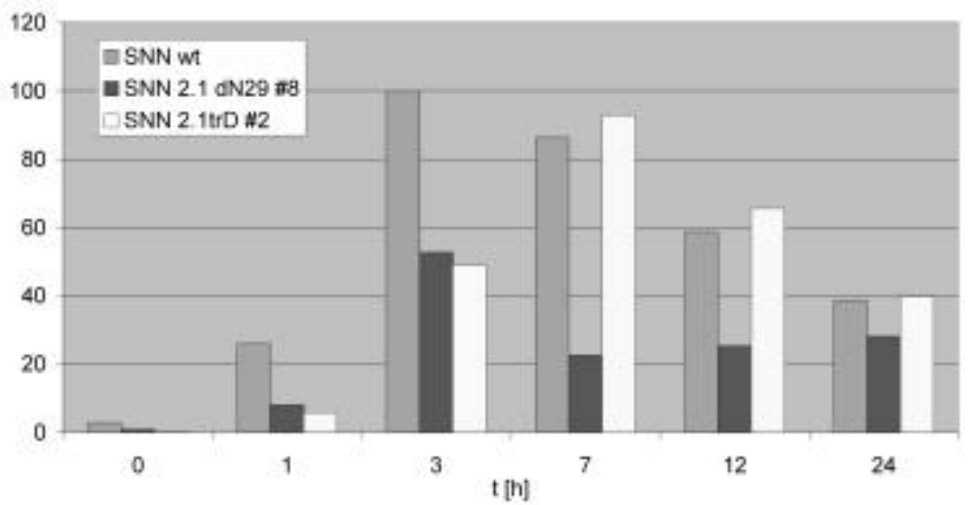

Abbildung 5-29: 2,4 D-induzierte Expression von parA in Tabaksuspensionskulturen. Die Induktion erfolgte mit $50 \mu \mathrm{M}$ 2,4 D. Die Hybridisierung der Filter erfolgte mit einer radioaktiv markierten Sonde gegen parA. Alle weiteren Parameter wie in Abbildung 5-26 beschrieben. 


\subsubsection{Analyse der in-vitro Bindung von SARP aus Suspensionskulturen}

\subsubsection{In-vitro-Bindungsaktivität an as-1-ähnliche Elemente in nativen Gesamtzellextrakten}

Um die Ursachen der Wirkung von TGA2.1 $\Delta \mathrm{N} 29$ auf die as-1-vermittelte Genexpression näher $\mathrm{zu}$ untersuchen, wurden in-vitro-Bindungsstudien mit nativen Gesamtzellextrakten (JUPIN und CHUA, 1996) aus Suspensionskulturen der Linien SNN wt und SNN 2.1 $\Delta$ N29 \#8 durchgeführt.

Zellen beider Linien wurden drei Tage vor Induktion in hormonfreiem Medium gewaschen und bis zur Induktion mit SA unter Schütteln in hormonfreiem Medium weiterkultiviert. Die Induktion erfolgte für eine Stunde durch Zugabe von $100 \mu \mathrm{M}$ SA bzw. DMSO. Nach Abnutschen des Mediums wurden in Gegenwart des Phosphatase-Inhibitors NaF [10 mM] aus den Zellen native Gesamtzellextrakte (nach JUPIN und CHUA, 1996) gewonnen und diese im EMSA auf ihre Bindeaktivität an as-1, pas-a und as-103 untersucht (Abbildung 5-30).

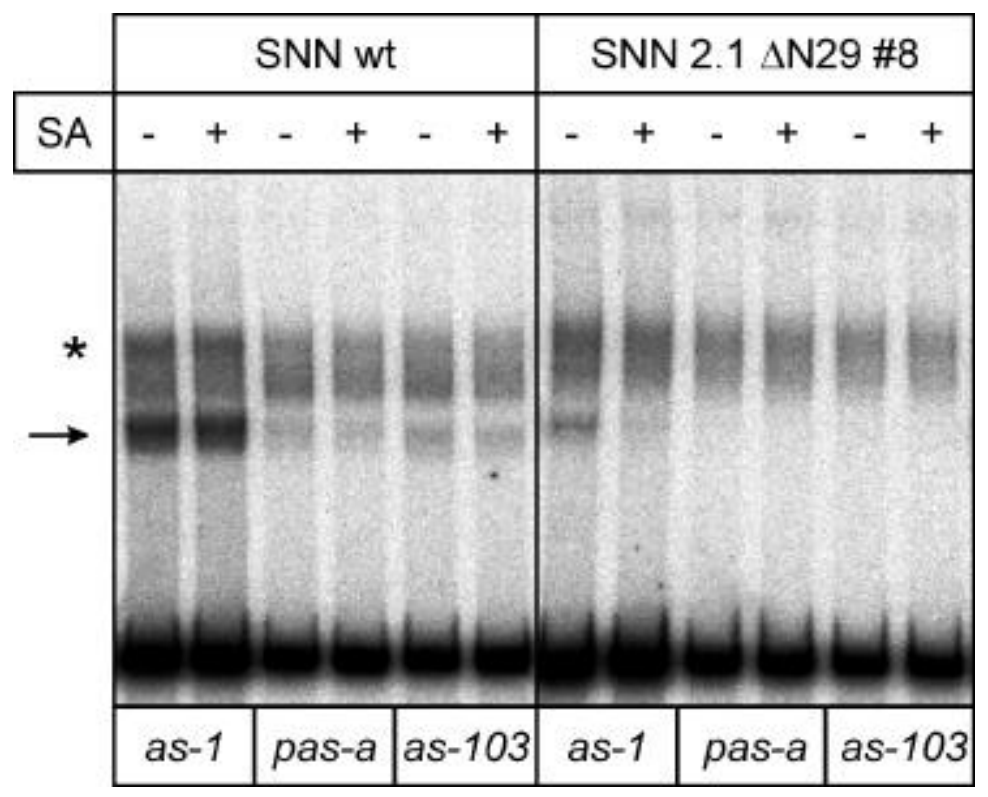

Abbildung 5-30: Untersuchung der Bindeaktivität an verschiedene as-1-ähnliche Elemente. Aus DMSO- (SA -) bzw. SA-behandelten (SA +) Suspensionskulturen der Linien SNN wt und SNN 2.1 $\Delta$ N29 \#8 wurden Gesamtzellextrakte gewonnen und im EMSA jeweils $10 \mu \mathrm{g}$ Protein auf ihr Bindeverhalten an die cis-Elemente as-1, pas-a und as-103 untersucht. Der Pfeil kennzeichnet die spezifische Bindung an eine Halbseite des jeweiligen cis-Elements, der Stern eine unspezifische Bindungsaktivität, die die Bande der Zweifachbesetzung überlagert. 
Die Ergebnisse lassen sich wie folgt zusammenfassen:

- Nach SA-Behandlung lässt sich im Wildtyp keine Veränderung der Bindung an die jeweiligen DNA-Fragmente erkennen.

- In SNN 2.1 $\Delta \mathrm{N} 29$ \#8 wurde nach SA-Induktion eine Bindungsverlust an as-1 beobachtet.

- In SNN 2.1 $\Delta \mathrm{N} 29$ \#8 ist die Bindeaktivität an eine Halbseite des as-1-Elements (Pfeil) deutlich gegenüber dem Wildtyp reduziert.

- Die Bindung an die weniger stark konservierten Motive pas-a und as-103 ist jeweils gegenüber der Bindung an das as-1-Element verringert. Bei der oberen, diffusen Bande ist diese Reduktion nur sehr gering ausgeprägt, was für die unspezifische Bindung eines weiteren Proteins an das verwendete Fragment spricht.

Aus diesen Ergebnissen resultiert die Frage nach der Zusammensetzung der gebundenen Komplexe. Einerseits wurde durch Kompetitionsexperimente mit einem Überschuss an nicht markierten Oligonucleotiden, die nur die 20 bp lange as-1-Sequenz beinhalteten, gezeigt, dass es sich bei der diffusen Bande nicht um eine as-1-spezifische Bindeaktivität handelt (Daten nicht gezeigt). Andererseits wurde durch Supershift-Analysen die Zusammensetzung des as-1-bindenden Komplexes untersucht.

Mit DMSO behandelte Extrakte beider Linien wurden im EMSA mit Antiseren gegen TGA2.1, TGA2.2 und TGA1a versetzt (Abbildung 5-31a)). Der Anteil des jeweils erkannten Proteins am Komplex errechnet sich wie folgt: (Prozent ASF-1 [Pfeil] vom Gesamtshift ohne Antiserum) - (Prozent ASF-1 [Pfeil] vom Gesamtshift mit Antiserum). Der Anteil von TGA2.1 und TGA2.2 an ASF-1 in Zellsuspensionen ist unter Berücksichtigung der reduzierten Gesamtbindeaktivität in der transgenen Linie SNN 2.1 $\Delta$ N29 \#8 in Abbildung 5-31b) grafisch dargestellt:

- Die Gesamtbindeaktivität in der transgenen Linie SNN 2.1 $\Delta$ N29 \#8 ist im Vergleich zum Wildtyp auf etwa $58 \%$ herabgesetzt.

- Im Wildtyp besteht ASF-1 zu etwa $54 \%$ aus TGA2.2, während TGA2.1 nur etwa $14 \%$ des bindenden Komplexes ausmacht.

- In der transgenen Linie SNN 2.1 $\Delta$ N29 \#8 ist TGA2.2 nur noch zu etwa $27 \%$ in ASF-1 anzutreffen. Die Menge an bindungsfähigem TGA2.1 hingegen bleibt unverändert.

- In beiden Linien ist TGA1a nicht Bestandteil von ASF-1. Die leichte Retardation bei Anwesenheit des TGA1a-Antiserums ist auch mit dem Präimmunserum nachzuweisen (NIGGEWEG, unveröffentlicht). 
a)

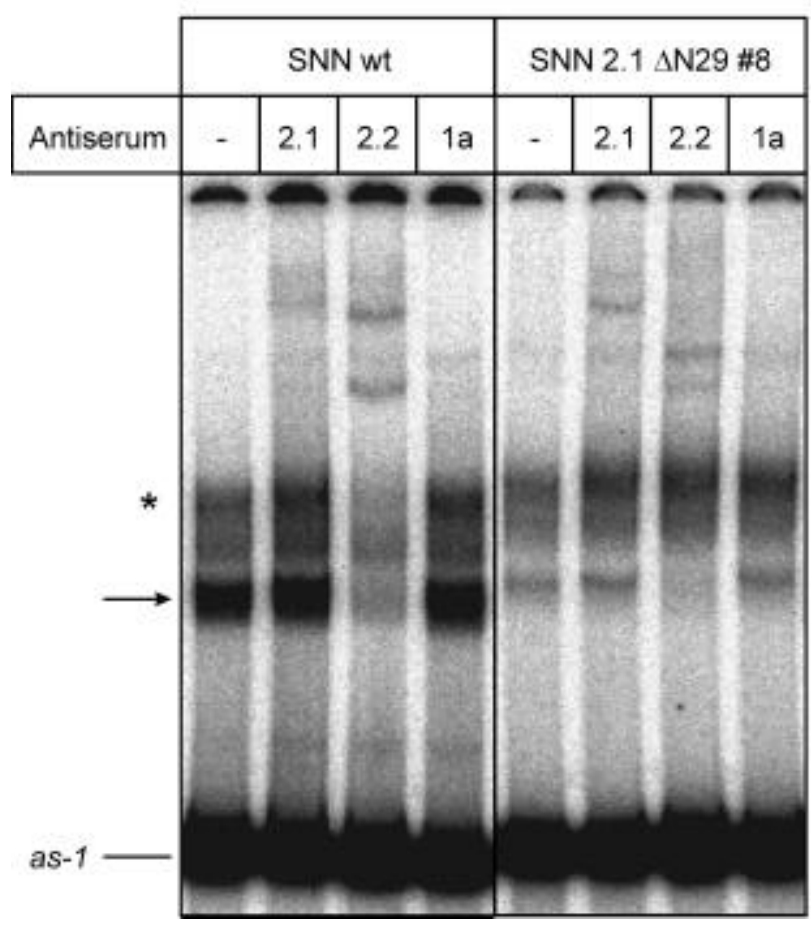

b)

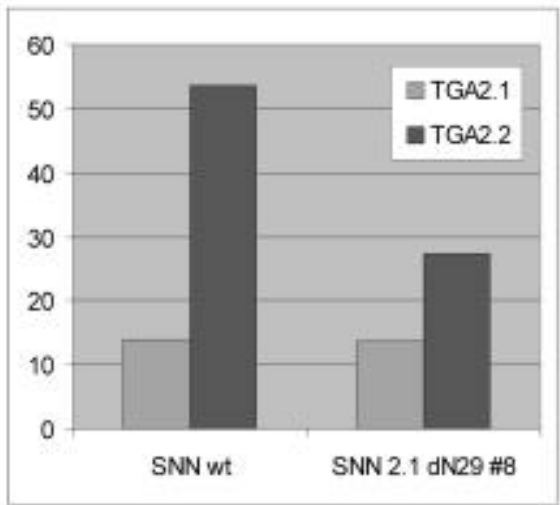

Abbildung 5-31: a) Supershift-Analyse der Zusammensetzung von SARP in Suspensionskulturen von SNN wt und SNN 2.1 $\triangle$ N29 \#8. Jeweils $10 \mu \mathrm{g}$ nativer Gesamtzellextrakte beider Linien wurden im EMSA mit Antiseren gegen TGA2.1, TGA2.2 und TGA1a versetzt. b) Quantifizierung der Beteiligung von TGA2.1 und TGA2.2 am Gesamtshift. Angaben in Prozent des insgesamt retardierten Fragments.

\subsubsection{Nachweis der Proteine TGA2.1 und TGA2.2 in Gesamtzellextrakten (nach JUPIN und CHUA, 1996) von SNN $2.1 \triangle$ N29 \#8- Suspensionskulturen}

In Abbildung 5-31 konnte keine erhöhte Menge an TGA2.1 im DNA-Bindekomplex nachgewiesen werden. Bezogen auf die Gesamtbindeaktivität war die Menge an TGA2.2, die im Komplex nachgewiesen werden konnte, zudem deutlich vermindert. Es sollte deshalb gezeigt werden, wie stark die Suspensionslinie SNN 2.1 $\Delta$ N29 \#8 die Proteine TGA2.1 und TGA2.2 exprimiert. Zu diesem Zweck wurden Immunoblot-Analysen durchgeführt. Es wurden jeweils $84 \mu \mathrm{g}$ Protein der mit DMSO behandelten nativen Gesamtzellextrakte von SNN wt und SNN 2.1 $\triangle$ N29 \#8 einer Fällung (nach WESSEL und FLÜGGE, 1984) unterzogen und anschließend mittels SDS-PAGE aufgetrennt. Nach Blotten der Proteine auf zwei PVDFMembranen wurden die Proteine TGA2.1 bzw. TGA2.2 mit Hilfe der entsprechenden affinitätsgereinigten Antiseren im Immunoblot mittels Chemilumineszenz detektiert (Abbildung 5-32). 

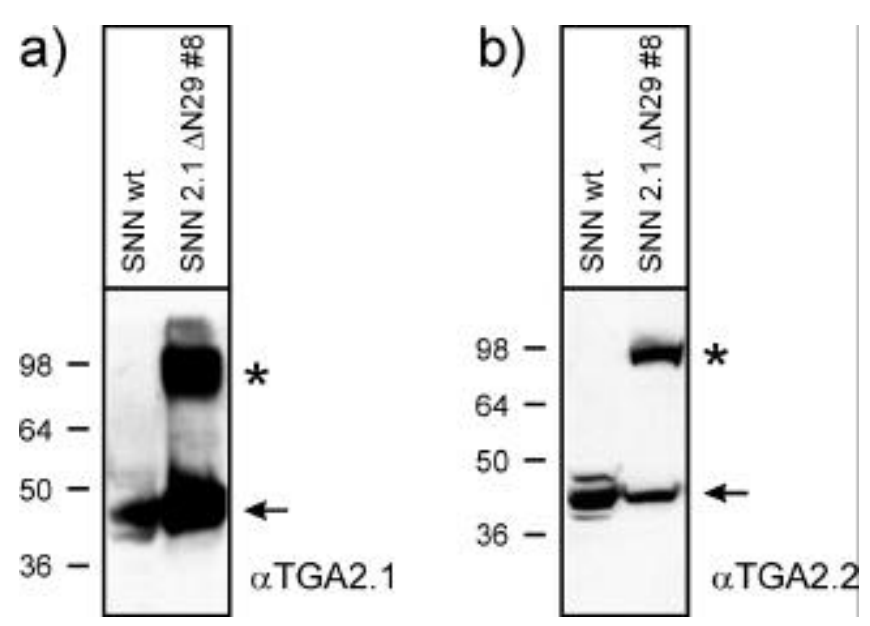

Abbildung 5-32: Immunoblot-Analysen zum Nachweis von TGA2.1 und TGA2.2 in Suspensionskulturen. Jeweils $84 \mu \mathrm{g}$ nativen Gesamtzellextrakts wurden nach vorheriger Fällung mittels SDS-PAGE aufgetrennt und auf PVDF-Membranen geblottet. Die immunologische Detektion erfolgte mit Hilfe affinitätsgereinigter Antiseren gegen a) TGA2.1 bzw. b) TGA2.2, der Pfeil kennzeichnet die Laufhöhe von TGA2.2, mit * ist ein immunologisch verwandtes Protein gekennzeichnet, das von beiden Antiseren auf gleicher Laufhöhe erkannt wird. Der Marker gibt die ungefähren Molekulargewichte in $\mathrm{kDa}$ an.

In SNN 2.1 $\Delta$ N29 \#8 lässt sich deutlich mehr TGA2.1 nachweisen als in SNN wt (Abbildung 5-32a)). TGA2.1 tritt jedoch nahezu vollständig in einer gekürzten Form (TGA2.1k) auf, die im Gel ein Molekulargewicht von etwa $45 \mathrm{kDa}$ aufweist. Das Problem der proteolytischen Abspaltung des N-Terminus von TGA-Faktoren ist aus Tabak (KEGLER, unveröffentlicht) und aus A. thaliana (ZHOU et al., 2000) bekannt. Die TGA2.2-Menge (Abbildung 5-32b)) ist in der Linie SNN 2.1 $\Delta$ N29 \#8 insgesamt nicht reduziert.

Von beiden Antiseren wird ein Protein erkannt, das ein Molekulargewicht von etwas weniger als $98 \mathrm{kDa}$ besitzt. Bei diesem Protein könnte es sich um ein kovalent verknüpftes Heterodimer zwischen TGA2.1 (50,1 kDa) und TGA2.2 (36,3 kDa) mit einer Gesamtgröße von etwa $86 \mathrm{kDa}$ handeln, welches durch SDS und $\beta$-Mercaptoethanol nicht mehr zu denaturieren ist. In beiden Proteinen findet sich im C-terminalen Bereich, welcher zumindest in TGAla für die Dimerstabilisierung verantwortlich gemacht wird (KATAGIRI et al., 1992), ein einzelner Cysteinrest, über den die kovalente Verknüpfung in Form einer Disulfid-Brücke erfolgen könnte. Dieses Phänomen wurde in mehreren unabhängigen, nach der gleichen Methode hergestellten Gesamtzellextrakten beobachtet. $\mathrm{Da}$ es in denaturierenden Gesamtzellextrakten nicht auftrat, konnte angenommen werden, dass es sich um ein Artefakt der Proteinextraktion handelt. Diese kovalente Verknüpfung könnte der Grund für die verringerte Bindung von TGA2.2 im EMSA sein. Aus diesem Grund wurden im Folgenden native Gesamtzellextrakte nach einem anderen Protokoll (FixProt, s. 4.5.1.5) hergestellt. 


\subsubsection{Einführung eines neuen Protokolls zur Gewinnung von nativen Gesamtzellextrakten (nach KEGLER, unveröffentlicht)}

Aus für zwei Stunden DMSO bzw. SA-behandelten Suspensionszellen der Linie SNNwt wurden native Gesamtzellextrakte gewonnen. Um einer möglichen Dephosphorylierung der TGA-Faktoren entgegenzuwirken, die u.U. das Bindungsverhalten an as-1 verändern könnte, wurden die FixProt-Extrakte in Anwesenheit bzw. Abwesenheit des Phosphatase-Inhibitors $\mathrm{NaF}$ hergestellt. In diesen Extrakten wurde mittels Immunoblot die Menge und das Laufverhalten von TGA2.1 im Vergleich zu denaturierenden Gesamtzellextrakten untersucht (Abbildung 5-33).

Im Vergleich von denaturierenden und nativen (FixProt) Extrakten zeigt sich, dass in den neuen nativen Extrakten nur ein sehr geringes Maß an Degradation von TGA2.1 nachweisbar ist. Für die Darstellung der Bindung von TGA2.1 an as-1 im EMSA sind diese Extrakte demnach geeignet. Im Immunoblot lässt sich zudem weder durch SA-Behandlung noch durch $\mathrm{NaF}$ (Daten nicht gezeigt) eine Beeinflussung von TGA2.1 beobachten.

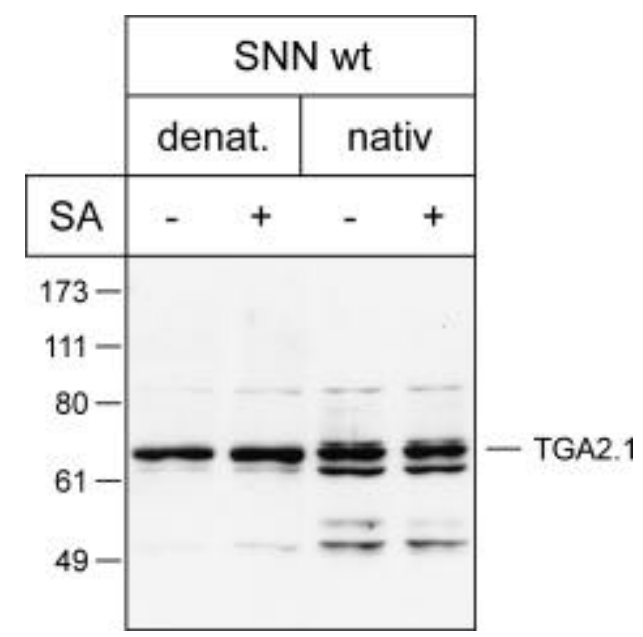

Abbildung 5-33: Immunoblot-Analyse von Gesamtzellextrakten aus Suspensionskultur von SNN wt zum Vergleich von denaturierenden und nativen Extrakten. Die hier dargestellten nativen Extrakte wurden in Gegenwart von NaF hergestellt. Vergleichbare Mengen Protein aus 2h DMSO- bzw. SAbehandelten Zellen wurden mittels SDS-PAGE aufgetrennt und auf PVDF-Membran geblottet. Die Detektion erfolgte mit dem affinitätsgereinigten Antiserum gegen TGA2.1. Das ungefähre Molekulargewicht ist in $\mathrm{kDa}$ angegeben. 


\subsubsection{Einfluss von Natriumfluorid auf das Bindeverhalten an as-1 in Suspensionskulturen}

Weiterhin wurde das as-1-spezifische Bindungsverhalten der Proteine in den nativen Extrakten von DMSO- bzw. SA-behandelten SNN wt-Zellsuspensionen $(-/+\mathrm{NaF})$ im EMSA untersucht.

Proteinextrakte, die ohne $\mathrm{NaF}$ aus Wildtypsuspensionen gewonnen wurden, zeigen im EMSA eine stark reduzierte Bindeaktivität an as-1 ohne und mit SA (Abbildung 5-34). Im Gegensatz dazu zeigen Extrakte, die in Gegenwart von $50 \mathrm{mM} \mathrm{NaF}$ hergestellt wurden, eine deutliche Bindeaffinität $\mathrm{zu} a s-1$. Es fällt auf, dass nach Behandlung nur mit DMSO die Doppelbesetzung (Pfeil 5 und 6) bevorzugt wird, während nach SA-Behandlung die Bindung so stark reduziert ist, dass nur noch eine Halbseite des as-1-Elements besetzt wird. Offenbar kommt es in Suspensionskulturen nach SA-Applikation zur reduzierten Bindung von TGA2.2 an das as-1-Element.

In SNN $2.1 \Delta$ N29 \#8 zeigt sich eine deutlich veränderte Situation. Bereits in Extrakten ohne $\mathrm{NaF}$ konnte sowohl im uninduzierten als auch im SA-induzierten Zustand eine starke Bindung an as-1 festgestellt werden. Die Bindungsaktivität lässt sich durch die Anwesenheit von $\mathrm{NaF}$ nicht weiter steigern. Aufgrund von vorherigen Studien (KEGLER, unveröffentlicht; NIGGEWEG et al., 2000b) kann unter Beachtung der Laufweite auf die Zusammensetzung der einzelnen Banden geschlossen werden (s. Abbildung 5-34 rechts). In hier nicht gezeigten Supershift-Analysen konnte diese Zuordnung für Zellsuspensionen erneut bestätigt werden. Während TGA2.2 in der Lage ist, effektiv als Homodimer die Einfach und die Doppelbesetzung am as-1-Element einzunehmen (Banden 1 und 5), zeigt TGA2.1 eine effektive Bindungsbereitschaft an beide Besetzungen nur als Heterodimer mit TGA2.2 (Banden 3 und 6) oder dem gekürzten TGA2.1k (Bande 4). Auch das Heterodimer aus TGA2.2 und TGA2.1k (Bande 2) ist zu detektieren. Durch die starke Überexpression von TGA2.1 $\Delta$ N29 liegt in SNN 2.1 $\Delta$ N29 \#8 ein größerer Anteil von TGA2.2 in Form von Heterodimeren mit TGA2.1 vor.

Wie oben erwähnt, muss es nach SA-Behandlung zur Ablösung von TGA2.2 vom as-1Element kommen. Da dieser Mechanismus in SNN 2.1 $\Delta$ N29 \#8 dereguliert erscheint, kommt es zum Verbleiben der TGA-Faktoren am cis-Element. Möglicherweise ist dies der Grund für die reduzierte Genexpression nach SA-Behandlung (Abbildung 5-26 und Abbildung 5-27). 


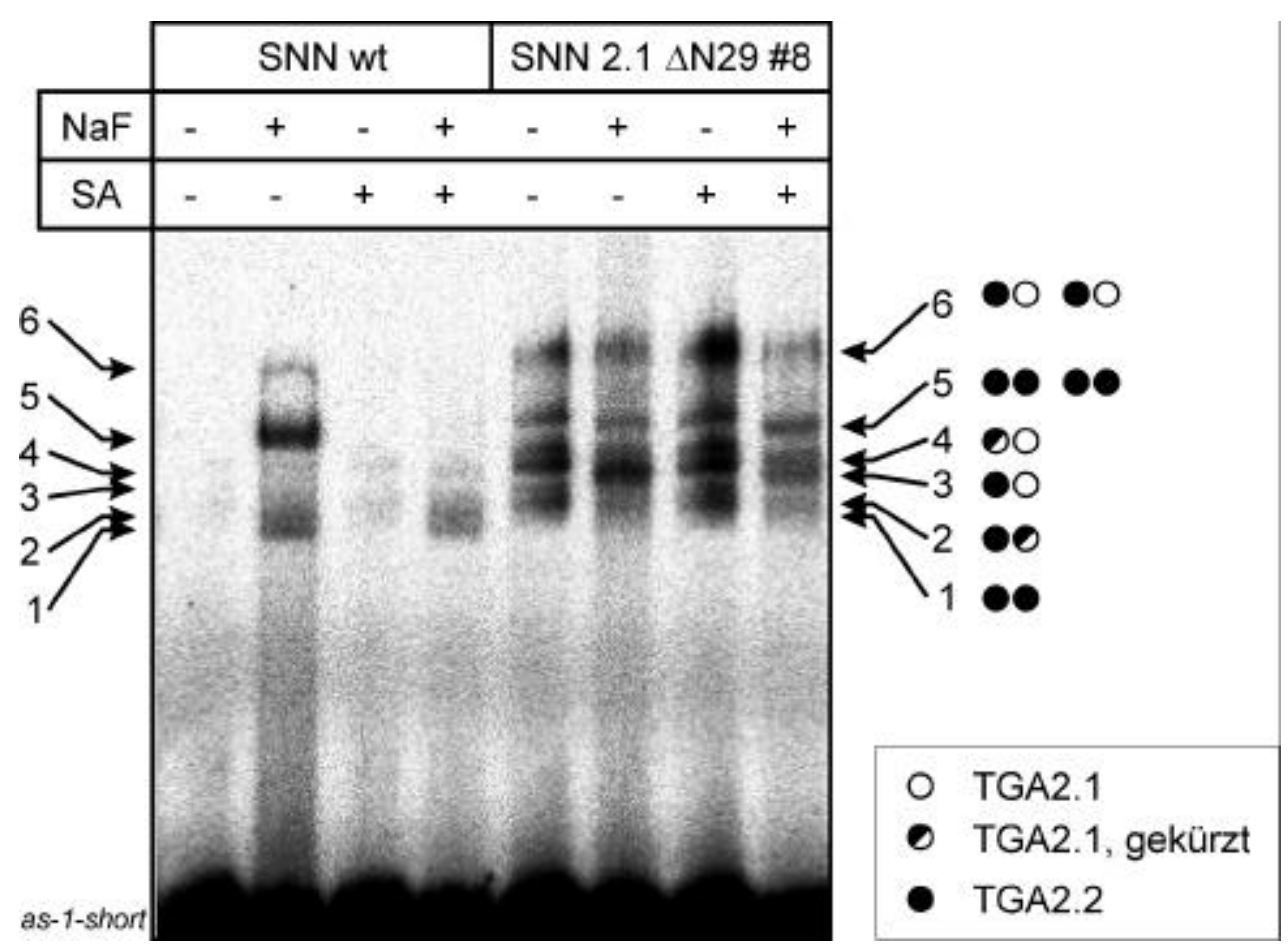

Abbildung 5-34: Veränderung der as-1-Bindeaktivität in nativen Extrakten von SNN wt Suspensionszellen nach SA-Behandlung und der Einfluss von NaF im EMSA. Pro Spur wurden 6,8 $\mu \mathrm{g}$ Protein aus nativen Extrakten von 2h DMSO- bzw. SA-behandelten SNN wt-Zellen (Extraktion - / + $50 \mathrm{mM} \mathrm{NaF}$ ) in Gegenwart von $20 \mathrm{mM} \mathrm{NaF}$ aufgetragen. Pfeile kennzeichnen den as-1-shortgebundenen Proteinkomplex.

\subsubsection{Einfluss von Quercetin auf das Bindeverhalten an as-1 in Suspensionskulturen}

Die folgenden Untersuchungen erfolgten ausschließlich an Wildtyp-Suspensionskulturen. Da der Phosphorylierungszustand der Proteine im Zellextrakt offensichtlich die Bindung an as-1 beeinflussen kann, wurde neben der Wirkung des Phosphatase-Inhibitors $\mathrm{NaF}$ auch die Wirkung des Kinase-Inhibitors Quercetin auf die as-1-Bindeaktivität untersucht. Zu diesem Zweck wurden Zellkulturen der Linie SNN wt für 2h mit DMSO bzw. $100 \mu \mathrm{M}$ SA inkubiert.

Dies geschah sowohl in Abwesenheit als auch in Gegenwart von $100 \mu \mathrm{M}$ Quercetin. Aus den so behandelten Zellen wurden in modifizierter Weise native Gesamtzellextrakte gewonnen. Abbildung 5-35 zeigt schematisch die Herstellung verschiedener nativer Extrakte unter Verwendung von Quercetin bzw. NaF. 


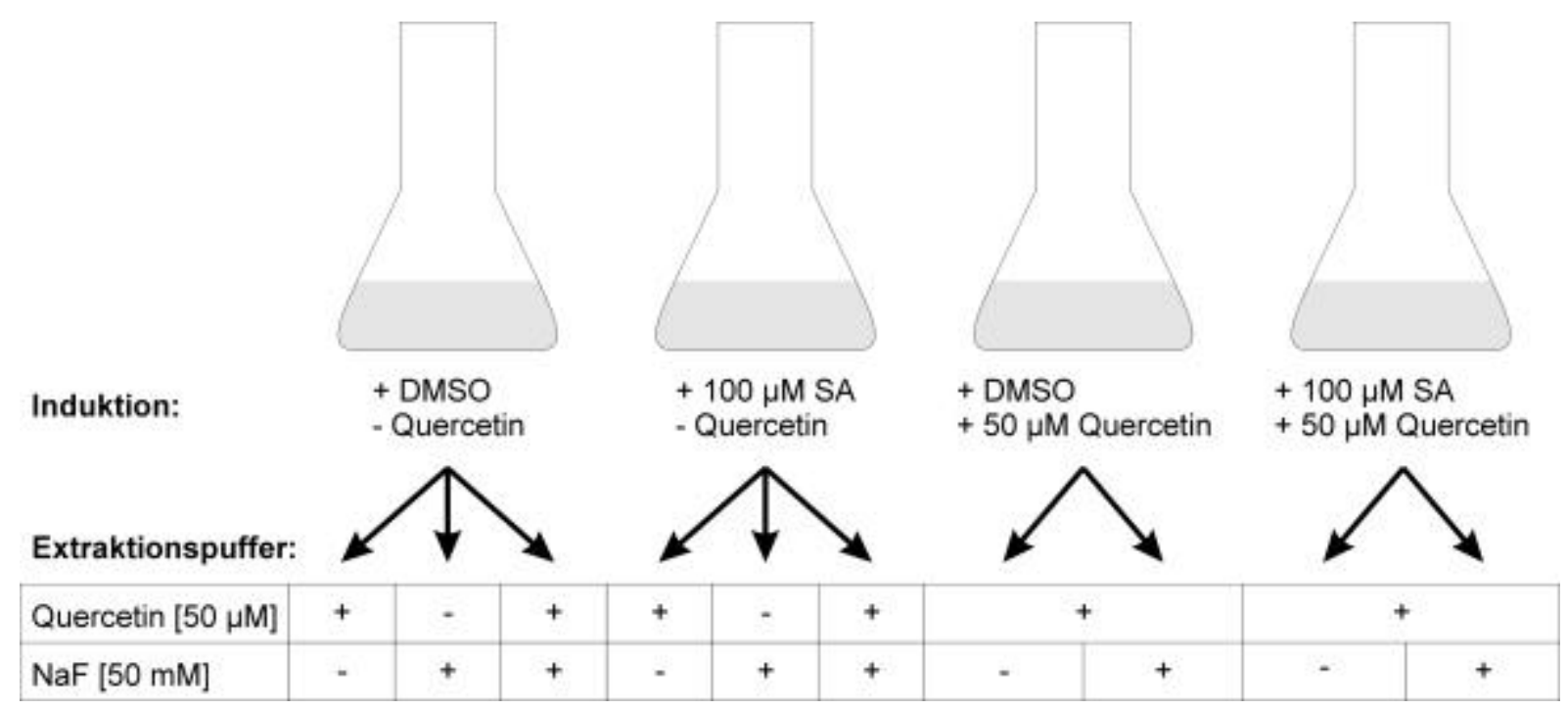

Abbildung 5-35: Schematische Darstellung der Induktionsversuche mit SA und Herstellung nativer Gesamtzellextrakte unter Verwendung der Hemmstoffe Quercetin und NaF.

Die Extrakte wurden verwendet, um das Bindeverhalten an as-1 unter den verschiedenen Bedingungen im EMSA zu untersuchen. Pro Spur wurden $5 \mu \mathrm{g}$ Protein unter Zusatz der jeweiligen Hemmstoffe im Bindeansatz mit radioaktiv markiertem as-1-Fragment inkubiert, im nativen Polyacrylamidgel aufgetrennt und autoradiografisch detektiert (Abbildung 5-36).

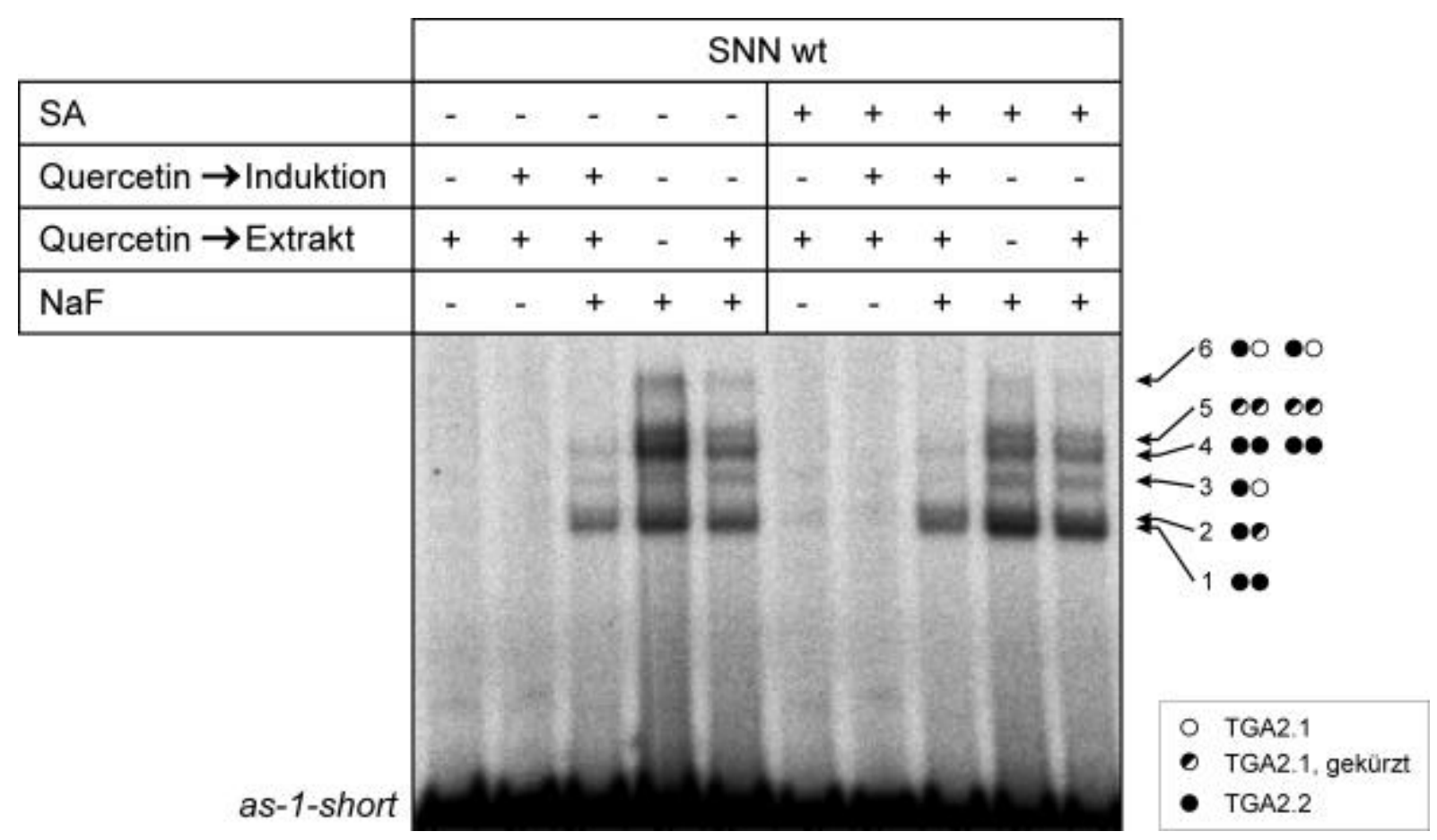

Abbildung 5-36: Einfluss von Quercetin und $\mathrm{NaF}$ auf die Bindung an as-1 in Suspensionskulturen. Native Extrakte $(5 \mu \mathrm{g})$ von für zwei Stunden DMSO- bzw. SA-behandelten SNN wt Suspensionen wurden in Gegenwart der angegebenen Inhibitoren (12,5 mM NaF bzw. 12,5 $\mu \mathrm{M}$ Quercetin) mit radioaktiv markiertem as-1-short-Fragment inkubiert, im nativen Polyacrylamidgel aufgetrennt und autoradiografisch ausgewertet. Pfeile bezeichnen die Besetzung des as-1-Elements mit den verschiedenen Homo- bzw. Heterodimeren. 
Nur in Gegenwart von NaF kommt es zu einer nachweisbaren Bindung an das as-1-Element. Die Bindung wird durch Anwesenheit von Quercetin bei der Extraktion leicht gehemmt. Bei zusätzlicher Anwesenheit von Quercetin im Suspensionsmedium wird die Hemmung weiter gesteigert. Diese Aussagen gelten sowohl für die Behandlung mit DMSO als auch mit SA. Die Stärke der Bindung an das as-1-Element ist also, wie bereits für Blätter beschrieben (JUPIN und ChUA, 1996; STANGE et al., 1997), abhängig von Phosphorylierungs- bzw. Dephosphorylierungsereignissen.

Bei Induktion mit SA konnte erneut die Bindungsreduktion mit dem Resultat der bevorzugten Besetzung nur einer Halbseite des as-1-Elements (Verstärkung der Banden 1 und 2) beobachtet werden, während die Doppelbesetzung reduziert war (Verringerung der Banden 4, 5 und 6). Die Bande 3, die das Heterodimer aus TGA2.1 und TGA2.2 enthält, bleibt nach SABehandlung in ihrer Intensität nahezu unverändert, was darauf schließen lässt, dass TGA2.1 nicht durch die vorgenommenen Behandlungen in seinen Bindungseigenschaften zu beeinflussen ist.

Die geschilderte Reduktion der Bindung nach SA konnte in weiteren unabhängigen Extrakten nachgewiesen werden (Daten nicht gezeigt). Die quantitative Auswertung der prozentualen Veränderung der Bandenintensitäten von insgesamt 12 unabhängigen Extrakten (sechs Paare + SA / + DMSO) belegt eine Verringerung von gesamt gebundenem Protein um 11,2 \% bei einer Standardabweichung von 2,8\%. Bei allen Extrakten spiegelt sich die Bindungsreduktion in einer Abschwächung der Doppelbesetzung (Banden 4 - 6) und einem Anstieg der Einfachbesetzung in Bande 1 und 2, nicht aber in Bande 3 wider. SA-Behandlung fuihrt also anders als in Blättern beschrieben (JUPIN und CHUA, 1996; STANGE et al., 1997) in Gesamtzellextrakten zur Reduktion der Bindung an das as-1-Element. 


\section{Diskussion}

\subsection{In Blättern kommt es nach Salicylsäure zur transienten Bindung der Transkriptionsfaktoren TGA2.1 und TGA2.2 an das as-1-Element}

\subsubsection{Experimenteller Ansatz}

Das Bindungsverhalten von Proteinkomplexen an das as-1-Element nach Behandlung mit Salicylsäure (SA) wurde bislang nur mit Hilfe von in-vitro-Experimenten untersucht (JUPIN und ChUA, 1996, Stange et al., 1997). Aufgrund dieser Studien wurde ein Modell für die Bindung an as-1 postuliert, nach dem die Bindungsaktivität eines als ASF-1 bzw. SARP bezeichneten Proteinkomplexes nach SA-Behandlung von Blättern durch die Dissoziation eines ASF-1/SARP - Inhibitorkomplexes ansteigt. Die Bindung von ASF-1 bzw. SARP zeigte sich in diesen Studien stimulierbar durch Applikation von SA, Cycloheximid (CHX) bzw. ATP und ist reprimierbar durch die Behandlung mit Phosphatase.

Im Rahmen dieser Arbeit wurde das in-vivo Bindungsverhalten der beiden Hauptkomponenten von ASF-1, TGA2.1 und TGA2.2 (NIGGEWEG et al., 2000a), mit Hilfe von VP16-Fusionsproteinen in transgenen Tabakpflanzen untersucht. Da nicht geklärt war, ob die zuvor erwähnten in-vitro-Bindungseigenschaften von ASF-1 mit der Situation in-vivo übereinstimmen, könnten zwei Mechanismen der SA-induzierten Aktivierung von as- 1 durch TGA2.1 bzw. TGA2.2 zutreffen. Die TGA-Faktoren könnten in einem inaktiven Zustand konstitutiv binden und erst nach SA-Behandlung aktiviert werden. In diesem Fall würde die Bindung von Fusionsproteinen zwischen TGA-Faktoren und VP16-Aktivierungsdomäne zu einer konstitutiven, starken Aktivierung der Zielgene ohne SA-Behandlung führen. Kommt es hingegen erst nach SA-Induktion zur Bindung der TGA-Faktoren, so wäre eine verstärkte, induzierte Aktivierung der Zielgene die Folge.

Es wurden transgene Pflanzen erzeugt und charakterisiert, die Fusionsproteine aus der VP16Aktivierungsdomäne und TGA2.1 bzw. TGA2.2 überexprimieren. Die VP16-Domäne wurde jeweils $\mathrm{N}$-terminal und $\mathrm{C}$-terminal angefügt. 


\subsubsection{Die Menge der Fusionsproteine übersteigt im Kern nicht die Menge der endogenen TGA-Faktoren}

Die transgenen Fusionsproteine und die transgenen Proteine der Kontrollinien konnten durch Immunoblot-Analysen in Gesamtzellextrakten eindeutig nachgewiesen werden (Abbildung 5-9). Die Detektion mit Antiseren gegen Streptag® II bzw. TGA2.1 ließ ein etwa gleich starkes Ausmaß der Überexpression für die meisten verwendeten transgenen Linien in Gesamtzellextrakten erkennen. Von den Linien, die für weitere Versuche herangezogen wurden, wiesen nur die Linie SNN 2.1 \#22 und SNN 2.2 \#8, die die unveränderten Faktoren überexprimieren, eine etwas geringere Expression des transgenen Proteins auf.

Immunoblot-Analysen mit Kernextrakten der Linien SNN VP2.1s \#4 und SNN 2.2VPs \#2 belegten durch Detektion mit dem Antiserum gegen Streptag® II eindeutig, dass die Fusionsproteine in den Zellkern gelangen (Abbildung 5-10c)). Dies ist die erste notwendige Voraussetzung für den angestrebten Einfluß der Fusionsproteine auf die Zielgene. Die Menge der im Kern nachweisbaren Fusionsproteine VP2.1s und 2.2VPs bewegt sich in derselben Größenordnung und ist auch drei Stunden nach SA-Induktion unverändert. Die Effekte auf die Expression von Zielgenen sind deshalb direkt miteinander vergleichbar.

Durch den halbquantitativen Vergleich der in verschiedenen Immunoblots ermittelten Proteinmengen in Abbildung 5-10 konnte für die Linien SNNwt, SNN VP2.1s \#4 und SNN 2.2VPs \#2 ein Gesamtbild der Mengenverteilung der verschiedenen TGA-Derivate im Kern gewonnen werden (Tabelle 5-1a)). Demnach ist die endogene TGA2.1-Menge in Kernen aller drei Linien mit 7,5\% der TGA2.2-Proteinmenge im Wildtyp (Bezugswert) gleich und ändert sich nicht nach dreistündiger SA-Behandlung (Abbildung 5-10d)). Obwohl die Untersuchung der endogenen TGA2.1-Transkriptmengen nach SA-Behandlung (Abbildung 5-21) eine Induzierbarkeit insbesondere in SNN VP2.1s \#4 belegt, schlägt sich diese Transkripterhöhung nicht in einer Steigerung der kernlokalisierten TGA2.1-Menge in dieser Linie nieder. Die Menge an transgenem Fusionsprotein VP2.1s ist mit $75 \%$ der WildtypTGA2.2-Menge zehnfach gegenüber der endogenen TGA2.1-Menge erhöht. Da in dieser Linie die kernlokalisierte Menge an endogenem TGA2.2 auf $200 \%$ des Bezugswerts erhöht ist, macht das transgene Protein nur etwa $36 \%$ der gesamten TGA2.x-Proteinmenge aus.

Für die Linie SNN 2.2VPs \#2 zeichnet sich ein ähnliches Bild ab. Die Menge an transgenem Protein 2.2VPs ist gleich der Menge von endogenem TGA2.2 im Wildtyp, und macht bei gleichzeitiger Steigerung der kernlokalisierten endogenen TGA2.2-Menge auf $200 \%$ des 
Bezugswerts in dieser Linie etwa $33 \%$ an der Gesamtmenge an TGA-Faktoren der Klasse II aus.

Bei Betrachtung der in Tabelle 5-1b) dargestellten Daten zur Heterodimerisierungssituation der TGA-Faktoren fällt auf, dass der Anteil der Dimere, die aus endogenen Faktoren entstehen (TGA2.1/TGA2.2 und TGA2.2/TGA2.2), in den transgenen Pflanzen im Vergleich zum Wildtyp nahezu unverändert bleibt. Der erhöhte TGA2.2-Anteil wird fast vollständig in Heterodimeren mit dem jeweiligen transgenen Protein gebunden.

Für eine sorgfältige Diskussion sind Daten zu berücksichtigen, die bei der genauen Analyse der Linie SNN 2.2 \#8 ermittelt wurden:

- Aus Studien an transgenen Pflanzen ist bekannt, dass die Überexpression von TGA2.2 die Expression der Zielgene Nt103 und IEGT effektiv steigern kann (NIGGEWEG et al., 2000a).

- Im Gesamtzellextrakt lässt sich im EMSA eine ca. dreimal stärkere Bindung an das as-1-Element feststellen, die durch eine gesteigerte Menge TGA2.2 hervorgerufen wird, und mit der Menge von TGA2.2 im Gesamtzellextrakt dieser Pflanzen korreliert (NIGGEWEG et al., 2000a).

- KLINGEBIEL konnte in bislang unveröffentlichten Untersuchungen zeigen, dass diese Pflanzen im Zellkern keine nachweisbar erhöhte Menge an TGA2.2 besitzen.

- Dennoch ist in Kernextrakten dieser Pflanzen im EMSA eine gesteigerte Bindung von TGA2.2 an das $a s$-1-Element nachzuweisen (KEGLER, unveröffentlicht).

Offenbar gibt es einen Mechanismus, der die Menge an TGA2.2 im Zellkern begrenzt. KLINGEBIEL konnte in bislang unveröffentlichten Untersuchungen weiterhin zeigen, dass die transgenen Linien SNN VP2.2s \#8 und SNN 2.2VPs \#2 eindeutig mehr TGA2.2 im Kern akkumulieren. Der Quervergleich mit diesen Daten in Abbildung 5-10 lässt vermuten, dass auch in der Linie SNN VP2.1s \#4 die kernlokalisierte TGA2.2-Menge erhöht ist.

Zur Erklärung dieser Beobachtungen kann lediglich ein Modell vorgeschlagen werden, da im Rahmen dieser Arbeit keine weiteren Daten zu diesem Thema gesammelt wurden. Die vorliegenden Resultate deuten auf einen Mechanismus hin, der selektiv die Menge an TGA2.2-Homodimeren im Zellkern begrenzt. Die Mengenbegrenzung könnte entweder durch kontrollierten Kernimport oder durch selektiven Kernexport der TGA2.2-Homodimere gewährleistet werden. Heterodimere zwischen TGA2.2 und TGA-VP16-Fusionsproteinen werden nicht erkannt und können im Kern akkumulieren, so dass die Gesamtmenge an 
TGA2.2 im Kern ansteigt, nicht aber die Menge an TGA2.2-Homodimeren. Für die ausschließliche Akkumulation von Heterodimeren aus TGA2.2 und Fusionsproteinen spricht die bereits erwähnte Beobachtung, dass die zusätzlichen TGA2.2-Moleküle im Kern fast ausschließlich als Heterodimere mit transgenen Proteinen vorliegen (Tabelle 5-1b)).

Die gesteigerte Zielgenexpression in SNN 2.2 \#8 ist indes nur dadurch zu erklären, dass sich die aus dem Zellkern ausgeschlossenen TGA-Faktoren im Cytosol anreichern und einen repressorischen Faktor der Bindung an das as-1-Element austitrieren. Dies könnte dazu führen, dass die gleiche Menge an kernlokalisierten TGA-Faktoren eine verstärkte Bindungsbzw. Zielgenaktivität hervorruft. Die Überexpression von Fusionsproteinen könnte den gleichen Effekt zur Folge haben.

Demnach könnte eine Verstärkung der SA-induzierten Zielgenexpression in diesen Pflanzen ebenfalls auf der Reduktion dieser repressorischen Funktion beruhen. Somit wäre keine Aussage über die in-vivo-Bindungseigenschaften der TGA-Faktoren möglich, solange nicht die Bindungsfähigkeit der Fusionsproteine nachgewiesen ist. Dieser Nachweis ist deshalb besonders wichtig, weil im EMSA die Bindung von in-vitro-translatierten Fusionsproteinen nicht nachgewiesen werden konnte.

\subsubsection{Direkte Effekte der Fusionsproteine aus die Zielgenexpression}

Bei Überexpression der TGA-VP16-Fusionsproteine kommt es zu einer erhöhten Basaltranskription der Zielgene Nt103 und as-1-GUS (Abbildung 5-11, Tabelle 6-1). Deshalb ist eine Restbindeaktivität der TGA-Faktoren wahrscheinlich. Insbesondere die Beobachtung, dass die Überexpression von TGA2.2 nicht zu einer Anhebung der Hintergrundaktivität führt, während diese in SNN 2.2VPs \#2 deutlich erhöht ist, legt die Vermutung nahe, dass dieses Phänomen sich nur bei Überexpression von TGA-Faktoren ausprägt, die über eine Aktivierungsdomäne verfügen. Konform mit dieser Vermutung zeigen Fusionsproteine aus TGA2.1 und VP16-Domäne ebenfalls eine erhöhte Basalaktivität der Zielgene. Auch die Überexpression von unverändertem TGA2.1, für den im Hefe Two-Hybrid-System eine Aktivierungsfunktion nachgewiesen werden konnte (NIGGEWEG et al., 2000b), hat eine solche Anhebung zur Folge (Tabelle 6-1). Diese ist jedoch nicht so stark, wie bei Anwesenheit der Fusionsproteine, was mit einem geringeren Transaktivierungspotential von TGA2.1 gegenüber der VP16-Aktivierungsdomäne begründet werden kann.

Ein entscheidender Punkt, der aus dieser Betrachtung resultiert, ist die funktionelle Bindung der VP16-Fusionsproteine an das as-1-Element. Weitere unveröffentlichte Untersuchungen 
von WEIGEL im Hefe One-Hybrid-System belegen die Fähigkeit von 2.2VPs, an DNA zu binden und die Aktivität eines Reportergens zu steigern. Da TGA2.1-VP16-Fusionsproteine wahrscheinlich als Heterodimere mit TGA2.2 im Zellkern vorliegen und TGA2.1/TGA2.2Heterodimere in-vitro etwa die gleiche Bindeaktivität zeigen wie TGA2.2-Homodimere, können diese Ergebnisse mit einiger Wahrscheinlichkeit auf Fusionsproteine aus TGA2.1 und VP16 übertragen werden.

Tabelle 6-1: Relative Transkriptmengen und Induktionsfaktoren der Zielgene as-1-GUS und Nt103 in verschiedenen transgenen Pflanzen uninduziert bzw. nach dreistündiger SA-Induktion. Relative Werte in Prozent der Wildtyp-Transkription nach SA-Induktion.

\begin{tabular}{l|ccc|ccc} 
& \multicolumn{3}{|c|}{$G U S$} & & & \\
Pflanze & \multicolumn{7}{|c|}{} & & & \\
& $0 \mathrm{~h} \mathrm{SA}$ & $3 \mathrm{~h} \mathrm{SA}$ & $3 \mathrm{~h} / 0 \mathrm{~h}$ & $0 \mathrm{~h} \mathrm{SA}$ & $3 \mathrm{~h} \mathrm{SA}$ & $3 \mathrm{~h} / 0 \mathrm{~h}$ \\
\hline \hline & 12 & 100 & 8 & 6 & 100 & 18 \\
SNN as-1-GUS & 34 & 255 & 8 & 46 & 697 & 15 \\
SNN VP2.1s \#2 & 32 & 272 & 8 & 51 & 558 & 11 \\
SNN VP2.1s \#4 & 36 & 242 & 7 & 24 & 757 & 32 \\
SNN 2.1VPs \#3 & 19 & 102 & 5 & 39 & 829 & 21 \\
SNN 2.1VPs \#6 & - & - & - & 20 & 537 & 27 \\
SNN 2.1 $\Delta$ N29 \#8 & - & - & - & 15 & 320 & 22 \\
SNN 2.1 \#22 & 37 & 201 & 5 & 27 & 393 & 15 \\
SNN 2.2VPs \#1 & 17 & 304 & 18 & 52 & 1125 & 22 \\
SNN 2.2VPs \#2 & 23 & 226 & 10 & 29 & 500 & 17 \\
SNN VP2.2s \#3 & 31 & 203 & 7 & 31 & 416 & 14 \\
SNN VP2.2s \#8 & - & - & - & 9 & 417 & 49 \\
SNN 2.2 \#8 & & & & & &
\end{tabular}

Für die Betrachtung der Effekte auf die Zielgenexpression in transgenen Pflanzen unter Kapitel 6.3 ist festzuhalten, dass mit großer Wahrscheinlichkeit von einer Funktionalität der Fusionsproteine auszugehen ist. 


\subsection{Die Bindung der Fusionsproteine zwischen VP16 und TGA2.1 bzw. TGA2.2 an das as-1-Element ist Salicylsäure-induziert und transient}

\subsubsection{ASF-1 ist im uninduzierten Zustand mit einem Bindungsinhibitor assoziiert}

In Pflanzen, die ein Fusionsprotein aus VP16-Aktivierungsdomäne und TGA2.1 bzw. TGA2.2 überexprimieren, konnte sowohl im uninduzierten Zustand als auch drei Stunden nach SA-Induktion eine Erhöhung der Transkription der Zielgene as-1-GUS und Nt103 gegenüber der Transkriptionsrate im Wildtyp beobachtet werden (Abbildung 5-11). Die Induzierbarkeit durch SA blieb dabei deutlich erhalten. Im Falle einer konstitutiven Bindung der VP16-Fusionsproteine sollte die Anwesenheit der VP16-Aktivierungsdomäne zu einer starken konstitutiven Transkription führen. Da dies nicht zu beobachten ist (Abbildung 5-11 und Tabelle 6-1), erscheint eine Bindung der Fusionsproteine im uninduzierten Zustand unwahrscheinlich. Dies Ergebnis unterstiitzt die Annahme von JUPIN und CHUA (1996), wonach SARP im uninduzierten Zustand mit einem Bindungsinhibitor SAI assoziiert vorliegt, und es nach SA-Induktion zur Dissoziation dieses Komplexes kommt. Weitere Studien (JOHNSON et al., 2001) belegen darüber hinaus die Assoziation des eng verwandten Transkriptionsfaktors TGA1a aus N.tabacum mit einem ca. 120 kDa großen Protein, wenn TGA1a nicht an die DNA bindet, bzw. deuten auf eine Dissoziation des TGA1a/InhibitorKomplexes nach Stimulus (in diesem Fall 2,4-D) hin. Die für die Interaktion seitens TGA1a verantwortliche Region konnte in der C-terminalen Region lokalisiert werden. Die Tatsache, dass TGA1a und die TGA-Faktoren 2.1 bzw. 2.2 im Bereich der bZIP-Domäne und des CTerminus auf Proteinebene eine 67\%ige bzw. 72\%ige Homologie (NIGGEWEG, 1999) aufweisen, lässt einen ähnlichen Regulationsmechanismus der Bindung auch für TGA2.1 bzw. TGA2.2 wahrscheinlich erscheinen.

\subsubsection{Die Bindungsaktivität von ASF-1 wird durch zwei getrennte Ereignisse reguliert}

Da die Modellvorstellung der Bindungsinhibition von ASF-1 im uninduzierten Zustand nach JUPIN und CHUA (1996) bezüglich der SA-induzierten Dissoziation des ASF-1/SAIKomplexes durch die zuvor beschriebenen Versuche in-vivo bestätigt werden konnte, sollten weitere in-vitro-Experimente der Autoren in-vivo nachvollzogen werden. Durch einstündige Behandlung der Pflanzen mit CHX konnten die Autoren im EMSA ein massive Verstärkung 
der Bindeaktivität an as-1 erzielen. Aufgrund dieser Daten wurde auf die CHX-Labilität des ASF-1/SAI-Komplexes geschlossen.

Im Gegensatz $\mathrm{zu}$ diesen Ergebnissen, konnte durch einstïndige Inkubation der transgenen Linien SNN VP2.1s \#4 und SNN 2.2VPs \#2 sowie des Wildtyps mit CHX keine Steigerung der as-1-GUS-Transkription erreicht werden (Abbildung 5-15b)). Nimmt man an, dass CHX die Dissoziation des SAI/ASF-1-Komplexes auch in-vivo bereits nach einer Stunde bewirken kann, so muss man andererseits postulieren, dass für eine effektive Bindung von ASF-1 die TGA-Faktoren eine weitere Modifikation (zu ASF-1*) erfahren müssen. Dabei könnte es sich z. B. um eine posttranslationale Modifikation wie Phosphorylierung handeln. Für diese Art der Modifikation konnte gezeigt werden, dass sie die Bindung von ASF-1 in-vitro beeinflussen kann (JUPIN und CHUA, 1996; STANGE et al., 1997). Gleichzeitig muss geschlossen werden, dass die Bedingungen für diese Modifikation bei SA-Behandlung gegeben sind, bei alleiniger CHX-Behandlung jedoch nicht.

Die Tatsache, dass es in allen Linien bei längerer alleiniger Einwirkung von CHX ebenfalls zur Akkumulation des GUS-Transkripts kommt, kann z. B. dadurch begründet werden, dass eine lange CHX-Behandlung die Umwandlung von ASF-1 zu ASF-1* begünstigt. Man kann also annehmen, dass nicht die Umwandlung $\mathrm{zu}$ ASF-1* sondern die Dissoziation von SAI/ASF-1 der geschwindigkeitsbestimmende Schritt in der Ereigniskette ist und es latent zu einer schwachen Konversion von ASF-1 nach ASF-1* kommt. Es ist möglich, dass diese normalerweise SA-induzierte Konversion von JUPIN und CHUA nicht gezeigt werden konnte, weil in den verwendeten Gesamtzellextrakten z. B. eine Kinase aktiv war, die das Gleichgewicht komplett zugunsten von ASF-1* verschoben hat. Für diese Annahme spricht, dass die Bindungsverstärkung durch Phosphatasebehandlung aufzuheben war.

Es kann nicht ausgeschlossen werden, dass ASF-1 mit einem zweiten Inhibitor assoziiert vorliegt, welcher nicht CHX-labil ist; für diese Möglichkeit gibt es jedoch keine zusätzlichen experimentellen Hinweise.

JUPIN und CHUA konnten ferner nachweisen, dass die gleichzeitige Behandlung von WildtypPflanzen mit SA und CHX im EMSA zu einer synergistischen Verstärkung der Bindung an das as-1-Element führt. Die Autoren begründen das synergistische Potential der ASF-1Bindeaktivität damit, dass es nach alleiniger SA-Behandlung nicht zur Dissoziation aller ASF-1/SAI-Komplexe kommt, und die CHX-Behandlung die Dissoziation weiter steigern kann. Ein ähnlicher synergistischer Effekt auf die Reportergenexpression konnte auch in den hier durchgeführten Versuchen in-vivo gezeigt werden (Abbildung 5-15c)). Nach entsprechender Behandlung kommt es zur Hyperakkumulation des GUS-Transkripts sowohl 
im Wildtyp als auch in Anwesenheit der Fusionsproteine. Dabei bleibt die relative verstärkende Wirkung der Fusionsproteine unverändert zu der Situation, die bei alleiniger SAApplikation zu beobachten ist. Das zitierte Modell konnte also in diesem Punkt bestätigt werden.

Zusammenfassend ist festzustellen, dass ASF-1 gemäß aller zur Verfügung stehenden Daten im uninduzierten Zustand mit einem Bindungsinhibitor SAI assoziiert ist. Dieser Komplex kann durch SA- und/oder CHX-Behandlung dissoziiert werden. ASF-1 kann in diesem Zustand jedoch noch immer nicht effizient binden. Die Bindungsbereitschaft wird durch ein zweites, SA-induziertes Ereignis, die Konversion zu ASF-1* verstärkt. Bei diesem Schritt könnte es sich z. B. um eine Phosphorylierung handeln. Diese Zusammenhänge sind der modellhaften Darstellung in Abbildung 6-1 zu entnehmen.

\subsubsection{Die transiente Bindung von ASF-1 wird durch einen Salicylsäure- induzierten Bindungsinhibitor gewährleistet}

Nach Behandlung mit SA kommt es zur transienten Bindung beider Fusionsproteine an das as-1-Element und somit zur verstärkten Aktivierung der as-1-GUS-Transkription (Abbildung 5-15a)). Um diese transiente Bindung zu erreichen, muss die Bindeaktivität der TGAFaktoren nach zunächst erfolgter Bindung durch ein weiteres Ereignis wieder herabgesetzt werden.

Wie aus Abbildung 5-15c) zu entnehmen ist, kommt es bei gleichzeitiger Behandlung mit SA und CHX nicht mehr zur Bindungsinaktivierung der TGA-Faktoren, sondern zu einer kontinuierlichen Akkumulation des GUS-Transkripts. Dieses Phänomen stimmt mit Daten von QIN et al. (1994) überein. Demzufolge kommt es nach alleiniger SA-Induktion zur Neusynthese eines Bindungsinhibitors der TGA-Faktoren (SIBI für SA-induzierter Bindungs-Inhibitor). Unter der Annahme, dass die Expression des Bindungsinhibitors auf transkriptioneller Ebene mit der gleichen Kinetik erfolgt wie die as-1-GUS-Transkription, kann unter Einbeziehung der Translationsdauer der transiente Verlauf der as-1-Aktivierung erklärt werden. Unterdrückt man mit Hilfe von CHX die Proteinneusynthese, so kommt es aufgrund des Fehlens des Bindungsinhibitors nicht mehr zur transienten, sondern zur kontinuierlichen as-1-vermittelten Aktivierung der Transkription durch die TGA-Faktoren und somit zur Hyperakkumulation des GUS-Transkripts.

Dieses Ergebnis wirft für die Zukunft die Frage auf, ob bzw. wie die mit SIBI assoziierten TGA-Faktoren die späte SA-induzierte Genexpression vermitteln. 


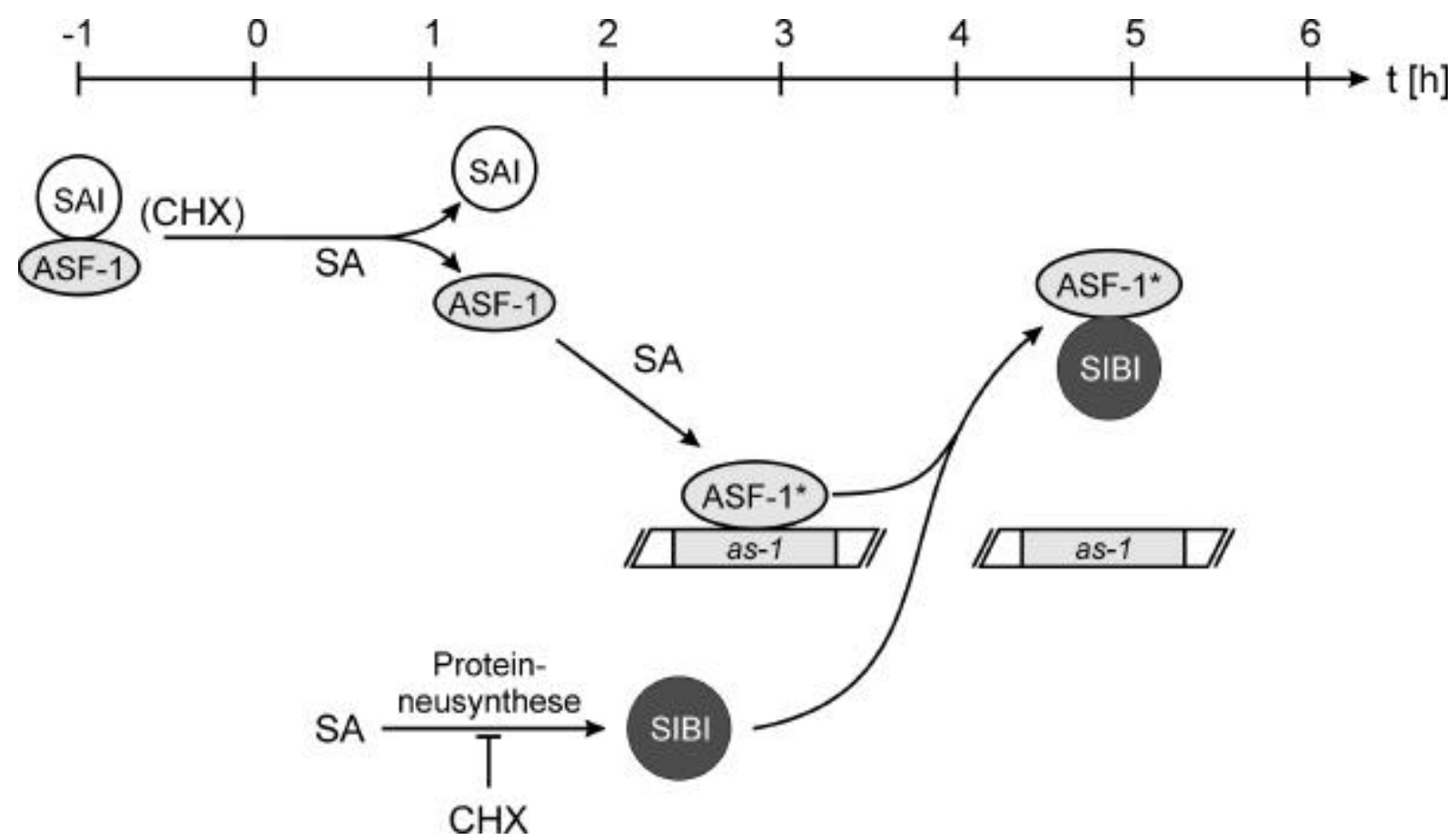

Abbildung 6-1: Modell der zeitlichen Bindungsregulation von ASF-1. SAl: SA-Inhibitor (JUPIN und CHUA, 1996), SIBI: SA-induzierter Bindungs-Inhibitor

\subsection{Der Promotorkontext der Zielgene moduliert den Einfluss as-1- ähnlicher Elemente auf die Transkription}

\subsubsection{Im Promotor von Nt103 übernehmen weitere cis-Elemente regulatorische Funktionen}

Das as-1-ähnliche cis-Element as-103 spielt für die SA-Induzierbarkeit des Nt103-Promotors eine entscheidende Rolle (DrOOG et al., 1995). Nach SA-Induktion wird für die Nt103Transkripton ein ähnlicher Einfluß der Fusionsproteine wie für as-1-GUS beobachtet (Abbildung 5-16a)). Da die Expression des Nt103-Promotors deutlich stärker ist, als die des as-1-Reportergens, muss auf die Existenz eines für den Nt103-Promotor spezifischen Faktors geschlossen werden, der zusammen mit ASF-1* in synergistischer Weise die Nt103Expression bewerkstelligt.

Im uninduzierten Zustand kommt es am Nt103-Promotor nicht zur Bindung der Fusionsproteine, während nach SA-Behandlung die Fusionsproteine VP2.1s und 2.2VPs die Transkription von Nt103 gegenüber dem Wildtyp steigern. Dies gilt für die Zeitpunkte $2 \mathrm{~h}$ und $3 \mathrm{~h}$ für beide Proteine und darüber hinaus für $5 \mathrm{~h}$ und $7 \mathrm{~h}$ nur für 2.2VPs. Da die Nt103Expression zwischen zwei Versuchsreihen leicht schwanken kann, wird diese Abweichung in SNN 2.2VPs \#2 nicht weitergehend diskutiert. 


\section{$+\mathrm{SA}$}

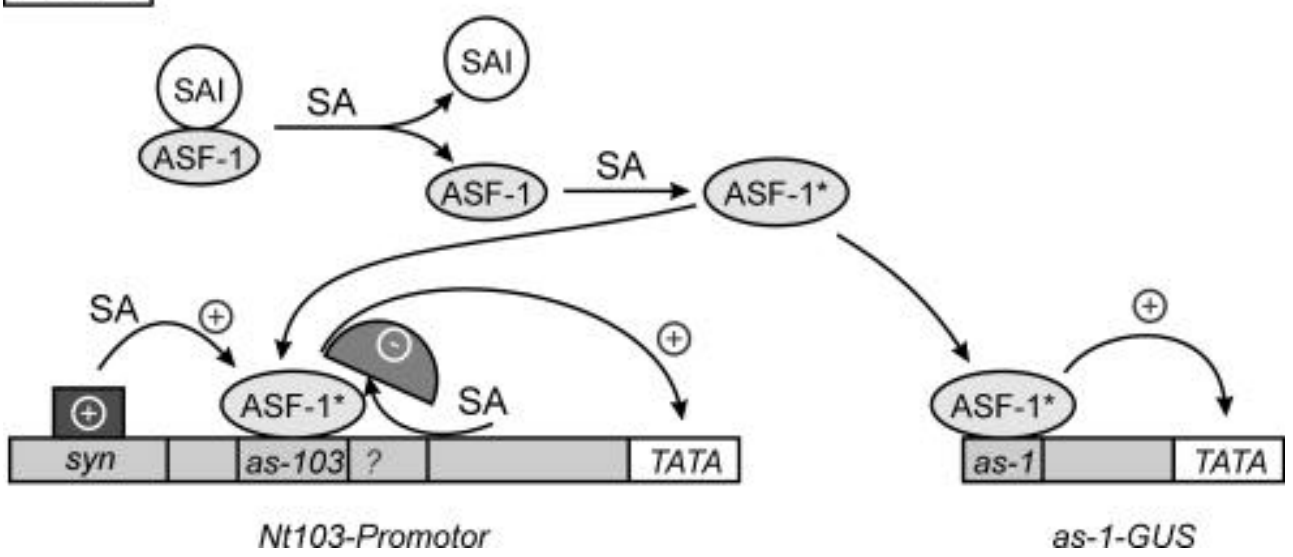

\section{$+\mathrm{CHX}$}

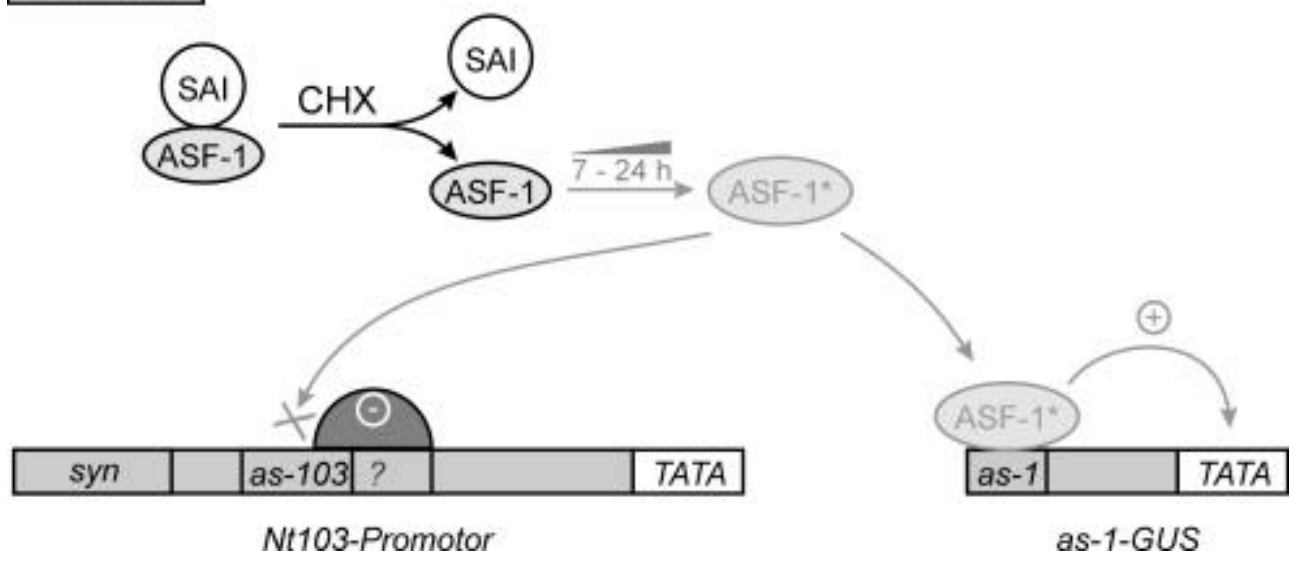

\section{$+\mathrm{SA}+\mathrm{CHX}$}

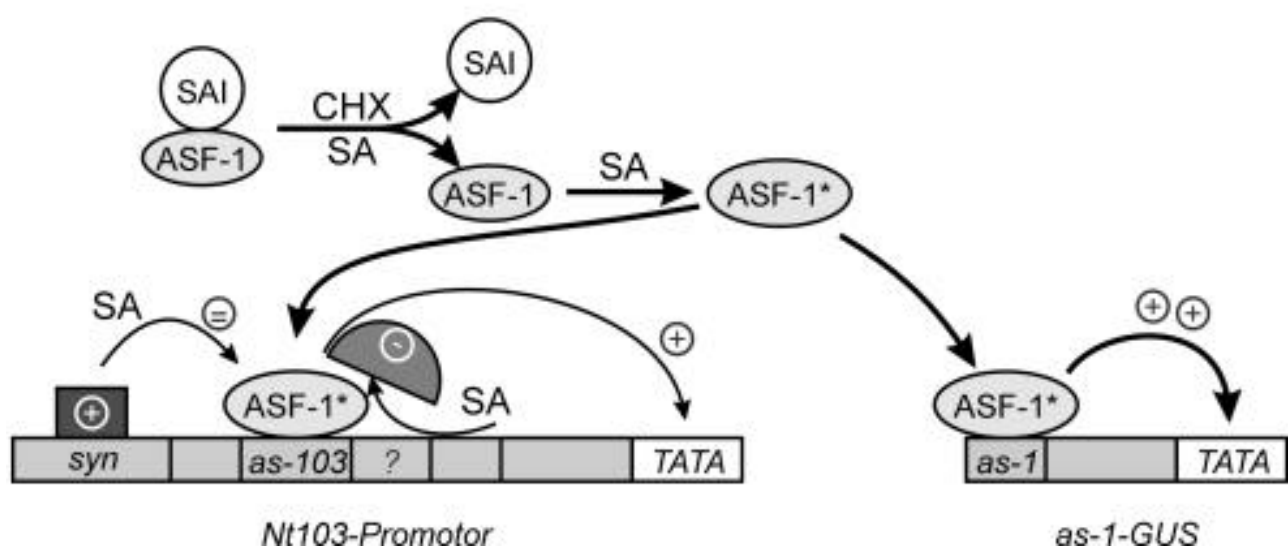

Abbildung 6-2: Modell der Bindungs- und Transaktivierungssituation an den Promotoren der Zielgene Nt103 und as-1-GUS. Legende: syn ist ein cis-Element, das einen synergistisch (+) und gleichzeitig bindungsbegrenzenden (=) trans-Faktor für ASF-1 bindet; ? ist ein nicht identifiziertes cis-Element mit repressorischer Funktion auf as-1. Halb gefüllt sind Ereignisse nach längerer CHX-Inkubation dargestellt. Weitere Erläuterungen sind den Abschnitten 6.2 und 6.3.1 zu entnehmen. 
Im Gegensatz zu as-1-GUS (vgl. Abbildung 5-15b)) ist nach CHX-Behandlung die Nt103Transkription auch im späten Verlauf nicht induzierbar (Abbildung 5-16b)). Es kann deshalb auf die Anwesenheit eines inhibitorischen Proteins geschlossen werden, das an ein benachbartes cis-Element im Promotor von Nt103 bindet, und die Aktivierung durch den sich anreichernden ASF-1* verhindert. Die DNA-Bindung bzw. Repressorfunktion dieses Proteins wird durch SA-Behandlung, jedoch nicht durch CHX-Behandlung aufgehoben.

Bei gleichzeitiger Behandlung mit SA und CHX kommt es im Gegensatz zu as-1-GUS (Abbildung 5-15c)) nicht zur weiteren Steigerung der Promotoraktivität (Abbildung 5-16c)). Dies gibt Grund zu der Annahme, dass der zuvor beschriebene Nt103-spezifische, synergistische Faktor begrenzend für die Transkriptionsaktivierung wird.

Abbildung 6-2 zeigt eine modellhafte Darstellung der wahrscheinlichen Situation am Nt103Promotor und am isolierten as-1-Element im Reporterkonstrukt as-1-GUS.

\subsubsection{Der CaMV 35S Promotor wird durch Cycloheximid-Behandlung hyperaktiviert}

Im Rahmen dieser Arbeit wurde erstmals der Einfluss von TGA2.1 und TGA2.2 auf die Expression des CaMV 35S Promotors untersucht (Abbildung 5-20). Anders als in der Literatur beschrieben (QIN et al., 1994), konnte in keiner der analysierten Linien eine SAInduzierbarkeit des 35S Promotors nachgewiesen werden (Abbildung 5-20a)). Unterschiede zwischen den beschriebenen Studien bestehen in der Verwendung verschiedener TabakKultivare (SR1 bei QIN et al., 1994; SNN in dieser Arbeit) und die Behandlung mit unterschiedlichen SA-Konzentrationen (2 mM SA bei QIN et al., 1994; $1 \mathrm{mM} \mathrm{SA}$ in dieser Arbeit). Zudem diente in dieser Arbeit als Reportergen nicht CaMV 35S::GUS sondern CaMV $35 S:: t e t R$.

Obwohl in-vitro (NIGGEWEG et al., 2000a; NIGGEWEG et al., 2000b) und in-vivo (diese Arbeit) eine Bindung von TGA2.1 und TGA2.2 an das as-1-Element des CaMV 35S Promotors nachgewiesen werden konnte, zeigt die Überexpression von Wildtyp- wie VP16Fusionsderivaten keine sichtbare Auswirkung auf die Expression des CaMV 35S Promotors nach SA-Induktion. Offenbar können die Fusionsproteine nicht an den CaMV 35S Promotor binden. Eine mögliche Erklärung ist die benachbarte Bindung eines anderen Proteins, das die Bindung an $a s-1$ verhindert. 
Eine einstïndige Behandlung der Blätter mit CHX führte sowohl in den transgenen Linien als auch im Wildtyp zu einer bislang nicht beschriebenen, etwa gleichförmig verstärkten Expression des Promotors (Abbildung 5-20b)), jedoch ohne nennenswerte Unterschiede zwischen den verschiedenen Linien. Dies belegt, dass es nach CHX-Behandlung nicht automatisch zur starken Bindung der TGA-Faktoren an das as-1-Element kommt (vgl. Abschnitt 6.2.2). Die CHX-induzierte Transaktivierung könnte entweder auf das Anschalten eines trans-Faktors an einem anderen cis-Elements oder auf die Unterdrückung einer repressorischen Funktion durch CHX zurückzuführen sein.

Bei gleichzeitiger Behandlung mit SA und CHX zeigen ausschließlich die Linien SNN 2.1 \#22 und SNN 2.1 $\Delta$ N29 \#8 eine eindeutige Verstärkung der CaMV 35S Promotoraktivität gegenüber dem Wildtyp (Abbildung 5-20c)). Diese TGA2.1-Derivate sind also in der Lage, an das as-1-Element im 35S Promotor zu binden und zur Aktivierung der Genexpression beizutragen. Die Tatsache, dass nur TGA2.1 diesen Effekt hervorrufen kann, spricht für eine selektive Erkennung von TGA2.1 am Promotor. Da weder 2.2VPs noch VP2.1s verglichen mit der Wildtypsituation einen verstärkenden Einfluß auf die Promotoraktivität zeigen, muss angenommen werden, dass keines dieser Fusionsproteine im Proteinkomplex am Promotor akzeptiert wird. Da TGA2.2 keine eigene Aktivierungsdomäne besitzt, kann in diesem Fall keine eindeutige Aussage getroffen werden.

Demnach können nur Dimere, die TGA2.1 enthalten, an den CaMV 35S Promotor binden. Außerdem spricht dieses Ergebnis sehr stark dafür, dass nach CHX-Einwirkung eine Bindungsinhibition an as- 1 aufgehoben wird, so dass es durch die in Domäne $\mathrm{B}$ gelegene, konstitutive Aktivierungsfunktion und die Transaktivierungsfunktion von ASF-1* zu einer synergistischen Verstärkung der Promotoraktivität kommt. Die synergistische Wirkung von Domäne B und Domäne A wurde bereits von BENFEY et al., 1990 vorgeschlagen. Für diese Annahme spricht außerdem, dass die Bindung an as-1 in as-1-GUS eine deutlich geringere Transkription hervorruft, als es beim CaMV 35S Promotor zu beobachten ist. Deshalb kann auch nicht ausgeschlossen werden, dass es nach alleiniger CHX-Behandlung zu einer latenten Bindung von ASF-1* an das as-1-Element kommt, diese sich jedoch nicht sichtbar auf die Promotoraktivität auswirkt. Ein Modell dieser Zusammenhänge ist in Abbildung 6-3 dargestellt. 


\section{$+\mathrm{SA}$}

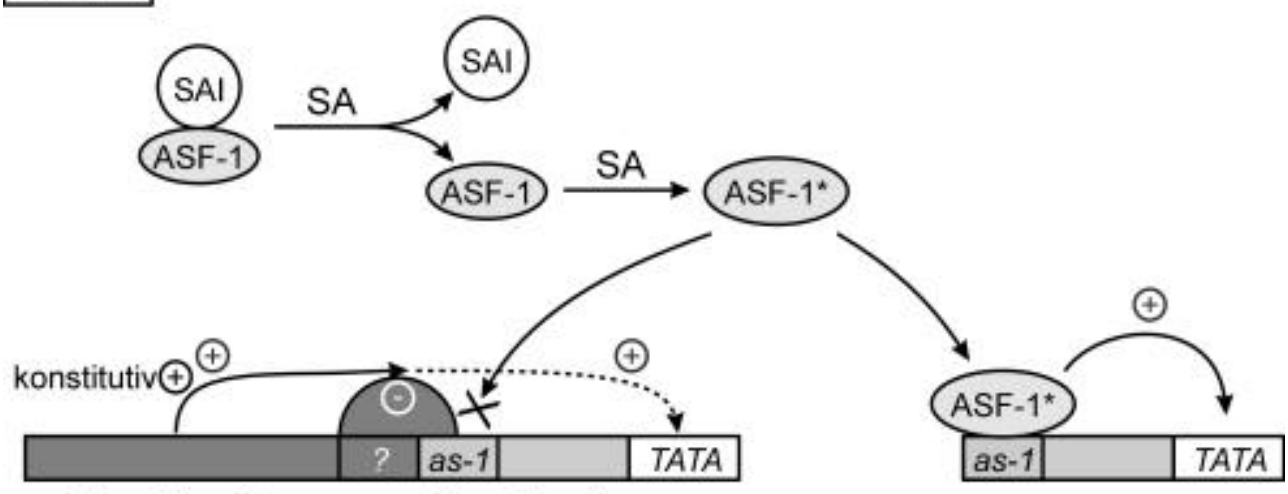

Domäne B

Domäne A

CaMV $35 S$

as-1-GUS

\section{$+\mathrm{CHX}$}
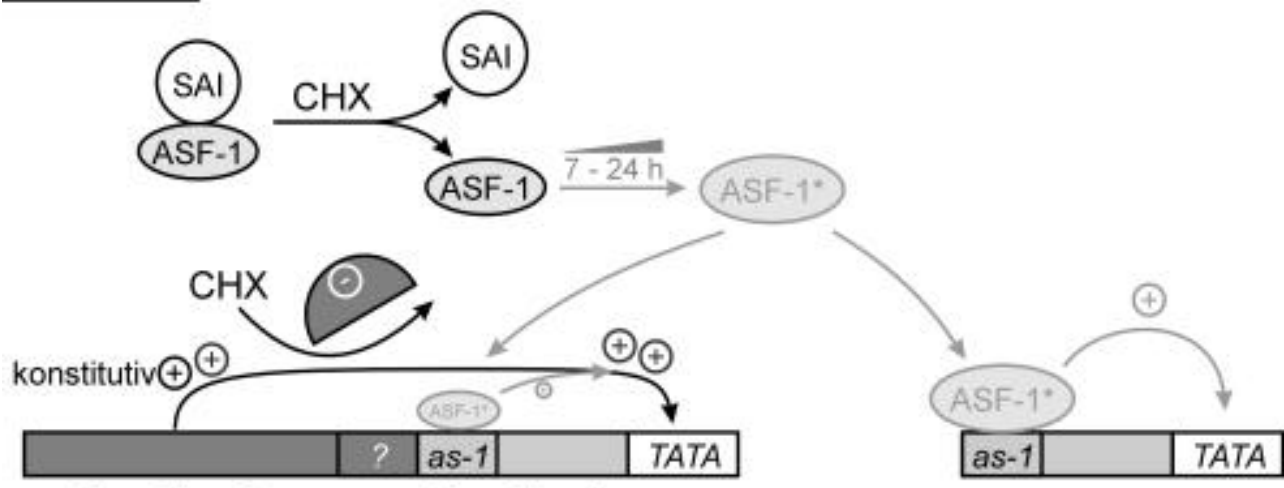

Domäne B

Domäne A

CaMV $35 S$

as-1-GUS

\section{$+\mathrm{SA}+\mathrm{CHX}$}

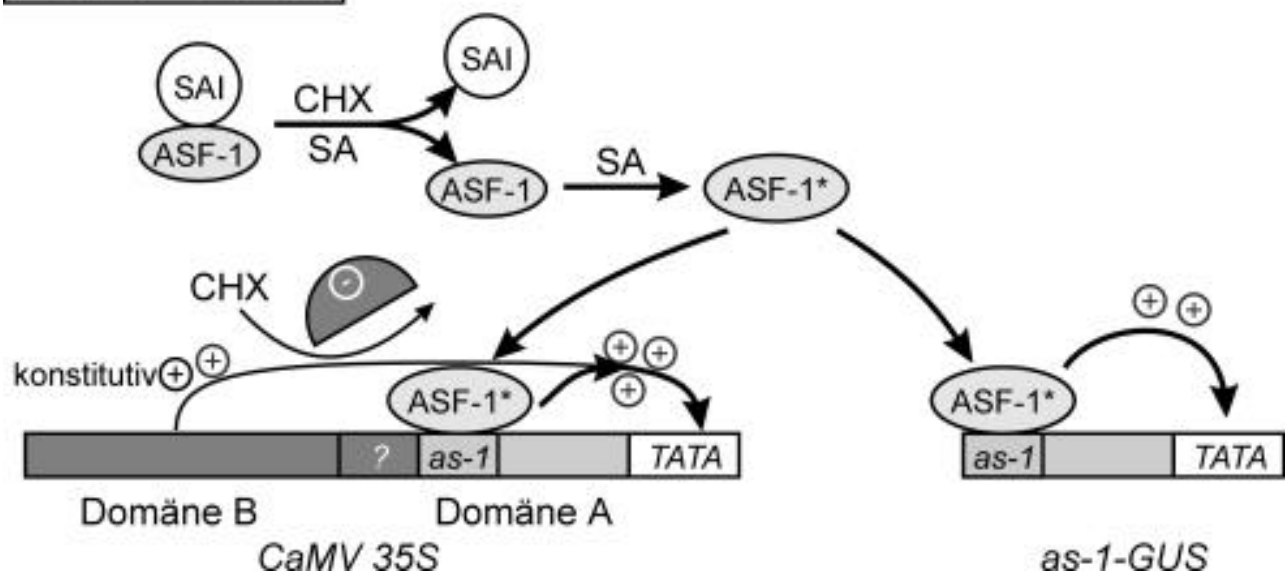

Abbildung 6-3: Modell der Bindungs- und Transaktivierungssituation an den Promotoren CaMV 35S und as-1-GUS. Legende: ? ist ein nicht identifiziertes cis-Element mit bindungsrepressorischer Funktion auf as-1. Halb gefüllt sind Ereignisse nach längerer CHX-Inkubation dargestellt. ASF-1* besteht am CaMV 35S Promotor vermutlich nur aus TGA2.1/TGA2.2-Heterodimeren. Weitere Erläuterungen sind den Abschnitten 6.2 und 6.3.2 zu entnehmen. 


\subsection{Die ENGRAILED-Silencerdomäne zeigt in Fusion mit TGA2.1 bzw. TGA2.2 keinen repressorischen Effekt auf die Expression von $\mathrm{Nt103}$}

Die Transkriptionsfaktoren TGA2.1 und TGA2.2 wurden neben der VP16Aktivierungsdomäne auch mit der Silencerdomäne von ENGRAILED aus D. melanogaster fusioniert. WERR konnte in bislang unveröffentlichten Experimenten zeigen, dass diese Domäne in Fusion mit Transkriptionsfaktoren, die die Entwicklung der Blüte in A. thaliana beeinflussen, repressorisch aktiv ist. Fusionsproteine aus der ENGRAILED-Silencerdomäne und TGA2.1 bzw. TGA2.2 führten, in transgenen Tabakpflanzen überexprimiert, nicht zur Repression von Zielgenen nach SA-Induktion (Abbildung 5-24). Vielmehr konnte für SNN 2.2ENGs \#3 eine leichte Steigerung der Transkription von Nt103 zu einem ungewöhnlich späten Zeitpunkt nach $7 \mathrm{~h}$ SA-Einwirkung beobachtet werden. Obwohl für ENGRAILED auch ein Transaktivierungspotential beschrieben ist (HEEMSKERK et al., 1991; SERRANO und MASCHAT, 1998), können die hier beobachteten Effekte nicht schlüssig erklärt werden, da das Maximum der Nt103-Expression zeitlich verzögert ist. Die Überexpression von 2.2ENGs in der Pflanze könnte zu pleiotropen Veränderungen geführt haben, die in einer Modifikation der Nt103-Transkription resultieren.

\subsection{Die SA-induzierte as-1-Aktivierung in Blättern und Suspensionszellen erfolgt in unterschiedlicher Weise}

Die in dieser Arbeit beschriebenen Analysen wie auch andere intensive Untersuchungen in der Arbeitsgruppe (KEGLER, unveröffentlicht) belegen, dass die Überexpression von TGA2.1 $\Delta$ N29 nach SA-Induktion in Blattgewebe zu einer deutlichen Steigerung der Expression von Nt103 führt, während ein weiteres Zielgen parA (TAKAHASHI et al., 1989) nur eine moderate Steigerung erfährt. Darüber hinaus konnte KEGLER zeigen, dass eine transdominante Suppressorvariante von TGA2.1, die nicht mehr in der Lage ist, an DNA zu binden, jedoch weiterhin Dimere mit anderen TGA-Faktoren bilden kann, in Blättern nur zu einer moderaten Unterdrückung der SA-induzierten Nt103- bzw. parA-Expression führt. Um mit Hilfe von pharmakologischen Untersuchungen den Einfluß von Inhibitoren auf die Signaltransduktionskette erfassen zu können, wurden Suspensionszelllinien von SNN wt und den vorhandenen transgenen Pflanzen SNN 2.1 $\triangle \mathrm{N} 29$ \#8 und SNN 2.1trD \#2 etabliert und bezüglich der SA-induzierten Transkription von Nt103 und parA charakterisiert. 
Beim Vergleich der Zielgenexpression in Zellkulturen zeigten sich deutliche Unterschiede zur Situation in Blättern (vgl. oben):

- Die SA-induzierte Expression von Nt103 war in Suspensionskulturen mit ca. $31 \%$ der Wildtyp-Expression moderat gedämpft (Abbildung 5-26, Angabe für $3 \mathrm{~h}-$ Wert).

- Die SA-induzierte parA-Expression wurde drastisch auf ca. $5 \%$ der WildtypExpression herabgesetzt (Abbildung 5-27, Angabe für $3 \mathrm{~h}$ - Wert).

In Suspensionszellen liegt also eindeutig ein anderer Regulationsmechanismus für diese Gene vor als in Blättern.

In EMSA-Analysen mit nativen Gesamtzellextrakten nach JUPIN und CHUA (1996) konnte zunächst konform zu den Erwartungen eine Reduktion der Bindeaktivität von SARP in SNN $2.1 \Delta$ N29 \#8 gegenüber Wildtyp-Extrakten nachgewiesen werden (Abbildung 5-30 und Abbildung 5-31a)). Immunoblot-Analysen zeigten jedoch, dass es in diesen Extrakten wahrscheinlich zu einer artifiziellen, kovalenten Verknüpfung der TGA-Faktoren TGA2.1 und TGA2.2 kommt (Abbildung 5-32). Deshalb wurden weitere Studien mit einem veränderten Protokoll nach KEGLER (FixProt, unveröffentlicht) durchgeführt. Diese Extrakte boten den Vorteil, dass die proteolytische Abspaltung des N-Terminus weitgehend unterdrückt war (Abbildung 5-33).

Bei der Untersuchung von FixProt-Extrakten aus für $2 \mathrm{~h}$ DMSO- bzw. SA-behandelten Wildtyp-Suspensionen im EMSA konnten folgende Beobachtungen gemacht werden (Abbildung 5-34, links):

- Nach SA-Behandlung kommt es zu einer deutlichen Bindungsreduktion von SARP am as-1-Element. SARP besteht in diesem Fall überwiegend aus TGA2.2-Homodimeren und zu einem geringen Teil aus TGA2.1/TGA2.2-Heterodimeren.

- Im dephosphorylierten Zustand (ohne den Phosphatase-Inhibitor NaF) kann keine effektive Bindung an das as-1-Element nachgewiesen werden.

Hier zeigt sich wiederum ein deutlicher Unterschied zur Situation in Blättern. Dort wurde eine SA-abhängige Bindungsverstärkung gezeigt, die jedoch ebenfalls durch Dephosphorylierung unterbunden werden konnte (JUPIN und CHUA, 1996; STANGE et al., 1997).

In Suspensionen erscheint ein Modell plausibel, nach dem es nach SA-Behandlung zur Bindungsreduktion von SARP an as-1 kommt. Die Transkriptionsaktivierung könnte durch einen anderen Faktor erfolgen, der in den hier gezeigten Experimenten im EMSA nicht nachzuweisen ist. Dabei ist $\mathrm{zu}$ berücksichtigen, dass in FixProt-Extrakten die 
Kernproteinfraktion stark unterrepräsentiert ist. Im dephosphorylierten Zustand (-NaF) ist die Bindung an as-1 inhibiert.

Führt man die gleichen Versuche mit FixProt-Extrakten aus SNN 2.1 dN29 \#8-Suspensionen durch (Abbildung 5-34, rechts), so ist folgende Situation zu beobachten:

- Es kommt zu einer konstitutiven starken Bindung an das as-1-Element. Ein Einfluß von SA auf die Bindung ist nicht nachzuweisen.

- Die Menge an TGA2.2-Homodimeren ist zugunsten des TGA2.1/TGA2.2Heterodimers reduziert.

- Es lassen sich keine nennenswerten Unterschiede zwischen NaF-behandelten und NaF-freien Zellextrakten erkennen. Im Gegensatz zum Wildtyp ist die Bindung nicht von der Phosphorylierung einer regulatorischen Komponente abhängig.

In das zuvor beschriebene Modell lassen sich diese Daten wie folgt integrieren:

In der transgenen Zelllinie SNN $2.1 \Delta \mathrm{N} 29$ \#8 kommt es nicht zur Ablösung des SARPKomplexes vom as-1-Element. Die SA-abhängige Bindungsreduktion greift nicht mehr, weshalb der transkriptionsaktivierende Faktor nicht wirksam werden kann. Dieses Phänomen lässt sich durch zwei alternative Annahmen erklären. Einerseits könnte es sein, dass das vorherrschend gebundene TGA2.1/TGA2.2-Heterodimer nicht von einem Inhibitor der Bindung erkannt wird, wodurch es zum Verbleib des Komplexes an der DNA kommt. Andererseits könnte durch die Überexpression von TGA2.1 $\Delta$ N29 ein Bindungsinhibitor austitriert werden, was ebenfalls in einem Verbleib der TGA-Faktoren an der DNA resultiert. Beide Möglichkeiten erklären die Unwirksamkeit des vermutlich über Dephosphorylierung wirkenden bindungsinhibierenden Mechanismus'.

Unterstïtzt wird dieses Modell einer phosphorylierungsabhängigen Bindungsregulation durch Ergebnisse aus Versuchen, in denen der Kinase-Inhibitor Quercetin appliziert wurde (Abbildung 5-36). In diesen Experimenten konnte gezeigt werden, dass sich die Verhinderung der Phosphorylierung sowohl in-vivo als auch in-vitro negativ auf die uninduzierte Bindung an das as-1-Element auswirkt.

Die beschriebenen Phosphorylierungsereignisse können entweder an der inhibitorischen Komponente oder direkt an den TGA-Faktoren stattfinden. Im Falle der letzteren Möglichkeit kann man durch Datenbankvergleiche potentielle Phosphorylierungsstellen ermitteln. Für die Vorhersage wurden die Aminosäuresequenzen von Proteinen mit hoher Homologie zu TGA2.1 und TGA2.2 mit Hilfe des Programms NetPhos 2.0 analysiert 
(http://www.cbs.dtu.dk/services/NetPhos/) und die Ergebnisse als Alignment in Abbildung 6-4 dargestellt. Potentielle Phosphorylierungsstellen mit einer Voraussagewahrscheinlichkeit über 0.5 für die Aminosäuren Serin, Threonin und Tyrosin wurden hervorgehoben. Besonders interessant für eine differenzielle Regulation von TGA2.1 und TGA2.2 sind potentielle Phosphorylierungsstellen, die nur in einem der beiden TGA-Faktoren anzutreffen sind.

Die Häufung von basischen Aminosäuren insbesondere in der DNA-Bindedomäne könnte zudem auf eine potentielle Interaktionsstelle für MAP-Kinasen hinweisen. Die Argininreste in der Aminosäuresequenz LRRL zu Beginn der basischen Domäne konnten von TANOUE et al.(2000) experimentell als essentiell für die Interaktion zwischen der MAP-Kinase ERK2 und der Phosphatase MKP3 aus Xenopus laevis nachgewiesen werden. Die Autoren machen generell ionische Wechselwirkungen zwischen gehäuft auftretenden basischen und sauren Aminosäureresten für diese Interaktionen verantwortlich. In TGA2.2 und verwandten Transkriptionsfaktoren fällt eine Häufung dieser Reste im Bereich der DNA-Bindedomäne auf.

Weiteren Aufschluss darüber, ob SARP oder ein assoziiertes Protein in seinem Phosphorylierungszustand modifiziert wird, könnten z. B. Immunopräzipitationsexperimente nach Inkubation mit radioaktiv markiertem Phosphat unter verschiedenen Bedingungen liefern. 
Nt TGA2 2 TaeHBP 1 b Nt TGA2. 1 ZMOBF 3.2 ZMOBF 3.1 AthHBP 1b Ath LEZI

Nt TGA 2.2 TaeHBP $1 \mathrm{~b}$ Nt TGA2 1 ZMOBF 3.2 ZMOBF 3.1 AthHBP 1 b Ath LEZI

NtTGA2.2
TaeHBP1b
NtTGA2.1
ZmOBF3.2
ZmOBF3.1
AthHBP1b
Ath LEZI

NtTGA2.2
TaeHBP1b
NtTGA2.1
ZmOBF3.2
ZmOBF3.1
AthHBP1b
Ath LEZI

Nt TGA2. 2 TaeHBP $1 \mathrm{~b}$ Nt TGA2. 1 ZMOBF 3.2 ZMOBF 3.1 AthHBP 1b Ath LEZI

NtTGA2.2
TaeHBP1b
NtTGA2.1
ZmOBF3.2
ZmOBF3.1
AthHBP1b
Ath LEZI

Nt TGA2. 2 TaeHBP $1 \mathrm{~b}$ Nt TGA2 . 1 ZMOBF 3.2 ZMOBF 3.1 AthHBP 1b Ath LEZI
$S$ TT $S$

MASKIGTAGN RSGTTGMPSF ISQIPVSNPM GTEANNTNTS RMSDFGVLEQ YLGFRIGDGA NVNRSPLFNMESRRGGSSA AAAEDAGGAM PSFGPTOHAI RADVNSMOPS RVTDFGALAO SAGFRIEDLA NLNANALFNL SS

71
$\mathbf{T}$

STATNP AVGF-----E VSGTINRTLA PSNTSLPTAT PRSQTMLLQS NLVSASGTHH ENWGESNM KPNSHTIDNS PLQFGNYGKS ISSHINTTEA TTAATRIDPQ LSAQQTGAQP ILVALPTGNM ENWGESAMF $S \quad T T$ TT 


\subsection{Ausblick}

Im Rahmen dieser Arbeit wurde mit Hilfe von Fusionsproteinen zwischen der VP16Aktivierungsdomäne und TGA2.1 bzw. TGA2.2 die Frage nach der in-vivoBindungsregulierung des as-1-bindenden Komplexes ASF-1 untersucht. Viele der vorgestellten Daten sprechen für eine induzierte Bindung der TGA-Faktoren nach SAInduktion. Letztendliche Gewissheit über diese Frage könnten Chromatin Immunopräzipitations-Experimente (CHIP) liefern, in denen die TGA-Faktoren mit der DNA quervernetzt, die entsprechenden Promotorabschnitte koimmunopräzipitiert und mittels PCR nachgewiesen werden.

Für das Verständnis der Regulationsmechanismen der as-1-vermittelten Genexpression erscheint weiterhin die Identifikation neuer Proteine wichtig, die mit ASF-1 / SARP interagieren. Durch Screening in geeigneten Hefe Hybrid-Systemen (One-Hybrid / TwoHybrid) könnten wichtige Regulatoren der ASF-1-Aktivität wie der Bindungsinhibitor SAI, ein Protein, das die Konversion von ASF-1 zu ASF-1* katalysiert und u. U. auch der späte Bindungsinhibitor SIBI isoliert werden.

Die hier gelieferten Modellvorstellungen bieten die Möglichkeit, auf diese Weise neu identifizierte Proteine gezielt in funktionellen Studien zu untersuchen. 


\section{Literatur}

Benfey, P. N., Ren, L., ChuA, N. H. (1989) The CaMV 35S enhancer contains at least two domains which can confer different developmental and tissue-specific expression patterns. Embo J 8: 2195-2202

Benfey, P. N., Ren, L., ChuA, N. H. (1990) Tissue-specific expression from CaMV 35S enhancer subdomains in early stages of plant development. The-EMBO-journal 9: 167784

Boot, K. J. M., VAn Der ZaAl, B. J., Velterop, J., Quint, A., Mennes, A. M., HooykaAs, P. J. J., LiBBENGA, K. R. (1993) Further characterization of expression of auxin-induced genes in tobacco (Nicotiana tabacum) cell-suspension cultures. Plant Physiol 102: 513520

Bouchez, D., Tokuhisa, J. G., Llewellyn, D. J., DenNis, E. S., Ellis, J. G. (1989) The ocs-element is a component of the promoters of several T-DNA and plant viral genes. The-EMBO-journal 8: 4197-204

BRADFORD, M. M. (1976) A rapid and sensitive method for the quantitation of microgram quantities of protein utilizing the principle of protein-dye binding. Anal Biochem 72: 24854

Bullock, W. O., FernandeZ, J. M., ShORT, J. M. (1987) XL1-Blue: a high efficiency plasmid transforming recA-Escherichia coli strain with beta galactosidase selection. Bio Techniques 5: 376-379

CAO, H., Bowling, S. A., Gordon, A. S., DONG, X. (1994) Characterization of an Arabidopsis mutant that is nonresponsive to inducers of systemic acquired resistance. Plant Cell 6: 1583-1592

CaO, H., Glazebrook, J., Clarke, J. D., Volko, S., Dong, X. (1997) The Arabidopsis NPR1 gene that controls systemic acquired resistance encodes a novel protein containing ankyrin repeats. Cell- 88: 57-63

ChEn, W., ChaO, G., Singh, K. B. (1996) The promoter of a $\mathrm{H}_{2} \mathrm{O}_{2}$-inducible, Arabidopsis glutathione S-transferase gene contains closely linked OBF- and OBP1-binding sites. Plant J 10: 955-66

CHEN, Z., KLessig, D. F. (1991) Identification of a soluble salicylic acid-binding protein that may function in signal transduction in the plant disease-resistance response. Proc Natl Acad Sci U S A 88: 8179-8183

Chuang, C. F., Running, M. P., Williams, R. W., Meyerowitz, E. M. (1999) The PERIANTHIA gene encodes a bZIP protein involved in the determination of floral organ number in Arabidopsis thaliana. Genes Dev 13: 334-44

Conrath, U., Chen, Z., Ricigliano, J. W., Klessig, D. (1995) Two inducers of plant defense responses, 2,6-dichloroisonicotinic acid and salicylic acid, inhibit catalase activity in tobacco. Proc Natl Acad Sci U S A 92: 7143-7147 
ConRath, U., Silva, H., Klessig, D. (1997) Protein dephosphorylation mediates salicylic acid-induced expression of PR-1 genes in tobacco. Plant J 11: 747-757

Cutt, J. R., DiXon, D. C., CARr, J. P., Klessig, D. F. (1988) Isolation and nucleotide sequence of cDNA clones for the pathogenesis-related proteins PR1a, PR1b and PR1c of Nicotiana tabacum cv. Xanthi nc induced by TMV infection. Nucleic-acids-research 16: 9861

CzEKO, A. (2000) Expression von TGA2.2-VP16 und TGA2.2-ENGRAILED in transgenen Tabakpflanzen: Analyse der Expression von TGA2.2-gesteuerten Zielgenen. Examensarbeit. Georg-August-Universität Göttingen, Göttingen

DANGl, J. L., DieTrich, R. A., RichBerg, M. H. (1996) Death don't have no mercy: cell death programs in plant-microbe interactions. Plant Cell 8: 1793-1807

Deblaere, R., Bytebier, B., De Greve, H., Deboeck, F., Schell, J., Van Montagu, M., LEEMANS, J. (1985) Efficient octopine Ti-plasmid derived for Agrobacterium-mediated gene transfer. Nucleic Acids Res 13: 4777-4788

Delaney, T. P., Uknes, S., Vernooij, B., Friedrich, L., Weymann, K., Negrotto, D., GafFNey, T., Gut-Rella, M., Kessmann, H., WARD, E., Ryals, J. (1994) A central role of salicylic acid in plant disease resistance. Science 266: 1247-1250

Despres, C., Delong, C., Glaze, S., Liu, E., Fobert, P. R. (2000) The Arabidopsis NPR1/NIM1 protein enhances the DNA binding activity of a subgroup of the TGA family of bZIP transcription factors [see comments]. Plant Cell 12: 279-90

DONG, X. (1998) SA, JA, ethylene, and disease resistance in plants. Curr Opin Plant Biol 1: 316-23

Dower, W., Miller, J., Ragsdale, C. (1988) High efficiency transformation of E. coli by high voltage electroporation. Nucleic Acids Res 16: 6127-45

Dröge-Laser, W., Kaiser, A., Lindsay, W. P., Halkier, B. A., LOAKe, G. J., Doerner, P., DIXON, R. A., LAMB, C. (1997) Rapid stimulation of a soybean protein-serine kinase that phosphorylates a novel bZIP DNA-binding protein, G/HBF-1, during the induction of early transcription-dependent defenses. Embo J 16: 726-38

Droog, F., Spek, A., van der Kooy, A., De Ruyter, A., Hoge, H., Libbenga, K., HOOYKAAS, P., VAN DER ZAAL, B. (1995) Promoter analysis of the auxin-regulated tobacco glutathione S-transferase genes Nt103-1 and Nt103-35. Plant Mol Biol 29: 413-29

Droog, F. N., HooykaAs, P. J., LibBenga, K. R., VAN DeR ZaAl, E. J. (1993) Proteins encoded by an auxin-regulated gene family of tobacco share limited but significant homology with glutathione S-transferases and one member indeed shows in vitro GST activity. Plant Mol Biol 21: 965-72

Du, H., KLESSIG, D. F. (1997) Identification of a soluble, high-affinity salicylic acid-binding protein in tobacco. Plant Physiol 113: 1319-1327 
DURNER, J., KLESSIG, D. F. (1996) Salicylic acid is a modulator of tobacco and mammalian catalases. The-Journal-of-biological-chemistry 271: 28492-501

ELION, E. A. (1998) Routing MAP Kinase cascades. Science 281: 1625-1627

Ellis, J. G., Tokuhisa, J. G., Llewellyn, D. J., Bouchez, D., Singh, K., Dennis, E. S., PEACOCK, W. J. (1993) Does the ocs-element occur as a functional component of the promoters of plant genes? Plant $J$ 4: 433-43

FEINBERG, A., VogELSTEIN, B. (1983) A technique for radiolabeling DNA restriction endonuclease fragments to. Anal Biochem 132: 6-13

Fourney, R., Miyakoshi, J., Day III, R. S., PAterson, M. C. (1988) Northern Blotting: Efficient RNA staining and transfer. Focus 10: 5-7

Fromm, H., KatagiRi, F., ChuA, N. H. (1989) An octopine synthase enhancer element directs tissue-specific expression and binds ASF-1, a factor from tobacco nuclear extracts. Plant Cell 1: 977-84

Fromm, H., KatagiRi, F., ChUA, N. H. (1991) The tobacco transcription activator TGA1a binds to a sequence in the 5' upstream region of a gene encoding a TGAla-related protein. Mol Gen Genet 229: 181-8

Gaffney, T., Friedrich, L., VernooiJ, B., Negrotto, D., Nye, G., Uknes, S., Ward, E., KeSSMANN, H., RYALS, J. (1993) Requirement of salicylic acid for the induction of systemic acquired resistance. Science 261: 754-756

GAtZ, C., KAISER, A., WendenbuRG, R. (1991) Regulation of a modified CaMV 35S promoter by the Tn10-encoded Tet repressor in transgenic tobacco. Mol Gen Genet 227: 229-37

Gatz, C., FrohBerG, C., WendenbURG, R. (1992) Stringent repression and homogeneous de-repression by tetracycline of a modified CaMV 35S promoter in intact transgenic tobacco plants. Plant J 2: 397-404

Görlach, J., Volrath, S., Knauf Beiter, G., Hengy, G., Beckhove, U., Kogel, K. H., OOstendorP, M., Staub, T., WARD, E., Kessmann, H., Ryals, J. (1996) Benzothiadiazole, a novel class of inducers of systemic acquired resistance, activates gene expression and disease resistance in wheat. Plant Cell 8: 629-43

HAMMOND-KOSACK, K. E., JONES, J. D. G. (1996) Resistance gene-dependent plant defense response. Plant Cell 8: 1773-1791

HANAHAn, D. (1983) Studies on transformation of Escherichia coli with plasmids. J Mol Biol 166: $557-80$

HeEmskerk, J., Dinardo, S., Kostriken, R., O'FaArrell, P. H. (1991) Multiple modes of Engrailed regulation in the progression towards cell fate determination. Nature 352: 404410 
Horsch, R. B., Fry, J. E., Hoffmann, D., Eichholtz, D., Rogers, S. G., Fraley, R. T. (1985) A simple and general method for transferring genes into plants. Science 227: 12291231

Horvath, D. M., ChuA, N. H. (1996) Identification of an immediate-early salicylic acidinducible tobacco gene and characterization of induction by other compounds. Plant Mol Biol 31: 1061-72

Horvath, D. M., Huang, D. J., ChuA, N. H. (1998) Four classes of salicylate-induced tobacco genes. Mol Plant Microbe Interact 11: 895-905

InOUE, H., Nojima, H., OKAYAMA, H. (1990) High efficiency transformation of Escherichia coli with plasmids. Gene 96: 23-8

ISH-Horrowicz, D., BURKe, J. F. (1981) Rapid and efficient cosmid cloning. Nucleic Acids Res 9: 2989-2998

Johnson, C., Glover, G., ARIAS, J. (2001) Regulation of DNA Binding and trans-Activation by a Xenobiotic Stress-activated Plant Transcription Factor. J Biol Chem 276: 172-178

JuPIN, I., ChUA, N. H. (1996) Activation of the CaMV as-1 cis-element by salicylic acid: differential DNA-binding of a factor related to TGA1a. Embo J 15: 5679-5689

KatagiRi, F., LAM, E., ChUA, N. H. (1989) Two tobacco DNA-binding proteins with homology to the nuclear factor CREB. Nature 340: 727-30

KAtagiRI, F., SeIPEl, K., ChUA, N. H. (1992) Identification of a novel dimer stabilization region in a plant bZIP transcription activator. Mol Cell Biol 12: 4809-16

Kawata, T., Imada, T., Shiraishi, H., OKada, K., Shimura, Y., IVABUChI, M. (1992) A DNA clone encoding an HBP-1b homologue in Arabidopsis thaliana. Nucleic Acids Res 20: $1141-1147$

Kinkema, M., WeIHUA, F., DONG, X. (2000) Nuclear localization of NPR1 is required for activation of $P R$ gene expression. Plant Cell 12: 2339-2350

Klessig, D. F., Malamy, J. (1994) The salicylic acid signal in plants. Plant-molecularbiology 26: 1439-58

KÖSTER-TÖPFer, M., Frommer, W. B., ROChA SOSA, M., Rosahl, S., Schell, J., WILLMITZER, L. (1989) A class II patatin promoter is under developmental control in both transgenic potato and tobacco plants. Molecular-and-general-genetics 219: 390-6

KOZAK, M. (1989) The scanning model for translation: an update. The-Journal-of-cell-biology 108: $229-41$

KRAWCZYK, S. (1999) Charakterisierung der DNA-Bindungseigenschaften des pflanzlichen bZIP-Transkriptionsfaktors TGA2.1 aus Nicotiana tabacum. Diplomarbeit. GeorgAugust-Universität Göttingen, Göttingen 
KumAR, D., Klessig, D. F. (2000) Differential induction of tobacco MAP kinases by the defense signals nitric oxide, salicylic acid, ethylene, and jasmonic acid. MPMI 13: 347351

KYHSE-ANDERSEN, J. (1984) Electroboltting af multiple gels: a simple appatatus without tank for rapid transfer of proteins from polyacrylamide to nitrocellulose. J. Biochem. Biophys. Methods 10: 203-209

LAEMMLI, U. K. (1970) Cleavage of structural proteins during the assembly of the head of bacteriophage T4. Nature 227: 680-685

LAM, E., Katagiri, F., ChUA, N. H. (1990) Plant nuclear factor ASF-1 binds to an essential region of the nopaline synthase promoter. J Biol Chem 265: 9909-13

LAM, E., LAM, Y. K. (1995) Binding site requirements and differential representation of TGF factors in nuclear ASF-1 activity. Nucleic Acids Res 23: 3778-85

LANDSchulz, W. H., Johnson, P. F., MCKNight, S. L. (1988) The leucine zipper: a hypothetical structure common to a new class of DNA binding proteins. Science- 240: 1759-64

Lawton, K. A., Friedrich, L., Hunt, M., Weymann, K., Delaney, T., Kessmann, H., StAub, T., RYALS, J. (1996) Benzothiadiazole induces disease resistance in Arabidopsis by activation of the systemic acquired resistance signal transduction pathway. Plant J10: $71-82$

Lebel, E., Heifetz, P., ThORne, L., Uknes, S., Ryals, J., WARd, E. (1998) Functional analysis of regulatory sequences controlling PR-1 gene expression in Arabidopsis. The Plant Journal 16: 223-233

MAlamy, J., CARR, J., Klessig, D. F., RAskin, I. (1990) Salicylic acid: a likely endogenous signal in the resistance response of tobacco to viral infection. Science 250: 1002-1004

Malamy, J., Hennig, J., Klessig, D. F. (1992) Temperature dependent induction of salicylic acid and its conjugates during the resistance response to tobacco mosaic virus infection. Plant Cell 4

Maleck, K., Levine, A., Eulgem, T., Morgan, A., Schmid, J., Lawton, K. A., Dangl, J. L., DiETRICH, R. A. (2000) The transcriptome of arabidopsis thaliana during systemic acquired resistance. Nat Genet 26: 403-10

MarchuK, D., Drumm, M., Saulino, A., Collins, F. S. (1990) Contruction of T-vectors, a rapid and general system for direct cloning of unmodified PCR products. Nucleic Acids Res 19: 1154

MiAO, Z. H., LIU, X., LAM, E. (1994) TGA3 is a distinct member of the TGA family of bZIP transcription factors in Arabidopsis thaliana. Plant Mol Biol 25: 1-11

MiAO, Z. H., LAM, E. (1995) Construction of a trans-dominant inhibitor for members of the TGA family of transcription factors conserved in higher plants. Plant J 7: 887-96 
Mizoguchi, T., Hayashida, N., Yamaguchi-ShinozaKi, K., Kamada, H., ShinOzaKi, K. (1995) Two genes that encode ribosomal protein S6-kinase homologs are induced by cold or salinity stress in Arabidopsis thaliana. Febs Letters 358: 199-204

Mizoguchi, T., IRIE, K., Hirayama, T., Hayashida, N., YAmaguchi-ShinOZaKi, K., MAtsumota, K., ShinOZAKI, K. (1996) A gene encoding a mitogen-activated protein kinase kinase kinase is induced simultanously with genes for a mitogen-activated protein kinase and an S6 ribosomal protein kinase by touch, cold, and water stress in Arabidopsis thaliana. Proc Natl Acad Sci U S A 93: 765-769

Mullis, K. B., FAlOONA, F. A. (1987) Specific synthesis of DNA in vitro via a polymerasecatalyzed chain reaction. Methods Enzymol. 155: 335-350

Neuhaus, G., Neuhaus-Url, G., Katagiri, F., Seipel, K., Chua, N. H. (1994) Tissuespecific expression of as-1 in transgenic tobacco. Plant Cell 6: 827-834

NigGEWEG, R., GATZ, C. (1997) Isolation of TGA2.1 (Accession No. U90214), a member of a new subclass of the TGA-family of bZIP-transcription-factors in Nicotiana tabacum. Plant Physiol 113: 1464

NIGGEWEG, R. (1999) Salizylsäure- und Auxin-induzierte Genexpression in Nicotiana tabacum: Funktionelle Bedeutung der TGA-Faktoren der Subklasse II. Doktorarbeit. Universität Bielefeld, Bielefeld

Niggeweg, R., Thurow, C., Kegler, C., GAtZ, C. (2000a) Tobacco transcription factor TGA2.2 is the main component of as-1-binding factor ASF-1 and is involved in salicylic acid- and auxin-inducible expression of as-1-containing target promoters. $J$ Biol Chem 275: 19897-905

Niggeweg, R., Thurow, C., Weigel, R., Pfitzner, U., Gatz, C. (2000b) Tobacco TGA factors differ with respect to interaction with NPR1, activation potential and DNA-binding properties. Plant Mol Biol 42: 775-88

Odell, J. T., NAGy, F., ChUA, N. H. (1985) Identification of DNA sequences required for activity of the cauliflower mosaic virus $35 \mathrm{~S}$ promoter. Nature 313: 810-2

OLMSTED, J. B. (1981) Affinity purification of antibodies from diazotized paper blots of heterogeneous protein samples. J Biol Chem 256: 11955-11957

Pascuzzi, P., Hamilton, D., Bodily, K., Arias, J. (1998) Auxin-induced stress potentiates trans-activation by a conserved plant basic/leucine-zipper factor. J Biol Chem 273: 266317

Perlman, D., Chikarmane, H., Halvorson, H. (1987) Improved resolution of DNA fragments in polysaccharide-supplemented. Anal Biochem 163: 247-54

Peterson, M., Brodersen, P., Naested, H., Andreasson, E., Lindhart, U., Johansen, B., Nielsen, H. B., Lacy, M., Austin, M. J., Parker, J. E., Sharma, S. B., Klessig, D. F., Martienssen, R., Mattsson, O., Jensen, A. B., Mundy, J. (2000) Arabidopsis MAP Kinase 4 negatively regulates systemic acquired resistance. Cell 103: 1111-1120 
PoOle, S. J., Kauvar, L. M., Drees, B., Kornberg, T. (1985) The engrailed locus of Drosophila: structural analysis of an embryonic transcript. Cell 40: 37-43

Prat, S., Willmitzer, L., SÁncheZ-Serrano, J. J. (1989) Nuclear proteins binding to a cauliflower mosaic virus 35S truncated promoter. Mol. Gen. Genet. 217: 209-214

Qin, X. F., Holuigue, L., Horvath, D. M., ChUA, N. H. (1994) Immediate early transcription activation by salicylic acid via the cauliflower mosaic virus as-1 element. Plant Cell 6: 863-74

RIEPING, M., FrITZ, M., Prat, S., GATZ, C. (1994) A dominant negative mutant of PG13 suppresses transcription from a cauliflower mosaic virus $35 \mathrm{~S}$ truncated promoter in transgenic tobacco plants. Plant Cell 6: 1087-98

Romeis, T., Piedras, P., Zhang, S., Klessig, D. F., HiRT, H., Jones, J. D. (1999) Rapid Avr9- and Cf-9 -dependent activation of MAP kinases in tobacco cell cultures and leaves: convergence of resistance gene, elicitor, wound, and salicylate responses. The-Plant-cell 11: $273-87$

Ross, A. F. (1961) Systemic acquired resistance induced by localized virus infections in plants. Virology 14: 340-358

Roxas, V. P., Lodhi, S. A., Garrett, D. K, Mahan, J. R., Allen, R. D. (2000) Stress tolerance in transgenic tobacco seedlings that overexpress glutathione $\mathrm{S}$ transferase/glutathione peroxidase. Plant Cell Physiol 4: 1229-1234

SaKaI, T., TAKahashi, Y., NAgata, T. (1998) The identification of DNA binding factors specific for as-1-like sequences in auxin-responsive regions of parA, parB and parC. Plant Cell Physiol 39: 731-9

SAMBROOK, J., Fritsch, E. F., MANiATIS, T. (1989) Molecular cloning: A laboratory manual. Cold Spring Harbor Laboratory Press, Cold Spring Harbor, New York, USA

Schenk, P. M., KaZAn, K., Wilson, I., Anderson, J. P., Richmond, T., Somerville, S. C., MANNERS, J. M. (2000) Coordinated plant defense responses in arabidopsis revealed by microarray analysis [In Process Citation]. Proc Natl Acad Sci U S A 97: 11655-60

SCHINDleR, U., BeckMAnN, H., CASHMORE, A. R. (1992) TGA1 and G-box binding factors: two distinct classes of Arabidopsis leucine zipper proteins compete for the G-box-like element TGACGTGG. Plant Cell 4: 1309-1319

SERRANO, N., MASCHAT, F. (1998) Molecular mechanism of polyhomeotic activation by Engrailed. Embo J 17: 3704-3713

ShaH, J., Kachroo, P., Klessig, D. F. (1999) The Arabidopsis ssi1 mutation restores pathogenesis-related gene expression in npr1 plants and renders defensin gene expression salicylic acid dependent. Plant Cell 11: 191-206

Stange, C., RamireZ, I., GomeZ, I., Jordana, X., Holuigue, L. (1997) Phosphorylation of nuclear proteins directs binding to salicylic acid-responsive elements. Plant J 11: 1315-24 
STRATHMANN, A. (1999) Identifizierung von Protein-Interaktionspartnern des bZIPTranskriptionsfaktors G/HBF-1 mit Hilfe des Hefe-"Two-Hybrid"-Systems. Diplomarbeit. Georg-August-Universität Göttingen, Göttingen

Strompen, G., Gruner, R., Pfitzner, U. M. (1998) An as-1-like motif controls the level of expression of the gene for the pathogenesis-related protein 1a from tobacco. Plantmolecular-biology 37: 871-83

Takahashi, Y., Kuroda, H., Tanaka, T., Machida, Y., Takebe, I., Nagata, T. (1989) Isolation of an auxin-regulated gene cDNA expressed during the transition from $\mathrm{G} 0$ to $\mathrm{S}$ phase in tobacco mesophyll protoplasts. Proc Natl Acad Sci U S A 86: 9279-83

TAKAhASHI, Y., NiwA, Y., MaChIDA, Y., NAGATA, T. (1990) Location of the cis-acting auxin-responsive region in the promoter of the par gene from tobacco mesophyll protoplasts. Proc Natl Acad Sci U S A 87: 8013-6

Takahashi, Y., Hasezawa, S., Kusaba, M., Nagata, T. (1995a) Expression of the auxinregulated parA gene in transgenic tobacco and nuclear localization of its gene products. Planta 196: 111-7

TAKAHASHI, Y., SAKAI, T., IshidA, S., NAGATA, T. (1995b) Identification of auxin-responsive elements of parB and their expression in apices of shoot and root. Proc Natl Acad Sci U S A 92: 6359-63

Tanoue, T., Adachi, M., Moriguchi, T., NishidA, E. (2000) A conserved docking motiv in MAP kinases common to substrates, activators and regulators. Nature Cell Biology 2: $110-116$

Uknes, S., Dincher, S., Friedrich, L., Negrotto, D., Williams, S., Thompson Taylor, H., POTTER, S., WARD, E., RYALS, J. (1993) Regulation of pathogenesis-related protein-1a gene expression in tobacco. Plant Cell 5: 159-69

Ulmasov, T., Hagen, G., GullfoYle, T. (1994) The ocs element in the soybean GH2/4 promoter is activated by both active and inactive auxin and salicylic acid analogues. Plant Mol Biol 26: 1055-64

van der ZaAl, B. J., Droog, F. N., Pieterse, F. J., HooykaAs, P. J. (1996) Auxin-sensitive elements from promoters of tobacco GST genes and a consensus as-1-like element differ only in relative strength. Plant Physiol 110: 79-88

VAn der ZaAl, E. J., Memelink, J., Mennes, A. M., Quint, A., LibBenga, K. R. (1987) Auxin-induced mRNA species in tobacco cell cultures. Plant Mol Biol 10: 145-157

van der ZaAl, E. J., Droog, F. N., Boot, C. J., Hensgens, L. A., Hoge, J. H., SCHILPEROORT, R. A., LiBBENGA, K. R. (1991) Promoters of auxin-induced genes from tobacco can lead to auxin-inducible and root tip-specific expression. Plant Mol Biol 16: 983-98

Vinson, C. R., Sigler, P. B., MCKNIGHT, S. L. (1989) Scissors grip model for DNA recognition by a family of zipper proteins. Science 246: 911-916 
Weinmann, P., Gossen, M., Hillen, W., Bujard, H., Gatz, C. (1994) A chimeric transactivator allows tetracycline-responsive gene expression in whole plants. Plant $J$ 5: $559-69$

Wendehenne, D., Durner, J., ChEN, Z., Klessig, D. (1998) Benzothiadiazole, an inducer of plant defenses, inhibits catalase and ascorbate peroxidase. Phytochemistry 47: 651-657

WeSSEL, D., FlüGGE, U. I. (1984) A method for the quantitative recovery of protein in dilute solution in the presence of detergents and lipids. Anal Biochem 138: 141-3

Xiang, C., MiaO, Z. H., LAM, E. (1996) Coordinated activation of as-1-type elements and a tobacco glutathione S-transferase gene by auxins, salicylic acid, methyl-jasmonate and hydrogen peroxide. Plant Mol Biol 32: 415-26

XIANG, C., MiAO, Z., LAM, E. (1997) DNA-binding properties, genomic organization and expression pattern of TGA6, a new member of the TGA family of bZIP transcription factors in Arabidopsis thaliana. Plant Mol Biol 34: 403-15

YANISCH-PERRON, C., VIEIRA, J., MESSING, J. (1985) Improved M13 phage cloning vectors and host strains: nucleotide sequences of the M13mp 18 and pUC19 vectors. Gene 33: 103-119

ZHANG, B., Foley, R. C., Singh, K. B. (1993) Isolation and characterization of two related Arabidopsis ocs-element bZIP binding proteins. Plant $J$ 4: 711-6

ZHANG, B., SINGH, K. B. (1994) ocs element promoter sequences are activated by auxin and salicylic acid in Arabidopsis. Proc Natl Acad Sci U S A 91: 2507-2511

Zhang, S., Klessig, D. F. (1997) Salicylic acid activates a 48 kD MAP kinase in tobacco. Plant Cell 9: 809-824

ZHANG, S., DU, H., KLESSIG, D. F. (1998) Activation of the tobacco SIP kinase by both a cell wall-derived carbohydrate elicitor and purified proteinaceous elicitins from Phytophthora spp. Plant Cell 10: 435-50

ZHANG, S., KLESSIG, D. F. (1998) The tobacco wounding-activated mitogen-activated protein kinase is encoded by SIPK. Proc Natl Acad Sci U S A 95: 7225-7230

Zhang, Y., FAn, W., KinKeMA, M., LI, X., DONG, X. (1999) Interaction of NPR1 with basic leucine zipper protein transcription factors that bind sequences required for salicylic acid induction of the PR-1 gene. Proc Natl Acad Sci U S A 96: 6523-8

Zhou, J. M., Trifa, Y., Silva, H., Pontier, D., Lam, E., Shah, J., Klessig, D. F. (2000) NPR1 differentially interacts with members of the TGA/OBF family of transcription factors that bind an element of the PR-1 gene required for induction by salicylic acid. Mol Plant Microbe Interact 13: 191-202 


\section{Anhang}

\subsection{Abkürzungen}

\section{2,4-D \\ 2.1 \\ 2.2 \\ ${ }^{32} \mathrm{P}$ \\ $35 \mathrm{~S}$ \\ ${ }^{35} \mathrm{~S}$ \\ 6-BAP}

A. tumefaciens

Amp $^{\mathrm{r}}$

APS

AS

as -1

as-103

ASF-1

ATP

bp

BPB

BSA

bZIP

bzw.

ca.

CaMV

cDNA

CHX

C-Terminus / terminal

CTP

cv.

D. melanogaster

dATP

dCTP

ddT

DEPC

dGTP

DMSO

DNA

DNase

dNTPs

ds

DTT

dTTP

$\mathrm{E}$

E. coli

EDTA

EMSA

ENG
2,4-Dichlorphenoxyessigsäure

TGA2.1 aus $N$. tabacum

TGA2.2 aus $N$. tabacum

Phosphorisotop der relativen Masse 32

35S Promotor aus Cauliflower Mosaic Virus

Schwefelisotop der relativen Masse 35

6-Benzylaminopurin

Agrobacterium tumefaciens

Ampicillin-Resistenz

Ammoniumpersulfat

Aminosäure(n)

Activating sequence 1

as-1-ähnliches Element des Nt103-Promotors aus N. tabacum

Activating sequence factor 1

Adenosintriphosphat

Basenpaar(e)

Bromphenolblau

Rinderserumalbumin (bovine serum albumine)

basische Region / Leucin-Zipper-Domäne

beziehungsweise

circa

Cauliflower Mosaic Virus (Blumenkohlmosaikvirus)

komplementäre Desoxyribonucleinsäure

Cycloheximid

Carboxy-Terminus / terminal

Cytidintriphosphat

Kultivar

Drosophila melanogaster

Desoxyadenosintriphosphat

Desoxycytidintriphosphat

Didesoxythymin

Diethylpyrocarbonat

Desoxyguanosintriphosphat

Dimethylsulfoxid

Desoxyribonucleinsäure

Desoxyribonuclease

Desoxyribonucleotidtriphosphate

Double stranded (doppelsträngig)

Dithiothreitol

Desoxythymidintriphosphat

Extinktion

Escherichia coli

Ethylenediamin-N,N,N',N'-tetraessigsäure

Electromobility shift assay

ENGRAILED-Silencerdomäne aus D. melanogaster 


\begin{tabular}{|c|c|}
\hline et al. & et alii (und andere) \\
\hline $\mathrm{EtBr}$ & Ethidiumbromid \\
\hline $\mathrm{EtOH}$ & Ethanol \\
\hline $\mathrm{g}$ & Erdbeschleunigung \\
\hline GST & Glutathion $S$-Transferase \\
\hline GTP & Guanosintriphosphat \\
\hline GUS & $\beta$-Glucuronidase \\
\hline HEC & Hydroxyethyl-Cellulose \\
\hline HEPES & N-[2-Hydroxyethyl]-pperazin-N''-[2-Ethansulfonsäure] \\
\hline HR & Hypersensitive response \\
\hline HSP & Heringsperma-DNA \\
\hline INA & 2,6-Dichloroisonicotinsäure \\
\hline IPTG & Isopropyl- $\beta$-D-thiogalactopyranosid \\
\hline JA & Jasmonic acid (Jasmonsäure) \\
\hline $\mathrm{Kam}^{\mathrm{r}}$ & Kanamycin-Resistenz \\
\hline $\mathrm{kb}$ & kilo Basenpaare \\
\hline $\mathrm{LB}$ & Luria Bertani \\
\hline MAP & Mitogen activated protein \\
\hline mcs & Multiple cloning site \\
\hline MOPS & 3-N-Morpholino-Propansulfonsäure \\
\hline mRNA & messenger RNA \\
\hline N. tabacum & Nicotina tabacum \\
\hline NAA & $\alpha$-Naphthalinessigsäure \\
\hline NPR1 & Nonexpresser of $P R$ genes 1 \\
\hline nt & Nucleotid(e) \\
\hline N-Terminus / terminal & Amino-Terminus / terminal \\
\hline $\mathrm{pA}$ & Polyadenylierungssignal \\
\hline PAA & Polyacrylamid \\
\hline pas-a & as-1-ähnliches Element aus parA-Promotor aus $N$. tabacum \\
\hline PCR & Polymerase chain reaction (Polymerase-Kettenreaktion) \\
\hline PEG & Polyethylenglycol \\
\hline $\mathrm{pH}$ & negativ dekadischer Logarithmus der Protonenkonzentration \\
\hline PMSF & Phenylmethylsulfonylfluoride \\
\hline PR & Pathogenesis related \\
\hline RNA & Ribonucleinsäure \\
\hline RNase & Ribonuclease \\
\hline ROS & Reactive oxygen species (Reaktive Sauerstoffspezies) \\
\hline rpm & Rounds per minute (Umdrehungen pro Minute) \\
\hline RT & Raumtemperatur \\
\hline s. & siehe \\
\hline SA & Salicylsäure \\
\hline $\operatorname{SABP}(2)$ & Salicylic acid binding protein(2) \\
\hline SAI & Salicylic acid inhibitor \\
\hline SAR & Systemic acquired resistance \\
\hline SARP & Salicylic acid response protein \\
\hline SDS & Natriumdodecylsulfat \\
\hline SDS-PAGE & SDS-Polyacrylamidgelelektrophorese \\
\hline sec & Sekunden \\
\hline SIPK & Salicylic acid induced protein kinase \\
\hline SNN & Samsun NN, Tabakkultivar \\
\hline SSC & Standard Saline Citrat Puffer \\
\hline
\end{tabular}


Taq

TBE

Tc

TE

TEMED

TetR

$\mathrm{T}_{\mathrm{m}}$

TMV

Tris

U

u. a.

UTR

UV

v/v

Vol.

VP16

$\mathrm{w} / \mathrm{v}$

wt

X-Gal

z. B.

ZIP

$\alpha$

$\lambda$
Thermus aquaticus

Tris-Borat-EDTA-Puffer

Tetracyclin

Tris-EDTA-Puffer

$\mathrm{N}, \mathrm{N}, \mathrm{N}^{\prime}, \mathrm{N}^{\prime}$ - Tetramethylethylendiamin

Tetracyclin Repressor von $\operatorname{Tn} 10$

Schmelztemperatur

Tabak Mosaic Virus

Tris-(hydroxymethyl-) aminomethan

definierte Einheit der Enzymaktivität (unit)

unter anderem

untranslatierte Region

Ultraviolettes Licht

Volume per volume (Volumenprozent)

Volumen

Virales Protein 16 aus Herpes simplex oder dessen Aktivierungsdomäne

weight per volume (Gewichtsprozent)

Wildtyp

5-Brom-4-chlor-3-indolyl- $\beta$-D-galactopyranosid

zum Beispiel

Leucin-Zipper-Domäne

Antiserum

Bakteriophage Lambda 


\subsection{Sequenzen verwendeter Nucleinsäuren}

Im folgenden sind Sequenzen und Sequenzübergänge wichtiger verwendeter bzw. hergestellter Nucleinsäuren mit für diese Arbeit und zur Orientierung relevanten Restriktionsschnittstellen aufgeführt.

\subsection{1 pSK-VP16 (NIGGEWEG, unveröffentlicht)}

Restsequenz: pSK

$\begin{array}{llllllllll}\text { Asp718 } & \text { Ppu10I XbaI } & \text { M } & \text { T } & \text { K } & \text { N } & \text { N } & \text { Y } & \text { G }\end{array}$

1 GGTACCTCGC GAATGCATCT AGATTCATAT GACGAAAAAC AATTACGGGT

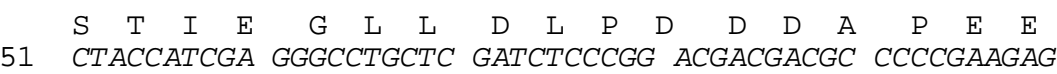

$\begin{array}{ccccccccccccccccc}\mathrm{A} & \mathrm{G} & \mathrm{L} & \mathrm{A} & \mathrm{A} & \mathrm{P} & \mathrm{R} & \mathrm{L} & \mathrm{S} & \mathrm{F} & \mathrm{L} & \mathrm{P} & \mathrm{A} & \mathrm{G} & \mathrm{H} & \mathrm{T} \\ 101 & \text { GCGGGGCTGG } & C G G C T C C G C G & C C T G T C C T T T & C T C C C C G C G G & \text { GACACACGCG }\end{array}$

SalI SacI

$\begin{array}{lllllllllllllllllll}R & L & S & T & A & P & P & T & D & V & S & L & G & D & E & L\end{array}$

151 CAGACTGTCG ACGGCCCCCC CGACCGATGT CAGCCTGGGG GACGAGCTCC

$\begin{array}{llllllllllllllllllllllllllll}H & L & D & G & E & D & V & A & M & A & H & A & D & A & L & D & D\end{array}$

201 ACTTAGACGG CGAGGACGTG GCGATGGCGC ATGCCGACGC GCTAGACGAT

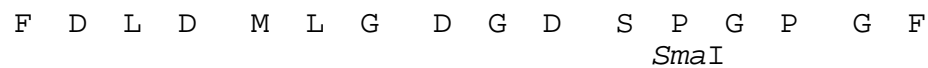

251 TTCGATCTGG ACATGTTGGG GGACGGGGAT TCCCCGGGTC CGGGATTTAC

$\begin{array}{llllllllllllllllllllll}P & \mathrm{H} & \mathrm{D} & \mathrm{S} & \mathrm{A} & \mathrm{P} & \mathrm{Y} & \mathrm{G} & \mathrm{A} & \mathrm{L} & \mathrm{D} & \mathrm{M} & \mathrm{A} & \mathrm{D} & \mathrm{F} & \mathrm{E}\end{array}$

301 CCCCCACGAC TCCGCCCCCT ACGGCGCTCT GGATATGGCC GACTTCGAGT

$\begin{array}{cccccccccccccccccc} & \mathrm{F} & \mathrm{E} & \mathrm{Q} & \mathrm{M} & \mathrm{F} & \mathrm{T} & \mathrm{D} & \mathrm{A} & \mathrm{L} & \mathrm{G} & \mathrm{I} & \mathrm{D} & \mathrm{E} & \mathrm{Y} & \mathrm{G} & \mathrm{G} & - \\ 351 & \text { TTGAGCAGAT } & \text { GTTTACCGAT } & \text { GCCCTTGGAA } & \text { TTGACGAGTA } & \text { CGGTGGGTAG }\end{array}$

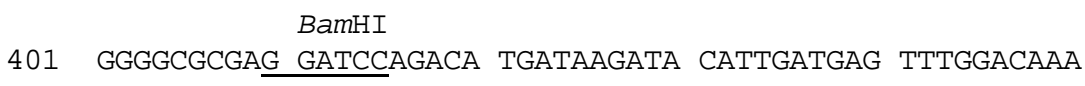

BamHI SmaI SalI PstI SmaI

451 CCACAACTAG AATGCAAATC GGATCCCGGG CCCGTCGACT GCAGCCCGGG

BamHI XbaI NotI SaCI

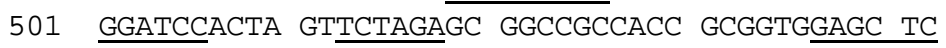




\subsection{2 pENGRAILED (WERR, unveröffentlicht)}

\section{Restsequenz: pUC}

PstI

1 GGCGCGCCAG CTTGCATGCC TGCAGGTCAA CATGGTGGAg CACGACACTC

51 TCGTCTACTC CAAGAATATC AAAGATACAg TCTCAGAAGA CCAGAGGGCT

101 ATTGAGACTT TTCAACAAAG GGTAATATCG GGAAACCTCC TCGGATTCCA

151 TTGCCCAGCT ATCTGTCACT TCATCGAAAG GACAGTAGAA AAGGAAGATG

201 GCTTCTACAA ATGCCATCAT TGCGATAAAg GAAAGGCTAT CGTTCAAGAA

251 TGCCTCTACC GACAGTGGTC CCAAAGATGG ACCCCCACCC ACGAGGAACA

301 TCGTGGAAAA AGAAGACGTT CCAACCACGT CTTCAAAGCA AGTGGATTGA

ECORV

351 TGTGATATCT CCACTGACGT AAGGGATGAC GCACAATCCC ACTATCCTTC

401 GCA $\overline{A G A C C C T}$ TCCTCTATAT AAGGAAGTTC ATTTCATTTG GAGAGGACCT

XhoI

451 CGAGAGCTTT ATTTTTACAA CAATTACCAA CAATAACAAA CAACAAACAA

501 CATTACAATT ACTATTTACA ATtACAgtCG AgCGGCCTTA AgCGAGTTGC

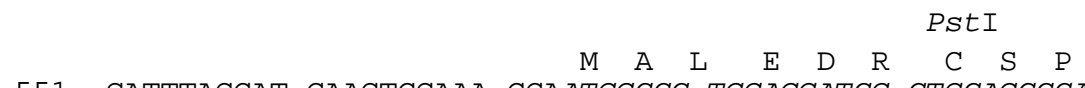

551 GAtTtAgCAT CAAGTCGAAA CCAATGGCCC TGGAGGATCG CTGCAGCCCA $\begin{array}{llllllllllllllllll}Q & S & A & P & S & P & I & \text { T } & \text { L } & Q & M & Q & H & \text { L } & \text { H } & \text { H } & \text { Q }\end{array}$ 601 CAGTCAGCGC CCAGCCCCAT TACCCTACAA ATGCAGCATC TTCACCACCA

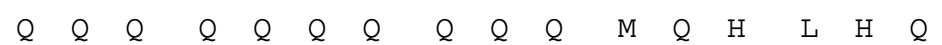

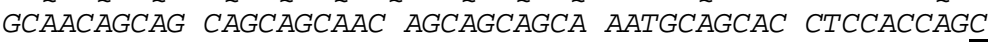

PstI PstI

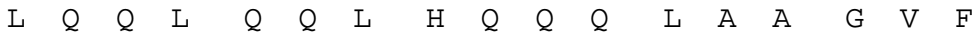

701 TGCAGCAACT GCAGCAGTTG CACCAACAGC AACTGGCCGC CGGTGTCTTC

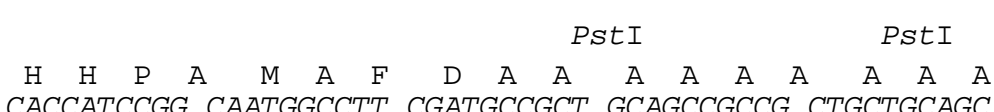

751 CACCATCCGG CAATGGCCTT CGATGCCGCT GCAGCCGCCG CTGCTGCAGC

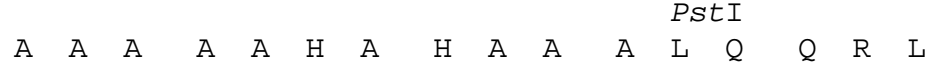

801 TGCTGCTGCG GCCGCCCACG CTCATGCTGC TGCACTGCAG CAGCGCCTCA

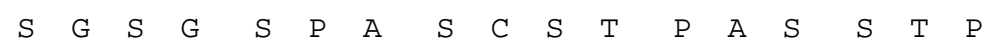

851 GTGGCAGTGG ATCGCCCGCA TCCTGCTCCA CGCCCGCCTC GTCCACGCCG

$\begin{array}{lllllllllllllllllllllllllllll} & \mathrm{L} & \mathrm{T} & \mathrm{I} & \mathrm{K} & \mathrm{E} & \mathrm{E} & \mathrm{E} & \mathrm{S} & \mathrm{D} & \mathrm{S} & \mathrm{V} & \mathrm{I} & \mathrm{G} & \mathrm{D} & \mathrm{M} & \mathrm{S} & \mathrm{F}\end{array}$ CTGACCATCA AGGAGGAGGA AAGCGACTCC GTGATCGGTG ACATGAGTTI

$\begin{array}{llllllllllllllll}\mathrm{H} & \mathrm{N} & \mathrm{Q} & \mathrm{T} & \mathrm{H} & \mathrm{T} & \mathrm{T} & \mathrm{N} & \mathrm{E} & \mathrm{E} & \mathrm{E} & \mathrm{E} & \mathrm{A} & \mathrm{E} & \mathrm{E} & \mathrm{D}\end{array}$

951 CCACAATCAG ACGCACACCA CCAACGAGGA GGAGGAGGCG GAGGAGGATG $\begin{array}{llllllllllllllllllllll}D & D & I & D & V & D & V & D & D & T & S & A & G & G & R & L & P\end{array}$

1001 ACGACATTGA TGTGGATGTG GATGATACGT CGGCGGGCGG ACGCCTGCCA

$\begin{array}{cccccccccccccccccc}\mathrm{P} & \mathrm{P} & \mathrm{A} & \mathrm{H} & \mathrm{Q} & \mathrm{Q} & \mathrm{Q} & \mathrm{Q} & \mathrm{S} & \mathrm{T} & \mathrm{A} & \mathrm{K} & \mathrm{P} & \mathrm{S} & \mathrm{L} & \mathrm{A} & \mathrm{F} & \mathrm{S} \\ & \end{array}$ SalI

$$
\begin{array}{lllllllllllllllll}
I & S & N & I & L & S & D & R & F & G & D & V & Q & K & P & G
\end{array}
$$

1101 CATCTCCAAC ATCCTGAGCG ATCGTTTCGG AGATGTCCAG AAGCCTGGCA $\begin{array}{lllllllllllllllllllll}K & S & I & E & N & Q & A & S & I & F & R & P & F & E & A & N & R\end{array}$

1151 AGTCGATTGA GAACCAGGCC AGCATATTCC GCCCCTTCGA GGCGAATCGC

$\begin{array}{cccccccccccccccccc} & \mathrm{S} & \mathrm{Q} & \mathrm{T} & \mathrm{A} & \mathrm{T} & \mathrm{P} & \mathrm{S} & \mathrm{A} & \mathrm{F} & \mathrm{T} & \mathrm{R} & \mathrm{V} & \mathrm{D} & \mathrm{L} & \mathrm{L} & \mathrm{E} & \mathrm{F} \\ 1201 & \text { TCCCAGACTG } & C C A C G C C C T C & C G C C T T T A C A & & \text { AGAGTGGATC } & \text { TGCTGGAGTT }\end{array}$ 
$\begin{array}{llllllllllllllll}S & R & Q & Q & Q & A & A & A & A & A & A & T & A & A & M & M\end{array}$

1251 TAGCCGGCAA CAGCAAGCTG CCGCCGCAGC CGCTACTGCG GCCATGATGC $\begin{array}{lllllllllllllllll}\mathrm{L} & \mathrm{E} & \mathrm{R} & \mathrm{A} & \mathrm{N} & \mathrm{F} & \mathrm{L} & \mathrm{N} & \mathrm{C} & \mathrm{F} & \mathrm{N} & \mathrm{P} & \mathrm{A} & \mathrm{A} & \mathrm{Y} & \mathrm{P} & \mathrm{R}\end{array}$

1301 TGGAACGGGC CAACTTCCTT AACTGCTTCA ATCCGGCTGC CTATCCCAGG

$\begin{array}{llllllllllllllllll}1 & \mathrm{H} & \mathrm{E} & \mathrm{E} & \mathrm{I} & \mathrm{V} & \mathrm{Q} & \mathrm{S} & \mathrm{R} & \mathrm{L} & \mathrm{R} & \mathrm{R} & \mathrm{S} & \mathrm{A} & \mathrm{A} & \mathrm{N} & \mathrm{A}\end{array}$

$$
\text { SacI }
$$

$\begin{array}{lllllllllllllllllll}\mathrm{V} & \mathrm{I} & \mathrm{P} & \mathrm{P} & \mathrm{P} & \mathrm{M} & \mathrm{S} & \mathrm{S} & \mathrm{K} & \mathrm{M} & \mathrm{S} & \mathrm{D} & \mathrm{A} & \mathrm{N} & \mathrm{P} & \mathrm{E}\end{array}$

1401 CGTCATCCCG CCGCCCATGA GCTCCAAGAT GAGCGATGCC AATCCAGAGA $\begin{array}{lllllllllllllllll}\text { K } & S & A & L & G & S & S & R & V & R & K & S & P & V & S & L & Y\end{array}$

1451 AATCTGCTCT GGGATCCTCT AGA GTCCGCA AATCACCAGT CTCTCTCTAC $\begin{array}{lllllllllllllll}K & S & I & S & \text { L } & Y & F & \text { L } & Q & N & N & V & -\end{array}$

1501 AAATCTATCT CTCTCTATTT TCTCCAGAAT AATGTGTGAG TAGTTCCCAG 1551 ATAAGGGAAT TAGGGTTCTT ATAGGGTTTC GCTCATGTGT TGAGCATATA

1601 AGAAACCCTT AGTATGTATT TGTATTTGTA AAATACTTCT ATCAATAAAA

1651 TTTCTAATTC CTAAAACCAA AATCCAGTGA CCTGCAGGCA TGCAAGCTGG 1701 CGCGCC

\subsection{3 pKVPL}

\section{Restsequenz: pUC57}

$\begin{array}{llllllllll}\text { ECORI ASP718 } & \mathrm{M} & \mathrm{T} & \mathrm{K} & \mathrm{N} & \mathrm{N} & \mathrm{Y} & \mathrm{G}\end{array}$

1 GAATTCGAGC TCGGTACCAT GACGAAAAAC AATTACGGGT//---VP16--

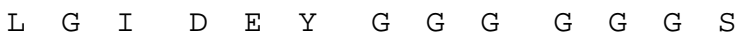
//CTCGGAATTG ACGAGTACGG TGGGGGAGGA GGTGGTTCAG BamHI

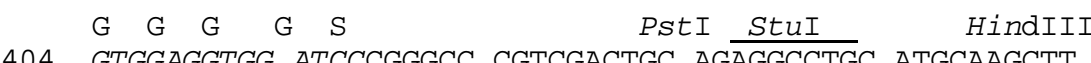

\subsubsection{PKENGL}

\section{Restsequenz: pUC57}

ECORI

1 GAATTCGAGC TCGGTACCTC GCGAATGCAT CTAGATTGGT ACCAACCATG

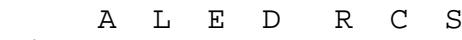

51 GCCCTGGAGG ATCGCTGCAGC//---------ENGRAILED----------// $\begin{array}{lllllllllllllllllllll}K & M & S & D & A & N & P & E & K & S & A & \text { L } & G & S & G & G & G\end{array}$

901 AGATGAGCGA TGCCAACCCA GAGAAATCTG CTCTGGGATC AGGAGGAGGT

\section{BamHI}

$$
\text { G S G G G G S BamHI_SmaI }
$$

951 GGTTCAGGTG GAGGTGGATC CAATCGGATC CCGGGCCCGT CGACTGCAGA 


\subsection{5 pK2.1L}

\section{Restsequenz: pUC57}

$\begin{array}{llllllllllllllll}\text { ECORI } & \text { Asp718 } & \text { M } & A & S & K & I & G & \text { T } & A & G & N & R & S & G\end{array}$

1 GAATTCGAGC TCGGTACCAA CCATGGCTAG TAAGATTGGT ACAGCAGGCA ATAGAAGTGG

$\begin{array}{rrrrrrrrrrrrr}\mathrm{R} & \mathrm{A} & \mathrm{L} & \mathrm{S} & \mathrm{S} & \mathrm{L} & \mathrm{W} & \mathrm{L} & \mathrm{A} & \mathrm{R} & \mathrm{P} & \mathrm{R} & \mathrm{E} \\ \end{array}$

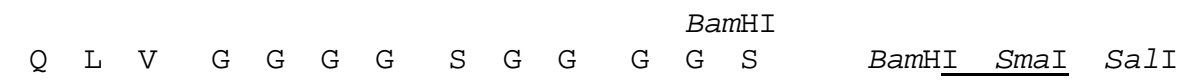

1381 GCAGTTAGTA GGAGGAGGTG GTTCAGGTGG AGGTGGATCC AATCGGATCC CGGGCCCGTC

$1441 \underline{\text { GACTGCAGAG GCCTGCATGC }} \underline{\underline{\text { AAGCTT }}}$

\subsection{6 pK2.2L}

\section{Restsequenz: pSK}

$$
\begin{array}{lllllllll}
\text { Asp718 M } & \text { A } & \text { D } & \text { I } & \text { S } & \text { P } & \text { S }
\end{array}
$$

1 GGTACCAACC ATGGCTGATA TCAGTCCTAG//---------TGA2.2-----

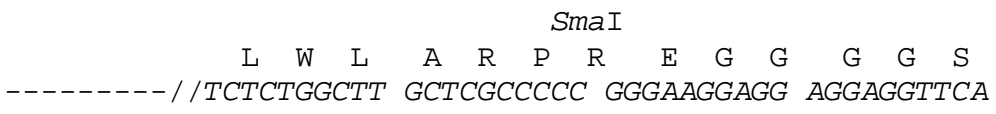

G G G $\begin{aligned} & \text { BamHI } \\ & \text { S SpeI XbaI NotI SacII }\end{aligned}$

1001 GGTGGTGGTG GATCCACTAG TTCTAGA $\overline{\text { NCG GCCGCCACCG CGG }}$

\subsection{7 pLVPs}

Restsequenz: pUC57

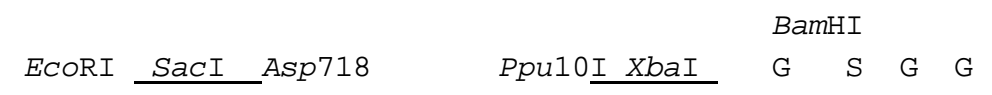

1 GAATTCGAGC TCGGTACCTC GCGA

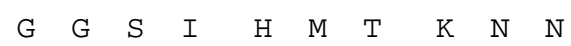

51 GTGGTTCAAT TCATATGACG AAAAACAAT//------------VP16-----

SunI

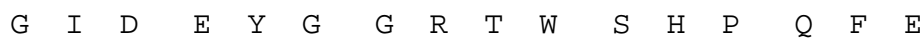

--//GGAATTGA CGAGTACGGT GGGCGTACGT GGAGTCATCC GCAGTTCGAA

$\mathrm{K}$ - BamHI SmaI SalI PStI HindIII

461 AAGTAGGATC CCGGGCCCGT CGACTGCAGA GGCCTGCATG CAAGCTT 


\subsection{8 pLENGs}

Restsequenz: pUC57

\begin{tabular}{llllll} 
& \multicolumn{4}{c}{ BamHI } \\
ECORI Asp718 & PPU10I & S & G
\end{tabular}

1 GAATTCGAGC TCGGTACCTC NTNA

$\begin{array}{lllllllllll}G & G & S & M & \text { A } & \text { L } & E & \text { D } & R & C & S\end{array}$

51 GTGGTTCAAT GGCCCTGGAG GATCGCTGCA GC//---ENGRAILED-----

901

$\begin{array}{lllllllll}\text { A } & N & P & E & K & S & A & L & G\end{array}$

901

/ TGCCAATCC AGAGAAATCT GCTCTGGGAT

SunI

$\begin{array}{lllllllllllll}S & R & T & W & S & H & P & Q & F & E & K & - & \text { BamHI SmaI }\end{array}$

951 CACGTACGTG GAGTCATCCG CAGTTCGAAA AGTA

1001 GACTGCAGAG GCCTGCATGC AAGCTT

\subsection{9 pL2.1s}

Restsequenz: pUC57

$\begin{array}{llllll} & & \text { BamHI } & & \\ \text { ECORI } & \text { Asp718 } & \text { S } & \text { G }\end{array}$

1 GAATTCGAGC TCGGTACCTC GCGAATGCAT CTAGATAGGA TCCGGAGGTG $\begin{array}{llllllllllllllllllll}G & G & S & M & A & S & K & I & G & T\end{array}$

51 GTGGTTCTAT GGCTAGTAAG ATTGGTACA//-------TGA2.1-------//

$\begin{array}{llllllllllllllllll} & \mathrm{L} & \mathrm{A} & \mathrm{R} & \mathrm{P} & \mathrm{R} & \mathrm{E} & \mathrm{Q} & \mathrm{L} & \mathrm{V} & \mathrm{R} & \mathrm{T} & \mathrm{W} & \mathrm{S} & \mathrm{H} & \mathrm{P} & \mathrm{Q} & \mathrm{F}\end{array}$

1401 TTGCCAGACC ACGAGAGCAG TTAGTACGTA CGTGGAGTCA TCCGCAGTTC

$\mathrm{E}$
1451
GAAAAGTAGG ATCCCGGGCC CGTCGACTGC AGAGGCCTGC ATGCAAGCTT

\subsubsection{0 pUC57 2.1-57s}

Restvektor: pUC57

$\begin{array}{lllllllllllll}\text { ECORI Asp718 } & \text { M } & \text { S } & A & \text { S } & \text { G } & \text { T } & \text { H } & \text { H } & \text { E }\end{array}$

1 GAATTCGAGC TCGGTACCAA CCATGTCAGC ATCAGGCACT CATCATGAGA $\begin{array}{rrrrrrrrrr}\text { W } & \text { L } & \text { A } & \text { R } & \text { P } & \text { R } & \text { E } & \text { Q } & \text { L } & \text { V } \\ \text { //----- TGA2.1------//TGGCTTGCC } & \text { AGACCACGAG } & \text { AGCAGTTAGT }\end{array}$ SunI

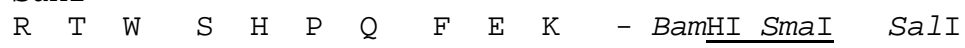

1051 ACGTACGTGG AGTCATCCGC AGTTCGAAAA GTAGGATCCC GGGCCCGTCG

1101 PstI StuI $\frac{\text { SphI }}{\text { ACTGCAGAGG CCTGCATGC }}$ 


\subsubsection{1 pUC57 parA}

Restvektor: pUC57

SaCI Asp718 PPU10I XbaI ECORV M E

1 GAATTCGAGC TCGGTACCTC GCGAATGCAT CTAGATGATA TCATGGAGAG HindIII
$\begin{array}{llll}\mathrm{N} & \mathrm{N} & \mathrm{V} & \mathrm{V}\end{array}$
$\begin{array}{llllll}K & H & K & L & G & L\end{array}$

CAACAACGTG GTT//-----parA-------//AAGCACAAG CTTGGTCTTG

A - BamHI SMaI

701 CTTGAACAAG AAACACTTCT TACCTAAGAT CTATCGGATC CCGGGCCCGT

SalI PStI StuI SphI HindIII

751 CGACTGCAGA GGCCTGCATG CAAGCTT 


\section{Danksagung}

Allen, die zum Gelingen dieser Arbeit beigetragen haben, möchte ich herzlich danken:

Frau Prof. Dr. C. Gatz danke ich für die Überlassung des interessanten Themas, ihre Diskussionsbereitschaft und die hilfreichen Anregungen.

Herrn PD Dr. G. Hinz, der sich freundlicherweise bereiterklärt hat, das Korreferat zu übernehmen, möchte ich ebenfalls danken.

Allen Mitarbeitern der Arbeitsgruppe Gatz ein herzliches Dankeschön für das gute Miteinander der letzten Jahre. Der ständig wechselnden Besatzung von Raum 338 gilt ein besonderer Dank:

An erster Stelle den beiden „Felsen in der Brandung“: Carsten und Andreas, für die ausgezeichnete Zusammenarbeit, Verlässlichkeit, Hilfs- und Diskussionsbereitschaft über die gesamte Zeit hinweg, und für die belebende Atmosphäre, die Ihr verbreitet habt, indem Ihr mich immer wieder mit neuen, sorgfältig ausgewählten Tonträgern aus Eurer Sammlung überrascht habt, die den Arbeitsalltag nie langweilig werden ließen.

Alex T., die mir besonders zu Anfang der Promotionszeit sehr geholfen hat, Ricarda, ohne die es dieses Thema ja gar nicht gegeben hätte, Alex F. für ihre exzellente Unterstützung, Carmen, Alex und Anke für ihre Geduld und die freundschaftliche Zusammenarbeit, und nicht zuletzt Annette für ihre Hilfe in der Endphase meiner Laborarbeit.

Auch Wolfgang und seinem Team sei herzlich gedankt, dass Ihr die alltäglichen Freuden und Sorgen mit mir geteilt habt.

All meinen Freunden ein besonderer Dank, für die schöne Zeit neben der Arbeit: Steffi und Thorsten, Alex und Markus, Anke und Thomas. Ich konnte mich immer auf Euch verlassen. Danke auch meiner ganzen Familie, die zu jeder auch noch so schweren und turbulenten Zeit hinter mir gestanden hat. Ein besonderer Dank gilt meiner Mutter, die sicher stolz auf mich wäre.

Mein allergrößter Dank aber gilt Andrea und Frederik, die mein Leben unendlich bereichern, und mich - jeder nach seinen Fähigkeiten - unterstützen. Auch wenn, oder gerade weil Ihr nicht immer ein ,ruhender Pol“" seid, könnte ich mir mein Leben ohne Euch nicht mehr vorstellen. Danke. 


\section{Erklärung}

Hiermit erkläre ich an Eides Statt, dass die Dissertation mit dem Thema

„Analyse der in-vivo Funktion der Transkriptionsfaktoren TGA2.1 und TGA2.2 aus Tabak nach Fusion mit einer konstitutiven Aktivierungsdomäne“"

selbständig und ohne unerlaubte Hilfe angefertigt wurde.

Göttingen, 21.03.2001 


\section{$\underline{\text { Curriculum vitae }}$}

$08 / 81-06 / 90$

$10 / 91-08 / 97$

$09 / 97-05 / 01$
Ingo Lenk

Geboren am 17.12.1970 in Herford

deutsche Staatsangehörigkeit

Gymnasium im Schulzentrum Aspe, Bad Salzuflen

Abschluß: Allgemeine Hochschulreife

Biologiestudium an der Universität Bielefeld

Anfertigung der Diplomarbeit am Institut für

Pflanzenphysiologie der Georg-August-Universität Göttingen

(Prof. Dr. C. Gatz)

„Konstruktion und Charakterisierung eines tetracyclinabhängigen Pflanzenpromotors“"

Abschluß: Diplom

Anfertigung der vorliegenden Dissertation am

Albrecht-von Haller-Institut für Pflanzenwissenschaften,

Abteilung ,allgemeine und Entwicklungsphysiologie der

Pflanze“" (Prof. Dr. C. Gatz) 